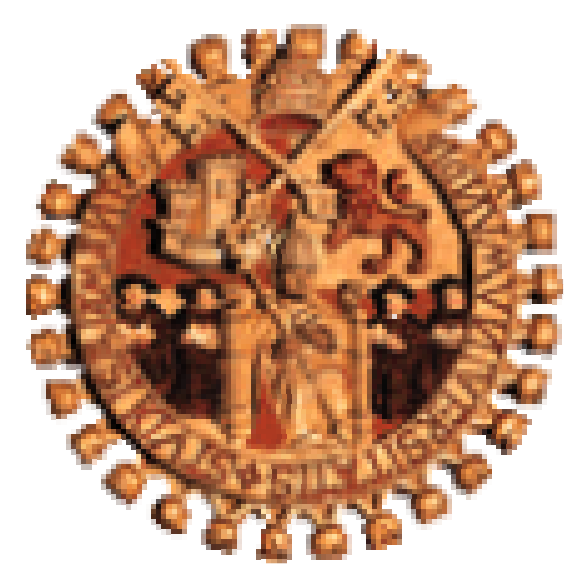

VALORACIÓN INTEGRAL, ANALÍTICA Y DEL METABOLISMO ÓSEO EN PERSONAS OBESAS SOMETIDAS A TRATAMIENTO DIETÉTICO

TESIS DOCTORAL

Ma Isabel Porras Guerra.

Dpto. Fisiología y Farmacología. Universidad de Salamanca. Servicio de Dietética y Nutrición. Hospital Universitario de Salamanca. 
DEDICATORIAS 
A mi hijo, por el tiempo que no le he dedicado.

A mis padres, por la oportunidad que me dieron de estudiar Medicina. A mi marido, por su apoyo incondicional en todo lo que hago. 
A los Directores de la Tesis Dres. D. Ricardo Tostado Menéndezy Dña. Consuelo Sancho Sánchez por su apoyo y ayuda.

En especial, a Piedad García Hernández, por ser confidente y amiga además de colaboradora mía.

Al Servicio de Medicina Nuclear del Hospital Universitario de Salamanca y sobre todo, a la Dra. Esther Martín Martín por su colaboración y facilidades para la realización de las densitometrías.

A Juan Carro, profesor de la Facultad de Psicología de Salamanca por sus lecciones de Estadística Aplicada que me ayudaron a la realización de la Tesis. 
ÍNDICE 


\section{Listado de variables. Pág 11}

\section{Listado de Tablas. Pág 13}

Introducción. Pág 15

1) Revisión. Pág 17

\section{Revisión I: Obesidad. Pág 18}

I.1- La obesidad como enfermedad. Pág 19

I.2- La obesidad y su importancia socio-sanitaria. Pág 21

I.3- Criterios para definir la obesidad. Pág 22

I.4- Fisiopatología y Gasto energético. Pág 23

I.5- Etiopatogenia de la obesidad. Pág 28

I.6- Tipos de obesidad. Pág 31

I.7- Valores de riesgo según la distribución de la grasa corporal. Pág 33

I.8- Complicaciones de la obesidad: Pág 33

a) Alteraciones metabólicas en obesos

b) Principales enfermedades asociadas a la obesidad

I.9- Tratamiento. Pág 40 


\section{Revisión II: Metabolismo mineral y óseo. Pág 41}

II. 1 - Metabolismo mineral y óseo. Pág 42

II.2 - Macroelementos y microelementos. Pág 42

II.3 - Metabolismo del calcio. Pág 43

II.4 - Metabolismo del fósforo. Pág 50

II.5 - Metabolismo del magnesio. Pág 52

II.6 - Metabolismo del cinc. Pág 54

II.7 - Metabolismo del cobre. Pág 56

II.8 - Metabolismo del flúor, cromo, manganeso, boro y silicio. Pág 57

II.9 - Cantidades necesarias de minerales. Pág 58

II.10- Estructura y química de los huesos. Pág 59

II.11- Dinámica ósea. Pág 60

II.12- Ingestas de calcio recomendadas. Pág 61

II.13- Acción de las distintas hormonas sobre los huesos: Pág 62

a) Efecto de la PTH

b) Efecto de la Vitamina D

c) Efecto de la Calcitonina

II.14 - Calcio iónico. Pág 66

II.15 - Marcadores bioquímicos de remodelado óseo: Pág 67

a) Marcadores bioquímicos de formación ósea

b) Marcadores bioquímicos de resorción ósea 


\section{Revisión III: Osteoporosis. Pág 71}

III.1- Osteoporosis. Pág 72

III.2- Etiología. Pág 75

III.3- Fisiopatología. Principales factores reguladores de remodelado óseo: Pág 78

a) Factores hormonales

b) Factor edad

III.4- Clasificación de osteoporosis. Pág 82
a) Primarias
b) Secundarias
c) Idiopáticas

III.5- Epidemiología. Pág 82

III.6- Factores de riesgo de osteoporosis. Pág 85

d) Principales factores clínicos de riesgo de osteoporosis

e) Medidas preventivas de osteoporosis no farmacológicas

III.7- Causas de fracturas osteoporóticas. Pág 90

III.8- Osteoporosis en el varón. Pág 93

III.9- Diagnóstico de osteoporosis. Medidas de masa ósea: Pág 94

f) Radiología

g) Densitometría ósea. Métodos

h) Ultrasonidos

III.10- Criterios diagnósticos de osteopenia y osteoporosis según la O.M.S. Pág 98

III.11- Indicaciones de Densitometría ósea. Pág 99 
2) Pacientes y métodos. Pág 100

3) Objetivos. Pág 107

4) Resultados. Pág 109

5) Discusión. Pág 171

6) Conclusiones. Pág 192

7) Bibliografía. Pág 195. 
LISTADO DE VARIABLES 
IMC $=$ índice de masa corporal

ICC $=$ índice cintura/cadera

C.C $=$ contorno de cintura

$\mathbf{S N S}=$ Sistema Nervioso Simpático

DEXA = densitometría ósea

DMO $=$ densidad mineral ósea

V.S.G. = velocidad de sedimentación globular

P.T.H = parathormona

F.A = fosfatasa alcalina

$\mathbf{T} / \mathbf{A}=$ tensión Arterial

D.M $=$ diabetes mellitus

HTA $=$ hipertensión arterial

A.F $=$ antecedentes familiares

A. fami. $\mathbf{1}=$ presencia de antecedentes familiares de obesidad

A. fami. $\mathbf{2}$ = presencia de antecedentes familiares de HTA

A. fami.3 = presencia de antecedentes familiares de diabetes

P.asoc. 1 = patología asociada que presentan los pacientes (HTA)

P.asoc. 2 = patología asociada que presentan los pacientes (DM)

P.asoc.3 = patología asociada que presentan los pacientes (Osteoarticular)

P.asoc.4 = patología asociada que presentan los pacientes (Estreñimiento)

P.asoc.5 = patología asociada que presentan los pacientes (Pat. Vascular)

P.asoc.6 = patología asociada que presentan los pacientes (otras patologías)

Fcos. $\mathbf{o b}=$ consumo de fármacos para combatir la obesidad

Fcos. HTA = consumo de fármacos contra la hipertensión arterial

Fcos.agai = consumo de fármacos analgésicos - antiinflamatorios

Fcos.snc $=$ consumo de psicofármacos

Fcos.vasc $=$ consumo de fármacos con efecto vasoprotector

Fcos.prot $=$ consumo de fármacos protectores gástricos

Fcos.otro = consumo de otros tipos de fármacos

C.L = columna lumbar

AREA C.L = valor área total de la columna lumbar

BMC C.L = valor gramos totales de columna lumbar

BMD C.L = valor gramos $/ \mathrm{cm} 2$ de columna lumbar

T. C.L. = valor respecto al pico de masa ósea de la columna lumbar

T. C.L.P = valor respecto al pico de masa ósea de columna lumbar en porcentaje.

Z. C.L = valor respecto a la edad del paciente de columna lumbar

Z. C.L.P = valor respecto a la edad del paciente de columna lumbar en porcentaje.

AREA.CAD $=$ valor área total de la cadera

BMC.CAD $=$ valor gramos totales de cadera

BMD.CAD $=$ valor gramos $/ \mathrm{cm} 2$ de columna

T30.CAD $=$ valor respecto al pico de masa ósea de cadera

T30.CAD.P = valor respecto al pico de masa ósea de cadera en porcentaje.

Z.CAD $=$ valor respecto a la edad del paciente de cadera

Z.CAD. $\mathbf{P}=$ valor respecto a la edad del paciente de cadera en porcentaje. 
LISTADO DE TABLAS 


\section{DISTRIBUCIÓN DE LA MUESTRA}

- $\quad \boldsymbol{T a b l a} \boldsymbol{n}^{\circ} \boldsymbol{1}=$ DISTRIBUCIÓN DE LA MUESTRA EN PORCENTAJE.

- $\boldsymbol{T a b l a}^{\circ} \mathbf{2}=$ CAUSAS DE OBESIDAD DISTRIBUIDAS POR GRUPOS

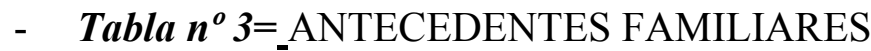

- $\quad \boldsymbol{T a b l a} \boldsymbol{n}^{\circ}$ 4= PATOLOGÍAS ASOCIADAS I

- $\quad$ Tabla $n^{0}$ 5= PATOLOGÍA ASOCIADA II

- $\quad \boldsymbol{T a b l a} \boldsymbol{n}^{\boldsymbol{o}} \boldsymbol{6}=$ DISTRIBUCIÓN DE FÁRMACOS CONSUMIDOS

\section{VARIABLES CUANTITATIVAS}

- $\quad \boldsymbol{T a b l a} n^{0} 7=$ DISTRIBUCIÓN DE LA MUESTRA.

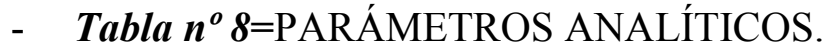

- $\quad \operatorname{Tabla} n^{\circ}$ 9= VALORES DEL PERFIL LIPÍDICO.

- $\quad$ Tabla $n^{\circ}$ 10=BIOQUÍMICA ÓSEA ESPECÍFICA. SUERO / PLASMA.

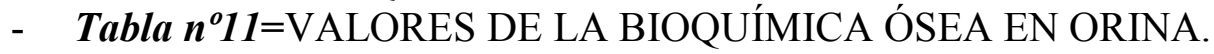

\section{MUJERES PREMENOPÁUSICAS Y MENOPAÚSICAS.}

- $\quad \boldsymbol{T a b l a ~} n^{0}$ 12=DISTRIBUCIÓN DE LA MUESTRA (MUJERES todas).

- $\quad \boldsymbol{T a b l a} \boldsymbol{n}^{\circ}$ 13= VALORES DE PARÁMETROS ANALÍTICOS.

- $\quad$ Tabla $n^{\circ}$ 14= VALORES DEL PREFIL LIPÍDICO.

- $\operatorname{Tabla} n^{0} 15=$ VALORES DE LA BIOQUÍMICA ÓSEA. SUERO / PLASMA.

- Tabla $n^{\circ}$ 16= VALORES DE LA BIOQUÍMICA ÓSEA EN ORINA.

\section{MEDIDAS ANTROPOMÉTRICAS. PLIEGUES Y CONTORNOS.}

- $\quad$ Tabla $\boldsymbol{A}=$ DISTRIBUCIÓN DE LA MUESTRA EN CONJUNTO.

- Tabla $\boldsymbol{B}=$ VARONES.

- $\quad$ Tabla $\boldsymbol{C}=$ MUJERES PREMENOPAÚSICAS.

- $\quad$ Tabla $D=$ MUJERES MENOPAÚSICAS.

- Tabla $\boldsymbol{E}=$ TODAS LAS MUJERES.

- $\quad$ Tabla $\boldsymbol{F}=$ VALORES DE LA T/A.

- $\quad$ Tabla $\boldsymbol{G}=$ CONTORNOS DE CINTURA/CADERA. VARONES.

- $\quad$ Tabla $\boldsymbol{H}=$ CONTORNOS DE CINTURA/CADERA. PREMENOPAÚSICAS.

- $\quad$ Tabla $I=$ CONTORNOS DE CINTURA/CADERA. MENOPAÚSICAS.

- $\quad$ Tabla $\boldsymbol{J}=$ RIESGO CARDIOVASCULAR.

\section{DEXA}

- $\quad$ Tabla $\boldsymbol{a}=$ VALORES DEXA. TODA LA MUESTRA.

- $\quad \boldsymbol{T} \boldsymbol{a b l a} \boldsymbol{b}=$ VALORES DEXA.VARONES.

- $\quad \boldsymbol{T a b l a} \boldsymbol{c}=$ VALORES DEXA. MUJERES PREMENOPAÚSICAS.

- $\quad$ Tabla $\boldsymbol{d}=$ VALORES DEXA. MUJERES MENOPAÚSICAS.

- $\quad$ Tabla $\boldsymbol{e}=$ VALORES DEXA. TODAS LAS MUJERES. 
Los hábitos alimentarios inadecuados, por exceso o por defecto, pueden provocar un impacto significativo sobre la incidencia y gravedad de muchas enfermedades durante toda la vida. Hay una relación directa entre factores nutricionales de riesgo y enfermedades de elevada prevalencia en el mundo occidental como son las patologías cardiovasculares, la DM tipo 2, algunos tipos de cánceres o la obesidad. El cáncer de colon, mama y próstata, son los tres tipos de cáncer más estrechamente relacionados, desde el punto de vista epidemiológico, con factores nutricionales de riesgo.

Las personas con sobrepeso tienen mayor riesgo de presentar intolerancia a la glucosa, HTA, alteraciones lipídicas y de sufrir otras muchas enfermedades. Se ha demostrado que la reducción de peso corporal, reduce estos riesgos. También se han vinculado factores nutricionales a osteoporosis, estreñimiento, enfermedad diverticular, anemia ferropénica, enfermedades bucales y desnutrición.

Estudios transversales sugieren que la menor ingesta de calcio sobre todo en mujeres jóvenes, puede ser un factor de riesgo importante para la desmineralización ósea y osteoporosis postmenopaúsica, y los estudios sugieren que el suplemento de calcio en la adolescencia y al principio de la edad adulta puede aumentar la densidad de los minerales en el hueso.

La OBESIDAD está considerada como la gran epidemia del siglo XXI. Son muchas las personas que ya la padecen y su número sigue en progresivo aumento. Las repercusiones de ésta enfermedad, tanto a nivel fisiopatológico, como económico (los gastos que ocasionan su seguimiento y su tratamiento son muy altos) y las consecuencias que derivan de ella, junto a las graves alteraciones de tipo psico-social que presentan los obesos, hacen de ésta patología, un problema de gran magnitud con repercusiones socio-sanitarias muy importantes.

La alta incidencia de la obesidad, su importancia a nivel socio-sanitario, tanto por su distribución, como por su difícil abordaje, control y seguimiento (enfermedad multicausal y multifactorial), además de por las múltiples alteraciones endocrino-metabólicas que origina y por la falta de un tratamiento efectivo, hacen que sea la obesidad, una patología idónea para su valoración, su seguimiento y su estudio.

Esta enfermedad es un factor predisponente para el padecimiento de muchas patologías: hipertensión arterial, diabetes, dislipémias, colelitiasis, hiperuricemia, osteoartrosis etc, pero... algunos trabajos y publicaciones apuntan también, que la obesidad protege frente a diversas patologías y que previene o retrasa la aparición de osteoporosis. 
REVISIÓN 
INTRODUCCIÓN I: OBESIDAD 
El aporte de alimentos debe ser suficiente para cubrir las necesidades metabólicas del cuerpo y no excesivo como para provocar OBESIDAD.

Los alimentos tienen distintas proporciones de proteínas, hidratos de carbono, grasas, minerales y vitaminas, por lo que se debe de mantener un equilibrio adecuado entre ellos de forma que, se puedan aportar los materiales necesarios a todos los segmentos de los sistemas metabólicos del cuerpo.

Si ingerimos cantidades de energía (alimentos) mayores de las que se gastan, el peso corporal aumenta. Por lo tanto, la obesidad, está producida por una entrada excesiva de energía con respecto a la salida. Por cada 9,3 calorías de exceso que entran en el organismo, se almacena 1gr de grasa. El exceso de aporte de energía se observa sólo durante la fase de aparición de la obesidad. Una vez que la persona se vuelve obesa, lo único necesario para seguir obesa es que el aporte de energía se iguale a la pérdida. Para que una persona reduzca peso, el aporte debe ser menor que la eliminación, de hecho se ha demostrado en estudios realizados en personas obesas, que la ingestión de alimentos en la mayoría de ellos, en el estadio estático de la obesidad (después de que se ha alcanzado ésta), es similar que la de las personas normales.

Cerca de una tercera parte de la energía utilizada cada día por una persona normal, va dirigida a la actividad muscular, y en el trabajo manual se utilizan hasta dos terceras partes o en ocasiones tres cuartas partes de la energía. Debido a que la actividad muscular es, con diferencia, el medio más importante por el que se gasta la energía, se dice con frecuencia que, la obesidad, en una persona, por lo demás normal, es el resultado de una proporción demasiado elevada entre la ingestión de alimentos y el ejercicio diario. La obesidad suele estar causada por una alteración en el mecanismo regulador de la ingestión de alimentos que puede ser el resultado de factores psicógenos que afecten a esta regulación o por alteraciones reales del propio sistema regulador.

\section{I.1.LA OBESIDAD COMO ENFERMEDAD}

La obesidad no fue definida como enfermedad hasta mediado de los años ochenta. Está considerada como un síndrome de etiología múltiple del que aún hoy, no se conocen bien los mecanismos bioquímicos que conducen a ella, aunque en principio, para acumular grasa en el organismo y por tanto, para engordar, hay que comer con exceso en relación a la energía que se gasta. 
En la práctica, la obesidad es el exceso de peso referido a una edad, sexo y talla determinada.(1) La Organización Mundial de la Salud (O.M.S) define la obesidad como una entidad en la que el exceso de grasa corporal afecta a la salud y al bienestar.

No existe otra patología en la actualidad que haya presentado un incremento tan rápido e importante afectando además, a todo el mundo desarrollado. Su importancia radica en que, el grado de obesidad se relaciona, de forma directa, con una disminución significativa en las expectativas de vida de las personas que la padecen (2) y con numerosas complicaciones médicas y psicosociales.(3)

La presión social también juega un papel muy importante ya que hace que, gran parte de la población se preocupe de modificar su peso corporal por métodos muy diversos, la mayoría de las veces, no comprobados e inútiles para los fines buscados. Gran parte del problema social que ocasiona la obesidad, procede de una inadecuada comprensión de su significado biológico y de sus causas bioquímicas reales. El desconocimiento de la etiología de la obesidad ocasiona la aparición de numerosos remedios para combatirla, sin base científica y más próximos al chamanismo que a la clínica médica. $(4,5)$

La obesidad en sí, no puede ser definida con exactitud más que en algunos casos ya que no existe un medio científico de distinguir entre el simple y funcional sobrepeso y los estadios más leves de obesidad. Esta identificación se suma al carácter patológico de la misma; no está claro que la obesidad sea una entidad nosocomial en todos los casos, de hecho, el sobrepeso ligero puede aportar una cierta protección contra algunas enfermedades. La obesidad sólo podría ser definida como una patología en los casos en los que se pueda demostrar que ocasiona problemas metabólicos y funcionales reales al paciente; probablemente, se podría limitar el término patológico para las obesidades de grado II o III según la terminología actual.(2,1)

Los factores que intervienen en el mantenimiento del peso corporal son diversos, factores genéticos, disfunciones endocrinas, lesiones hipotalámicas, factores ambientales como el estrés o las infecciones, contenido de grasa en la dieta, etc

La obesidad en el momento actual, se considera un fenómeno relacionado con la sociedad de consumo, aumentando claramente el número de personas afectadas con relación a los cambios en los hábitos de vida. $(2,4,6)$ Para cuantificarla se recomienda utilizar el llamado Índice de Quetelet o índice de masa corporal (IMC), que define la relación peso-talla $(\mathrm{Kg} / \mathrm{talla} / \mathrm{m} 2)$. Su inconveniente: no tiene en cuenta el sexo del paciente. 
Pero...el problema de la obesidad no es solamente de cantidad; también es un problema de cualidad y de distribución de la grasa corporal, ya que, ésta distribución, incrementa el riesgo de padecer o no, determinadas patologías que se han asociado con ella. Los parámetros antropométricos (peso, talla, índice de masa corporal, contorno de cintura, índice cintura/cadera, pliegues cutáneos) son factores predictivos de adiposidad general o del porcentaje de grasa visceral o abdominal. La medida del pliegue cutáneo, que introdujo Ritcher, se ha generalizado y su correlación con la grasa subcutánea es buena.

\section{I.2.LA OBESIDAD Y SU IMPORTANCIA SOCIO-SANITARIA.}

A pesar de ser el trastorno metabólico más frecuente en los países desarrollados y en algunos en vías de desarrollo, es una enfermedad infravalorada, poco estudiada y desatendida por el sistema sanitario. Más de mil millones de personas presentan actualmente en todo el mundo sobrepeso $u$ obesidad.(7) Los estudios epidemiológicos más recientes revelan que la prevalencia media de la obesidad en los países europeos está entre el entre el $10-20 \%$ en varones y el $10-25 \%$ en mujeres. $(8,9)$

En nuestro país, los datos son alarmantes, independientemente del criterio diagnóstico utilizado, superamos globalmente una frecuencia del 14\%. Un 14,5\% de la población española entre los 25 - 60 años es obesa, lo que indica que tiene un IMC superior a 30. Afecta más a mujeres que a hombres; de la población femenina un $15,7 \%$ presenta obesidad y un 13,3 de los varones sufre la enfermedad. Un 39\% presenta un IMC entre 25 y 29 que es indicativo de sobrepeso afectando este aumento de peso más a los varones (45\% frente al $32 \%$ en mujeres).(8)

La importancia de la obesidad como enfermedad crónica radica en dos factores, la elevada tasa de complicaciones y comorbilidades que genera, y una relación directa entre su intensidad y la mortalidad.(10)

Las complicaciones suponen elevados costes económicos, $(6,9 \%$ del gasto sanitario) la mayor parte de esa cifra corresponde a costes sociales (servicios y productos que gastan los obesos para combatir la obesidad) y el resto se destina al tratamiento de enfermedades asociadas como la Diabetes tipo 2, enfermedades cardiovasculares y alteraciones del metabolismo lipídico, dislipemias, hipertensión arterial y a la artrosis de rodilla. (11) 
La esperanza de vida desciende en relación inversa al porcentaje de sobrepeso; ésta disminución, se estima en 4 años para sobrepeso del 25\% y $\quad 9-10$ años para los pesos superiores al 100\%. El riesgo de muerte súbita es tres veces mayor cuando el exceso de peso supera el $20 \%$ y la tasa de mortalidad estandarizada en los obesos es superior para numerosas patologías.

El objetivo sanitario no debe ser conseguir un peso ideal sino, una reducción del mismo ya que, una disminución, aunque sólo sea de un 5\% del peso, se considera suficiente para obtener mejorías clínicamente significativas de los trastornos asociados a la obesidad y una pérdida de $10 \mathrm{~kg}$, se relaciona con una disminución de un $20 \%$ de la mortalidad global.(3) Lo más difícil del tratamiento de la obesidad, es la intención de modificar hábitos y estilos de vida lo que complica el cumplimiento de los tratamientos basados en dieta y ejercicio físico y hace más fácil el cumplimiento de un tratamiento mediante productos de origen farmacológico. Sólo el 34\% de los obesos sigue algún tratamiento médico para controlar su peso. Si a esto añadimos el enorme fracaso terapeútico de la obesidad a medio y largo plazo, el desconocimiento sobre la etiopatogenia de la enfermedad y el escaso interés del personal sanitario directamente involucrado en su control, nos encontramos con la necesidad de estudios que investiguen, evalúen y hagan su seguimiento para avanzar en su conocimiento. Debemos conseguirlo desde un marco de método científico para poder contrarrestar el inmenso mercado de "remedios y soluciones milagrosas" con las que se estafa y daña constantemente a los pacientes obesos que recurren a cualquier lugar donde les ofrezcan soluciones para su enfermedad.

\section{I.3.CRITERIOS PARA DEFINIR LA OBESIDAD}

Se padece obesidad, cuando el peso corporal supera más del $20 \%$ del considerado peso ideal.(12) En la práctica, la obesidad es el exceso de peso referido a una edad, sexo y talla determinada.(l) El aumento cuantitativo de la grasa en el organismo nos lo determina el IMC que es el parámetro objetivo más preciso. Padece obesidad toda aquella persona con un IMC igual o superior a $30 \mathrm{~kg} / \mathrm{m} 2$. Según el índice de masa corporal se clasifica a los pacientes en distintos grados: I, II y III. 


\section{Criterios para definir la obesidad en grados según el IMC (WHO-OMS).}

\section{Valores límite del IMC (kg/m2)}

Normopeso

Sobrepeso

Obesidad tipo I

Obesidad tipo II

Obesidad tipo III
$18,5-24,9$

$25,0-29,9$

$30,0-34,9$

$35,0-39,9$

$>40 \quad I M C=$ indice de masa corporal

WHO.Obesity, 1998. Guidelines

OMS: Organización Mundial de la Salud

\section{Sobrepeso y Obesidad según el IMC}

Peso insuficiente
Normopeso
Sobrepeso grado I
Sobrepeso grado II (preobesidad)
Obesidad de tipo I
Obesidad de tipo II
Obesidad de tipo III (mórbida)
Obesidad de tipo IV (extrema)

Peso insuficiente

$18,5-24,9$

$25-26,9$

$27-29.9$

$30-34,9$

$35-39,9$

$40-49.9$

$>50$

(SEEDO 2000 - 2007)

Los pacientes con IMC mayor de 30 tienen mayor riesgo de padecer DM, HTA, colelitiásis, hiperlipémias, enfermedades respiratorias y cardiopatía isquémica.(3) Además un IMC de más de 30 tiene un riesgo de mortalidad que se incrementa según aumenta la masa corporal.(13,14,15) La distribución de la grasa también es indicador de riesgo de padecer complicaciones asociadas a la obesidad.

\section{I.4.FISIOPATOLOGÍA DE LA OBESIDAD Y GASTO ENERGÉTICO.}

La obesidad se produce por un desequilibrio entre ingesta calórica y gasto energético. El estado de obeso se caracteriza por un incremento del número de adipocitos y por un aumento de tamaño de los mismos. El adipocito es el determinante de la obesidad por ser el almacén principal de la grasa y por su condición de órgano secretor de sustancias con efectos bioquímicos importantes ya que produce:

- Leptina: hormona que participa en la homeostasis del peso corporal y del gasto energético aumentando el gasto de energía y la termogénesis, a través de su acción sobre el neuropéptido $\mathrm{Y}$, tiene también una acción simpática central mediada por la tirotropina, que favorece el incremento de la T/A, es por eso, entre otras razones, que el obeso mantiene el apetito y es propenso además a la HTA. 
Participa en el sistema de señales de acción de la insulina con efectos de bloqueo, que explicarían la insulinorresistencia del obeso.

- Angiotensinógeno: es producido por el hígado, su RNAm se expresa en el tejido adiposo al ser capaz de convertirse en angiotensina I. Su expresión aumenta en la obesidad y su síntesis adipocitaria, que es mayor en el tejido adiposo visceral, está influenciada por el estado nutricional (aumenta con el peso corporal).

- Inhibidor del activador tisular del plasminógeno (ITP-1): su producción es estimulada, por la insulina y la leptina, y guarda una estrecha relación con la grasa abdominal.

- Interleukina 6: (IL6) tiene gran relación con el IMC ya que un tercio de ella se produce en el tejido adiposo, sobre todo en la grasa visceral.

- FNTalfa: La cantidad total que se produce está relacionada con la adiposidad corporal y la hiperinsulinemia. Está incrementado en el obeso, y tambien en los estados de insulinorresistencia.

- Factor de necrosis tumoral beta (FNTbeta): Está aumentada en el obeso por estímulo del FNTalfa. Estimula la proliferación preadipocitaria, lo que favorece el elevado número de células del tejido graso del obeso.

- Factor de crecimiento celular: Produce proliferación de diferentes células. Es mediador de la hormona del crecimiento.

- Ácidos grasos libres (AGL): Su liberación, está aumentada en la mayoría de los obesos por lo que se inhibe la captación de glucosa y la síntesis de glucógeno dependiente de la insulina y disminuyen su oxidación. Antagonizan a nivel hepático la acción de la insulina, favorecen un estado de resistencia que lleva a un incremento en la síntesis de glucosa endógena. Los ácidos grasos libres potencian la secreción basal de insulina, y la liberación de insulina dependiente de glucosa que lleva a hiperglucemia, hiperinsulinemia e insulinorresistencia.

- Adipsina: se correlaciona con la adiposidad por un sistema regulador dependiente del aumento de la insulina y los glucocorticoides.

- Adiponectina: Su secreción está modulada por la insulina, por lo que depende de factores nutricionales. Está disminuida en el obeso. Estimula la oxidación lipídica, disminuye los triglicéridos y aumenta la sensibilidad a la insulina, inhibe la aterogénesis y la inflamación. Es un marcador de resistencia insulínica y de riesgo cardiovascular. - Prostaglandinas: PGI-2 y PGF-2. 
En una persona no obesa el aporte de energía y el gasto energético deben mantenerse en equilibrio. En la obesidad el aporte supera al gasto y éste exceso se acumula en el organismo en forma de grasa. El gasto energético basal está en relación con la edad (menor gasto energético a mayor edad), sexo (es mayor en los varones), y sobre todo, con la talla y el peso o superficie corporal. El gasto energético basal es aproximadamente de un $60 \%$ - 70\% del gasto energético total.(1)

$$
\begin{aligned}
& \text { Hombres }=1 \mathrm{kcal} \times \text { hora } \mathrm{x} \mathrm{kg} \text { de peso. } \\
& \text { Mujeres }=0,9 \mathrm{kcal} \times \text { hora } \mathrm{x} \mathrm{kg} \text { de peso. }
\end{aligned}
$$

Con la edad y por disminución de todos sus componentes, el gasto energético total de va disminuyendo.(16) El metabolismo (gasto energético basal), es máximo en los primeros años de vida y su descenso es moderado y progresivo hasta los 20 años. Entre los 20 y los 30 años se mantiene estable y a partir de los 30-40 hay una disminución de un 3\% aproximadamente cada diez años. El gasto energético muscular también va disminuyendo según se va perdiendo masa muscular y va decreciendo la actividad y el ejercicio físico. Este descenso del gasto energético, conlleva menor movilización de la grasa de reserva, menor oxidación y por ello facilita el aumento de peso y su perduración.(1,12)

En la obesidad el gasto energético es normal, pero el gasto energético muscular y por actividad mínima es inferior que en el normo-peso.(17)

Diferentes trabajos con personas obesas han encontrado correlaciones entre los depósitos grasos corporales y la oxidación lipídica. Podría ser que la expansión de los depósitos grasos producida por dietas con un alto contenido en grasas, facilitará la posterior oxidación en estadíos postdinámicos. En personas post-obesas, el consumo de dietas ricas en grasas, a medio-largo plazo, podría conducir a la instauración de obesidad a causa de las alteraciones existentes en el metabolismo lipídico.

Otros trabajos han encontrado que individuos genéticamente predispuestos a la ganancia de peso corporal, aumentan las reservas adiposas cuando son sometidos a dietas ricas en grasa durante largos períodos de tiempo. También se ha demostrado que la ingesta de alimentos ricos en grasa suprimía en menor medida el apetito en los individuos obesos que en los delgados. Los mecanismos que afectan a esta susceptibilidad en los individuos predispuestos pueden estar relacionados con su menor capacidad para oxidar grasas. 
El aporte lipídico de la dieta se ha relacionado tradicionalmente con la hiperfagia, a causa de su bajo poder saciante, elevadas palatabilidad y densidad energética, así como por su pobre regulación metabólica. Hoy en día, sin embargo, no se conoce si la cantidad y el tipo de lípido consumido pueden determinar la cantidad de grasa corporal en los humanos. La literatura científica indica que los incrementos agudos en la cantidad de grasa de la dieta inducen cambios metabólicos y conductuales que favorecen el depósito adiposo, pero en el hombre no se han encontrado relaciones causales entre grasa de la dieta y obesidad; se han observado diferentes efectos sobre el balance lipídico en relación a la composición de la grasa dietética; un alto consumo de grasa en forma de ácidos grasos poli-insaturados hace que la acumulación corporal de grasa sea menor que con ácidos grasos mono y saturados.

Los obesos parecen tener menor capacidad para aumentar la oxidación lipídica en respuesta a los aumentos de su ingesta, que los hace más susceptibles a ganar peso corporal al aumentar los depósitos adiposos a la vez que oxidan, en igual proporción, mayor cantidad de hidratos de carbono y menor de grasas cuando se compara con los delgados, quizás por una menor sensibilidad a la insulina que aumenta las concentraciones plasmáticas de la hormona, manteniendo la utilización de los glúcidos y limitando la lipolisis, afectando así la oxidación y el balance de grasa total.

El organismo tiene la capacidad para alcanzar un balance de los sustratos en condiciones de equilibrio energético. El gasto energético por tono muscular es menor en los obesos por ser menos activos y musculosos y por tanto tener menor proporción de fibras musculares tipo I, fibras de contracción lenta que consumen grasa, respecto a las de tipo II que son de contracción rápida y consumen glucosa.

Aunque en principio la acumulación de tejido adiposo en el organismo depende básicamente del comportamiento alimentario y del metabolismo energético, ambos factores están condicionados por, la predisposición genética y los factores ambientales, que pueden modular la tendencia genotípica y pueden ser los que finalmente determinen el que se produzca o no, el disbalance energético y por tanto la obesidad. Una vez establecida, la obesidad produce una alteración endocrino-metabólica que tiende a perpetuarla.

En el desarrollo de la obesidad hay fases estáticas, donde se mantiene el peso constante seguidas por fases dinámicas, durante las que se gana peso; el aumento ponderal se acompaña del incremento en el gasto energético para equilibrar ingesta y gasto y con el tiempo alcanzar una nueva "meseta" con un mayor peso corporal. 
Los períodos cortos de sobrealimentación suponen aumentos en los depósitos de glucógeno, pero si este período se alarga, el exceso energético se acumula sobre todo como grasa y pequeños incrementos de la masa magra corporal. La distribución de macronutrientes de la dieta interviene en la regulación del peso y composición corporal, así como en las respuestas metabólicas originadas. La regulación del balance energético a corto plazo se consigue mediante cambios en la utilización de los nutrientes, a medio plazo el peso y la composición corporal parecen depender de la regulación de la ingesta. Los cambios en la oxidación de sustratos en respuesta a alteraciones en la ingesta, puede predecir los efectos de la composición de la dieta en el peso y la composición corporal a largo plazo. Las dietas altas en grasas llevan a la ganancia de peso y aumento de los depósitos grasos por estimulación de la sobrealimentación e inhibición de la oxidación de grasas y aumento de la lipogénesis. El metabolismo se ajusta a la composición en macronutrientes de la dieta ya que la mayoría de las células del organismo utilizan sustratos derivados de todos los macronutrientes, excepto el sistema nervioso central, dependiente de un adecuado aporte de glucosa, o en su defecto de cuerpos cetónicos.

La mezcla de sustratos metabólicos utilizada por el organismo varía a lo largo del día, las oscilaciones afectan poco al contenido proteico y mantiene estables las concentraciones de glucógeno hepático. El organismo ha desarrollado mecanismos metabólicos que adaptan la oxidación de glucosa y aminoácidos a la ingesta de hidratos de carbono y proteínas por encima del mantenimiento del balance de grasas. Las diferencias en los balances energéticos diarios pueden ser rápidamente acomodadas por ganancias o pérdidas en los depósitos grasos. La composición de la mezcla de sustratos energéticos se controla principalmente por cambios en los niveles de sustratos y hormonas circulantes, que a su vez están regulados por la ingesta de nutrientes, por el ejercicio físico, por las necesidades proteicas, el grado de depleción del glucógeno hepático y la masa del tejido adiposo. Las desviaciones en los balances de sustratos (diferencia entre la ingesta y la oxidación), conducen a cambios en la composición de los diferentes compartimentos corporales hasta alcanzar un nuevo equilibrio.

En personas predispuestas y como factores independientes de la herencia que pueden desencadenar o favorecer la obesidad podemos citar a los fármacos que aumentan el apetito y a los que frenan la lipolísis produciendo un ahorro energético.

También los fármacos que favorecen la insulino-resistencia pueden contribuir y favorecer la persistencia de la obesidad. Ciertos medicamentos potencian la ganancia ponderal y además pueden afectar de forma negativa el adelgazamiento cuándo se instaura el tratamiento.(l) 


\section{I.5.ETIOPATOGENIA DE LA OBESIDAD}

La obesidad se define como un exceso de grasa corporal debido a un balance positivo en la ecuación energética, que puede provenir de una ingesta excesiva, o de un descenso en el gasto energético, o a ambos factores. Se estima que del $40-70 \%$ de la variación en los fenotipos relacionados con la obesidad es hereditario, mientras que las influencias ambientales podrían explicar cerca del 30\% de los casos de obesidad. Existen inter-acciones entre genotipo y factores ambientales, aunque hay diferencias interindividuales en las distintas respuestas a interacciones dietéticas.

1) Obesidad y genética

La variabilidad interpersonal que se produce en la respuesta de variación de peso, a una misma ingesta y actividad física, está determinada por factores genéticos.(18) La predisposición genética está relacionada tanto con el control de la ingesta como con el del gasto energético, e interactúa con los elementos ambientales que a la larga, definen la masa corporal de un sujeto.(12) Muchos genes están implicados en la obesidad, algunos en el control de la ingesta (neuropéptido, leptina, POMC, $\mathrm{CCK}, \mathrm{MCH}$, etc.), otros en la regulación de la termogénesis (receptores adrenérgicos $b 2$ y b3, proteínas desacoplantes, leptina, ...), en la adipogénesis, etc. Hay enfermedades autonómico dominantes (PraderWilli), recesivas (Bardet-Bield), ligadas al cromosoma X (Wilson-Turner) en las que la obesidad es una manifestación clínica. La susceptibilidad genética puede actuar sobre el metabolismo basal, disminuyendo la oxidación macronutrientes, sobre el perfil hormonal, incluyendo la sensibilidad a la insulina, sin descartar posibles interacciones entre genes. De todas formas la obesidad es un síndrome complejo de origen multifactorial, que podría ser explicado por mutaciones monogénicas, y en la mayoría de los casos parece resultar de interacciones poligénicas, a su vez afectadas por factores ambientales. Las formas monogénicas, más asociadas con obesidades mórbidas, suelen ser formas autonómicas recesivas, que pueden presentar alteraciones de las vías centrales que controlan la ingesta de alimentos (vía leptina-propiomelanocortina). La mayoría de los cuadros clínicos se asocian a una herencia de carácter poligénico o multifactorial, junto con los determinantes ambientales. Las interacciones del genotipo con factores ambientales son un determinante para establecer el papel de la dieta y la actividad física sobre la genética de la obesidad, también asociada a diversos cuadros metabólicos influenciados por la herencia, como son los perfiles de lípidos y lipoproteínas plasmáticas y distintos fenotipos ligados al metabolismo de la glucosa y de la insulina. 
2) Obesidad y nutrición y metabolismo

El balance energético viene determinado por la ingesta de macronutrientes, el gasto energético y la oxidación de los sustratos energéticos. La mayor parte de los individuos alcanzan un peso y la composición de los sustratos energéticos que oxidan se ajusta con la distribución de macronutrientes en su dieta El ajuste individual entre la composición de los sustratos que oxidada y la distribución de macronutrientes de la dieta podría determinar la estabilidad del peso a corto y largo plazo.

La ganancia de peso puede también depender de la distribución de los sustratos energéticos de la dieta, ya que pueden condicionar el metabolismo y el apetito, así como la respuesta del sistema nervioso simpático, el balance energético y el peso corporal. (159) En individuos sanos que reciben una dieta rica en glúcidos frente a una dieta hipergrasa presentan altas tasas de oxidación de glucosa, mayor efecto termogénico e incremento de la frecuencia cardiaca como indicador de la actividad simpática; en una intervención dietética similar en obesos, se apreció que estos sujetos fueron menos eficientes al oxidar la grasa y tenían una tasa de lipogénesis superior. La influencia de la grasa de la dieta sobre la obesidad es discutida, existen argumentos contradictorios sobre la implicación de la grasa dietética en la obesidad, ya que la reducción del consumo de grasa y el uso frecuente de productos bajos en calorías en algunos países se ha relacionado con un incremento paradójico en la prevalencia de obesidad.

3) Obesidad y actividad física

El gasto energético puede influenciar el peso y la composición corporal mediante cambios en el metabolismo basal, en el efecto termogénico de los alimentos y en la necesidad energética por la actividad física. Los resultados existentes sugieren que una situación de sedentarismo es un factor importante de incremento en la prevalencia de la obesidad. Así una baja actividad físico-deportiva o un alto número de horas de actividad sedentaria en el trabajo son predictores significativos de padecer obesidad.

Las interacciones entre la herencia genética y el ejercicio físico han sido valoradas en gemelos y se ha concluido que la predisposición genética puede modificar el efecto de la actividad física sobre los cambios de peso en ambos sexos, y que el estilo de vida puede tener un efecto específico sobre la obesidad dependiendo de la predisposición genética.(159) El peso tiende a permanecer constante en el adulto por largos periodos de tiempo, a pesar de las fluctuaciones en la ingesta y el gasto energético, para lo que existen procesos de regulación, que ajustan el aporte de nutrientes y las demandas de energía. 
El control del peso corporal y la composición depende de tres componentes relacionados entre sí: apetito, metabolismo de nutrientes y termogénesis y los depósitos grasos corporales, y existen mecanismos entre ellos de retroalimentación, aunque hay que asumir que el peso corporal está determinado por la interacción de factores genéticos, dietéticos, actividad física y psicosociales que actúan por mecanismos reguladores del apetito y del metabolismo energético. La distribución de los macronutrientes en la dieta, o la diferente participación de los componentes del gasto energético y el metabolismo de nutrientes específicos influencian también la ecuación energética. El control del apetito se ha atribuido a la existencia de un nivel fisiológico fijado para el peso corporal, a procesos glucostáticos o glucogenostáticos, la utilización homeostática de sustratos energéticos, la participación del sistema nervioso y la existencia de un adipostato mediado por señales producidas en el tejido adiposo.

4) Obesidad y fármacos con riesgo iatrogénico.

En personas predispuestas y como factores independientes de la herencia que pueden desencadenar o favorecer la obesidad, existen fármacos que aumentan el apetito y que frenan la lipolísis produciendo un ahorro energético.(12) Otros fármacos, favorecen la insulino-resistencia y pueden contribuir y favorecer la persistencia del aumento de peso. Existen medicamentos que potencian la ganancia ponderal y además pueden afectar de forma negativa el adelgazamiento cuándo se instaura el tratamiento.(1)

Los fármacos con efectos demostrados sobre el peso son los siguientes:

- hipotensores : mayor riesgo los B-bloqueantes por presentar resistencia insulínica y los diuréticos que producen una alteración homeostásica de la glucosa.

- psicotropos: sobre todo ansiolíticos y antidepresivos aumentan el apetito y producen un aumento de peso.

- glucocorticoides: tienen efectos hiperglucemiantes, movilizan grasas que se acumulan en distintas zonas por efectos de la insulina.

- anticonceptivos hormonales orales y estrógenos pueden ocasionar retención de líquidos; en tratamiento con terapia hormonal sustitutiva, los efectos sobre el peso dependen de la susceptibilidad individual y de la dosis de progestágenos.

- antidiabéticos orales tienden a producir ganancia de peso. La insulina favorece el depósito de grasa en los adipositos.

- antimigrañosos aumentan el apetito de forma dosis dependiente.

- antiepilépticos favorecen el incremento de peso al aumentar la biodisponibilidad de los ácidos grasos (sobre todo el valproato). 
- antihistamínicos aumentan el apetito y pueden producir incremento de peso.

5) Obesidad y edad

La edad también es un factor muy importante a considerar. El sobrepeso aumenta a partir de los 55 años en el hombre y los 50 años en la mujer.(2,16,19)

También el nivel de educación y el económico/profesional parecen tener influencia en la aparición del sobrepeso ya que, es más frecuente en personas de bajo nivel cultural y en sujetos con ingresos económicos más bajos.(2,10,12) El peso suele aumentar después del matrimonio y en las mujeres el IMC aumenta con la paridad.(2)

6) Obesidad de causa secundaria:

\section{Síndromes endocrinológicos}

Hipotiroidismo

Síndrome de Cushing

Hipogonadismos (Síndrome de Klinefeltter)

Insulinoma

Ovario poliquístico

Pseudohiperparatiroidismo.

\section{Síndromes hipotalámicos}

Tumores

Traumatismos

Enfermedades inflamatorias

Síndrome de la silla turca vacía

Distrofia adiposogenital

Síndrome de Parder

Otros

Lipomatosis múltiple

Lipodistrofia

\section{I.6.TIPOS DE OBESIDAD}

Adelgazar, si uno es obeso no es fácil. La pérdida de grasa es un mecanismo muy complejo que depende de muchos factores como la regulación de la insulina, del sistema nervioso, hormonas glucocorticoideas, estrógenos, andrógenos y progesterona $\mathrm{y}$ también, de la herencia genética.(18), además los cambios en el peso y la redistribución de la grasa tienen una relación clara con la edad.

La progesterona aumenta el apetito, enlentece el transito intestinal asimilándose más nutrientes, disminuye la sensibilidad a la insulina y aumenta la retención hídrica. 
La bajada de estrógenos produce un aumento de peso aunque no está demostrado claramente como se produce.(20)

La distribución de la grasa "androide" o abdominal por un lado y "ginoide" o glútea por otro, tiene especial interés desde el punto de vista pronóstico y sirve para valorar el riesgo que lleva asociado padecer la enfermedad.(21,22) La distribución de la grasa posee una gran importancia a la hora de predecir las posibles complicaciones derivadas de la obesidad. El índice cintura/cadera (ICC) es una determinación muy sencilla (circunferencia de la cintura / circunferencia de la cadera) y la más utilizada para valorar la distribución de la grasa. (Este índice se considera un factor de riesgo mayor para enfermedad coronaria y muerte, independientemente del sexo del paciente y de cual sea su IMC).(3,13,19,22,23,24)

\section{Tipos:(10,25)}

1) Obesidad androide, central o abdominal. El exceso de grasa se localiza sobre todo en cara, tórax y abdomen. Se asocia a mayor riesgo de diabetes, enfermedad cardiovascular, dislipémias, y de mortalidad en general.

2) Obesidad ginoide o periférica. La grasa se acumula básicamente en cadera y muslo. Se relaciona principalmente con problemas del retorno venoso en las extremidades inferiores (varices) y artrosis de rodilla (gonartrosis).(14,26)

3) Obesidad homogénea. El exceso de grasa se distribuye por todo el cuerpo, no predomina en ninguna zona en particular. Además de las patologías propias de la obesidad aparecen problemas articulares y alteraciones psíquicas con más frecuencia

Para determinar el tipo de obesidad hay que dividir el perímetro de la cintura por el de la cadera; si en caso de la mujer es mayor de 0,8 y en el varón superior a 1 se considera la obesidad de tipo androide. Aunque la obesidad por sí misma aumenta la morbilidad y la mortalidad, en el caso de que el exceso de grasa sea visceral, ésta asociación es más fuerte. La obesidad abdominal constituye por sí misma, un factor de riesgo que incrementa, de forma considerable, la mortalidad sobre todo, por enfermedad cardiovascular $(5,13)$ debido a tres factores fundamentales como son su localización, sus peculiaridades metabólicas (los adipocitos del tejido adiposo visceral son metabólicamente muy activos con mayor sensibilidad a estímulos lipolíticos y poco sensibles a estímulos antilipolíticos) y su especial sensibilidad a estímulos hormonales y nerviosos (alteración eje hipofiso-suprarrenal por estrés, depresión, ansiedad, tabaco, alcohol... alteración en la secreción de andrógenos...) (1,2,19,24) 


\section{I.7.VALORES DE RIESGO SEGÚN LA DISTRIBUCIÓN DE LA GRASA CORPORAL.}

(Datos antropométricos)

Criterio

Índice cintura/cadera

Circunferencia de la cintura (SEEDO)

National Institutes of Health (NIH)

Diámetro sagital
Valores límite

$\begin{array}{ll}\text { Varones } & \text { Mujeres } \\ >1 & >0,90^{*} \\ >1 & >0,85^{* *} \\ >95 \mathrm{~cm} & >82 \mathrm{~cm} \text { valores de riesgo } \\ >102 \mathrm{~cm} & >90 \mathrm{~cm} \text { valores de riesgo elevado } \\ >102 \mathrm{~cm} & >88 \mathrm{~cm} \text { valores de riesgo } \\ >25 \mathrm{~cm} & \text { valores de riesgo } \\ * \text { SEEDO } 95 & * * \text { SEEDO } 2000\end{array}$

La distribución de la grasa, si se presenta sobre todo, en el hemicuerpo superior, produce importantes complicaciones y cambios metabólicos en el paciente que la padece. $(1,2,3,19)$

\section{I.8.COMPLICACIONES DE LA OBESIDAD}

La obesidad es un síndrome metabólico que se asocia a una elevada morbilidad y mortalidad ligada a enfermedades como la arterioesclerosis, la HTA, la DM, enfermedades cardiovasculares, osteoarticulares, dislipémias, determinados tipos de cáncer... $(1,2,3,10,19,27,28)$ Los aumentos de peso discreto tienen poca repercusión sobre la mortalidad, pero aumenta, cuando el IMC supera la puntuación de 25 a 27.

El incremento de mortalidad está relacionado sobre todo con los problemas cardiovasculares que aumentan incluso en obesidades moderadas, aunque no debemos olvidarnos de otras complicaciones posibles, como la diabetes o la hipertensión arterial.(29) La enfermedad coronaria, los accidentes cerebrovasculares y la diabetes mellitus son la principal causa de muerte en los obesos. Diferenciado por sexos, los varones con un incremento del 10\% del peso, supone un aumento de un $30 \%$ del riesgo coronario. El riesgo que supone la obesidad para la salud está muy influido por el patrón de distribución de la grasa corporal. Distintos datos epidemiológicos permite afirmar que la obesidad central es un dato predictivo de mortalidad global.(24,30,31,32)

La relación obesidad - enfermedades cardiovasculares y metabólicas es muy alta cuando la acumulación de grasa es predominantemente central.(1,3) El tejido adiposo intraabdominal, a diferencia del subcutáneo, es más celular, más vascularizado, tiene más receptores esteroideos y androgénicos así, como más cantidad de lipolísis inducida por catecolaminas. Esto lo convierte en un tejido metabólico más activo y más susceptible a estímulos hormonales y cambios en el metabolismo lipídico. 


\section{a) ALTERACIONES METABOLICAS EN OBESOS}

- Incremento del colesterol total

- Aumento de cLDL y descenso de cHDL

- Escasa respuesta antilipolítica a la insulina en el tejido adiposo visceral

- Elevación de la tasa de ácidos grasos libres portales y sistémicos

- Hiperinsulinemia e insulinoresistencia

- Disminución de la captación hepática de insulina

- Aumento en la síntesis de VLDL

- Incremento de concentraciones plasmáticas de Apo B

- Hipertrigliceridemia

- Disminución de la actividad lipoproteinlipasa plasmática y muscular

- Elevación de la actividad de la trigliceridolipasa hepática

- Disminución de cHDL2 y aumento cHDL3

- Elevación del cociente colesterol total/cHDL

- Incremento de los triglicéridos en HDL y LDL

- Presencia de LDL pequeñas y densas

- Exacerbación de la hiperlipémia postprandial

- Incremento en la oxidación de las lipoproteínas

- Alteración en la secreción de esteroides sexuales

(SEEDO 2000)

\section{b) PRINCIPALES ENFERMEDADES ASOCIADAS A LA OBESIDAD}

- Diabetes Mellitus tipo 2

- Hipertensión Arterial

- Dislipémias: hipertrigliceridemia, aumento de c-LDL y disminución de c-HDL

- Cardiopatía isquémica

- Alteraciones osteoarticulares: coxofemoral, femorotibial, tobillo y columna

- Insuficiencia venosa en extremidades inferiores

- Accidentes cerebrovasculares

- Hiperuricemia y gota

- Enfermedades digestivas: esteatosis hepática, hernia de hiato y litiasis biliar

- Apnea del sueño

- Insuficiencia respiratoria

- Trastornos psicológicos

- Alteraciones cutáneas

- Tumores malignos: colon, recto, próstata, ovario, endometrio, mama, vesícula biliar. 
La prevalencia de la Diabetes Mellitus tipo 2 está aumentando por el envejecimiento de la población y el aumento de la obesidad.(l) Un 75\% de los diabéticos no insulino-dependientes son obesos y este incremento se convierte en el factor de riesgo más importante para padecer Diabetes tipo 2 en edades medias de la vida.(1) Una vez instaurada la diabetes los pacientes con mayor grado de obesidad tienen mayor riesgo de mortalidad que los diabéticos delgados.(15)

La asociación obesidad-HTA es muy conocida aunque no se han determinado de forma exacta los mecanismos patógenos que las unen; se habla de sensibilidad a la sal, hiperreactividad del SNS, hiperinsulinemia y resistencia insulínica.

Las alteraciones lipídicas que aparecen con mayor frecuencia en el obeso son, la hipertrigliceridémia y el descenso de los valores de cHDL en ayunas. La dislipémia es más frecuente en la obesidad de predominio visceral que en la no visceral, lo que indica que la acumulación de grasa en la cavidad abdominal es un factor de riesgo significativo para la DM, enfermedad cardiovascular y para la mortalidad que se relaciona con ellas.

La arterioesclerosis, es más frecuente en obesos por las dislipémias que presentan y por el aumento de los fenómenos oxidativos.

El incremento de peso guarda una estrecha relación con los problemas osteoarticulares que van a presentar los obesos. La artrosis de rodilla tiene una correlación clara con el IMC lo que hace pensar en un factor biomecánico como causa de patología articular.(1) Pérdidas de peso aunque sean discretas en sujetos obesos o con sobrepeso hacen que se reduzcan entre un 20 y un $50 \%$ el riesgo de presentar gonartrosis y si ésta patología ya está presente una pequeña pérdida del peso corporal mejora la sintomatología del paciente.

A la obesidad también se la relaciona con la hiperuricemia y en el caso de la mujer, con la litiásis biliar.

También se relaciona a la obesidad con algunos tipos de cáncer al aumentar su incidencia.(28)

La obesidad no sólo produce patología orgánica. Los efectos de la enfermedad a nivel psíquico y social ocasionan a estos pacientes problemas personales, laborales y de relación muy importantes con graves consecuencias y de difícil solución y tratamiento.

El tratamiento médico de la obesidad basado fundamentalmente en medidas higiénico-dietéticas, que asocian dieta, ejercicio físico y la modificación del comportamiento alimentario, se asocia a resultados pobres a largo plazo. 


\section{Obesidad y diabetes mellitus tipo 2}

La DM tipo 2 es un trastorno heterogéneo donde el $85 \%$ de los diabéticos de éste tipo es por resistencia a la insulina y la causa más importante de insulinoresistencia es la obesidad.(1) a pesar de que la mayoría de los obesos (80 \%) no desarrollan DM tipo 2, y es que se necesita una base genética favorable para que se produzca. Cuanto más temprano comience la obesidad a instalarse, más temprano es también el debut de la diabetes; la edad de inicio de la DM tipo 2 está en relación con la edad de inicio de la obesidad. A medida que el peso corporal aumenta, disminuye la sensibilidad a la insulina. La respuesta es un incremento en la secreción de insulina por un aumento en la masa de células beta del páncreas. En las personas con predisposición genética para esta enfermedad, se ha comprobado una disminución de la masa de célula beta de hasta un $60 \%$. Se calcula en cerca de 200 millones, el número de personas en el mundo con diabetes, cifra que aumentará para alcanzar los 330 millones para el año 2025, debido en gran medida al crecimiento de la población, el envejecimiento, la obesidad y la vida sedentaria.

En España, la Diabetes Mellitus constituyen la tercera causa de mortalidad en las mujeres y la séptima en los varones, cifras influidas por el aumento de los casos de obesidad en el país. El 80\% de las personas con diabetes tipo 2 sufre sobrepeso o es obeso. Además de la predisposición genética, la obesidad es el principal factor de riesgo de la enfermedad en edades medias de la vida.(l) La probabilidad de desarrollar diabetes cuando se es obeso depende de la interacción varios factores: el grado de obesidad, el nivel de grasa abdominal, la predisposición genética a desarrollar resistencia a la insulina y la capacidad de producción de insulina.

La presencia de DM tipo 2 y la obesidad tiene consecuencias muy negativas, su prevalencia es muy alta, la obesidad favorece su aparición y desarrollo, y aumenta sus consecuencias. A esto hay que sumar la frecuente presencia de otros factores de riesgo cardiovascular junto a estas patologías, constituyendo el "Síndrome Metabólico" (dislipemia, insulinorresistencia, obesidad e HTA), con alta morbimortalidad.

La relación obesidad-insulinorresistencia e hiperinsulinemia es un hecho probado según numerosos estudios, donde se observa que un aumento de 10 puntos en el IMC, hace que la sensibilidad a la insulina disminuya en un $25 \%$, aunque la correlación mas fuerte se establece entre acúmulo de grasa visceral y resistencia a la insulina. Los mecanismos que explican cómo el exceso de grasa visceral favorece la resistencia a la insulina debida a que en la obesidad hay un incremento del TNF $\alpha$ que afecta al principal transportador de glucosa GLUT- 4, alterando el sistema de señales de insulina. 
El aumento del tejido adiposo conlleva que se altere el metabolismo lipídico acumulándose los triglicéridos en hígado y músculo; alteran el sistema de señales de la insulina y su transporte; potencian la secreción de insulina y disminuyen su captación periférica, lo que contribuye a la hiperinsulinemia con insulinorresistencia; compiten con la glucosa como fuente de energía, provocando mayor hiperglucemia. Existe una alteración en la secreción hormonal del adiposito (resistina, adiponectina...). La insulinorresistencia es un proceso inflamatorio crónico desarrollado a bajo ruido y un factor predecesor de DM tipo 2, y otras patologías. El perfil metabólico de la insulinorresistencia incluye: obesidad abdominal, hipertrigliciridemia, disminución de la HDLc, hiperuricemia, aumento del inhibidor del activador tisular del plasminógeno 1, hiperagregabilidad plaquetaria y disfunción endotelial. Es en el endotelio donde se desarrollan la mayoría de los eventos que dan origen a las complicaciones de la obesidad y a la insulinorresistencia: la agregabilidad plaquetaria, la adhesividad, el depósito de lipoproteínas, la hiperreactividad, la proliferación celular y la coagulabilidad, fenómenos directamente proporcionales a la sobreproducción de sustancias en un adipocito hiperplasiado y/o hipertrofiado.

\section{Obesidad e Hipertension arterial}

La asociación obesidad e HTA está bien establecida, aunque no se conocen de forma exacta sus mecanismos patógenos pero el $50 \%$ de los obesos desarrollan HTA en algún momento de la enfermedad. Los mecanismos patogénicos son múltiples; por una parte la hiperinsulinemia provoca aumento de la reabsorción de sodio y agua; el sistema nervioso simpático desempeña una función importante ya que la actividad simpática aumenta con la ingesta, la hiperinsulinemia y la hiperleptinemia del obeso, además de provocar una disminución de la vasodilatación arteriolar. El angiotensinógeno aumenta según lo hace el tejido graso.

La presencia de HTA en el obeso confluye frecuentemente con las alteraciones lipídicas, lo que añade un riesgo a las alteraciones vasculares.

\section{Obesidad, enfermedad coronaria y dislipidemia}

Las alteraciones lipídicas más frecuentes en el obeso son, la hipertrigliceridémia y la disminución de los valores de cHDL en ayunas. En sujetos más jóvenes, el índice de masa corporal también se relaciona con el colesterol total y el LDL-colesterol.(l)

La obesidad constituye uno de los principales factores de riesgo para el desarrollo de la enfermedad coronaria, (29) y si el inicio de la obesidad es a edades tempranas (infancia o adolescencia), la aparición de la enfermedad coronaria es también temprano. 
La arterioesclerosis se incrementa en obesos por las anomalías lipídicas que presentan y por un incremento de los fenómenos oxidativos (muestran una mayor oxidación de partículas lipoproteícas sobre todo, VLDL y LDL). La dislipémia es mayor en la obesidad de predominio visceral, lo que indica que la acumulación de grasa abdominal es un factor de riesgo significativo para la enfermedad cardiovascular e incluso para la mortalidad derivada de ella. Una disminución de la sensibilidad a la insulina lleva asociado un incremento en el riesgo de la enfermedad coronaria, lo que no es raro teniendo en cuenta las alteraciones que esto provoca. El perfil lipídico que más se observa en el obeso, y que por sí solo causa lesión vascular, es el incremento de los triglicéridos expresado en un aumento de las lipoproteínas de muy baja densidad (VLDL), y una disminución de las lipoproteínas de alta densidad (HDL), a lo que pueden añadirse otras alteraciones que como resultado final originan un perfil aterogénico ya que:

a) las VLDL pueden atravesar la pared vascular y acumularse en la placa de ateroma, y al ser ricas en colesterol, liberar más colesterol por partícula a la pared

b) la disminución de las HDL y ApoA-1 significa menor función antiaterogénica y antioxidante en el endotelio

c) las LDL pequeñas y densas son más aterogénicas.

A estas circunstancias se une el estado procoagulante que favorece la obesidad y explica el aumento del riesgo de enfermedad coronaria que se produce en ella.

\section{Obesidad y SAOS}

El SAOS o Síndrome de Apnea Obstructiva del Sueño, es un trastorno respiratorio relacionado con el sueño, que consiste en la obstrucción completa y/o parcial recurrente de las vías respiratorias durante el sueño, con persistencia de la actividad de los músculos respiratorios y diafragmáticos, un reducido o ausente flujo naso-bucal, hipercapnia y desaturación oxihemoglobínica(33). Se caracteriza por presencia de apneas, con caída de la saturación de oxígeno tisular y ronquido intenso durante el sueño, que conlleva a una desectructuración del mismo y que desencadena los síntomas que asocia como la excesiva somnolencia diurna, perdidas de memoria, hipertensión arterial,... etc. El SAOS lo presenta un alto porcentaje de los pacientes con obesidad, más en varones.

\section{Obesidad y enfermedad cerebrovascular}

La enfermedad cerebrovascular es la tercera causa de muerte en el mundo desarrollado y su influencia en la morbilidad y discapacidad es también grande. La obesidad es un factor de riesgo importante para su desarrollo. 
Los cambios endoteliales, producidos por el incremento del tejido adiposo y la liberación de mediadores y sustancias por el adiposito, favorecen la coagulación y la adherencia plaquetaria. La coexistencia de HTA, dislipémia, enfermedad coronaria y DM tipo 2, favorecen la enfermedad y aumentan el riesgo de un evento cerebrovascular.

\section{Obesidady alteraciones osteoarticulares}

Aumento de peso y problemas osteoarticulares van generalmente asociados sobre todo la artrosis de rodilla. Pequeñas pérdidas de peso mejoran notablemente la sintomatología osteoarticular que refieren los obesos. Además de la artrosis de rodilla, en la obesidad se incrementa el riesgo de presentar patologías a nivel coxofemoral, femorotibial, tobillo y columna.

\section{Obesidad e hiperuricemia}

También se relaciona obesidad con hiperuricemia y ésta, a su vez, con el riesgo de sufrir cardiopatía isquémica. Las personas que presentan aumento del ácido úrico tienden a presentar intolerancia a los hidratos de carbono, dislipémia, obesidad e HTA.

\section{Obesidad y litiasis biliar}

En la mujer, la litiásis biliar se relaciona con la obesidad presentándose en un alto porcentaje de los casos. En los varones la frecuencia es menor.

\section{Obesidad y cáncer}

También se relaciona a la obesidad con algunos tipos de cáncer ya que aumenta su incidencia.(28) Es factor de riesgo de carcinoma de mama, endometrio, ovario, cervix, vesícula y vías biliares en la mujer. En el varón se ha visto que aumenta la incidencia de presentar carcinoma de colon, recto y próstata.(1)

\section{Obesidad y psicología}

Además de la afectación orgánica, la obesidad desencadena importantes consecuencias psicosociales ya que produce limitaciones vitales, laborales, dificulta las relaciones interpersonales y origina una disminución de la calidad de vida que supone afectación en el funcionamiento físico, mental y en el bienestar del paciente obeso.

En general la población obesa sufre un incremento de la mortalidad total y presenta mayor riesgo mortalidad precoz.(2) 


\section{I.9.TRATAMIENTO}

La presión social juega un papel trascendente ya que hace que una parte muy importante de la población se preocupe de modificar su peso corporal mediante métodos muy diversos, la mayoría de las veces, no comprobados e inútiles para los fines buscados.(5) El tratamiento médico de la obesidad basado en medidas higiénicodietéticas, que asocian dieta, ejercicio físico y la modificación del comportamiento alimentario, se asocia a resultados pobres a largo plazo.

Gran parte del problema social que ocasiona la obesidad, procede de una inadecuada comprensión de su significado biológico y de sus causas bioquímicas reales. El desconocimiento de la etiología de la obesidad origina la aparición de remedios para combatirla, sin base científica y generalmente ineficaces. $(1,2,3,4)$

No está claro que la obesidad sea una entidad nosocomial en todos los casos, de hecho, el sobrepeso ligero puede aportar una cierta protección contra algunas enfermedades.

La obesidad sólo podría ser definida como una patología en los casos en que sí se pueda demostrar que ocasiona problemas metabólicos y funcionales reales al paciente; probablemente, se podría limitar el término patológico para las obesidades de grado II o III según la terminología actual.(1,2)

Los objetivos del tratamiento van encaminados a disminuir la grasa corporal, manteniendo la masa magra, mantener la pérdida de peso lograda a largo plazo, prevenir las ganancias futuras y mejorar la capacidad funcional y la calidad de vida. Hay que conseguir disminuir los factores de riesgo cardiovasculares (hipertensión) y metabólicos (dislipémia, hiperglucémia, hiperuricémia, etc.) y disminuir el dolor lumbar o de rodillas en pacientes con artrosis agravada con la sobrecarga de peso. Esto se logra con una reducción del 5 al $10 \%$ del peso corporal.

Debemos modificar los hábitos alimentarios, reestablecer el equilibrio psicosomático y mejorar la autoestima y realizar una valoración nutricional del paciente obeso de forma individual según sus características y su situación personal.

En la actualidad, además de las medidas higiénico-dietéticas basadas en modificación de hábitos alimentarios con dietas saludables, evitando hábitos tóxicos y ejercicio físico adaptadas según las características del paciente, existen fármacos, algunos aún en fase de estudio, para el tratamiento de la obesidad que actúan a distintos niveles como son reduciendo el apetito, aumentando la eliminación de grasas, estimulando la termogénesis, regulando la saciedad... 
REVISIÓN II:METABOLISMO MINERAL 


\section{II.1.METABOLISMO MINERAL Y ÓSEO}

El conjunto normal del esqueleto depende de una ingesta adecuada de proteínas, minerales y vitaminas esenciales en la dieta. La normalidad orgánica precisa, no sólo de las funciones minerales, sino de un adecuado equilibrio entre los mismos.

Las sales minerales, son necesarias en el organismo humano para cubrir sus exigencias funcionales, además de para mantener un adecuado equilibrio hidroelectrolítico e iónico para que las funciones vitales se produzcan con normalidad. Los principales componentes iónicos del organismo son los cationes sodio, potasio, calcio y magnesio así como los aniones cloruro, sulfato y bicarbonato.

La matriz mineral del hueso está principalmente integrada por calcio y fósforo, junto con cantidades traza de otros iones como sodio, magnesio, cinc, citrato y carbonato. Debido a que la mayor parte del calcio total del organismo, se encuentra en el esqueleto, los cambios en el contenido cálcico del organismo son indicativos de cambios en la masa ósea. La máxima cantidad de hueso ganada durante el crecimiento es factor determinante de la masa ósea del adulto, así como del riesgo de fractura. Los factores genéticos son importantes para la determinación del pico de masa ósea, pero existen otros factores ambientales como la nutrición y la actividad física que también intervienen.(34) El desarrollo óptimo del tejido óseo está en relación directa con el contenido de calcio que se ingiere con la alimentación.(35,36,37) Durante la tercera década de la vida es cuando se produce la maduración del tejido óseo, y se necesita un balance positivo de calcio con la dieta durante este periodo. A partir de esta edad, el proceso se invierte y comienza una pérdida de masa ósea progresiva.(38)

Componentes de la dieta influyen sobre la absorción, metabolismo y excreción del calcio con efectos positivos o negativos sobre la masa ósea.

El organismo puede aumentar la eficiencia de absorción, o reducir la excreción cuando hay una aportación limitada de calcio o aumentan los requerimientos aunque, esta adaptación, puede tardar meses en reestablecer el equilibrio, y puede ser menos efectiva en personas de edad avanzada.

Estudios recientes han demostrado la existencia de mayor densidad ósea y menor incidencia de fracturas en grupos de población con una dieta rica en productos lácteos.(39,40) La malnutrición, el síndrome de malabsorción intestinal, dietas pobres en calcio etc, originan un pico de masa ósea inadecuado y asocian un mayor riesgo de padecer alteraciones óseas a lo largo del tiempo. La nutrición puede causar alteraciones en la estructura y función ósea originadas por deficiencias o por excesos nutricionales. 
De las posibles alteraciones, es de especial interés, por su alta prevalencia, sobre todo, la osteoporosis. Aunque determinados elementos nutritivos están en relación con ésta enfermedad, la información actual no es concluyente, la relación de la osteoporosis con el calcio es una determinación muy compleja. Además del calcio, otros nutrientes están relacionados con alteraciones óseas de mayor o menor severidad como ocurre con determinadas vitaminas y algunos minerales.

\section{II.2.MACROELEMENTOS Y MICROELEMENTOS}

Los elementos minerales del organismo, agua y alimentos, se clasifican de forma cuantitativa, en dos grupos con importancia desde el punto de vista nutricional. Se distinguen los llamados macroelementos minerales que están presentes en concentraciones altas y los microelementos u oligoelementos que están presentes en pequeñas concentraciones.

$\begin{array}{lrcr}\text { Macroelementos } & \mathbf{m g} / \mathbf{k g} & \text { Microelementos } & \mathbf{m g} / \mathbf{k g} \\ \text { Calcio } & 14.000 & \text { Hierro } & 50-60 \\ \text { Fósforo } & 11.000 & \text { Cinc } & 30 \\ \text { Azufre } & 2.000 & \text { Flúor } & 40 \\ \text { Potasio } & 2.000 & \text { Cobre } & 1,2 \\ \text { Sodio } & 1.400 & \text { Boro } & 0,7 \\ \text { Cloro } & 1.200 & \text { Yodo } & 0,2 \\ \text { Magnesio } & 300 & \text { Manganeso } & 0,2 \\ \text { Selenio } & 0,2 & & \\ \text { Cromo } & 0,1 & & \\ \text { Molibdeno } & 0,1 & & \\ \text { Arsénico } & 0,1 & & \\ \text { Cobalto } & 0,03 & & \\ \text { Vanadio } & 0,3 & & \\ \text { Níquel } & 0,1 & \text { (Schroeder, 1982). } \\ \text { Litio } & 0,04 & & \end{array}$

\section{II.3.METABOLISMO DELCALCIO}

En los mamíferos más del 95\% del calcio, 85\% del fósforo y más del 50\% del magnesio total de su economía, se localiza en el esqueleto óseo(45) que además de armazón mecánico, es una reserva dinámica y fuente de éstos elementos. 
En el adulto el contenido de calcio es de 1.000 a 1.200 gr y más del 95\% se acumula en el tejido óseo en forma de hidroxiapatito. Su acumulación varía con la edad, aumenta los primeros años de vida y a partir de la edad adulta disminuye progresivamente. El resto del calcio corporal se encuentra en los líquidos intra y extracelular y desempeña numerosas funciones celulares.

La concentración total de calcio en el plasma o suero sanguíneo es constante. La calcémia suele descender levemente con la edad, en el hombre junto con la disminución de las proteínas plasmáticas y la albúmina; en la mujer, sin embargo, los valores plasmáticos de calcio se mantienen prácticamente constantes. Las propiedades fisiológicas del calcio están en función del calcio iónico libre. El calcio ligado a proteínas, sobre todo a la albúmina y globulina representa un $46 \%$ del total y entre ellas, la que tiene mayor afinidad es la prealbúmina. El grado de unión a las proteínas y de ionización depende del $\mathrm{pH}$, que si es ácido, la unión es menor. También influye los electrolitos fosfato, magnesio, bicarbonato...

\section{Calcio intracelular}

La mayor parte está en forma de sales de fosfato tricálcico en las mitocondrias; un flujo de iones calcio, por transporte activo, mantiene los gradientes de concentración entre las mitocondrias, el citosol y el medio extracelular, al tiempo que permite, que se realicen intercambios rápidos entre estos tres compartimentos. Este calcio intracelular representa sólo 11 gr. de los 1.100gr. del calcio total. El tejido óseo presenta dos compartimentos, uno de tejido óseo profundo, y otro que alberga el calcio de intercambio rápido y en el que se depositan (aposición) y del que se extraen, (resorción) a diario, de 300 - 500mg. de calcio. El valor de la calcémia depende, por último, del equilibrio de los movimientos de calcio entre estos compartimentos, así, como de la absorción intestinal y de las pérdidas intestinales y urinarias; todos estos mecanismos son objeto de regulación hormonal.(41,42,43,44,45)

\section{Calcio extracelular}

El calcio en sangre, es aproximadamente de $9,5 \mathrm{mg} / \mathrm{dl}$ y va descendiendo con la edad, correlacionándose con los niveles plasmáticos de albúmina.

El calcio extracelular se encuentra de tres formas:

a) unido a proteínas plasmáticas, sobre todo albúminas y globulinas (40\%).

b) combinado con sustancias del líquido extracelular como citrato y fosfato (10\%).

c) calcio ionizado. Es la forma fisiológicamente activa (50\% del total del plasma). (45) 


\section{Calcio óseo}

La estructura ósea está compuesta de un $35 \%$ en peso, de matriz orgánica que contiene colágeno y proteoglicanos principalmente y un $65 \%$ de componentes inorgánicos (calcio y fósforo principalmente).

El calcio óseo se encuentra de dos formas:

1) Calcio intercambiable: es fácilmente depositado y reabsorbido, está en forma de cristales amorfos de fosfato monocálcico, poco fijados al hueso y muy pequeños, lo que permite una fácil movilización tanto para depositarse como para reabsorberse. Representa un $1 \%$ aproximadamente del calcio óseo total.

2) Calcio en depósito: es menos intercambiable. Constituye el 99\% del calcio óseo. La forma química es hidroxiapatito formando cristales en los cuales además de los iones indicados hay sodio, magnesio, carbonatos y citratos.(45)

\section{Dinámica ósea}

En la edad adulta existe un equilibrio entre depósito de calcio y reabsorción ósea (remodelado óseo) que es de aproximadamente 180gr. de calcio al año y que permite que no haya cambio neto en la masa ósea. A partir de la cuarta o quinta década de la vida se produce una alteración en ese equilibrio; predomina la reabsorción sobre la deposición ósea y en consecuencia, hay una pérdida de masa ósea que varia, especialmente, en función del sexo, siendo mayor en la mujer; esa pérdida puede alcanzar el 1\% al año. La citada disminución es independiente de las variaciones en la ingesta cálcica y otros hábitos alimentarios.(38)

La formación y reabsorción óseas dependen de:(46)

a) Osteoblastos y osteocitos. Responsables de la formación ósea. Los osteocitos son osteoblastos que han formado la matriz orgánica y se encuentran rodeados por ella.

b) Osteoclastos. Son células multinucleadas que dan lugar a monocitos circulantes macrófagos tisulares y son responsables de la destrucción ósea.

\section{Función}

- Estructural: El calcio es fundamental en la configuración estructural del hueso y dientes. - Mensajero intracelular: El calcio implicado en este mecanismo sería el calcio ionizado, que es sin duda el transmisor biológico de señales más común que se conoce.

- Cofactor proteico.

\section{Absorción.}

De los 0,5 a 1 gr de calcio que se ingieren de media al día, se absorbe del 25 al 70\% en función de diversos factores dietéticos y hormonales.(47) Durante el crecimiento la absorción alcanza hasta el 75\%, mientras que en los adultos disminuye al $30-60 \%$. 
Entre los factores que afectan a la absorción del calcio se encuentran el nivel de calcio ingerido, edad, ingesta de vitamina D y el estado general del equilibrio del calcio.(45)

\section{Mecanismos de absorción.}

Para su absorción a través del epitelio intestinal, el calcio debe de estar en solución. El calcio puede estar en estado soluble en el alimento o puede ser solubilizado en el aparato digestivo con la acción combinada del ácido gástrico, enzimas intestinales y actividad motora gastrointestinal. El calcio se absorbe por este epitelio a través de la célula o entre ellas.

\section{Transporte transcelular.}

Es un proceso activo saturable, localizado en intestino proximal, sobre todo, duodeno y primera porción del yeyuno. Existe en la membrana en cepillo una proteína capaz de fijar calcio dependiente de vitamina D. La entrada se realiza a favor de un gradiente electrónico.

\section{Transporte paracelular.}

En el adulto, la absorción se estima en un 35\% respecto a la cantidad ingerida posible, pero en realidad, la absorción del calcio depende de distintos factores que la influencian en mayor grado.

\section{Factores que afectan a la absorción.}

\section{Factores hormonales.}

La hormona D es un importante regulador de la absorción de calcio; también la PTH aumenta el transporte intestinal del catión, de manera indirecta, estimulando la síntesis del 1,25(OH)2D3. La cortisona y otros corticoides, a altas dosis, disminuyen la absorción de calcio. Tambien afectan a la citada absorción y metabolismo del calcio la hormona del crecimiento y somatomedina, estrógenos, hormonas tiroideas, insulina y glucagón.

\section{Factores dietéticos.}

Se ha sugerido que el fosfato y ciertos iones (sodio, potasio, estroncio, magnesio) disminuyen la absorción intestinal de calcio.(35,36) La existencia de sustancias quelantes, capaces de precipitar el mineral, disminuyen la cantidad de calcio disponible para ser absorbido, entre ellas se encuentran los oxalatos y fitatos. El inhibidor más importante del mineral es el ácido oxálico, muy abundante en espinacas y en ciertas leguminosas. El ácido fítico presente en cereales y otros alimentos es un inhibidor débil de la absorción de calcio. Mejorando la absorción están azúcares (lactosa, sacarosa) y ciertos aminoácidos (lisina, arginina).(47) El papel de la lactosa es controvertido, parece que es cierto en lactantes, pero deja de favorecer la absorción de calcio de forma significativa, a mayor edad y adultos. 
En cuanto a las proteínas la calidad y cantidad proteica mejoran la absorción del mineral y con relación a la grasa, ésta, sólo limita su absorción en caso de esteatorrea.

Las brasicáceas (coles, coliflor, bróculi, coles de Bruselas, berzas...) son ricas en calcio y éste, muestra una buena disponibilidad, al parecer del orden del calcio lácteo.

\section{Metabolismo}

Una parte del calcio óseo existe también en forma de cristales amorfos combinados con fosfato. La relación normal calcio-fosfato en el hueso es de 1,5 / 1, ligeramente menor que la que se encuentra en la hidróxiapatita pura. El proceso de cristalización ósea implica la transformación del fosfato de calcio amorfo en hidróxiapatito, en el espacio extracelular óseo, el fosfato cálcico está en equilibrio con los iones calcio y fosfato.

El hueso participa activamente en la homeostasis de calcio, ya que puede ser estimulado por determinadas hormonas o agentes metabólicos. Al contrario que el mineral del esmalte dentario, el hueso está continuamente sometido a un proceso de remodelación y movimiento, que normalmente libera a la sangre y después reacumula entre $250 \mathrm{mg}$ y 1gr. al día. El recambio del calcio esquelético varía con la edad.(38,48,49,50) En el adulto, una vez finalizado el crecimiento longitudinal, la tasa de recambio es aproximadamente del 2 al 4\% anual. El crecimiento esquelético no cesa durante la vida adulta. A partir de la $4^{\mathrm{a}}-5^{\mathrm{a}}$ década predomina la resorción ósea, por lo que la masa esquelética disminuye paralelamente al aumento de la edad, a un ritmo de $0,7 \%$ año de la masa total aproximadamente. Las características más señaladas son que en adultos jóvenes la masa esquelética es mayor en el varón que en la mujer, la pérdida comienza antes en la mujer que en el varón y en la mujer, aunque se instaura antes de la menopausia, la pérdida es claramente acelerada por ella.(51)

No se sabe axactamente cómo se produce el intercambio entre el calcio óseo y el circulante. Este proceso dispone de menos del 1\% de calcio corporal total y, junto con el calcio óseo intercambiable, comprende el depósito de calcio rápidamente difusible. Dado que la mayor parte de calcio esquelético se encuentra en una forma no rápidamente intercambiable, para evitar la hipocalcémia y mantener la homeostasis, es necesario que el calcio sea movilizado por procesos de resorción activa. Los cambios en la resorción ósea consecuencia de la actividad en la maquinaria celular existente dependen de la continua transformación de los restos celulares no diferenciados en osteocitos, osteoblastos y osteoclastos. La respuesta osteocítica y osteoclástica a la PTH es el mejor mecanismo de control facilitador de la resorción ósea. Inhibe la resorción ósea la calcitonina, que es secretada por las células parafoliculares del tiroides y su actividad sobre los osteoclastos es rápida y de corta duración ante una elevación del calcio ionizado circulante. 
La calcitonina y PTH constituyen un doble sistema de control proporcional que mantiene constante la concentración de calcio extracelular.

El calcio que se absorbe con la dieta, entra a formar parte del calcio circulante extracelular (1.000mg), que es captado por todos los tejidos del organismo, se establece una relación especial con el hueso y está en equilibrio con el calcio óseo intercambiable. Con el calcio menos intercambiable se instaura el proceso de remodelado óseo, dónde $500 \mathrm{mg} /$ día se depositan en el hueso y $500 \mathrm{mg}$ /día se liberan por resorción ósea.

La regulación homeostática del calcio plasmático lo mantiene a una concentración aproximada de $2.5 \mathrm{mM}(9-10 \mathrm{mg} / \mathrm{dl})$ por la actuación de varias hormonas que actúan a nivel del calcio intercambiable; si la concentración de calcio plasmático disminuye, se libera PTH que produce un aumento del aclaramiento renal de fosfato y una activación de la vitamina D para producir la forma activa (hormona D) que incrementa la absorción intestinal de calcio y la activación de las zonas de reabsorción ósea con aumento de la actividad osteoclástica y un aumento de la reabsorción tubular renal de calcio.

El riesgo de hipercalcemia, que puede ocurrir si se altera la regulación metabólica se soluciona de manera diferente en adultos y en niños. En los primeros se produce una disminución en el umbral renal para el calcio, lo que facilita la excreción de un exceso del mismo y en los niños por su pequeño volumen de líquido extracelular, el riesgo de una hipercalcemia puede existir tambien por una ingesta excesiva. Esto se soluciona a través de la calcitonina, que es estimulada por la citada hipercalcemia y a través de señales enviadas por hormonas gastrointestinales que informan del grado de absorción intestinal de calcio. La calcitonina reduce o detiene la actividad osteoclástica, disminuyendo la reabsorción ósea.

En el adulto la menor absorción de calcio y el mayor volumen del líquido extracelular impiden una hipercalcémia por ingesta excesiva de calcio.

\section{Excreción}

La excreción de calcio se produce por heces y orina principalmente. También por sudor, piel descamada, los pelos y las uñas. La excreción fecal, resulta de la porción no absorbida del alimento, más el calcio endógeno que procede de células mucosales descamadas y de las secreciones salival, gástrica, intestinal y biliar, y que puede llegar a ser de 100 a 150mg/día. Los valores normales de excreción urinaria de calcio al día van de 100 a 300gr. La excreción por sudor y fecal es poco importante. La cantidad de calcio filtrado a través del riñón, está determinada por la tasa de filtración glomerular y la concentración plasmática de calcio ultrafiltrable (calcio ionizado y el unido a aniones de bajo peso molecular), siendo en el adulto de 7 a 10gr/día. 
Del calcio filtrado, más del 98\% se absorbe a nivel tubular renal, dos terceras partes en el túbulo proximal y el tercio restante en el asa de Henle, túbulo contorneado distal y túbulos colectores. El calcio no reabsorbido se excreta por orina, entre 100 y 200mg/día.

\section{a) Regulación hormonal de la excreción urinaria.}

En el túbulo proximal el calcio es reabsorbido mediante un mecanismo pasivo y entra en la célula mediante canales de calcio y sale fundamentalmente vía ATPasa Ca2+. Además de la vitamina $\mathrm{D}$, también regula la excreción renal de calcio la PTH que incrementa la reabsorción tubular del ión, mientras aumenta la excreción de fosfato. La hormona de crecimiento y las hormonas tiroideas provocan hipercalciúria al igual que los glucocorticoides, estos últimos posiblemente por producir aumento de la proteolísis ósea.

\section{b) Factores nutricionales que afectan a la excreción urinaria de calcio.}

Existe una relación exponencial entre el calcio de la dieta y el urinario, por lo que grandes variaciones en la ingesta conducen paralelamente a leves cambios en la excreción. La excreción urinaria, se ve más afectada por la absorción de calcio intestinal que por la ingesta, cuanto mayor sea la absorción, mayor será el cambio absoluto en el calcio urinario. Las variaciones en la excreción son superiores en los jóvenes que en los ancianos, ya que en éstos la capacidad de absorción no ha disminuido. El aumento de la ingesta de fosfatos inorgánicos produce disminución de la excreción urinaria de calcio y disminuye su depuración renal. Hay hipercalciúria en la depleción severa de fosfato.(35,36)

Una elevada ingesta de magnesio también produce hipercalciúria, al igual que la elevada ingesta proteica y la acidosis, en este último caso parece ser por un incremento de la resorción ósea. La parathormona aumenta la reabsorción tubular distal de calcio, la calcitonina causa hipercalciúria como también las hormonas del crecimiento, tiroideas y los glucocorticoides. Los estrógenos disminuyen la excreción urinaria del calcio indirectamente ya que antagonizan la acción de la PTH. Diversos componentes alimentarios afectan a la excreción urinaria de calcio sobre todo el sodio dietético ya que ambos comparten el mismo sistema de transporte en el túbulo proximal. Por cada 2,3gr de incremento de sodio excretado por la orina, se excretan conjuntamente $24-40 \mathrm{mg}$ de calcio, lo que puede ser especialmente importante en la mujer postmenopaúsica ya que un gramo de exceso de sodio al día puede llegar a provocar una pérdida adicional de calcio del $1 \%$ anual.

Las proteínas afectan al calcio óseo en dos sentidos: la deficiencia conduce a la descalcificación y el exceso también.(52) 


\section{Deficiencia.}

El déficit alimentario de calcio provoca problemas relacionados con la desmineralización ósea. Las causas más importantes por las que se produce deficiencia de calcio y desmineralización ósea son el escaso aporte de vitamina $\mathrm{D}$, insuficiente ingesta de calcio en la dieta, excreción aumentada del catión, relación calcio/ fósforo muy baja en la alimentación $(35,36)$ y todos los factores que estimulan la secreción de la PTH. Están implicados en la desmineralización ósea progresiva con la edad: disminución de la relación estrógenos/andrógenos, menor actividad física y el tipo de dieta.(34,38,53,54)

\section{Toxicidad}

La hipercalcemia puede llegar a producir una pérdida importante de tono muscular, estreñimiento, poliuria, naúseas y finalmente confusión mental, coma y muerte. En cuanto a problemas de litiasis renal por ingesta excesiva de calcio, ocurre en individuos susceptibles y cuando esto sucede se debe más bien y sobre todo a una gran excreción urinaria de calcio, en general producida por una reabsorción ósea aumentada.

El recambio diario aproximado de calcio en el adulto es el siguiente:

$\begin{array}{lr} & \text { mg } \\ \text { Ingestión } & 1.000 \\ \text { Absorción intestinal } & 350 \\ \text { Secreción de los jugos gastrointestinales } & 250 \\ \text { Absorción neta sobre la secreción } & 100 \\ \text { Pérdida por las heces } & 900 \\ \text { Excreción por la orina } & 100\end{array}$

\section{II.4.METABOLISMO DEL FÓSFORO}

El fósforo junto al calcio, forman los cristales de apatita que se depositan sobre la matriz del colágeno y que representan el $85 \%$ del fósforo del organismo. La concentración plasmática de fosfatos es más elevada en el niño y disminuye con la edad, se estabiliza sobre los 25 años. Las concentraciones de fósforo inorgánico en el interior de los espacios intracelulares oscilan entre 5 y $20 \mathrm{mmol}$ lo que le permite ser uno de los principales amortiguadores de $\mathrm{pH}$ de éstos líquidos.(45) Esto es importante si se considera que en la menopausia se produce un descenso de estrógenos (sustancia fosfatúrica) y existe una correlación positiva entre el fósforo sérico y el grado de resorción ósea en las mujeres de mediana edad y ancianas. Además del fósforo inorgánico, el plasma contiene unos $9 \mathrm{mg} / 100 \mathrm{ml}$ de fosfatos en forma de ésteres y fosfolípidos 
A diferencia de lo que ocurre con el calcio, cuya concentración es muy estable, la de fosfatos experimenta variaciones relacionadas con la ingesta, con la excreción renal y con un ritmo circadiano: los valores mínimos se observan por la mañana y van seguidos de una elevación en el transcurso del día hasta alcanzar un máximo hacia las 20 horas. La excreción urinaria de fosfatos sigue estas fluctuaciones.

La regulación del fosfato plasmático no se explica tan bien como la del calcio ya que el fosfato circulante está en equilibrio con el inorgánico esquelético, con el celular y con un elevado número de compuestos orgánicos resultantes del metabolismo celular. Esta regulación se establece por la excreción urinaria y es independiente de la PTH.

El fósforo del hueso tiene función estructural y constituye el mayor reservorio del organismo mientras que el depositado en los tejidos cumple funciones metabólicas y estructurales.

\section{Absorción}

La absorción depende del nivel de ingesta dietética y de la fuente alimentaria. Con una ingesta normal se absorbe entre el 60 y $70 \%$ y con un ingesta muy baja se puede llegar a un $90 \%$. La absorción de fosfato aumenta con el $\mathrm{pH}$ intraluminal sobre los límites de 3,3 - 7,9, aunque se cree que los pH más alcalinos interfieren en la absorción promoviendo la formación de sales de fosfato insolubles. También modifican la absorción de fosfatos los ácidos grasos insaturados, el hierro y el aluminio.

En determinados estados fisiológicos, la PTH y la hormona del crecimiento podrían aumentar dicha absorción. Actualmente se cree que la vitamina D puede estimular dos mecanismos de absorción del fosfato: un proceso duodenal que depende del calcio y un sistema yeyuno independiente de calcio. Intestino, hueso y riñón constituyen los principales órganos involucrados en el mantenimiento del balance de fósforo.

\section{Metabolismo}

El metabolismo del fosfato está regulado por tres hormonas, PTH, 1,25(OH)2D3 y calcitonina. La PTH aumenta la reabsorción ósea del fósforo e incrementa la excreción urinaria de fosfatos, al estimular la actividad de la adenilciclasa de las células de los túbulos proximales.

El incremento plasmático de calcitonina disminuye la reabsorción renal de fosfatos.

\section{Excreción.}

La excreción principal es por riñón. Los cerca de $600 \mathrm{mg}$ /día que se excretan son resultado de la filtración glomerular, la reabsorción tubular proximal y la eventual secreción tubular distal. La mayor parte de fosfato urinario está constituido por fósforo inorgánico, cuya cantidad depende de la que haya sido absorbida por el aparato digestivo. 
Con una función renal normal, la proporción aproximadamente de fósforo urinario suele ser de dos tercios del fosfato de la dieta.

Se sabe que el cortisol y la hormona de crecimiento aumentan la reabsorción y los estrógenos, hormona paratiroidea, tratamientos prolongados con cortisol y elevaciones en el calcio plasmático lo disminuyen.

La cantidad de fósforo diario recomendado es igual a la del calcio, a pesar de que la proporción calcio / fósforo de las dietas ingeridas actualmente es inferior a 0,75.

\section{Efectos metabólicos de la hipofosfatemia.}

Cuando se produce déficit de fósforo aparece una deficiencia de ATP y 2,3 DPG a nivel del glóbulo rojo con la consecuente hemólisis y alteración de la fórmula normal, debilidad y dolor óseo con una osteodistrofia caracterizada por osteomalacia provocando hipercalcémia, hipercalciúria y un equilibrio negativo de calcio, también alteraciones renales que producen disfunción renal y una debilidad muscular debido a un deterioro de la glucólisis celular.

\section{Hiperfosfatemia}

Las principales consecuencias clínicas de la hiperfosfatemia severa se relacionan con la propensión al depósito en tejidos blandos de sales de calcio y fosfato.

\section{Fuentes alimentarias.}

El fosfato abunda en los alimentos sometidos a distintos tratamientos de elaboración, en las bebidas refrescantes del tipo de cola, y en otras bebidas no alcohólicas. También hay concentraciones altas de fosfato en los alimentos ricos en proteínas, como carnes y pescados.

\section{II.5.METABOLISMO DEL MAGNESIO}

El magnesio es uno de los iones intracelulares más abundantes en plantas y animales y juega un papel esencial en muchas reacciones celulares. (45) Las más simples reacciones productoras de energía requieren de magnesio.(glucolísis anaerobia)

\section{Contenido corporal.}

El magnesio está ampliamente distribuido por el organismo, la cantidad total es de unos 20 a 28 gr. Un $60-65 \%$ del total se encuentra en el hueso. El magnesio en plasma puede encontrarse libre (55\%) en complejos (13\%) o unido a proteínas (32\%). 


\section{Funciones.}

Participa en numerosos procesos bioquímicos. El magnesio activa el sistema piruvato oxidasa del cerebro, la fosfatasa alcalina del riñón, eritrocitos y hueso, las fosfatasas ácidas de la próstata etc.

El ión magnesio es un nutriente necesario para la actividad de muchos sistemas enzimáticos que también dependen de distintas vitaminas y minerales traza. El magnesio interviene en el sistema de transporte que introduce calcio en la terminal nerviosa y en el proceso de liberación de acetilcolina.

\section{Absorción}

El magnesio se absorbe en torno al 45 - 70\%. Más del 90\% en el intestino delgado, aunque también a nivel del colon puede absorberse entre un $35-40 \%$. El calcio, los fosfatos, citratos, ácidos grasos, el ácido fítico y las sales biliares disminuyen su absorción, ya que forman con él, compuestos insolubles. Una vez absorbido es transportado a distintos tejidos.

\section{Metabolismo.}

El magnesio del tejido óseo está en una proporción del 20-30\% en la superficie de los cristales de hidroxiapatito y es fácilmente intercambiable. Este magnesio se ve influido por los niveles séricos. El resto se encuentra íntimamente incorporado y no es intercambiable. Una tercera parte del magnesio que ingerimos con la dieta es excretado por la orina, siendo ésta excreción urinaria mínima cuando la ingesta es deficitaria y se estabiliza cuando los aportes son superiores a los normales. El riñón es fundamental en la homeostasis del catión. Del 95 al 97\% del magnesio filtrado es reabsorbido y sólo un 3$5 \%$ es excretado. Diversas hormonas influyen de forma directa o indirecta sobre la eliminación renal de magnesio, siendo la PTH y calcitonina las que aumentan la reabsorción tubular mientras que la hormona somatotropa, la antidiurética, hormonas suprarenales, andrógenos y estrógenos parecen aumentar la magnesúria. Pueden afectar a la biodisponibilidad del magnesio dietético las altas cantidades de calcio y fósforo, la cantidad de proteína que se ingiere puede causar balances positivos o negativos de magnesio, dependiendo de las cantidades relativas de ambos, el exceso de vitamina $\mathrm{C}$ da lugar a un descenso en la concentración tisular de magnesio y el déficit de vitamina $\mathrm{E}$ induce una deficiencia de magnesio.

\section{Toxicidad.}

La infusión de calcio contrarresta la toxicidad del magnesio. 


\title{
Fuentes alimentarias.
}

Son alimentos ricos en magnesio la levadura de cerveza, chocolate en polvo, los frutos secos, legumbres, cereales, frutas, verduras y hortalizas.

\section{II.6.METABOLISMO DEL CINC}

El cinc está presente en todas las células del organismo, en determinados tejidos es más abundante. La cantidad total de cinc en el individuo adulto oscila entre 1,4 y 2,5 g. Su concentración en tejidos blandos como músculo, cerebro, pulmón y corazón es relativamente estable e independiente de los niveles en la dieta. El contenido de cinc en el hueso, testículos, cabello y sangre tiende a reflejar la ingesta del ión. El tejido muscular contiene el $60 \%$ del cinc corporal y junto con el hueso contabiliza el $90 \%$ del total. En plasma cerca de $100 \mathrm{microgr} / \mathrm{ml}$. La sangre total contiene unas diez veces más de cinc que el plasma, debido a la presencia del catión en el enzima eritrocitario anhidrasa carbónica. El cinc unido a la membrana representa una gran parte del cinc celular y parece estar relacionado con su función y estabilidad. (55,56,57)

Este elemento es necesario para el funcionamiento normal de más de 120 enzimas implicados en el metabolismo de los hidratos de carbono, lípidos y proteínas, en los procesos de degradación y síntesis de ácidos nucleicos, en el transporte del bióxido de carbono y en otras muchas reacciones; al formar parte de diferentes deshidrogenasas, actúa en los mecanismos de desintoxicación corporal del alcohol etílico y en el metabolismo de la vitamina A. También participa en la síntesis hepática de la proteína transportadora de retinal. Una de las consecuencias más importantes de la deficiencia de cinc es la inhibición del crecimientola cual puede ser explicada en parte por la anorexia a que da lugar. (55)

\begin{abstract}
Absorción.
El cinc se absorbe sobre todo en el intestino delgado regulado por la síntesis intestinal de metalotioneína, proteína rica en cistina que liga cinc, cobre y otros cationes divalentes. La absorción del cinc oscila del 20 al 50\% según el tipo de dieta y disminuye con la edad. Algunos componentes de la dieta como la fibra y los fitatos disminuyen su absorción. El cobre y el calcio parecen tener poco efecto sobre su absorción, pero los suplementos de calcio pueden incrementar las pérdidas intestinales del ión.(55) Las interacciones entre distintos minerales pueden ser uno de los factores que más influencia tenga en la disponibilidad del cinc.
\end{abstract}


La incorporación tisular de cinc es influída por su ingesta y los glucocorticoides que disminuyen los niveles plasmáticos e incrementan la captación hepática.

\section{Metabolismo.}

El cinc liberado desde las células es transportado por la albúmina. La concentración plasmática de albúmina puede determinar su absorción. Los diferentes tejidos captan de la sangre cantidades variables de cinc, siendo el hígado el que presenta una mayor captación, seguido del hueso, la piel, el riñón y el timo. El estrés, la inflamación y procesos agudos dan una redistribución corporal del cinc. El cinc no se almacena en el organismo y el exceso es eliminado. La excreción del mismo se realiza vía fecal a través de la secreción pancreática, biliar, mucosal y por células mucosales descamadas. En condiciones normales la excreción urinaria es pequeña, aunque puede incrementarse en las enfermedades que dan lugar a un excesivo catabolismo muscular o proteinúria por disfunción renal. La homeostasis del ión es regulada por cambios sobre todo en la absorción y también por la excreción, en respuesta a las distintas ingestas dietéticas. Durante los periodos de bajas ingestas, la homeostasis se mantiene aumentando la absorción y a la reducción de la excreción urinaria y endógena fecal mientras que, con altas ingestas, en la regulación de la homeostasis juega un papel primordial el aumento de las pérdidas endógenas.

\section{Requerimientos de cinc}

Las necesidades de cinc vienen determinadas por factores fisiológicos y dietéticos. Entre los primeros están la edad, el crecimiento, la gestación y la lactancia. De los dietéticos influye la presentación química del ión en los alimentos, su inter-reacción entre el cinc y otros nutrientes y la presencia de compuestos que modifiquen su absorción.

\section{Deficiencia.}

El déficit de cinc ocasiona anorexia, reducción del crecimiento y alteraciones de la maduración sexual. Quemados o pacientes con alteraciones renales suelen presentar déficit de cinc, como también presentan deficiencias pacientes con nutrición parenteral o hemodiálisis. Las interacciones entre distintos minerales pueden ser uno de los factores que más influencia tenga en la disponibilidad del cinc.

El cinc es el menos tóxico de todos los oligoelementos.

\section{Fuentes alimentarias.}

El contenido de cinc en los alimentos difiere ampliamente, destacando la riqueza de las ostras, y en menor proporción los crustáceos, moluscos, carnes rojas y leguminosas. Las grasas, pescados y dulces son relativamente bajos. 


\section{II.7.METABOLISMO DEL COBRE}

Participa en gran número de funciones catalíticas que permiten un funcionamiento correcto del organismo.(56,57) En un adulto de unos $70 \mathrm{~kg}$ de peso el contenido corporal de cobre oscila de 50 a $120 \mathrm{mg}$. El cobre se distribuye entre el hígado un 13\%, el cerebro $9 \%$ y el contenido muscular que se aproxima al $40 \%$. El hígado y bazo parecen actuar como almacén, aunque la capacidad del organismo para almacenar cobre es pequeña.

La principal función del cobre es formar parte de los diversos enzimas.

\section{Absorción.}

Se absorbe sobre todo en duodeno y no varía demasiado con la edad y el sexo. La absorción oscila del 50 al 75\%. Algunos aminoácidos y el citrato incrementan su absorción mientras que la fibra, fitato y ácido ascórbico, pueden disminuirla. Pueden modificar negativamente la biodisponibilidad del cobre, son el cinc, la fructosa y el ácido ascórbico. Las dietas ricas en cinc darán lugar a un descenso de la captación de cobre.

\section{Metabolismo.}

Una vez absorbido el cobre se une sobre todo a la albúmina y en menor proporción a la transcuprina. En algunos órganos se ha visto la existencia de sitios de unión específicos para la ceruloplasmina. Hay una serie de factores fisiológicos, hormonales... que pueden afectar a la síntesis y liberación de ceruloplasmina. La administración crónica de esteroides reduce los niveles séricos de cobre. La gestación y el uso de anticonceptivos orales a base de estrógenos incrementan en dos o tres veces los niveles de ceruloplasmina como también el tabaco y las drogas anticonvulsionantes.

\section{Excreción.}

El cobre se excreta fundamentalmente por el tracto gastrointestinal, siendo la bilis la secreción que más contribuye.

El cobre procedente de la bilis se absorbe poco pero el cobre de las secreciones salivales, gástricas e intestinales es reabsorbido en mayor proporción. Sólo una pequeña parte del ión (menos del 3\%) es excretado por vía urinaria.

\section{Cobre y enfermedad.}

La distribución corporal y metabólica del cobre se encuentra alterada en distintos procesos cancerosos que cursan con elevadas concentraciones séricas de cobre y ceruloplasmina. En los estados inflamatorios también suelen encontrarse elevados el cobre y la curuloplasmina sérica. 
Esta misma situación suele darse en el embarazo, en enfermedades hepático-biliares, en el infarto agudo de miocardio y algunas enfermedades infecciosas como tuberculosis, fiebres tifoideas, hepatitis, bronquitis.

La ingesta de una relación cobre / cinc baja se asocia a mayor incidencia de cáncer de estómago. Se ha observado una relación inversa entre niveles séricos de colesterol (contenido en las LDL) y deficiencia de cobre. Además parece existir una relación entre la ingestión de dietas pobres en cobre (o con alto índice cinc / cobre) e hipercolesterolemia, sugiriéndose que el déficit de cobre puede contribuir a la hipercolesterolemia o hipertrigliceridemia. Si existe déficit de cobre aparecen bajas concentraciones séricas de cobre y ceruloplasmina, puede padecerse anemia microcítica hipocrómica, neutropenia, desmineralización esquelética, degeneración del tejido vascular con aneurismas arteriales, despigmentación cabello y piel, degeneración cerebral/cerebelar, hipotonía e hipotermia.

\section{Fuentes alimentarias.}

Porción germinal de los cereales integrales, frutos secos, leguminosas, hígado, crustáceos y moluscos. La carne, leche y derivados, cereales refinados y productos de panadería son alimentos con contenidos relativamente bajos en cobre.

\section{II.8.METABOLISMO DEL FLÚOR, CROMO, MANGANESO, BORO, SILICIO}

\section{Flúor}

La mayor parte está en los huesos en forma de fluorapatito. Esta sal conserva la dureza del esmalte en dientes y contribuye a mantener estable la matriz mineral ósea.(68)

\section{Cromo}

Se acumula en hígado, riñón, testículos, bazo y hueso. Contienen alto contenido en cromo setas, levadura de cerveza, pimienta negra...

El signo más usual de la deficiencia de cromo es la intolerancia a la glucosa, altos niveles circulantes de insulina, glucosuria, además de anormalidades en el metabolismo de los lípidos y desórdenes nerviosos, menor longevidad, altos niveles séricos de colesterol y TG, alteraciones en el crecimiento, neuropatías, encefalopatías...(56,57)

\section{Absorción y metabolismo.}

El cromo es uno de los elementos con más baja absorción. La presencia de transferrina o albúmina en la sangre podría incrementar la absorción de cromo por difusión pasiva. 


\section{Manganeso}

El manganeso del tejido óseo sólo se libera como resultado del metabolismo normal del hueso o en situaciones que aceleran la resorción ósea. (56,57)

\section{Boro}

Su deficiencia conduce a alteraciones del metabolismo óseo, o del estado oxidativo celular e incluso de funciones cerebrales y de desarrollo psicomotor. $(56,57)$

\section{Silício}

Es cofactor enzimático en la biosíntesis del colágeno, actúa en la formación de hueso, cartílago, tendones y tejido conectivo en general. Su déficit se acompaña de alteraciones óseas, cartilaginosas, arteriales y con el proceso de envejecimiento. (56,57).

\section{II.9. CANTIDADES NECESARIAS DE MINERALES}

$\begin{array}{lc}\text { Sodio } & 3,0 \mathrm{gr} . \\ \text { Potasio } & 1,0 \mathrm{gr} . \\ \text { Cloro } & 3,5 \mathrm{gr} . \\ \text { Calcio } & 1,2 \mathrm{gr} . \\ \text { Fósforo } & 1,2 \mathrm{gr} . \\ \text { Hierro } & 18,0 \mathrm{mg} . \\ \text { Yodo } & 150 \mathrm{microgr} . \\ \text { Magnesio } & 0,4 \mathrm{gr} . \\ \text { Cobre } & \text { desconocido } \\ \text { Cinc } & 15 \mathrm{mg} . \\ \text { Manganeso } & \text { desconocido. }\end{array}$




\section{II.10.ESTRUCTURA Y QUÍMICA DEL HUESO}

El hueso es un tejido muy vascularizado y en continuo remodelamiento, compuesto por células de origen mesenquimal, (osteoblastos, osteocitos y osteoclastos) y una matriz extracelular que, a su vez, posee un componente orgánico (35\%) y otro inorgánico (65\%). Aunque cuantitativamente las células representan una parte muy pequeña del volumen óseo, funcionalmente sintetizan y segregan la matriz orgánica, regulan su distribución y reabsorción, y son claves en el mantenimiento de la calcemia.(46) La matriz orgánica o sustancia osteoide está compuesta de colágeno tipo I (más del 90\%) y pequeñas cantidades de proteínas séricas como la albúmina, y otras quince que no tienen origen plasmático como actina, proteoglicanos, osteonectina y osteocalcina. La albúmina y la alfa-2-glicoproteína presentes en la matriz orgánica, no son sintetizadas por los osteoblastos, proceden de la sangre y se depositan en el hueso durante la mineralización. Osteonectina y osteocalcina son sintetizadas por los osteoblastos. La osteocalcina representa un $25 \%$ de las proteínas no colágenas del hueso. La síntesis de osteocalcina es estimulada por $1,25(\mathrm{OH}) 2$ vitamina $\mathrm{D}$, y por la acción intermediaria de la osteocalcina en la mineralización ósea producida por el metabolito de ésta vitamina.(63) La fracción inorgánica de la matriz ósea es básicamente calcio y fosfato, y en menor proporción magnesio, sodio,manganeso y potasio en forma de fosfatos, carbonatos, citratos, fluoruros e hidróxido.(41,42,43,44) La relación calcio/fósforo varia según la dieta.

Osteoblastos, osteocitos y osteoclastos son la parte celular del hueso. Los osteocitos tienen dos formas: activa o de primer orden e inactiva o de segundo orden. Los osteocitos activos sintetizan colágeno, proteoglicanos, osteonectina y osteocalcina de la matriz osteoide. Según se extienden hacia la matriz osteoide los osteoblastos activos, se alinean unos al lado de otro y después se separan para formar osteocitos tipo II o inactivos. Al quedar los osteoblastos rodeados por matriz sintetizada por ellos se llaman osteocitos. Los osteoclastos son células resultantes de la fusión de fagocitos mononucleares, derivados a su vez de monocitos circulantes en sangre. Tienen una vida media corta (2 días), gran movilidad a lo largo de la superficie ósea y capacidad para reabsorber su matriz.

\section{Mineralización y remodelado óseo}

Los osteoblastos sintetizan abundante fosfatasa alcalina que podría causar un aumento local de fosfato en los nucleos de cristalización, y activar así la mineralización. Al pasar parte de la fosfatasa alcalina a sangre, suele ser buen indicador de la tasa de formación de hueso. El colágeno también influye en la mineralización. 
La combinación de calcio y fosfato con determinados aminoácidos de las fibrillas facilitaría el inicio de éste proceso. El remodelado óseo depende de la acción conjunta de osteoclastos (reabsorción) y osteoblastos (formadores de hueso), que se produce durante toda la vida del individuo y permite la sustitución continua de hueso "viejo" por “nuevo".(46) Los osteoblastos tienen receptores de PTH sobre su membrana, cuando se fija la hormona, estimula a los osteoblastos que secretan factor estimulante de los osteoclastos y los activan para que reabsorban hueso. La actividad de resorción de hueso de los osteoclastos se encuentra bajo la regulación de dos hormonas: paratiroides y calcitonina producidas por las glándulas paratiroides y tiroides respectivamente. El aumento de la actividad de la paratiroides causa una rápida absorción de sales de calcio del hueso, con la consiguiente hipercalcemia en el líquido extracelular y a la inversa, la hipofunción paratiroidea provoca hipocalcemia, que con frecuencia provoca tetania. La PTH es importante en el metabolismo del fosfato.

El remodelamiento comienza con la activación de los osteoclastos, se sigue de la reabsorción que cuando finaliza, los osteoblastos invaden el área reabsorbida e inician la formación de hueso nuevo. La secuencia -activación de osteoclastos-reabsorciónformación de hueso- constituye la base del concepto de acoplamiento en el remodelamiento óseo, según el cual, existe una coordinación tanto espacial como temporal entre la reabsorción y la formación de hueso. Los procesos de formación y remodelamiento óseo estarán influidos por factores mecánicos, hormonas calciotropas (PTH, calciferoles, calcitonina), hormonas sistémicas (hormona de crecimiento, glucocorticoides, hormonas tiroideas, insulina, hormonas sexuales), factores locales (PGE2), factores de crecimiento óseo, factor activador de los osteoclastos), factores de crecimiento (factor de crecimiento epidérmico, factor de crecimiento de los fibroblastos, factor de crecimiento derivado de las plaquetas, somatomedina) e iones (calcio, $\mathrm{PO} 4 \mathrm{H} 2$ ). $(41,42,58,59)$

\section{II.11.DINAMICA OSEA}

\section{Crecimiento óseo.}

Durante el crecimiento, la formación de hueso es mayor que la destrucción y aumenta la masa esquelética. El pico de masa ósea, donde se alcanza el mayor grado de mineralización está entre los 20-30 años siendo más tardío en la mujer que el del hombre. 
Después hay un equilibrio hasta los 40 años, a partir de aquí la resorción supera la absorción.El equilibrio entre formación y resorción es clave en la homeostasis del calcio. Hasta el $15 \%$ de la masa ósea total sufre remodelado cada año.

\section{Formación ósea.}

La osteona es la unidad funcional de remodelado óseo. Los osteoblastos sintetizan colágeno y constituyen la matriz orgánica donde se depositarán los cristales fosfocálcicos.

\section{Resorción ósea.}

En éste proceso no se extrae calcio sino que éste se libera por proteolísis de la matriz orgánica mediante los osteoclastos, que llevan a cabo su proceso mediante la secreción de ácido láctico y cítrico que ayudan a disolver la parte mineral y por enzimas lisosomales, colagenasa y fosfatasas que degradan la matriz orgánica. El organismo regenera, permanente y durante toda la vida, la matriz mineral del hueso en un ciclo continuo aunque las alteraciones óseas están en relación con la edad. Por esto y conociendo las causas y los posibles factores de riesgo modificables, podemos prevenir la aparición de patologías óseas o en su defecto, retrasarlas. Hay que asegurar una ingesta de calcio adecuada durante el crecimiento para adquirir una masa ósea máxima, sobre todo en la niñez y hasta la treintena. La menopaúsia, por la disminución de estrógenos conlleva una pérdida ósea más acelerada que su reposición; $25 \%$ de su densidad los primeros 5 años.(33)

En los jóvenes el desarrollo del hueso excede a su resorción y en el adulto, completado el crecimiento, el desarrollo de hueso nuevo está en equilibrio con la resorción por lo que se conserva la masa ósea. La resistencia es proporcional al cuadrado de la densidad ósea, por lo que la resistencia es muy sensible a pequeños cambios en la masa esquelética y explica que el riesgo de padecer fracturas es el doble en sujetos con su densidad ósea por debajo del $10-15 \%$ respecto al valor normal. $(41,42)$

\section{II.12.INGESTAS DE CALCIO RECOMENDADAS}

(Instituto Nacional de Salud estadounidense. 1994)

Edad

Hasta los 6 meses

6 - 12 meses

$1-5$ años

$6-10$ años

$11-24$ años

Varones 25-70 años

Mujeres premenopausicas

Mujeres menopausicas con THS

Mujeres menopausicas sin TSH

Embarazo y lactancia

Mayores de 70 años

\section{Ingestión mg/día de calcio}

$$
\begin{aligned}
& 400 \\
& 600 \\
& 800 \\
& 800-1.200 \\
& 1.200-1.500 \\
& 1.000 \\
& 1.000 \\
& 1.000 \\
& 1.500 \\
& 1.200-1.500 \\
& 600
\end{aligned}
$$




\section{Equilibrio entre depósito de hueso y su absorción}

Normalmente, las tasas de depósito y reabsorción de hueso son iguales entre sí, de forma que la masa ósea total permanece constante.

\section{Valoración del remodelado contínuo del hueso.}

El depósito y la reabsorción continuos de hueso tienen cierto número de funciones fisiológicas importantes. El hueso suele adaptar su resistencia al grado de tensión al que se le somete y aumenta de espesor cuando está sometido a cargas importantes. Incluso la forma del hueso puede cambiar de disposición para soportar las fuerzas mecánicas mediante el depósito y reabsorción ósea según los patrones de sobrecarga. El hueso viejo se vuelve frágil y débil y se necesita nueva matriz orgánica a medida que degenera la vieja así, la dureza normal del hueso se mantiene. El hueso se deposita según las cargas de compresión que ha de soportar. La sobrecarga física continua estimula el depósito de los osteoblastos y la calcificación del hueso.

\section{II.13.ACCIÓN DE LAS DISTINTAS HORMONAS SOBRE LOS HUESOS}

\section{FORMACIÓN ÓSEA}

Estimulación

Hormona del crecimiento

Insulina

Estrógenos

Hormona D3

Factor de crecimiento Beta

Factor de crecimiento esquelético

Factor de crecimiento derivado del hueso

Factor de crecimiento de plaquetas

Calcitonina

\section{Inhibición}

Hormona paratiroidea

Cortisol

Calcitonina

Factor de crecimiento Beta

Alfa-Interferon.

\section{RESORCIÓN ÓSEA}

Hornona paratiroidea

Hormona D3

Cortisol

T3 y T4

Prostaglandinas

Interleucina 1

Factor de necrosis tumoral

Estrógenos

Andrógenos

\section{a) EFECTOS DE LA PTH}

En líquido extracelular provoca la reabsorción de calcio y fosfato del hueso y disminuye la excreción renal de calcio, además, el descenso de la concentración de fosfato, es originado por un potente efecto renal de la PTH que produce fosfaturia excesiva, que generalmente supera el aumento de la reabsorción de fosfato del hueso.(43)

Sobre el hueso provoca absorción de calcio y fosfato. Una fase es rápida, se activan las células óseas y se produce absorción de calcio y fósforo y una segunda fase mucho más lenta que aumenta la reabsorción osteoclástica del propio hueso y no sólo de fosfato cálcico. 
a) fase rápida: osteoilísis. La PTH provoca la eliminación de sales del hueso, de la matriz ósea vecina a los osteoclastos a lo largo de la superficie del mismo y también, del hueso amorfo.

b) fase lenta: activación de los osteoclastos. La PTH activa los osteoclastos a pesar de que no tienen proteínas de membrana receptores de la parathormona. Se cree que los osteoblastos y osteocitos envían una" señal" secundaria para activar a los osteoclastos y estos comienzan a reabsorber hueso. La activación de los osteoclastos se produce en dos etapas, una de activación inmediata de los osteoclastos ya formados y otra con la formación de nuevos osteoclastos. Si persiste la estimulación, la reabsorción de hueso puede producir una estimulación secundaria de los osteoblastos que intentan corregir la debilidad ósea. El efecto tardío es que se estimulan tanto los osteoblastos como los osteoclastos, sin embargo en presencia de exceso de PTH, aún en fases más tardías existe más reabsorción de depósito de hueso. La administración ó secreción prolongada de parathormona a lo largo de un periodo de tiempo origina una reabsorción ósea muy evidente. La administración de PTH produce una pérdida rápida e inmediata de fosfato por la orina debido a la disminución de la reabsorción tubular proximal de iones fosfato.

También aumenta la reabsorción tubular de calcio al mismo tiempo que disminuye la reabsorción de fosfato, además incrementa la tasa de reabsorción de iones de sodio, potasio y aminoácidos de forma similar a como lo hace el fosfato. De no ser por el efecto de la PTH sobre los riñones para aumentar la reabsorción de calcio, la eliminación continua de este elemento por la orina implicaría la pérdida completa del calcio óseo. Esta hormona, tambien facilita la absorción de calcio y fosfato en el intestino y aumentando en los riñones la formación de 1,25 dihidrocolecalciferol.

Una mínima disminución de la concentración de calcio iónico en el líquido extracelular hace que las glándulas paratiroideas aumenten rapidamente su tasa de secreción. A su vez, cualquier situación que eleva la concentración de calcio iónico por encima de cifras normales, disminuye la actividad y reduce el tamaño de las paratiroides.

La relación entre la concentración plasmática de calcio y la concentración plasmática de PTH indican que un ligero descenso de la concentración de calcio por debajo de la normalidad puede multiplicar o triplicar la PTH plasmática.

\section{b) EFECTO DE LA VITAMINA D}

La vitamina D desempeña importantes funciones en la reabsorción y en el depósito de hueso. La administración de dosis muy altas causa reabsorción de hueso de forma similar a como actúa la PTH. En ausencia de vitamina D, el efecto de la PTH de provocar reabsorción ósea se reduce mucho o incluso desaparece. 
La vitamina $\mathrm{D}$ en cantidades pequeñas promueve la calcificación ósea al aumentar la absorción de calcio y fósforo en el intestino y facilitando la mineralización ósea.

\section{c) EFECTO DE LA CALCITONINA}

Se secreta en el tiroides por las células parafoliculares o células C. Reduce la concentración sanguínea de calcio iónico con un efecto opuesto a la acción de la PTH y es varias veces más rápido. Disminuye la concentración plasmática de calcio al disminuir la actividad resortiva de los osteoclastos y el posible efecto osteolítico por todo el hueso, por lo que se facilita el depósito de calcio. La calcitonina tambien disminuye la formación de nuevos osteoclastos. Debido a que la reabsorción osteoclástica del hueso ocasiona secundariamente actividad osteoblástica, el resultado neto es una gran reducción de la actividad osteoclástica y osteoblástica. El efecto sobre la calcemia es transitorio.

Los efectos de la calcitonina sobre el calcio a nivel túbulos renales y tubo digestivo son opuestos a la PTH. La calcitonina tiene un efecto débil sobre la concentración plasmática de calcio en el adulto. Cualquier reducción inicial de la concentración de calcio iónico que causa, lleva en horas, a una poderosa estimulación de la secreción de PTH que casi supera el efecto de la calcitonina; además, en el adulto, las tasas diarias de reabsorción y depósito de calcio son bajas. Un aumento de la concentración plasmática de calcio de un $10 \%$ aproximadamente causa un aumento de la tasa de secreción de calcitonina que activa un segundo mecanismo de retroacción hormonal de control de la concentración de calcio iónico plasmático que funciona en dirección opuesta al mecanismo de la PTH. Existen dos diferencias entre los sistemas de retroacción de la calcitonina y la parathormona. El mecanismo de la calcitonina actúa con mayor rapidez, alcanzando un máximo en menos de una hora a diferencia de las tres o cuatro horas que han de transcurrir para que se alcance una actividad máxima dependiendo del comienzo de la secreción de la PTH. La segunda diferencia es que el mecanismo de la calcitonina sólo actúa débilmente y como regulador a corto plazo de la concentración de calcio iónico, debido a que es superado rápidamente por el mecanismo de control paratiroideo, mucho más potente. Durante un periodo prolongado, el sistema paratiroideo es el que establece casi en exclusiva el nivel de calcio iónico en el líquido extracelular.(43) 


\section{II.14.CALCIO IÓNICO}

Las sales de calcio intercambiables de los huesos, son compuestos de fosfato cálcico amorfo en equilibrio reversible con los iones de calcio y fosfato del líquido extracelular; estas sales, disponibles para el intercambio, suponen entre el 0,5 y el $1 \%$ del total de sales de calcio del hueso. Es fácil que estas sales intercambiables se depositen y se vuelvan a disolver, un aumento de la concentración de iones calcio y de fosfato en el líquido extracelular mayor de lo normal causa el depósito inmediato de sales intercambiables. Igual sucede a la inversa, una disminución de estas concentraciones provoca la inmediata reabsorción de sal intercambiable. Esta reacción es tan rápida que el paso de sangre rica en calcio a través del hueso, eliminará la mayor parte de su exceso. La rapidez de este efecto es porque los cristales del hueso amorfo son muy pequeños, y la superficie total de ellos expuesta a los líquidos del hueso es de 40 veces o más.

El 5\% de toda la sangre fluye a través de los huesos cada minuto, cerca del $1 \%$ del total del líquido extracelular enese tiempo. Alrededor de la mitad de cualquier exceso de calcio en el líquido extracelular se elimina por la acción amortiguadora de los huesos en algo más de una hora. Además de los huesos, las mitocondrias de muchos tejidos del organismo, sobre todo del hígado y del intestino, contienen una cantidad razonable de calcio intercambiable, que proporciona un sistema amortiguador adicional para ayudar a mantener constante la concentración extracelular de calcio iónico.

También existe un control hormonal de la concentración de calcio iónico por la PTH y la calcitonina que actúa al mismo tiempo que el mecanismo del calcio intercambiable de los huesos. En unos minutos tras un aumento agudo de la concentración de calcio iónico, la secreción de PTH disminuye y se ponen en marcha diferentes mecanismos para reducir la concentración de calcio iónico hacia tasas normales por un proceso lento. A la vez que disminuye la PTH aumenta la calcitonina. En exceso de calcio o déficit prolongados, sólo el mecanismo de la PTH tiene importancia real en el mantenimiento de una concentración normal de calcio iónico. En caso de déficit dietético continuo de calcio, la PTH estimula la reabsorción de calcio de los huesos como para mantener una concentración plasmática normal aunque si perdura mucho tiempo el déficit los huesos se quedarían sin calcio. Los huesos son un gran reservorio amortiguado de calcio que puede ser manipulado por la PTH, pero, cuando el reservorio óseo se agota o se satura de calcio, el control a largo plazo de la concentración extracelular de calcio iónico depende de la acción de la parathormona y de la vitamina $\mathrm{D}$ en la regulación de la absorción de calcio del intestino y de la excreción por la orina. 


\section{II.15.MARCADORES BIOQUIMICOS DE REMODELADO OSEO}

El hueso es un tejido con una actividad constante de formación y de destrucción. En el adulto, en circunstancias normales, las tasas de formación y de resorción ósea se encuentran en equilibrio, sin embargo, determinadas patologías alteran este equilibrio entre ambas actividades y resulta de gran interés la medida de las actividades formativa y resortiva óseas, bien como valor diagnóstico o para el seguimiento de algún tratamiento. $(38,46,60,61,62)$

Los marcadores bioquímicos son moléculas sintetizadas por los osteoblastos o procedentes de la reabsorción de la matriz ósea que se pueden medir en el plasma y en la orina y nos dan información de la actividad del hueso en ese momento. $(63,64,65)$

Los marcadores de formación más utilizados son la osteocalcina y la fosfatasa alcalina. Los marcadores de resorción ósea son la fosfatasa alcalina tartrato resistente, hidroxiprolina, piridolina, péptidos derivados de la degradación de moléculas precursoras de colágeno. La deoxipiridolina en orina y el telopéptido carboxiterminal del colágeno tipo I son los más específicos y los que mejor se relacionan con los valores de densidad mineral ósea.

El calcio es el componente mineral óseo más necesario para el crecimiento y desarrollo del hueso. El depósito de calcio en hueso depende de la cantidad total de calcio presente en la alimentación, de su capacidad de absorción intestinal y de su eliminación por vía urinaria. En situaciones de déficit de aporte cálcico, puede incrementarse su absorción por encima de los valores normales siempre que los niveles de vitamina $\mathrm{D}$ sean adecuados, sin embargo, un aporte excesivo del mismol no implica un incremento lineal de la absorción del calcio. Algunos autores proponen la existencia de un umbral por encima del cual ya no se absorbería más calcio, que sería independiente de la cantidad presente en la dieta. La eliminación urinaria de calcio aumenta con la edad. La calciúria depende de la cantidad total de calcio absorbido y del proveniente de la movilización del hueso. En el riñón, la reabsorción tubular del calcio es favorecida por la PTH e inhibida por aportes elevados de proteínas en la dieta. La calciúria en el adulto es de 200mg/24h.

La valoración del grado de actividad de osteoblastos y osteoclastos se puede cuantificar en suero determinando la actividad enzimática propia con la fosfatasa alcalina o la fosfatasa ácida tartrato resistente, o bien, determinando productos sintetizados por las células óseas como la osteocalcina o productos de degradación vertidos a la circulación durante la resorción, procedentes de la fase mineral (calcio), o de la matriz ósea (hidroxiprolina). (63,65) 
La medida del remodelado óseo se puede hacer también de modo directo mediante histomorfometría ósea o indirectamente, a través de radiografías o densitometría ósea.

Los marcadores bioquímicos de remodelado óseo tienen la ventaja de no ser un método invasivo con respecto a la histomorfometría. Las radiografías o densitometrías constituyen una medida de lo que está pasando en el hueso en ese momento; los métodos de imagen son la medida del resultado de un proceso que puede seguir en marcha o haber finalizado.

\section{MARCADORES BIOQUIMICOS DE RECAMBIO ÓSEO (61,65) \\ FORMACIÓN \\ RESORCIÓN}

Séricos o plasmáticos

F. A total

Isoenzima ósea de la F. A.

Péptidos de extensión del procolágeno I

Osteocalcina

\section{Urinarios}

Hidroxiprolina no dializable

Piridolinas y péptidos relacionados
F. A. tartrato-resistente

Piridolinas

Calcio en ayunas

Cociente calcio/creatinina

Hidroxiprolina en orina

\section{Marcadores bioquímicos de formación ósea}

Son productos sintetizados por los osteoblastos y que reflejan su actividad y el grado de actividad ósea. Los marcadores séricos más importantes son la fosfatasa alcalina total, su isoenzima ósea, la osteocalcina y los péptidos de extensión del procolágeno tipo I.

En la orina el marcador más importante es la hidróxiprolina.

\section{Fosfatasa alcalina total en suero.}

La fosfatasa alcalina total sérica, se utiliza como un marcador clásico de formación ósea.(65) Durante el proceso de mineralización del hueso, los osteoblastos liberan al exterior, a partir de su membrana celular, unas vesículas muy ricas en fosfatasa alcalina.

La actividad de la fosfatasa alcalina ósea es proporcional a la actividad de formación del hueso. El problema de este marcador es su falta de especificidad, ya que la fosfatasa en suero no es exclusiva osteoblástica (isoenzima ósea), existen también otras isoenzimas como la placentaria, la renal, la intestinal y la hepática. Las que contribuyen en mayor proporción a la actividad total sérica son la hepática y la ósea.

Con función hepática normal, la actividad de la fosfatasa alcalina total se sigue utilizando de modo rutinario como marcador de formación ósea.(66) 
Se considera normal un rango entre 41 y $117 \mathrm{UI} / \mathrm{L}$, y debemos tener en cuenta que los niveles de ésta enzima se elevan de manera considerable durante el crecimiento, declinando a los niveles del adulto al final de la segunda década.

\section{Isoenzima ósea de la fosfatasa alcalina.}

La actividad de la fosfatasa alcalina total en suero, no refleja únicamente la derivada de los osteoblastos (actividad ósea), también están presentes otras isoenzimas. La cuantificación de ésta isoenzima es, en teoria, ideal como marcador de actividad osteoblástica, debido a su especificidad. Sin patología hepática, la determinación de la isoenzima ósea no representa una ventaja respecto a la fosfatasa alcalina total en el estudio de algunas enfermedades sin embargo, sí parece ser más sensible en el estudio del remodelado óseo en la osteoporosis y en la osteodistrofia renal. Está totalmente indicada en caso que se desee cuantificar la formación ósea en presencia de niveles altos de otras isoenzimas de la fosfatasa alcalina en el suero.(66)

\section{Osteocalcina.}

La osteocalcina, proteína de 49 aminoácidos es sintetizada por los osteoblastos y se une a la fase mineral del hueso; cuando es liberada por el osteoblasto, una parte pasa al suero y la otra se une a la fase mineral del hueso. Al ser un producto específico de síntesis del osteoblasto, se utiliza como marcador bioquímico de formación ósea $(63,65)$ aunque la osteocalcina sérica, no procede sólo del osteoblasto activo (marcador de formación), sino también de la unida al hueso y liberada durante la resorción(marcador de resorción), esto ha hecho que la osteocalcina se utilice actualmente más como marcador de remodelado en general, que como marcador de formación ósea.

La síntesis de osteocalcina es dependiente de la vitamina D. Los corticoides la inhiben de forma dosis-dependiente. Hay trabajos que señalan que los cambios de la osteocalcina con la edad y en relación con el sexo en la diabetes están disminuidos y fármacos estimulantes de la formación ósea, como el flúor, la elevan y contrarrestan el efecto inhibidor de los corticoides. Drogas y alcohol descienden sus valores.

\section{Peptidos de extensión del colágeno.}

Los péptidos de extensión del procolágeno, tanto el aminoterminal como el carboxiterminal, son eliminados y circulan por la sangre, por lo que, son marcadores de la formación del colágeno óseo. Se correlacionan tanto con la fosfatasa ósea, como con la osteocalcina, pero frente a ambas, se ha visto que es menos sensible. Por otro lado, el colágeno tipo I, aunque prioritario en el hueso también es sintetizado en otros tejidos y esto le resta especificidad como marcador biológico de formación ósea. 


\section{Marcadores bioquímicos de resorción}

Son moléculas procedentes de la reabsorción de la matriz ósea.(65)

\section{Calcio e hidroxiprolina en orina en ayunas.}

El calcio urinario determinado en ayunas, en índice con la creatinina, es un marcador biológico de resorción. Su determinación se hace después de $12 \mathrm{~h}$ en ayunas (67) así todo el calcio eliminado procederá de la resorción ósea. Está elevado en enfermedades que cursan con alto remodelamiento, excepto en el hiperparatiroidismo primario por el aumento de la resorción tubular de calcio que ocasiona la PTH que hace que disminuya su eliminación.

La hidroxiprolina, también expresada como índice con la creatinina, y también determinada en ayunas como el calcio es un buen marcador biológico de resorción ósea. La hidroxiprolina representa un $13 \%$ de la molécula de colágeno. Cuando se degradada del hueso no vuelve a ser reutilizada en la nueva osteoformación, por lo que toda la que se determina es ósea. Es un eficaz, pero no específico, marcador biológico de resorción.

\section{Cociente calcio/creatinina en orina.}

Es una medida indirecta de resorción ósea (65) ya que durante la etapa de destrucción del hueso, el calcio presente en el hueso pasa al líquido extracelular y de aquí al riñón. Hay que tener en cuenta que, el hallazgo de los niveles elevados de calcio en orina puede tener dos orígenes: óseo o renal, y es necesario descartar un a anomalía renal para que éste parámetro evalúe correctamente el índice de resorción del hueso.

\section{Fosfatasa ácida tartrato resistente.}

Es una enzima liberada por el osteoclasto activo.(65) El suero contiene otras isoenzimas de la fosfatasa ácida, pero sólo la procedente de los hematíes y la ósea son resistentes al tartrato. Es una medida específica de resorción ósea.

En circunstancias normales la fosfatasa ácida tartrato resistente disminuye con la menarquia y aumenta después de la menopausia; (se ha visto una correlación lineal entre los niveles de esta enzima y la densidad mineral ósea en mujeres con osteoporosis postmenopaúsica); se encuentra incrementada en enfermedades que se acompañan de alto remodelamiento. Se relaciona de forma negativa con la masa ósea y de forma positiva con la fosfatasa alcalina; es muy sensible al efecto de fármacos que enlentecen el remodelamiento y la actividad osteoclástica. Los valores sanguíneos, como ya se ha señalado, dependen de que la determinación se haga en el suero o en el plasma. 


\section{Hidroxiprolina}

La hidroxiprolina es un aminoácido muy abundante en el colágeno.(65) Durante la resorción ósea, al degradarse la matriz del hueso, pasa a la circulación $90 \%$ en forma libre y $10 \%$ unida a péptidos de degradación del colágeno que son excretados en la orina, mientras que la mayoría del aminoácido libre es reabsorbido en el riñón y degradado posteriormente a $\mathrm{CO} 2$ y urea, ya que no puede ser reutilizada para la síntesis del colágeno.

La hidroxiprolina urinaria es un marcador de resorción del hueso con limitaciones, aunque el hueso es la principal fuente existen otras como la elastina, acetilcolinesterasa y el componente $\mathrm{C} 1 \mathrm{q}$ del sistema del complemento. Además, puede proceder no sólo de la degradación del colágeno maduro, sino de los péptidos de extensión $\mathrm{N}$-terminales del procolágeno y de moléculas de colágeno neosintetizadas que nunca llegaron a convertirse en colágeno maduro. La determinación urinaria se realiza en orina de 24 horas. Hay que tener en cuenta que durante la época del crecimiento, al igual que en el caso de la fosfatasa alcalina sérica, los niveles de hidroxiprolina urinaria total se encuentran muy elevados. Los niveles urinarios de hidroxiprolina suelen expresarse en cociente con la creatinina. La hidroxiprolina se utiliza en el diagnóstico y seguimiento de enfermedades metabólicas óseas como marcador de reabsorción del hueso.

\section{Puentes de piridolina y desoxipiridolina}

Antes de formar su estructura definitiva dentro de la matriz ósea, las moléculas de colágeno van "madurando", y experimentan una serie de transformaciones químicas, a la vez que se establecen puentes de conexión entre ellas. Uno de estos tipos de enlace son los puentes de piridolina. Durante el proceso de resorción estos puentes quedan libres y son liberados al suero y aclarados por el riñón, dado que estas estructuras derivan del proceso de degradación del hueso, su concentración será proporcional a la actividad osteoclástica y se están utilizando como marcadores de resorción del hueso. (65)

Telopéptidos aminoterminales del colágeno I unidos por puentes de piridolina en orina.

Existe poca bibliografía al respecto, pero parece que este marcador de resorción del hueso presenta una elevada sensibilidad para detectar los cambios de remodelado óseo.

\section{Telopéptido carboxiterminal de la cadena alfa-1 del colágeno tipo I (crosslaps).}

La sensibilidad de este marcador para detectar cambios en la tasa de resorción ósea parece ser muy grande, de acuerdo con trabajos publicados recientemente.

A partir de los 50 años, edad aproximada de la menopausia en mujeres, los valores son mayores en ellas que en los varones. 
REVISIÓN III: OSTEOPOROSIS 
Al igual que la obesidad, la OSTEOPOROSIS también está considerada como una gran epidemia, pero a diferencia de la primera, esta patología es una epidemia silente porque presenta escasa repercusión clínica. A diferencia de la obesidad que es una manifestación evidente, la pérdida de masa ósea, que por otra parte, va asociada a la edad, se produce de forma discreta, generalmente inadvertida, pero sin embargo, también son considerables y muy importantes las consecuencias fisiopatológicas que origina y los costes que genera, ya que su prevalencia también es muy alta.

La osteoporosis, como muchas de las enfermedades crónicas tiene un origen multifactorial. La importancia clínica de esta patología radica en las fracturas consecuencia de la fragilidad ósea que se produce por la disminución de masa ósea dónde también se ve afectada la calidad del hueso al deteriorarse su microarquitectura.

Determinados factores influyen o determinan la obtención, conservación y pérdida de masa ósea, entre ellos destacan la predisposición genética, déficit de nutrientes y baja ingesta de calcio, sedentarismo, hábitos tóxicos (consumo habitual de tabaco y alcohol), toma de fármacos, enfermedades carenciales y el bajo peso entre otros.

La OMS propuso definir los grados de pérdida de masa ósea mediante la DEXA.

\section{III.1.OSTEOPOROSIS}

Durante el Congreso Mundial de Osteoporosis celebrado en Ámsterdam en 1994,(173) la osteoporosis fue definida como una enfermedad sistémica, caracterizada por la disminución de la masa ósea y el deterioro de su microarquitectura con el consecuente incremento de la fragilidad ósea y susceptibilidad para las fracturas, posteriormente, en el año 2.001, se definió como la enfermedad del esqueleto caracterizada por una resistencia ósea alterada con un aumento del riesgo de fractura.(69)

Es una enfermedad multifactorial que sigue un proceso contínuo, subclínico, pero detectable,(70,71) y que lleva a fragilidad esquelética caracterizada por la reducción del material mineral del tejido óseo que puede ir acompañada por una disminución de los componentes orgánicos del hueso y que deriva a la aparición de fracturas que, según diferencias fisiopatológicas y locales, aparecen principalmente en cadera y vértebras, con consecuencias clínicas, sociales y económicas diferentes.(72) Su manifestación más grave es la fractura de cadera.(73) 
Es la enfermedad ósea más frecuente en los adultos, sobre todo en edades avanzadas lo que origina que las fracturas por osteoporosis sean la segunda enfermedad, tras la patología cardiovascular, en términos de coste económico. La osteoporosis entendida únicamente como pérdida de masa ósea no tiene impacto sobre la calidad de vida, pero la aparición de fracturas ocasiona incapacidad física y disfunción psicosocial. (74) En la osteoporosis se altera el equilibrio entre la reabsorción y la formación de hueso que se va perdiendo gradualmente del esqueleto. Este proceso resulta relativamente lento en el caso del hueso cortical o compacto que supone un $80 \%$ del esqueleto pero es bastante más rápido en el hueso trabecular o esponjoso como consecuencia de un elevado cociente superficie/volumen, la pérdida ósea trae consigo una reducción en la resistencia esquelética y en el caso concreto del hueso trabecular una pérdida de estructura.(75,76) A lo largo de la vida, cambia la cantidad de hueso presente en el cuerpo humano. La masa ósea aumenta durante la niñez y adolescencia debido al crecimiento del esqueleto y aunque no se conoce con absoluta certeza a qué edad se alcanza la masa ósea máxima, los hallazgos actuales sugieren que la masa cortical llega a su pico hacia los 30-35 años, y que puede producirse mucho antes en el hueso trabecular, quizás al término del crecimiento lineal. Las mujeres pueden alcanzar su masa ósea máxima antes que los varones. Cuando el hueso ha terminado de crecer, aún sigue calcificándose hasta alcanzar el pico de masa ósea, a partir de ese momento, la masa ósea se mantiene constante o disminuye poco hasta los 45 a 50 años.

Las mujeres tienen un pico de masa ósea más bajo que los hombres y una mayor pérdida relacionada con la edad, acelerándose con la menopausia,(51) aunque la pérdida de hueso comienza antes de que ésta se presente. Se sabe que la masa ósea se pierde a una velocidad de 0,1 a $0,15 \%$ al año en el caso del hombre. En la mujer tras la menopausia, y durante unos 5 a 10 años aproximadamente la pérdida es mayor. Pasados esos años, la velocidad de pérdida ósea es similar a la indicada para el hombre.(77,78) La proporción de pérdida de hueso durante los primeros años postmenopaúsia, aumenta siete veces. El hueso trabecular se pierde más rápidamente que el cortical con tasas de un $2 \%$ - $4 \%$ y el $1 \%$ - $2 \%$ por año respectivamente. Una mujer puede perder del 10 al $15 \%$ del hueso cortical y del 25 al 30\% del hueso trabecular durante este tiempo. Además, la velocidad de pérdida de hueso varía considerablemente de unas mujeres a otras. No se sabe por qué algunas mujeres son "perdedoras rápidas" de hueso.(79) Las pérdidas óseas tras la menopausia y en la edad avanzada dependen de muchos factores, como la instauración de una masa adecuada y densidad ósea en la época adulta joven, la presencia de determinados fármacos y diversos factores físicos, sociales y psicológicos. $(34,72,80,81)$ 
Los factores hereditarios pueden llegar a representar un 70 a $80 \%$ de la influencia potencial total en comparación con el 20 a 30\% debido a factores ambientales. (Tras la menopausia en el caso de la mujer, estos últimos contribuyen hasta en un $60 \%$ en la variabilidad de su masa ósea.(38))

La resistencia ósea viene determinada en base a la densidad y a la calidad ósea. La calidad ósea conlleva características del tejido óseo relacionadas con la macroestructura del hueso, por el tamaño del cuerpo vertebral o la longitud del eje femoral, con la microestructura por la porosidad cortical, conectividad trabecular o características del recambio óseo como el grado de resorción o de absorción ósea y propiedades tisulares como el grado de mineralización secundaria, acumulación de microlesiones y los enlaces del colágeno.(69,82) Los factores que determinan la cantidad de hueso que presentamos son, el pico de masa ósea alcanzado y la cantidad de hueso que perdemos.

La pérdida de hueso está asociada con otras anormalidades estructurales y cualitativas, que contribuyen a la pérdida de la fortaleza del esqueleto. Estos cambios incluyen modificaciones en el recambio óseo para reparar el daño por fatiga y la pérdida de los elementos trabeculares. La pérdida de masa ósea que se produce a partir de los 45-50 años es una pérdida degenerativa, es un proceso natural e inevitable, sin embargo la velocidad a la que se produce esta descalcificación fisiológica, más rápida en mujeres postmenopaúsicas, se puede reducir. Con la edad se produce descalcificación del esqueleto que conlleva aumento de la fragilidad ósea: involución senil; este concepto ha cambiado en los últimos años al reconocer que se trata de uno de los principales factores de riesgo en la génesis de las fracturas.(49) Desde un punto de vista clínico, es una pérdida generalizada de masa ósea que produce una fragilidad de los huesos, que se fracturan ante traumatismos mínimos.(83) Desde un punto de vista morfológico, la osteoporosis puede definirse como una disminución de la masa ósea por unidad de volumen de hueso, con una mineralización normal de éste.

Los consejos para prevenir la osteoporosis, insisten en la actividad física, dieta con ingesta de calcio adecuada, exposición a los rayos solares y evitar hábitos tóxicos.(84)

Los factores de riesgo de osteoporosis se han analizado sobre todo en las mujeres y aunque también son aplicables a los varones, hay que tener en cuenta, que en ellos, la presencia de la enfermedad se asocia en un 50-70\% a otros procesos patológicos. Las patologías más frecuentes como causa de osteoporosis en el varón son el hipogonadismo, ingesta crónica de alcohol y el tratamiento glucocorticoideo.(85) Al ser la osteoporosis una enfermedad asociada a la edad, el envejecimiento de la población occidental hace suponer que el problema va a incrementarse de forma considerable.(86,87) 


\section{III.2.ETIOLOGÍA DE OSTEOPOROSIS}

La osteoporosis es multifactorial, muchos factores pueden originarla o contribuir a su desarrollo además, es característica de estados de enfermedad como diabetes, hipertiroidismo, afecciones gastrointestinales y alcoholismo, aunque también aparece en hombres y mujeres sanas como parte del proceso de envejecimiento. $(88,89,90,91,92)$

Las causas más importantes por las que se produce deficiencia de calcio y desmineralización ósea son el escaso aporte de vitamina $\mathrm{D}$, insuficiente calcio disponible en la dieta, excreción aumentada del calcio por una relación calcio/fósforo muy baja en la alimentación y todos los factores que estimulan la secreción de la PTH. Aunque la concentración corporal de calcio sea la correcta hay situaciones donde se produce desmineralización ósea si en la dieta existe una desproporción entre el contenido de calcio y de fosfato. Estudios realizados indican que las bebidas carbonatadas y las dietas a base de alimentos preparados pueden llegar a aportar $1.000 \mathrm{mg}$ de fósforo diario, es posible que este hecho pueda explicar la aparición de osteoporosis en nuestra sociedad desarrollada.(35,36) Están implicados en la desmineralización ósea progresiva que se produce con la edad, la disminución de la relación estrógenos/andrógenos, menor actividad física y el tipo de dieta (93,94)

El ejercicio físico regular a lo largo de la vida reduce significativamente las pérdidas de mineral del esqueleto óseo. Por el contrario, la ausencia de actividad física incrementa la velocidad de desmineralización de los huesos y aunque no está claro el mecanismo por lo que esto se produce, la PTH y la calcitonina influyen en ellos.

Causa la enfermedad la falta de estrés físico sobre los huesos por la inactividad, la malnutrición al no poder formarse suficiente matriz proteica, la falta de vitamina $\mathrm{C}$, necesaria para la secreción de las sustancias intercelulares incluyendo la formación de osteoide por los osteoblastos, la falta de secreción de estrógenos en la postmenopaúsia, por su actividad estimulante de los osteoclastos,(93,94) la edad ósea avanzada al disminuir la hormona del crecimiento y otros factores estimuladores del mismo, además muchos factores del anabolismo proteico son escasos y no se puede depositar correctamente matriz que causan disminución del depósito de proteínas, aumento de catabolismo proteico y además deprimen la actividad osteoblástica. Por tanto muchas enfermedades con deficiencias del metabolismo proteico pueden causar osteoporosis. 
En cuanto a la dieta, la relación fosfo-calcica, puede producir desmineralización ósea si el índice de esta relación está elevado ya que facilita la secrección de PTH que activa la vitamina $\mathrm{D}$ que actúa sobre el hueso, riñón y tracto gastrointestinal por lo que la historia nutricional de los pacientes es importante para determinar la causa de la osteoporosis.

\section{CAUSAS DE OSTEOPOROSIS (95)}

\section{Enfermedades:}

Enfermedades endocrinológicas **

Enfermedades neoplásicas:

Mieloma múltiple

Enfermedades mielo o linfoproliferativas

Mastocitosis sistémicas

Metástasis óseas

Enfermedades congénitas del colágeno:

Osteogénesis imperfecta

Síndrome de Marfan

Síndrome de Ehles-Danlos

Otras enfermedades y trastornos:

Enfermedad de Gaucher; hipofosfatasia del adulto, hemoglobinopatías (talasemias).

Enfermedades crónicas (artritis reumatoide, diabetes mellitus, hepato y nefropatías)

\section{Hábitos de vida:}

-Inmovilización

-Tabaquismo crónico

- Nuliparidad

-Ejercicio físico excesivo (amenorrea)

-Drogadicción (amenorrea)

-Menarquia tardía, menopausia precoz

-Herencia

-Estado hormonal

-Composición corporal: existe asociación entre masa magra y masa ósea en ambos sexos.

-Inactividad física

-Inmovilidad

-Alcohol: la acción sobre el hueso se debe a la acidosis que afecta a la masa ósea.

-Cafeína: provoca un ligero aumento de las pérdidas urinarias de calcio a corto plazo

( 1 a 3 horas), que en condiciones normales no parece afectar al balance neto de calcio. No obstante, en el caso de personas ancianas con baja ingesta de calcio, el efecto de la cafeína podría ser significativo. 


\section{Factores nutricionales}

Intolerancia a la leche

Ingestión deficiente de calcio

Excesivo consumo de alcohol

Ingestión excesiva y continuada de proteínas animales

Desnutrición proteico-calórica.

\section{Idiopática}

Juvenil, del adulto.

\section{Fármacos}

-Laxantes y catárticos

-Anoréxicos

-Glucocorticoides

-Anticonvulsivantes

-Diuréticos

-Sedantes

-Tirosina: efectos proteolíticos óseos.

-Anticoagulantess (heparina)

-Poliquimioterapia antineoplásica.

**Causas endocrinas de osteopenia y osteoporosis (95)

Déficit de estrógenos:

Insuficiencia ovárica primaria

Déficit de gonadotropinas

Hiperprolactinemia y prolactinoma

Agonistas y antagonistas de $\mathrm{GnRH}$

Otras enfermedades hipotalámicas e hipofisarias

Disregulación hipotalámica/hipofisaria

\section{Exceso de glucocorticoides}

Exceso de hormona tiroidea

\section{Exceso de hormona paratiroidea}

\section{Déficit de vitamina $D$ :}

Déficit de calciferol (vitamina D)

Déficit de calcifediol (25-hidroxivitamina D)

Déficit de calcitriol (1,25 dihidroxivitamina D)

Resistencia intestinal al calcitriol

\section{Déficit de hormona del crecimiento o de IGF}

\section{Causas mixtas:}

Anorexia nerviosa

Amenorrea producida por exceso de ejercicio

Menarquia tardía 


\section{Causas endógenas:}

Exceso o déficit de mineralocorticoides

Exceso o déficit de andrógenos

\section{Déficit de andrógenos:}

Insuficiencia testicular primaria

Déficit de gonadotropinas

Hiperprolactinemia

Agonistas y antagonistas de $\mathrm{GnRH}$

Otras enfermedades hipotalámico/hipofisarias.

\section{III.3.FISIOPATOLOGÍA.}

\section{Pricipales factores reguladores de remodelado óseo.}

\section{a) Factores hormonales}

En la postmenopaúsia desaparece la inhibición de la actividad osteoclástica y se produce una ineficacia en la absorción intestinal de calcio alimentario por la ausencia de estrógenos ováricos.(96,97,98) La redución de calcio provoca un aumento de secreción de PTH que incrementa la resorción ósea. Aunque esta hormona estimula la síntesis renal de la hormona D3, que favorecerá la absorción de calcio, el efecto es de pérdida de masa ósea. La resorción ósea aumenta la eliminación urinaria de calcio y metabolitos del colágeno.(80,81) La velocidad de formación ósea tambien se encuentra aumentada en el déficit de estrógenos y aparece un aumento de fosfatasa alcalina sérica, fosfatasa alcalina específica del hueso y osteocalcina. Los valores de remodelado óseo (piridonolina, desoxipiriridolina, piridinolina libre en orina y $\mathrm{N}$-telopéptido urinario) están aumentados un 30-100\% en mujeres postmenopáusicas, que indica un metabolismo óseo acelerado. La disminución de estrógenos aumenta los efectos resortivos de la PTH que produce un aumento leve de las concentraciones de calcio sérico. Este efecto se produce, sobre todo en el hueso trabecular de fémur, vértebras y huesos del antebrazo cortical disminuyendo así la resistencia del tejido óseo y aumentando así el riesgo de fracturas.(92,99,100,101) Finalizado el periodo de pérdida rápida de hueso, ésta, continúa a lo largo de la vida a una velocidad más gradual.

La cantidad de hueso en la postmenopaúsia va a depender en parte del pico de masa ósea que se alcanzó en la adolescencia y postadolescencia inmediatas, hasta el punto de que, si aquél fue optimo, se puede llegar al riesgo de fractura hasta diez años más tarde que si el pico de masa ósea no hubiera sido adecuado. 


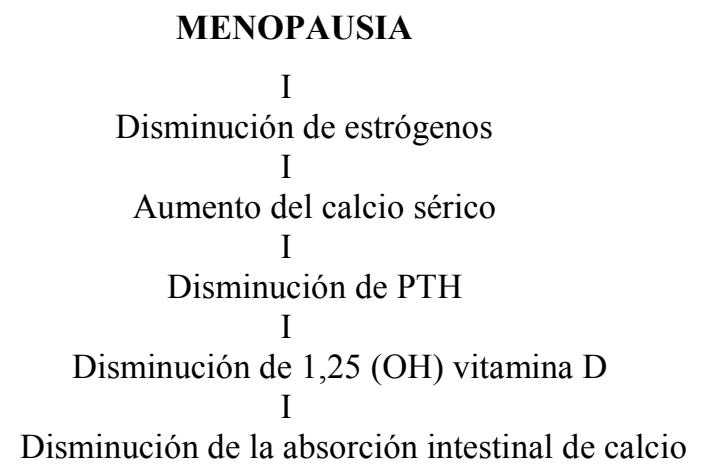

Fisiopatología de la osteoporosis postmenopaúsica o tipo I.(93)

\section{b) Factor edad.}

En la edad avanzada, en ambos sexos, aparece un desequilibrio entre la formación y resorción ósea que lleva a una pérdida de masa ósea por la disminución de la absorción del calcio alimentario. El aumento de los niveles de PTH que se produce con la edad provoca resorción ósea y disminución de la absorción intestinal de calcio, y reducción de función osteoclástica. $(51,86,87,102,103,104)$ La PTH es un potente estimulador de la resorción ósea si se mantiene aumentada de forma persistente. También tiene un papel importante la vitamina D ya que, con la edad, la capacidad de la piel para sintetizarla va disminuyendo y la exposición al sol de los ancianos es menor. El déficit de vitamina D favorece a su vez el aumento de PTH de forma secundaria por lo que favorece la resorción ósea.

En la mujer, la disminución de estrógenos y la edad son los principales factores determinantes de baja masa ósea.(105) En el varón los andrógenos, importantes para la obtención del pico de masa ósea, con la edad también disminuyen.(58,106,107) Se considera que la pérdida ósea asociada al envejecimiento se produce porque la cantidad de hueso formada en cada ciclo de remodelado es menor que el que se ha reabsorbido. Como consecuencia disminuye el volumen trabecular, hay adelgazamiento de las trabéculas y un aumento de la porosidad. Se sabe que la pérdida de hueso trabecular cesa después de muchos años de déficit de estrógenos pero que continúa una lenta pérdida de hueso global ya que, la osteoporosis tipo II está asociada a un descenso de masa ósea cortical y trabecular y son frecuentes las fracturas de cadera, pelvis, muñeca, húmero y tibia proximal y cuerpos vertebrales. $(80,81)$

En el varón la pérdida ósea tiene una velocidad constante, en torno al 0,5\% que es similar a la pérdida que sufre la mujer en la postmenopaúsia tardía.

Es difícil separar la osteoporosis tipo I y II ya que pueden solaparse ambos síndromes. 


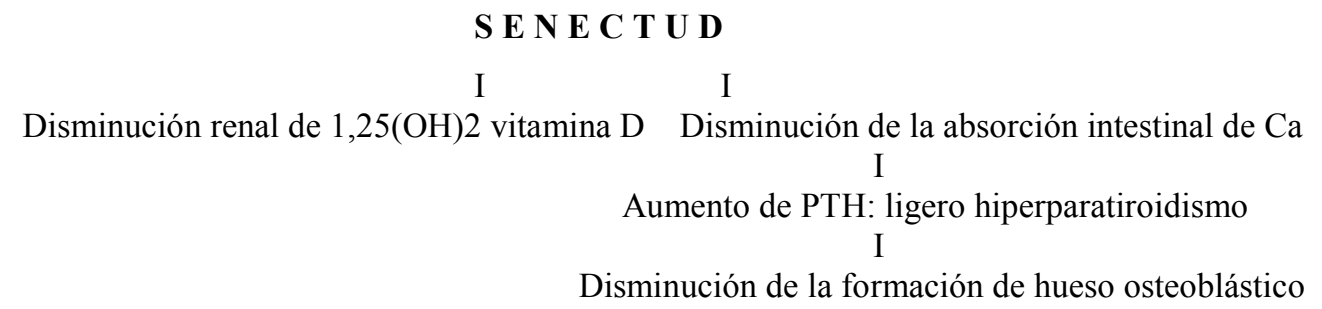

Fisiopatología de la osteoporosis senil o tipo II.(93)

\section{III.4.CLASIFICACIÓN DE OSTEOPOROSIS}

En la actualidad sigue vigente la siguiente clasificación:

- Primaria: dos tipos: Tipo I: relacionada con bajos niveles de estrógenos.

Tipo II: relacionada con la edad avanzada.

- Secundaria: relacionadas con enfermedades o toma de fármacos

- Idiopática: son aquellas de etiología desconocida.

Cuando los varones tienen niveles de hormonas sexuales por debajo de lo que se puede considerar fisiológico según la edad, también pueden presentar osteoporosis tipo I. Por otra parte, mujeres con menopausia quirúrgica o aquellas que presentan amenorrea crónica pueden presentar también osteoporosis tipo I debido a los bajos niveles de estrógenos plasmáticos.

La osteoporosis es una situación osteopénica donde la masa ósea es inferior a 2,5 desviaciones estándar (DS) por debajo del valor medio de ésta masa ósea en el adulto joven (20-29 años) y además, aparece una mala calidad de hueso a nivel microscópico. Si la pérdida de masa ósea está entre -1 y $-2,5$ DS, hay osteopenia.

\section{Osteoporosis primarias.}

Aunque la osteoporosis es característica de estados de enfermedad, también aparece en hombres y mujeres sanos como parte del envejecimiento. Las fracturas ocasionadas por la osteoporosis involutiva son un grave problema de salud pública.

Los estudios europeos indican que alrededor de los 70 años, más del $25 \%$ de las mujeres habrán padecido una o más fracturas osteoporóticas. 
Tres tipos diferentes:

- Tipo I: posmenopaúsico. Afecta a mujeres entre 50-75 años o 15 - 20 años después de presentar la menopausia. Es una osteoporosis de alto recambio con excesiva actividad osteoclástica, los osteoblastos funcionan normalmente y se produce acumulación de productos de degradación del colágeno en orina.(78) Se acelera la pérdida ósea, descienden los niveles de patathormona y 1,25- dihidroxivitamina $\mathrm{D}$, y disminuye además la absorción de calcio debido a la falta de estímulo estrogénico; la pérdida ósea oscila entre $2-3 \%$ de la masa total, sobre todo los 6-10 primeros años postmenopaúsia.(62) Hay con más frecuencia fracturas vertebrales.

- Tipo II: senil. Afecta a hombres y mujeres de edad avanzada, mayores de 75 años. Es una situación de bajo recambio donde los osteoclastos funcionan normalmente, los osteoblastos no producen osteoide y no se origina acumulación de productos de degradación del colágeno en la orina. Disminuye la absorción de calcio y puede incrementarse la secreción de $\mathrm{PTH}$, pero los niveles de 1,25-dihidroxi-vitamina D, pueden ser bajos, debido a la disminución de su conversión desde 25-dihidroxivitamina $\mathrm{D}$ en el riñón. Afecta a hueso trabecular y cortical. Se fractura sobre todo fémur proximal, también húmero y pelvis. Las mujeres se afectan el doble de los varones. La pérdida ósea en la osteoporosis senil no es acelerada.(77)

- Tipo III: poco frecuente. Aparece en mujeres postmenopaúsicas. La clínica es similar a la del tipo II pero en pacientes más jóvenes Aumentan los niveles de PTH se reduce la producción de 1,25-dihidroxi-vitamina $\mathrm{D}$, y baja la absorción de calcio.

\section{DIFERENCIAS ENTRE OSTEOPOROSIS TIPO I Y TIPO II}

\begin{tabular}{|l|l|l}
\hline & TIPO I & TIPO II \\
\hline Denominación & Postmenopaúsica & Senil \\
\hline Edad & $51-75$ & $>70$ \\
\hline Proporción & $6: 1$ & $2: 1$ \\
\hline Tipo de perdida ósea & Trabecular & Trabecular y cortical \\
\hline Ritmo de perdida ósea & Rápido & Lenta \\
\hline Fracturas & Vértebras y radio distal & Vértebras y cadera \\
\hline Función paratiroidea & Disminuída & Aumentado \\
\hline Absorción intestinal de calcio & Disminuída & Disminuída \\
\hline $\mathbf{1}$ alfa hidroxilación renal & Disminuída secundariamente & Disminuida primariamente \\
\hline Causa fundamental & Menopausia & Envejecimiento
\end{tabular}




\section{Osteoporosis secundarias.}

Diversas enfermedades metabólicas, endocrinas, nutricionales, tóxicas o genéticas pueden producir osteoporosis y aumentar el riesgo de fractura. En el varón, la enfermedad tiene un origen secundario en un porcentaje muy elevado de los casos siendo, como ya se ha comentado, el consumo de alcohol, el tratamiento con corticoides y el hipogonadismo las principales causas de osteoporosis en estos pacientes,(85)

Las causas más frecuentes de osteoporosis secundaria en ambos sexos son el hipogonadismo, las enfermedades endocrinas como la tirotoxicosis, hiperparatiroidismo, síndrome de Cushing, diabetes mellitus tipo 1, hiperprolactinemia etc. También enfermedades gastrointestinales: gastrectomía, malabsorción intestinal, enfermedades reumáticas: artritis reumatoidea y espondilitis anquilosante, enfermedades hematológicas: como el mieloma múltiple, linfoma, leucemia, anemia perniciosa, talasemia, amiloidosis, hemocromatosis, hemofilia y otros procesos como la esclerosis múltiple, escoliosis idiopática, enfermedad pulmonar obstructiva crónica, nutrición parenteral, anorexia nerviosa, insuficiencia renal crónica, enfermedad hepática crónica, hipercalciúria idiopática, trasplante de órganos, fibrosis quística, sarcoidosis, alcoholismo, osteogénesis imperfecta y tratamientos prolongados de glucocorticoides, exceso de hormona tiroidea, anticonvulsivos, heparina, ciclosporina y metotrexato.(108)

\section{III.5.EPIDEMIOLOGÍA}

La osteoporosis, al igual que la obesidad, por su alta prevalencia conlleva consecuencias muy importantes, no sólo para los pacientes que la padecen, sino también, para el sistema sanitario y para la sociedad en general. (62,72,74,109,110) Esta patología tiene una gran repercusión socioeconómica.(74) Es la enfermedad metabólica ósea más frecuente. Una de cada tres mujeres mayores de 55 años padece osteoporosis y su incidencia está aumentando también en los varones.

En España existen tres millones y medio de pacientes, de ellos, dos millones y medio son mujeres y sólo una de cada diez personas está siendo tratada.(64) $\mathrm{Su}$ frecuencia se iguala a las enfermedades cardiovasculares y el riesgo de que una mujer padezca una cardiopatía es el mismo que el de que pueda sufrir una fractura osteoporótica. Este riesgo está estimado en un 40\%. Dependiendo del tipo de fractura que ocasione la enfermedad, puede producir, desde una limitación funcional más o menos importante a dolores intensos e incapacitantes que llevan asociado un reposo estricto y un tratamiento enérgico. (111,112,113,114) 
La fractura más grave y que produce peores consecuencias es la fractura de fémur con alta mortalidad, que ve incrementado su porcentaje sobre todo durante el primer mes postfractura.(73) Se ha estimado que esta fractura reduce la esperanza de vida en un $12 \%$ además de producir un deterioro en la calidad de la misma. En general un tercio de los pacientes que sufren una fractura vuelve a la normalidad, un tercio sufre una invalidez total o parcial y otro tercio muere por la fractura. Los factores que conllevan un mayor riesgo de mortalidad e incapacidad después de sufrir una fractura son la edad, el mal estado prefractura y la presencia de un cuadro de demencia de base. $(48,102)$

La incidencia de fracturas osteoporóticas aumenta con la edad en ambos sexos en relación a cambios en la cantidad de tejido óseo del esqueleto ya que con la edad la masa ósea disminuye. $(51,86,87,102,115)$

En la osteoporosis, la pérdida de masa ósea es consecuencia de la acción de diversos factores sobre el metabolismo óseo.(91) Cerca de un $70 \%$ de todas las fracturas en sujetos mayores de 45 años se asocian a osteoporosis. Otras situaciones clínicas aumentan el riesgo de fractura como son los antecedentes de fractura por fragilidad después de los 40 años, el antecedente de fractura en un familiar de primer grado junto con la edad avanzada.(33,60,116) El antecedente de haber padecido una fractura aumenta el riesgo de sufrir nuevas fracturas independientemente de la localización. Este riesgo oscila entre 1,7 y 2,2 cuando se compara con la población sin fracturas previas.(33)

A nivel asistencial, el promedio de camas ocupadas por pacientes con fractura de fémur, los ingresos por ésta causa y el número de intervenciones quirúrgicas que ocasiona es muy elevado y si tenemos en cuenta, el grupo poblacional que con mayor frecuencia sufre estas lesiones, las necesidades de atención hospitalaria son considerables. $(64,110,112,117)$

A nivel económico, el coste que suponen estas fracturas es muy alto a la vez que difícil de calcular ya que, es imposible determinar lo que cuesta que un familiar deje su trabajo, los desplazamientos, contratación de personas para atender a los pacientes...además de los gastos que se originan por rehabilitación, medicación, asistencia doméstica etc. $(64,110,112,117)$

La osteoporosis afecta al $20 \%$ de las mujeres mayores de 65 años y sólo al $6 \%$ de los hombres.(76,109) Este grupo de población presenta un riesgo de fracturas muy elevado siendo las más frecuentes las vertebrales (sobre todo lumbares), las de muñeca (fractura de Colles), costillas y fémur proximal (cuello del fémur), aunque pueden producirse en cualquier lugar debido a la generalizada pérdida esquelética de masa y densidad $(112,113,118)$ 
Las fracturas de cadera, en las mujeres, son las que mayor repercusión tienen sobre morbi-mortalidad. El 15\% de la población femenina tiene riesgo de sufrir fractura de cadera a lo largo de su vida, además este riesgo se duplica cada siete años, a medida que avanza la edad. Comparando entre sexos, el riesgo de la mujer de sufrir una fractura de cadera es de dos veces la del hombre.(134) La prevalencia de fractura vertebral en mujeres de más de 65 años ronda el 33\%, un tercio de ellas la presenta.(119)

La incidencia en España de las fracturas vertebrales anuales es de 764 por cada 100.000 habitantes; la vertebral es la más frecuente de las fracturas osteoporóticas. Ocasiona dolor y limitación de la movilidad de la columna, cifosis, disminución de la talla, discapacidad y pérdida de la calidad de vida.(52) En España se calculaque se producen unas 33.300 fracturas de cadera anuales con 31.000 intervenciones quirúrgicas, colocación de unas 10.000 prótesis totales de cadera y unas 767.800 estancias en la fase aguda. Todo ello conlleva unos costes millonarios a los que hay que añadir además, los costes de los cuidados crónicos y rehabilitadores que las fracturas osteoporóticas precisan. (117) Las fracturas de cadera son una carga para el individuo y para la comunidad. Sólo el $50 \%$ de los individuos recuperan la movilidad e independencia de las que gozaban antes de la fractura.(111,112,113,114,120,121,122) Las fracturas vertebrales por aplastamiento producen dolor y deformidad, las fracturas de cadera causan una importante morbilidad y mortalidad, por ésta razón, la aparición de una fractura sin antecedente traumático importante, puede ser suficiente para realizar el diagnóstico e iniciar tratamiento, incluso en ausencia de osteoporosis densitométrica. En pacientes que hayan presentado una fractura osteoporótica, el riesgo de nuevas fracturas se multiplica por 3-4 frente a la población control.(52)

En los países industrializados el problema tiende a incrementarse. El envejecimiento de la población aumenta el número de personas expuestas a la osteoporosis. En España el 42\% de las mujeres entre los 50 y los 59 años tienen osteopenia en la columna lumbar y el 9,1\%, osteoporosis, cifras que ascienden al 50 y al $24,3 \%$ respectivamente, cuando hablamos de mujeres entre los 60 y los 69 años.(109,123)

Incidencia de fracturas osteoporóticas en la población general (1.000mujeres/año). (51)

$\begin{array}{lccc}\text { 50 años } & \text { Muñeca } & \text { Vértebras } & \text { Cuello fémur } \\ \mathbf{6 0} \text { años } & 4 & 2 & 1 \\ \mathbf{7 0} \text { años } & 6 & 3 & 1,5 \\ \mathbf{8 0} \text { años } & 6 & 5 & 3 \\ & 6 & 10 & 10\end{array}$




\section{Correlación comparada entre factor de riesgo y proceso patológico. (119)}

\author{
Factor \\ Hipercolesterolemia \\ Tabaquismo \\ Osteoporosis
}

\section{Proceso patológico}

Infarto de miocardio

Cáncer de pulmón

Fractura de fémur

\section{Correlación (\%)}

$21 \%$

$78 \%$

$85 \%$

La densidad mineral ósea es un riesgo que se puede cuantificar; actualmente, el diagnóstico del paciente que aún no ha sufrido una fractura por fragilidad se basa en sus valores.(123,124) El diagnóstico de osteoporosis se realiza actualmente mediante la densitometría ósea que detecta la pérdida de masa ósea en fases tempranas, así como su evolución y cambios en relación con medidas terapeúticas. Una baja masa osea es riesgo de fracturas por fragilidad en base a difrentes estudios, lo que nos indican que una masa ósea reducida puede predecir un futuro riesgo de fractura. $(34,60,69,83,125,126,127)$

Recientemente la Sociedad Internacional de Densitometría clínica ha apoyado el diagnóstico de osteoporosis basado en criterios densitométricos Se debe utilizar para el diagnóstico el valor más bajo obtenido en cualquiera de las cuatro localizaciones esqueléticas analizadas habitualmente, columna lumbar, cuello de fémur, trocánter o fémur total, excluyendo los valores obtenidos en el triángulo de Ward debido al riesgo de sobrestimar el riesgo de fractura cuando se analiza esta área femoral.(128)

La $O M S$ apoya su definición en que la baja masa ósea es el principal determinante de riesgo de fractura y por cada reducción de una DS en la DMO se dobla el riesgo.(129)

En Europa, las recomendaciones para realizar una DMO se basan en la búsqueda selectiva de casos en función de los factores de riesgo de fractura y masa ósea baja(61,130)

\section{III.6.FACTORES DE RIESGO DE LA OSTEOPOROSIS}

Se ha comprobado la relación entre determinados factores de riesgo y la existencia de una masa ósea baja.(46,76,,91,131,132,133,237)

\section{Peso y composición corporal}

La tensión a que se somete al hueso favorece una mayor densidad ósea, por lo que un mayor peso se asocia a mayor densidad y menor riesgo de fracturas. Los componentes de la masa corporal, la masa libre de grasa, sobre todo el músculo y el tejido adiposo, pueden ejercer influencia sobre el hueso ya que el tejido graso es fuente de estrógenos endógenos importante en la postmenopaúsia donde disminuye o se anula su producción, pero un exceso de grasa se asocia a un aumento de morbimortalidad. 
A su vez, la masa muscular está determinada por factores que son capaces de estimular la formación ósea como la actividad física, insulina, andrógenos y hormona del crecimiento. $(59,92,99,100,101,103,104)$

\section{Factores nutricionales.}

Estos factores de riesgo pueden afectar a muchos nutrientes, tanto macronutrientes como de micronutrientes y así, tanto un adecuado aporte de energía como de proteínas son necesarios para la formación de la matriz orgánica del hueso. $(46,92,134,135,136)$

\section{Calcio.}

Elemento clave en la composición ósea, pero presenta limitaciones para cubrir los requerimientos del mismo, por su escasa presencia en el conjunto de alimentos que lo contienen y su difícil absorción intestinal. La osteoporosis es una enfermedad provocada por la deficiencia de calcio alimentario, aspecto éste difícil de demostrar, aunque en investigaciones con animales de experimentación, la deficiencia de calcio alimentario ocasiona osteoporosis, pero no puede aceptarse que la osteoporosis se relacione sólo con el aporte de calcio. Ante un escaso aporte alimentario, el hueso no puede presentar ni un crecimiento ni remodelado adecuado. La repercusión de un aporte insuficiente en el remodelado óseo es un aumento en la secreción de PTH, que aumenta la resorción ósea y por tanto disminuirá la masa y densidad óseas.

Un déficit en el aporte de calcio siempre es negativo para el hueso por lo que, hay que asegurar un aporte adecuado.(35,36,92) El metaanálisis que realizó Cochrane Library sobre 15 estudios que valoraban el efecto del calcio sobre la prevención de la pérdida de masa ósea y de las fracturas osteoporóticas encontraron un efecto positivo significativo sobre la densidad mineral ósea en casos de prevención secundaria pero no significativo en caso de prevención primaria.(39,40)

\section{Fósforo.}

La ingesta habitual de fósforo supera las de calcio, no existe ningún problema de aporte ya que prácticamente todos los alimentos contienen cantidades importantes de fosfatos y su absorción es buena. Existen situaciones en que hay bajos niveles de fósforo sérico, especialmente en personas de edad avanzada, debido a malnutrición, uso excesivo de antiácidos que se unen al fósforo y malabsorción intestinal.

\section{Magnesio.}

El déficit de magnesio es muy común, especialmente en mujeres con hipermenorrea y/o metrorragias y en ancianos. Además facilitan el déficit de magnesio, el uso de diuréticos y el consumo de alcohol. Muchas mujeres que sufren osteoporosis tienen un contenido óseo de magnesio disminuido.(137) 


\section{Vitamina D.}

En edad avanzada hay menores niveles circulantes de 25-hidróxi-vitamina D. Esta deficiencia de hormona D3 puede ser debida a una baja exposición solar, disminución de la capacidad de síntesis cutánea, reducida actividad enzimática de la 1-hidróxilasa y baja ingesta vitamínica. La deficiencia genera un hiperparatiroidismo secundario que agrava la desmineralización ósea. La vitamina $\mathrm{D}$ reduce la incidencia de fracturas vertebrales de forma significativa aunque el efecto protector sobre ellas no es significativo. (138)

\section{Vitamina K.}

La vitamina $\mathrm{K}$ se necesita para la síntesis de la osteocalcina, que es segregada por los osteoblastos y es importante en la fase inicial de la mineralización de la matriz orgánica del colágeno del hueso.

\section{Proteínas.}

Cuando la ingesta de proteínas es excesiva, existe una pérdida urinaria aumentada de calcio que se debe al aumento del glucagón en respuesta a la gran cantidad de aminoácidos que aporta un exceso de proteína alimentaria, ésta elevada ingesta proteica aumenta el riesgo de osteoporosis.(92) Otro riesgo debido al exceso de proteínas de origen animal es el exceso de hidrogeniones y su efecto a nivel de descalcificación ósea. Estos efectos aparecen con ingestas muy altas, no con las habituales aunque sean superiores a las recomendadas.

\section{Grasa.}

La grasa saturada puede quelar el calcio alimentario a nivel intestinal, lo que en determinados excesos podría afectar al balance global del mineral.

\section{Sodio.}

La ingesta elevada de sodio aumenta la calciúria más, si la ingesta de calcio es baja.

\section{Flúor.}

Al nivel de ingestas recomendadas, el flúor ejerce un efecto positivo aumentando la dureza de la superficie en los cristales óseos.

\section{Otros nutrientes.}

Otros nutrientes afectan también al metabolismo óseo, especialmente en lo que se refiere a la formación de la matriz orgánica. Así el hierro y la vitamina C son claves en la conversión de los residuos de prolina y lisina en hidroxiprolina e hidroxilisina en la molécula de colágeno. 
Otras vitaminas como la B6, folato, B12 y la vitamina A, también tienen funciones en el metabolismo óseo, por lo que un mal estado nutricional general o específico para algunos nutrientes, puede afectar en mayor o menor grado a la estructura ósea.

\section{Menopaúsia}

Factor de riesgo más importante sobre todo para la osteoporosis tipo I. $(49,76,96,97)$ En los varones su equivalente sería el hipogonadismo.(80,100,101) La edad media para la presentación de la menopausia en la mujer occidental son los 48 años por lo que la mujer que tenga la menopausia después de los 52 tendrá un importante factor protector, por el contrario, la mujer que presente menopausia precoz, menor de 40 años tendrá un riesgo importante, sobre todo si se produce como consecuencia de una anexectomía.

Otros autores la relacionan con los años que la mujer está menstruando, a más años con menstruación mayor exposición a los estrógenos y por tanto menor riesgo de osteoporosis y viceversa menarquia más tardía mayor riesgo de osteoporosis.( 80) Ya que las células óseas no poseen receptores para los estrógenos se cree que la relación huesoestrógenos es indirecta.

\section{Edad}

Es el otro factor de más peso en la aparición de osteoporosis tipo II o senil. Con la edad se producen modificaciones fisiopatológicas, menor actividad osteoblástica, menor absorción intestinal de calcio y desarrollo de hiperparatiroidismo secundario que en determinadas ocasiones conlleva a la osteoporosis. La edad es un factor de riesgo más específico para el varón, por encima de los 75 años la proporción mujer/varón con osteoporosis es de 2:1, en edades más jóvenes la proporción es de 6:1. $(48,51,62,86,87,102,103,104,115,134)$

\section{Factor genético/racial}

Es más frecuente en hijas de madres osteoporóticas y se ha demostrado en gemelas univitelinas, que existe una gran concordancia en la masa ósea aunque no se ha podido establecer un patrón de transmisión genética específico de la enfermedad. La enfermedad es más frecuente en la raza blanca o asiática que en la raza negra. (139)

\section{Alcohol}

El consumo crónico de alcohol se ha asociado a la aparición de enfermedad metabólica ósea por la acidosis que provoca y se a descrito en desarrollo de osteopénia y un aumento en la incidencia de fracturas destacando las de cadera.(139)

El alcohol produce alteraciones en el metabolismo mineral del calcio, fósforo, magnesio y vitamina $\mathrm{D}$, alteraciones endocrinas que dan alteraciones a nivel del propio hueso. En general, éste problema es mayor en el hombre que en la mujer. 


\section{Café}

Algunos estudios han asociado el consumo de cafeína con una menor masa ósea y mayor riesgo de fracturas al aumentar las pérdidas urinarias de calcio, aunque, por si solo, es muy difícil de valorar el riesgo del café sobre ésta patología.(139)

\section{Tabaco}

Se relaciona el consumo de tabaco con menor masa ósea y mayor riesgo de fracturas(139) y se ha establecido una correlación inversa entre masa ósea y cantidad de cigarros consumidos. De forma aislada, es poco probable que el tabaco produzca osteoporosis, el efecto viene por su acción antiestrogénica ya que las mujeres fumadoras suelen presentar la menopausia más precoz que las no fumadoras. También debe tenerse en cuenta el efecto sobre el peso corporal dado el efecto anorexígeno del tabaco. Las mujeres fumadoras son más delgadas que las no fumadoras atribuyéndose a éste menor peso el riesgo de padecer osteoporosis.

\section{Ejercicio}

Puede ser el estímulo más importante en el crecimiento y remodelación del hueso y contribuye la presión y la tensión muscular. La inmovilización tiene efecto negativo sobre el hueso, con pérdida acelerada del mismo ya que se producen trastornos en el metabolismo mineral y posibilidad de desarrollar osteoporosis y fracturas.

Se ha comprobado en un metaanálisis que realizó Cochrane Library sobre 18 estudios aleatorizados, que en pacientes que realizaron ejercicio físico aeróbico o programas de musculación de forma continuada durante 1 o 2 años seguidos aumentaron su densidad mineral ósea; los efectos de la marcha no fueron significativos en columna lumbar pero sí en cuello femoral.(54)

El estudio National Osteoporosis Risk Assesment (NORA)(53) que evaluó la relación existente entre la medición periférica de la masa ósea en mujeres con los factores de riesgo y la aparición de fracturas a corto plazo indicó que, los principales factores de riesgo asociados son la edad, la historia de fractura, la raza, el abuso del tabaco y la toma de corticoides. También se comprobó que un índice de masa corporal alto, la raza negra, el uso de estrógenos o diuréticos, la realización de ejercicio físico regular y el consumo de alcohol son factores que aumentan la masa ósea.

La presencia deosteoporosis aumentó 4 veces el riesgo de sufrir una fractura con respecto a una masa ósea normal. La presencia de osteopénia aumentó el riesgo 1,8 veces. 


\section{PRINCIPALES FACTORES CLÍNICOS DE RIESGO DE OSTEOPOROSIS}

- Edad avanzada (>65años)

- Sexo femenino

- Fracturas leves por traumatismos previos a partir de los 45 años

- Baja ingesta de calcio de larga duración

- Uso crónico de fármacos: corticoides, antiepilépticos, litio, heparina...

- Mujer menopáusica con al menos un factor de riesgo:

historia familiar de osteoporosis

delgadez $(\mathrm{IMC}<19 \mathrm{Kg} / \mathrm{m} 2)$

tabaquismo, alcohol

menopausia precoz $(<45$ años $)$

ooforectomía bilateral antes de la menopausia fisiológica

amenorrea $>1$ año

- Enfermedades osteopenizantes.(34,60,88,91,126,127,140,141)

MEDIDAS PREVENTIVAS NO FARMACOLÓGICAS

(Estilos de vida) $(142,143)$

1. No fumar

2. Evitar el consumo excesivo de alcohol

3. Evitar el sedentarismo, caminar una hora al día o ejercicio físico equivalente

4. Alimentación equilibrada (1000-2000mg calcio) con ingesta suficiente de proteínas

5. Evitar el déficit de vitamina $D$

6. Evitar el riesgo de caídas

\section{III.7.CAUSAS DE FRACTURAS OSTEOPORÓTICAS.}

La patogenia de las fracturas se relaciona con factores genéticos, la menopausia, la senectud, inmovilización y los traumatismos.(75,91,92,144) La fortaleza ósea está relacionada con su masa por lo que, a menor masa ósea menor traumatismo se precisa para producir una fractura. Mientras la masa ósea está disminuyendo, el riesgo de fractura está incrementándose debido a cambios fisiológicos extraesqueléticos. $(75,76,92,132,133,136,145)$ La disminución de la masa ósea puede deberse a que la cantidad de hueso formada durante el desarrollo haya sido insuficiente o bien a que el tejido óseo se ha perdido posteriormente en una proporción o velocidad excesiva; ambos factores son de la mayor importancia en la patogenia de la fractura osteoporótica.

\section{Factor edad}

La pérdida de hueso relacionada con la edad es la forma más frecuente de osteoporosis. $(51,86,87,102,103,104,115)$ La osteoporosis de tipo II o senil se observa en varones y mujeres de más de 70 años de edad y la relación mujer/varón es de 2:1 a 3:1.(134) 
En general estos pacientes presentan fracturas de cadera y vertebrales y no son raras las fracturas de pelvis, del húmero proximal y de la tibia.

\section{Factores hormonales}

El déficit estrogénico por una menopausia temprana o una menarquia tardía son factores importantes de riesgo. La deprivación estrogénica conlleva un aumento del remodelado óseo. $(92,98,101,146,147)$ Una pérdida acelerada de peso junto con un pico de masa ósea reducido incrementan el riesgo de fracturas osteoporóticas. Una menarquia precoz aumenta dicho riesgo.(49)

Las atletas con amenorrea, las mujeres con hiperprolactinemia, las que han sufrido una ovariectomía y las mujeres con endometriosis con menopausia artificial inducida por agonistas de la hormona liberadora de luteína sufren pérdida acelerada de hueso.

El hipogonadismo masculino también conlleva una pérdida de hueso que responde al tratamiento con testosterona. En relación con el hueso la testosterona desempeña en el varón un papel similar al de los estrógenos en la mujer. El fallo gonadal es uno más de los factores que lesionan el hueso. (85)

\section{Factores genéticos}

La osteoporosis tiene un origen multifactorial. Un 46-62\% de las variaciones de la densidad ósea están genéticamente determinadas. Son factores determinantes de baja masa ósea el sexo femenino, la edad avanzada y la raza blanca. $(92,116)$

\section{Factores constitucionales}

La masa corporal es uno de los determinantes fundamentales del pico de masa ósea. $(92,99,101,103,104,134,135)$ Aunque las personas de elevada estatura tienen huesos largos, el peso corporal es un factor más importante que la estatura. Los cambios del peso corporal también determinan la incidencia de fractura de cadera; en mujeres postmenopáusicas cuyo peso corporal ha aumentado en más del 50\% desde los 25 años de edad tienen una incidencia de fractura de cadera 6 veces menor que las mujeres que no han llegado a este peso con el transcurso de los años.

\section{Factores ambientales}

- Nutrición: Un aporte adecuado de calcio es obligado en la consecución de un pico de masa ósea genéticamente determinado.(35,36,37,92) Se precisa una ingestión elevada de calcio en la senectud, así como en la prevención de la pérdida de hueso que se produce con la menopausia debido a que en ésta etapa, la absorción está disminuida y la excreción renal aumentada.(148) Los estudios epidemiológicos no han demostrado que la ingestión de calcio reduzca el riesgo de fracturas. Por ello, los beneficios del aporte a largo plazo de calcio no están bien definidos. 
La dieta rica en fosfatos limita la absorción de calcio y hace que aumente la parathormona (PTH) que aumenta el riesgo de padecer osteoporosis. (35,36) También la ingesta aumentada de proteínas eleva la posibilidad de padecer la enfermedad al aumentar la eliminación urinaria de calcio. Igual ocurre con la alta ingesta de sodio.

- Hábitos de vida: La actividad física y el ejercicio son claramente beneficiosos para el esqueleto. Tanto las mujeres premenopausicas como las postmenopausicas que realizan ejercicio de forma regular tienen mayor masa ósea que las mujeres sedentarias.

El ejercicio regular también disminuye el riesgo de fractura de cadera, aunque éste beneficio no quede del todo explicado por la consecución de una mayor densidad ósea. El ejercicio físico mantiene la fuerza, el equilibrio y la agilidad, lo que contribuye también a la prevención de las fracturas. $(37,92,149,150,151)$

Con un IMC disminuido y un bajo peso, la densidad mineral ósea es más pequeña debido a que la menor carga mecánica sobre el hueso disminuye el poder osteoblástico a la vez que la carencia de tejido adiposo, conlleva menor depósito hormonal que implica menor inhibición osteoclástica.

- Tóxicos: El abuso de alcohol se asocia con un estado de bajo metabolismo óseo aunque el consumo moderado en la mujer postmenopaúsica no es un importante factor de riesgo de osteoporosis.

El tabaquismo crónico tiene una influencia negativa sobre la densidad mineral ósea y sobre la tasa de pérdida de hueso tanto en varones como en mujeres.

El consumo elevado de cafeína también se asocia con disminución de la masa ósea y a diferencia del tabaco, si que es considerado como un factor de riesgo de fractura de cadera, independiente de la densidad ósea ya que, aumenta la eliminación urinaria de calcio.(139,149,150)

\section{CAUSAS DE FRACTURAS OSTEOPOROTICAS.}

\section{No modificables}

- edad

- menopausia precoz

- antecedentes familiares

- raza blanca o amarilla

\section{Modificables}

- estilos de vida

- escasa ingesta de calcio

- tabaco

- sedentarismo

- nuliparidad

- excesivo consumo de alcohol

- abuso de café

- enfermedades (*)

- fármacos $(* *)$ 
(*) Enfermedades: Acromegalia

Tirotoxicosis

Hiperparatiroidismo

Anorexia nerviosa

Síndrome de Cushing

Artritis reumatoide
(**) Fármacos: Reemplazamiento tiroideo

Glucocorticoides

Anticoagulantes

Anticonvulsivantes

Tratamiento crónico con litio

Quimioterapia

\section{FACTORES DE RIESGO DE FRACTURA Y MASA ÓSEA BAJA (33)}

\begin{tabular}{|l|l|}
\hline Factores Mayores & Factores Menores \\
\hline Edad $>65$ años & Artritis Reumatoide \\
Antecedentes de fractura vertebral & Hipertiroidismo \\
Fractura por fragilidad después de los 40 años & Baja ingesta de calcio \\
Fractura en un familiar de primer grado & Tabaquismo \\
Tto con glucocorticoides más de tres meses & Alcoholismo \\
Síndrome de malaabsorción & Exceso de cafeína \\
Hiperparatiroidismo primario & Peso $<57 \mathrm{~kg}$ \\
Propensión a caídas & Pérdida de peso $>10 \%$ respecto al de los \\
Osteopenia radiológica & 25 años \\
Hipogonadismo & Tto crónico con antiepilépticos \\
Menopausia prematura( $<45$ años $)$ & Tto crónico con heparina \\
\hline
\end{tabular}

\section{III.8.OSTEOPOROSIS EN EL VARÓN}

La pérdida de masa ósea en relación con la edad es común tanto en varones como en mujeres. En el varón de edad avanzada, la pérdida de masa ósea se produce de forma más lenta y tardía que en la mujer pues el declive de la función gonadal, es un proceso lento y progresivo que se desarrolla de forma gradual. La concentración plasmática de testosterona empieza a caer a los 50-60 años lo que ocasiona un aumento de la resorción ósea. (77,115) En el estudio TROURBACH et al,(139) se constató que hay una pérdida acelerada de la masa ósea en la mujer entre los 50-57 años que sólo se ve en los varones después de los 68 años. 
Los factores de riesgo de osteoporosis se han evaluado sobre todo en las mujeres pero también son aplicables al sexo masculino (152) aunque, en los varones, el desarrollo de la enfermedad se asocia en un $50-75 \%$, a otros procesos patológicos (85,153) y todavía no están bien definidas las pautas de actuación.(154) El tratamiento estará en función de la etiología. Hay trabajos que demuestran correlación entre contenido mineral óseo y niveles de hormonas sexuales, en ambos sexos, por lo que un déficit gonadal hace que aumente la reabsorción ósea. También se produce déficit de 1,25-dihidroxivitamina $\mathrm{D}$ que se da en los varones con osteoporosis idiopática similar al proceso que padece la mujer con la menopausia, aumenta la PTH y la malabsorción de calcio aumenta la reabsorción ósea. Otros factores que contribuyen a pérdida de masa ósea en el varón son la raza blanca, la delgadez, baja ingesta de calcio, reducida actividad física, la inmovilización prolongada, el excesivo consumo de alcohol y el tabaquismo. (58,77,134,135,155) Hay un mayor riesgo de osteoporosis con fracturas vertebrales en varones que fuman y consumen alcohol haciendo que la incidencia sea mayor cuando se suman ambos hábitos tóxicos ya que presentan un efecto acumulativo aunque sean factores independientes.(102,134) El alcohol aumenta le eliminación de calcio urinario y además estos pacientes generalmente, van acompañados de malnutrición.

Los estudios realizados demuestran una incidencia similar de osteoporosis en ambos sexos a partir de los 75 años y al igual que ocurre con las mujeres, hay estudios que demuestran que la obesidad tiene efecto protector frente a la pérdida de masa ósea. El mayor esfuerzo que realiza una persona obesa durante la actividad física, condiciona un aumento de tensión sobre el esqueleto que estimula la formación ósea.

Las causas más frecuentes de osteoporosis en el varón son el tratamiento con corticoides, el hipogonadismo, el alcoholismo, enfermedad hepática, la malabsorción intestinal, inmovilización, enfermedades reumáticas, osteoporosis en la juventud y la malnutrición.(77,85,135,156) En España se calcula que son más de 700.000 los varones que padecen osteoporosis.(156)

\section{III.9.DIAGNOSTICO DE OSTEOPOROSIS. MEDIDAS DE MASA ÓSEA}

Las fracturas son un punto evolutivo de un proceso en el que están implicados distintos factores de riesgo asociados a una baja masa ósea.(123) 
La valoración de estos factores de riesgo, la determinación de la masa ósea, el desarrollo de fracturas o el aumento del riesgo de caídas deben aparecer en la anamnesis del paciente con sospecha de osteoporosis.(157,161)

El concepto de masa ósea es fundamental ya que está en relación directa con la debilidad o fortaleza del esqueleto.(37) El "pico de masa ósea" se alcanza alrededor de la treintena, cualquier factor que afecte a su adquisición o que contribuya a su pérdida en edades más tardías van a aumentar la posibilidad de padecer la enfermedad.(38,146)

Las mujeres padecerán más osteoporosis que los varones porque parten de una situación desfavorable para ellas al poseer menor cantidad de masa esquelética, mayores pérdidas de hueso (menopausia) y mayor número de condicionantes para perder calcio (embarazo y lactancia). A los 70 años la velocidad de regresión se iguala en ambos sexos pero existe una considerable variación individual sin relación con las cifras hormonales. $(80)$

La edad, el peso corporal, los años de vida fértil y el número de embarazos se asocian, de forma independiente con densitometría ósea anómala. La valoración de la masa ósea es indispensable para determinar el riesgo de osteoporosis, puesto que los factores de riesgo por sí solos no permiten identificar de una forma precisa a la población de mujeres con baja densidad ósea.(158,159) Además de la edad y del efecto de la menopausia,(72,96,97,109) el otro factor que más influye es el peso corporal.(50)

El estudio realizado por González-Macias et al en el que analizó la prevalencia de los factores de riesgo de osteoporosis y fracturas en la población femenina española mayor de 65 años mostró que un $25 \%$ de las pacientes estudiadas presentaron menopausia precoz, un 20\% tenían antecedentes de fracturas osteoporóticas, un 16,7\% antecedentes familiares de ese tipo de fracturas y un 14,6\% tenían un peso menor de $57 \mathrm{~kg}$. En un $56 \%$ de las mujeres estuvo presente alguno de estos cuatro factores. En nuestro país, se estimó en 60.000 el número de fracturas osteoporóticas en 2002.

El $70-80 \%$ de la fortaleza del hueso está determinada por la masa ósea que se define como la cantidad de hueso, trabecular (80\%) y cortical, que tiene un individuo.(160) Ambos componentes óseos, trabecular y cortical sufren variaciones dependientes de la morfología o tipo de hueso, así, los huesos largos tienen más masa ósea cortical en su diáfisis y más trabecular en sus epífisis por lo que pueden presentar y sufrir cambios distintos dependientes de la enfermedad causal. Se sabe que las fuerzas de compresión que hay que aplicar para fracturar un hueso esponjoso son proporcionales al cuadrado de la densidad mineral ósea, su disminución aunque sea leve, producen grandes disminuciones de su resistencia. 
Los densitómetros permiten cuantificar hueso cortical y trabecular simultáneamente pero no aisladamente, y no de forma taxativa, ya que la proporción cortical-trabecular varía dependiendo del tipo de hueso e incluso de un mismo hueso.

La correlación existente entre masa ósea y riesgo de fracturas es continua, así, las fracturas osteoporóticas aumentan según disminuye la densidad mineral ósea.(48)

Estudios prospectivos de determinación de masa ósea han demostrado que el riesgo relativo de sufrir fracturas se incrementa el doble por cada descenso de una desviación standar en la DMO. (125,129)

La DMO se ha correlacionado con el peso como resultado de la carga mecánica que éste supone, a la que el esqueleto responde con una estimulación de la actividad osteoblástica, aunque podría influir también la mayor conversión de andrógenos suprarrenales a estrógenos en el tejido adiposo.(158)

En algunos estudios se encuentra asociación del estado óseo con el peso, la talla y el IMC y en otros, la asociación entre peso y masa ósea es más fuerte que entre peso y masa ósea e IMC indicando que los factores mecánicos pueden ser más importantes que la adiposidad. Otros trabajos encuentran que en las mujeres posmenopaúsica, la edad, el peso corporal y los años transcurridos desde la menopausia son las variables más significativas en los análisis de regresión. Los factores que mayor influencia presentan en los parámetros ultrasónicos son el peso y la edad, siendo la influencia de ésta diferente según las mujeres hubieran tenido o no la menopausia.(72,91)

La osteoporosis se define como una pobreza de masa ósea, siendo el hueso que queda, cualitativamente normal. Por su impacto socio-económico, ha motivado el desarrollo de metodologías que permiten la cuantificación de la masa ósea, y por ella definir los individuos con riesgo de padecer la enfermedad. Lo que si parece evidente es que el diagnóstico de osteoporosis, en una mujer menopaúsica con un colapso o fractura vertebral sin trauma previo y en la que se excluyen otras causas posibles (hiperparatiroidismo mieloma,...) no precisa la cuantificación de su masa ósea con fines diagnósticos.(161)

Bajo un punto de vista práctico para diagnosticar osteoporosis no hace falta ningún método,(162) y su uso sólo está justificado con el fin de detectar pacientes con riesgo de padecer la enfermedad y/o para observar los cambios de la masa ósea dependientes del tipo de población, patología, y/o régimen terapeútico, y la elección del método es controvertida, no sólo cual es el mejor método sino en que sitio hay que utilizarlo.(161) 


\section{Radiografía}

Sólo es diagnóstica en enfermedad avanzada y cuando la pérdida es mayor del $30 \%$. Los estudios radiológicos de columna dorsal y lumbar son muy útiles para valorar la existencia y la severidad del proceso. La existencia de aplastamiento y acuñamientos vertebrales típicos nos permiten realizar el diagnóstico e indica el riesgo elevado del paciente de sufrir fracturas.Actualmente la determinación de la masa ósea es la prueba diagnóstica de osteoporosis por excelencia ya que permite realizar el diagnóstico precoz debido a la buena correlación existente entre la masa ósea con la fortaleza del hueso y con el riesgo de fracturas.(34,158,159,163,164,165,166)

\section{Densitometría. Métodos.}

1) Tomografía axial computerizada. (TAC).

2) Absorciometría.

3) Absorciometría de un solo fotón. (SPA).

4) Absorciometría dual. (DPA).

5) Densitometría de rayos $X$ de doble energía. (DEXA).

\section{- Densitometria de rayos $X$ de doble energía}

Esta técnica de densitometría, que utiliza una fuente de rayos $\mathrm{X}$ de doble energía, ha sido llamada QDR o DEXA. Permite medir la masa ósea a nivel de columna lumbar y cuello de fémur. $(60,118,125,167)$ Con este método, se ha podido calcular el llamado umbral de fractura, valor de la densidad mineral ósea por debajo del cual se encuentran situados el $90 \%$ de los enfermos con aplastamientos vertebrales. Permite calcular el riesgo de fractura de cada persona en un momento determinado, aunque su definición absoluta no esté lograda.(84,161) La DEXA es un método preciso y reproduciblede medición del contenido y la densidad mineral del hueso(50,158,163,164,165,168,169,170) y ha demostrado en numerosos estudios prospectivos que predice el riesgo futuro de fracturas osteoporóticas, $(84,165,171) \sin$ embargo, no hay acuerdo acerca de cómo utilizarla como cribado de la población diana para seleccionar a las personas de alto riesgo candidatas a prevención y/o tratamiento. $(161,162,172,173)$

Aunque las indicaciones prácticas son las mismas que las de la absorciometría dual (DPA), la reproductividad es del 99\% aunque en estudios a corto plazo, es aún mayor. Acorta el tiempo de exploración, en columna lumbar es de 20 a 30 minutos con el DPA, de 8 a 10 minutos con el TAC, y no llega a los cinco minutos con este método.

La gran correlación de los valores obtenidos con esta técnica y con el DPA, hacen a ambos métodos muy fiables para medir la masa ósea.(50,168) Los puntos analizados más frecuentemente son C.L (valor medio entre L2- L4) y el cuello fémoral.(60,118,125) 
Los valores vienen expresados en contenido mineral óseo (CMO) en $\mathrm{gr} / \mathrm{cm}$ o en densidad mineral ósea $(\mathrm{DMO})$ en $\mathrm{gr} / \mathrm{cm} 2$. Se suele referir a los valores de la población normal. Dicha referencia se expresa como z-score (diferencia en el número de desviaciones estándar en relación con el grupo de su misma edad y sexo) o t-score (diferencia en el número de desviaciones estándar (DS) en relación a masa ósea máxima obtenida entre los 20 y 30 años). Esta técnica permite calcular la DMO y el CMO en diferentes partes del cuerpo o el cuerpo total, así como a nivel de huesos periféricos e incluso en huesos periprotésicos cuando se implantan prótesis de cadera y así evaluar su capacidad de implante.(167)

Un grupo de expertos de la $O M S$, ha propuesto unos criterios diagnósticos de osteoporosis y osteopenia basados en la determinación de DMO.(34)

- Osteopenia: valores de masa ósea, situados entre -1 y - 2,5 DE del pico de masa ósea (PMO) que se corresponde con el máximo valor de masa ósea alcanzado por el adulto.

- Osteoporosis: valores situados por debajo de - 2,5 DE del PMO. Con este valor, un 30\% de las mujeres americanas tienen osteoporosis, lo que coincide aproximadamente con el número de fracturas a lo largo de toda la vida de las mujeres adultas americanas. En este trabajo, se define osteoporosis establecida a aquellas personas con osteoporosis densitométrica y con existencia añadida de fracturas osteoporóticas.

\title{
III.10.CRITERIOS DIAGNÓSTICOS DE OSTEOPENIA Y OSTEOPOROSIS SEGÚN LA OMS. (SEGÚN LA DETERMINACIÓN DE DENSIDAD MINERAL ÓSEA).
}

\author{
Normal DMO superior a -1 DE del t-score \\ Osteopenia DMO entre -1 y $-2,5$ DE del t-score \\ Osteoporosis DMO inferior a $-2,5$ del $t$-score \\ Osteoporosis establecida DMO inferior a $-2,5$ del t-score junto con fracturas espontáneas o \\ inducidas por un traumatismo mínimo.
}

En la actualidad, la absorciometría de rayos X de doble energía o DEXA, es la mejor técnica para determinar la masa ósea.(60,69,125,158,159,166,170,174) La DMO se determina en la columna lumbar y la cadera, considerándose para su valoración el nivel de masa ósea más bajo de cualquiera de las dos regiones determinadas.(128)

Durante los primeros años tras la menopausia se produce una mayor pérdida de masa ósea en el hueso trabecular, por lo que en las personas de menos de 60 años la columna lumbar, donde el $50 \%$ de hueso es trabecular es la región más sensible. 
En las personas con más de 60 años suele existir una artrosis de columna y la disminución de la masa ósea es más generalizada, por lo que la cadera es el lugar donde se alcanza una mayor rentabilidad diagnóstica. (157)

\section{- Ultrasonidos}

La transmisión de ultrasonidos a través de un hueso depende de la masa ósea, de su estructura y de la calidad que presente el hueso. Está mucho menos desarrollada que la densitometría, aunque aporta nuevas oportunidades de utilización. Su fácil manejo y la carencia de exposición radiológica permiten su uso de una manera más amplia.

\section{III.11.INDICACIONES DE LA DENSITOMETRIA}

Menopausia precoz $(<45$ años $)$

(Según la NFO = Fundación Americana de Osteoporosis)

Episodios prolongados de amenorrea

Antecedentes de fracturas por fragilidad

Tratamiento con glucocorticoides de más de tres meses de duración

Inmovilización prolongada

Trasplantes de órganos y de médula ósea.

Hiperparatiroidismo primario

Estudios epidemiológicos

Osteopenia radiológica

Deformidades vertebrales

Antecedentes familiares de osteoporosis

Monitorización de nuevos fármacos. Control de tratamientos.

Hipogonadismo. Enfermedad de Cushing.

Enfermedades crónicas con pérdida ósea 
PACIENTES Y MÉTODOS 
La muestra fue obtenida a partir de pacientes que acuden con regularidad al Servicio de Dietética y Nutrición del Hospital Universitario de Salamanca. Los pacientes incluidos son de ambos sexos, tienen edades comprendidas entre los 29 y 78 años y presentan un índice de masa corporal (IMC) igual o mayor a 25 lo que supone que toda la muestra, está formada por pacientes que presentan sobrepeso u obesidad. El total de la muestra está constituida por 101 pacientes de los que 19 son varones y 82 mujeres, de ellas, 34 estaban en edad fértil y 48 presentaban la menopausia.

Se estableció un protocolo de recogida de datos igual para toda la muestra constituido por historia clínica, historia dietética, datos antropométricos, estudio analítico, tensión arterial y estudio densitométrico. A todos los pacientes se les proporcionaba unas medidas higiénico-dietéticas y una dieta para su control de obesidad que, aunque siguiendo unos criterios comunes y generales para todos, eran individualizadas en cada caso dependiendo de la situación particular de cada paciente, de su grado de obesidad, situación personal y familiar, actividad laboral, patologías y tratamiento de cada paciente.

Las dietas se confeccionaban de forma individualizada, procurando reducir progresivamente un $10-20 \%$ de la ingesta calórica y adecuar el consumo a una dieta equilibrada. Llegamos a utilizar dietas de muy bajo contenido calórico de unas 900 calorías aproximadamente para obesos con un índice de masa corporal alto y poca actividad física hasta dietas que rondaban las 2.500 calorías para pacientes con actividad laboral intensa. En cada paciente se realiza una valoración de su dieta habitual y del gasto energético total para elaborar un plan personalizado de medidas higienicodietéticas encaminado a conseguir una reducción ponderal. En cuanto a la actividad física en general se recomendaba la realización de ejercicios aeróbicos como caminar, correr, bailar, nadar... durante aproximadamente una hora al día.

Los pacientes, acudían a la consulta cada tres meses para control y seguimiento. Se valoraba el cumplimiento de las medidas higiénico-dietéticas prescritas y la regularidad del ejercicio físico recomendado. También se les interrogaba si se había producido alguna modificación en su estado de salud y/o en su tratamiento habitual. Se les controlaba el peso y la tensión arterial y se les determinaba el I.M.C.

En total se realizaron varias analíticas de control a los pacientes durante su seguimiento, la primera (inicio del trabajo) y la última (final del seguimiento) fueron completas, se les solicitaron todos los parámetros analíticos establecidos al comenzar el estudio con bioquímica general, hemograma completo, V.S.G. y metabolismo óseo tanto en sangre como en orina. 
En las determinaciones de control que se les realizó durante el seguimiento no se les solicitó a los pacientes las determinaciones del metabolismo óseo. La primera y la analítica final se realizaron coincidiendo lo más posible con la realización de las pruebas densitométricas. También se realizaron mediciones antropométricas durante las consultas de seguimiento y coincidiendo con las DEXA y con las analíticas en las que se solicitaba el metabolismo óseo.

Se interrogaba a los pacientes sobre sus antecedentes familiares y personales, patologías asociadas que presentaban y si recibían tratamiento farmacológico continuado, además de obtener información sobre su nivel cultural, ocupación laboral, actividad física y doméstica, hábitos tóxicos y hábitos dietéticos.

En el caso de la muestra femenina se les preguntó sobre su edad de menarquia, años de vida fértil, edad de menopausia y número de hijos. La recogida de datos se realizó mediante encuesta.

Se realiza una valoración del estado nutricional mediante estudio dietético que comprende: encuesta de hábitos alimentarios y frecuencia de consumo de alimentos, registro de tres días de ingesta y cuestionario de recuerdo de 24 horas. Los cuestionarios de registro de alimentos se adjuntan. En ellos se anotan los alimentos y bebidas consumidas, incluyendo cantidades y forma de cocinado. En la encuesta de frecuencia de consumo se interroga especialmente sobre consumo de lácteos, carne, pescado, huevos, cereales, legumbres, vegetales y hortalizas, frutas, aceites, dulces, alcohol...

En el momento de inclusión se determinó también la edad, el peso, la talla, el índice de masa corporal, la tensión arterial y se les interrogó sobre como había sido la evolución de su peso a lo largo del tiempo. Se les solicitó una analítica de sangre completa con bioquímica general que incluía las determinaciones siguientes: glucosa, urea, creatinina, urato, calcio, fósforo, magnesio, sodio, potasio, fosfatasa alcalina, enzimas hepáticas (GOT, GPT y GGT), proteínas totales, albúmina, osmolaridad, calcio iónico, perfil lipídico completo con determinación de colesterol, triglicéridos, colesterol HDL, colesterol LDL, índice colesterol total-colesterol HDL y también índice colesterol total-colesterol LDL.

Se midieron también la osteocalcina, fosfatasa alcalina ósea, hormona paratiroidea y la deoxipiridolina en la segunda orina de la mañana (Metabolismo mineral y óseo). Se solicitaron también elementos traza (cobre y zinc), hemograma y velocidad de sedimentación globular (VSG). En orina (de 24 horas) se determinaron calcio, fósforo, magnesio cobre y zinc. 
Se realizaron las medidas antropométricas con valoración de los pliegues tricipital, subescapular y suprailíaco o abdominal y los contornos de cadera, cintura y brazo y a todos los pacientes de la muestra, se les realizó una densitometría al inicio del estudio y otra al finalizar el mismo; aproximadamente a los dos años de iniciado el seguimiento.

En todos los casos la encuesta, la toma de tensión arterial, la realización de las medidas antropométricas y el seguimiento de los pacientes fue realizado por la misma persona.

Las extracciones de sangre se realizaron en condiciones estándar, dentro del mismo horario de $8: 30 \mathrm{~h}$ a $11 \mathrm{~h}$ en la sala de extracciones del Hospital Universitario de Salamanca y las muestras de sangre venosas fueron obtenidas a través de un sistema de vacío (Vacutainer) con tapón siliconado y después fueron remitidas al laboratorio del mismo centro hospitalario para su centrifugado y procesamiento. Se recogió también la orina, según criterio del laboratorio dependiendo de la determinación de las pruebas urinarias.

Todas las determinaciones bioquímicas fueron realizadas en un único laboratorio con un intervalo máximo de 36 horas tras la extracción de la muestra y procesadas en un autoanalizador (Hitachi 704, Boehringer-Mannheim, Alemania). La obtención de las muestras, tanto de sangre como de orina se realizaron en ayunas y siguiendo medidas estandares del laboratorio central del Hospital. Las concentraciones de osteocalcina se realizaron mediante método RIA. Se analizaron muestras de orina, la segunda orina de la mañana para la determinación de deoxipiridolina y en orina recogida en 24 horas para el calcio, fósforo y magnesio mediante autoanalizador. Los valores obtenidos se calcularon y ajustaron en función del aclaramiento en $1,73 \mathrm{~m} 2$.

Para la medición de la altura en bipedestación y el peso se siguieron unos criterios establecidos, con los sujetos sin zapatos y con ropa ligera. La altura fue medida con una precisión de $0,5 \mathrm{~cm}$ y el peso con una precisión de $100 \mathrm{gr}$, usando siempre la misma báscula y el mismo medidor de pared fijo.

El IMC fue calculado como el peso en kilogramos dividido por el cuadrado de la talla en metros.

Las medidas antropométricas (pliegues tricipital, subescapular y el pliegue abdominal) se realizaron con un calibre en $\mathrm{mm}$, siempre el mismo. Se midieron también los contornos del brazo, el contorno de la cadera y el de la cintura con una cinta métrica convencional. 
La circunferencia de la cintura se midió en el punto en el que ésta era menor, entre la cresta ilíaca y la última costilla, después de una espiración normal. En sujetos obesos sin una cintura natural, la medición se realizó en el punto medio entre la costilla y la cresta ilíaca. La circunferencia de la cadera se midió en el punto donde ésta era máxima.

El índice cintura cadera (ICC) fue calculado dividiendo la circunferencia de la cintura (CCI) entre la circunferencia de la cadera (CCA).

La circunferencia del brazo se determinó en la zona media del brazo.

La medición de los pliegues también se realizó siguiendo una misma pauta para todos los pacientes; el pliegue tricipital se midió a unos dos centímetros por encima del olécranon, el subescapular por debajo del pico de la escápula y el pliegue abdominal por delante de la cresta ilíaca.

La presión arterial se midió en el brazo izquierdo, en sedestación. Se empleó un esfigmomanómetro de mercurio. Se utilizó siempre el mismo aparato.

La información sobre actividad física fue obtenida por entrevista, durante la realización de la historia clínica, preguntando si hacían deporte o no, o tipo de actividad física que realizaban y durante cuanto tiempo, si realizaban trabajo domestico o no y el número de horas que le dedicaban.

La actividad laboral se clasificó en cuatro niveles según grado de actividad. Así el primer nivel es para activo intenso, segundo activo medio o moderado, activo sedentario y el último nivel para inactividad.

El nivel cultural se diferenció en estudios primarios, medios y superiores.

Las densitometrías se realizaron con un densitómetro radiológico de doble energía (DEXA) para establecer la densidad mineral ósea a nivel de la columna lumbar (L2, L3 y L4) y en fémur derecho (cuello de fémur, triángulo de Wards y región trocantérea). El resultado se expresa en valores absolutos de densidad mineral ósea, en $\mathrm{gr} / \mathrm{cm} 2$ y en desviaciones estándar en relación con una población de referencia.

El valor de $\mathrm{T}$ corresponde al número de desviaciones estándar con relación a la población joven y el valor de $\mathrm{Z}$ al número de desviaciones estándar respecto a la población sana de su misma edad.

Se consideraron los criterios de la OMS para la definición de osteopénia (valores de densidad mineral ósea situados entre -1 y $-2,5$ desviaciones estándar con respecto a la media del adulto joven, $\mathrm{o}-1>$ índice o T-escore $>-2,5$ ) y de osteoporosis (valores de DMO situados en valores iguales o inferiores a $-2,5$ desviaciones estándar con respecto al adulto joven, o índice $\mathrm{T}<-2,5)$. 
Se empleó un aparato Hologic QDR 1.000. Las densitometrías se realizaron en el Servicio de Medicina Nuclear del Hospital Universitario de Salamanca en condiciones standard y en horario de mañana o tarde según agenda de citaciones del servicio.

\section{MÉTODOS ESTADÍSTICOS}

Se realizó una estadística descriptiva para cada una de las distintas variables, en las que se determinó el mínimo, máximo, media y desviación estándar para variables cuantitativas y la distribución de frecuencias y porcentaje en caso de variables cualitativas empleándose tablas de contingencia y pruebas de Chi cuadrado para establecer la significación de la diferencia entre las mismas.

La estadística descriptiva se realizó al total de la muestra, en global, por grupos separando la muestra: varones, mujeres premenopáusicas y mujeres menopaúsicas y por sexos: hombres y mujeres.

Se realizaron tablas con los resultados obtenidos al inicio y al final del seguimiento, de la bioquímica general y también de la bioquímica ósea específica en suero/plasma y en orina, perfil lipídico, control de tensión arterial y medidas de pliegues y contornos, en conjunto, por grupos y por sexos.

En el caso de las dos densitometrías óseas que se practicaron a los pacientes, se realizaron estudios descriptivos siguiendo las mismas características que para el resto de determinaciones y variables que se estudiaron, en global, por grupos y por sexos, al inicio del trabajo y al final del mismo.

La comparación de grupos se realizó con análisis de la varianza y con contraste de igualdad de medias usando el test de la t de Student con intervalo de confianza del 95\%. Se consideró estadísticamente significativo una $\mathrm{p}<0,005$. La asociación de las distintas variables entre sí fue analizada usando técnicas uni y multavariables con ajuste de comparaciones de Bonferroni. También se utilizó la correlación de Pearson para la asociación entre distintas variables

En los factores asociados a la densidad mineral ósea se realizó análisis univariado de cada uno de los factores asociados a la masa ósea para valorar la relación entre ellos.

Las variables cualitativas fueron recodificadas a variables binarias $(0,1)$. El valor de 1 indica presencia del factor y 0 ausencia del mismo.

Todo el análisis estadístico se realizó utilizando el programa Stadistical Package for Social Sciences (SPSS versión 11.0). 
EDAD: SEXO: $\quad$ ESTUDIOS:

$\mathbf{N}^{0}$ de historia:

OCUPACIÓN LABORAL: Inactivo: Activo Sedentario: Activo Intenso:

ACTIVIDAD DOMÉSTICA: Si: No: $\quad \mathrm{N}^{\circ}$ de Horas (tiempo empleado):

ACTIVIDAD FíSICA:Sedentario: Caminar: Natación: Otros Deportes: Tiempo:

TRATAMIENTO ANTI-OBESIDAD:Si: No: Especificar:

\section{HISTORIA CLÍNICA}

HÁBITOS TÓXICOS: Tabaco: Alcohol: Drogas: Consumo:

FÁRMACOS QUE TOMAN ACTUALMENTE: Especificar:

MENARQUIA: EDAD FÉRTIL: MENOPAUSIA:

EMBARAZOS/ABORTOS/VIVOS:

FORMA DE SER: Nerviosa: Tranquila:

ANTECEDENTES FAMILIARES: Obesidad: DM: HTA:

\section{ENFERMEDADES PREVIAS}

PATOLOGÍA MAMARIA: (B) (M) Especificar:

PATOLOGÍA GINECOLÓGICA: (B) (M) Especificar:

PATOLOGÍA REUMATOLÓGICA: Osteoporosis: Artrosis: Otras:

PATOLOGÍA CARDIOVASCULAR: HTA: IAM: Angina: Varices:

PATOLOGÍA RESPIRATORIA: BC: Asma: Alergias:

PATOLOGÍA ENDOCRINOLÓGICA:DMID: DMNID: Pat. Tiroides:

PATOLOGÍA DIGESTIVA: Estasis Biliar: Litiasis: Estreñimiento:

PATOLOGÍA RENAL: IRA: IRC: Litiasis: OTRAS:

\section{NUTRICIÓN}

HÁBITOS ALIMENTICIOS: Frecuencia de consumo de alimentos: -pastas y arroces: -carnes y pescados: -frutas y verduras: -lácteos:

Preparación y $\mathbf{n}^{0}$ de tomas:

Consumo día anterior:

MODELO DE ENCUESTA QUE SE REALIZÓ A TODA LA MUESTRA. 
La presencia de obesidad está asociada a determinadas situaciones de riesgo para su padecimiento y lleva añadida, a su vez, una alta posibilidad de presentar diversas patologías y alteraciones analíticas además de ser considerada un factor protector contra la osteoporosis.

Los objetivos del estudio fueron evaluar la existencia de los diferentes factores de riesgo que determinan el padecimiento de la obesidad y estudiar la presencia de enfermedades asociadas a un IMC elevado además de valorar, la influencia de estos factores sobre la masa ósea en una muestra de pacientes obesos todos ellos en tratamiento higienico-dietético para control de su patología basado en dieta hipocalórica con el número de calorías adaptadas a las necesidades energéticas y al IMC de los pacientes y realización de ejercicio físico regular adaptado de forma personalizada.

\section{OBJETIVOS}

1- Determinar la presencia de factores de riesgo de obesidad, enfermedades asociadas, alteraciones analíticas y valorar la existencia de otros determinantes que puedan influir en la enfermedad.

2- Presencia de co-morbilidades en la muestra según grado y tipo de obesidad.

3- Estado de la masa ósea en la muestra y evolución de la misma durante el tiempo de seguimiento.

4- Relación del estado de la masa ósea con las distintas variables y factores que puedan influir sobre ella. 
RESULTADOS 
Todos los pacientes de la muestra presentaban un IMC mayor o igual a 25. Dividí la muestra por sexos, en grupos y según diferentes variables para posteriormente relacionarlas entre sí y determinar la influencia de unas sobre otras.

La distribución de la muestra en global se realizó por grupos en varones, mujeres premenopaúsicas y mujeres menopaúsicas, por edad, en tres grupos, según el IMC en sobrepeso, obesidad tipos I y II y en obesidad mórbida.

También según el nivel cultural de los pacientes en estudios primarios (todos los pacientes sabían leer y escribir aunque no los hubieran completado), estudios medios y universitarios o superiores.

La actividad física estaba dividida según la actividad laboral y la actividad física que realizaban distinta de la laboral; así se clasificaron de inactivos los pacientes que no trabajaban fuera de casa ni realizaban actividad física de forma regular (1 hora/día), activo sedentario los que trabajaban fuera de casa pero no realizaban actividad física, activo moderado los pacientes que realizaban actividad laboral no intensa pero sí realizaban actividad física y activos intensos los que realizaban actividad laboral intensa y además realizaban ejercicio físico de forma regular. La mayoría de la muestra aparece en el grupo de inactivos ya que no tenían actividad laboral y no realizaban ejercicio físico regular aunque, en el caso de las mujeres, todas ellas realizaban las tareas domésticas y aunque algunas caminaban o realizaban algún tipo de actividad física no cumplía los criterios predeterminados para la definición de ejercicio físico regular ni en el tiempo de realización del mismo (1 hora) ni en la regularidad (diario).

\section{DISTRIBUCIÓN DE LA MUESTRA}

Muestra por grupos: varones, mujeres premenopaúsicas y menopaúsicas, edad, IMC, nivel cultural y la actividad físico-laboral que realizaba la muestra.

\begin{tabular}{|l|c|c|}
\hline GRUPOS & n & \% \\
\hline Varones & 19 & 18,8 \\
\hline Premenopáusicas & 34 & 33,7 \\
\hline Menopaúsicas & 48 & 47,5 \\
\hline Total & 101 & \\
\hline
\end{tabular}

\begin{tabular}{|l|c|c|}
\hline$\underline{\text { EDAD }}$ & $\mathbf{n}$ & $\mathbf{\%}$ \\
\hline $29-44,9$ años & 29 & 28,7 \\
\hline $45-64,5$ años & 50 & 49,5 \\
\hline$>65$ años & 22 & 21,6 \\
\hline Total & 101 & \\
\hline
\end{tabular}

Por sexos los varones representan el 18,8

el resto $(81,2 \%)$ mujeres; $33,7 \%$ premenopaúsicas

y $47,5 \%$ menopaúsicas. 
$\underline{\text { IMC }}$

\begin{tabular}{|l|c|cr|c|c|c}
\hline Grupo estudio & IMC (kg/m2) & & $\mathbf{0}$ & $\begin{array}{c}\text { Varones } \\
\mathbf{\%}\end{array}$ & $\begin{array}{c}\text { Premenopausia } \\
\mathbf{\%}\end{array}$ & $\begin{array}{c}\text { Menopausia } \\
\mathbf{\%}\end{array}$ \\
\hline Obesidad I & $(25-29,9)$ & 39 & 38,6 & 52,6 & 58,8 & 18,7 \\
\hline Grupo II & $(30-34,9)$ & 33 & 32,7 & 36,8 & 20,6 & 47,9 \\
\hline Grupo III & $(35-39,9)$ & 14 & 13,9 & 10,5 & 5,9 & 14,6 \\
\hline Grupo IV & $>40$ & 15 & 14,9 & 0 & 14,7 & 18,7 \\
\hline Total & & \multicolumn{2}{|c|}{101} & 19 & 34 & 48
\end{tabular}

NIVEL CULTURAL

ACTIVIDAD FISICO-LABORAL

\begin{tabular}{|l|c|c|}
\hline ESTUDIOS & $\mathbf{n}$ & $\mathbf{\%}$ \\
\hline Estudios primarios & 73 & 72,3 \\
\hline Estudios medios & 19 & 18,8 \\
\hline Estudios superiores & 9 & 8,9 \\
\hline Total & 101 & \\
\hline
\end{tabular}

\begin{tabular}{|l|c|c|}
\hline ACTIVIDAD & $\mathbf{n}$ & $\mathbf{\%}$ \\
\hline FÍSICA & & \\
\hline Inactivos & 46 & 44,7 \\
\hline Activo sedentario & 16 & 15,5 \\
\hline Activo moderado & 18 & 17,5 \\
\hline Activo intenso & 21 & 20,4 \\
\hline Total & 101 & 98,1 \\
\end{tabular}

DISTRIBUCIÓN DE LA MUESTRA EN PORCENTAJE.

$\underline{\text { Tabla no } 1}$

\begin{tabular}{|l|c|c|c|c|}
\hline & Total & Varones & $\begin{array}{c}\text { Mujeres } \\
\text { premenopaúsicas }\end{array}$ & $\begin{array}{c}\text { Mujeres } \\
\text { menopaúsicas }\end{array}$ \\
\hline n & 101 & 18,81 & 33,66 & 47,52 \\
\hline Sobrepeso & 38,65 & 25,61 & $\mathbf{5 1 , 2 8}$ & 23,10 \\
\hline Obesidad & 46,54 & 19,14 & 19,14 & $\mathbf{6 1 , 0 7}$ \\
\hline O. Mórbida & 14,92 & $\mathbf{0}$ & 33,33 & $\mathbf{6 6 , 6 6}$ \\
\hline ICC & 0,86 & 0,94 & 0,81 & 0,84 \\
\hline Estudios: & & & & \\
Primarios & 72,27 & 12,32 & 27,39 & $\mathbf{6 0 , 2 7}$ \\
Medios & 18,81 & $\mathbf{3 6 , 8 4}$ & 47,36 & 15,78 \\
Superiores & 8,91 & 33,33 & $\mathbf{5 5 , 5 5}$ & 11,11 \\
\hline Actividad: & & & & $\mathbf{8 4 , 0 9}$ \\
Inactivo & 44,74 & 4,54 & 11,36 & 16,66 \\
Act.sedentario & 15,52 & $\mathbf{4 4 , 4 4}$ & 38,88 & 6,25 \\
Act. Moderado & 17,50 & 12,50 & $\mathbf{8 1 , 2 5}$ & 30,43 \\
Act. intenso & 20,43 & 30,43 & $\mathbf{3 9 , 1 3}$ & \\
\hline
\end{tabular}

La media de edad de la muestra son los 50,7 años, el peso $82,6 \mathrm{~kg}$ y el IMC 32 . La mayoría de los pacientes presentaban sobrepeso, presenta estudios primarios y no realizan actividad laboral ni ejercicio físico regular.

El sobrepeso presenta un porcentaje más alto en las mujeres premenopaúsicas, la obesidad y la obesidad mórbida son más frecuentes en las mujeres menopaúsicas.

Respecto al nivel cultural lo más frecuente son los estudios primarios, que son más frecuentes en general y en el grupo de mujeres menopaúsicas, estudios superiores son más frecuentes en las mujeres premenopaúsicas y los medios en los varones. 
La mayoría de la muestra presenta inactividad laboral e inactividad física. Cerca del 23\% y con similar porcentaje, una parte de la muestra trabajaba fuera de casa pero no hacía ejercicio físico y otra no trabajaba fuera de casa pero si realizaba ejercicio físico de forma regular.

\section{CAUSAS DE OBESIDAD DISTRIBUIDAS POR GRUPOS}

Tabla no 2

\begin{tabular}{|c|c|c|c|c|c|c|c|c|c|c|}
\hline & \multicolumn{2}{|c|}{ Varones } & \multicolumn{2}{|c|}{$\begin{array}{l}\text { Mujeres Pre- } \\
\text { menopaúsicas }\end{array}$} & \multicolumn{2}{|c|}{$\begin{array}{l}\text { Mujeres } \\
\text { Menopaúsicas }\end{array}$} & \multicolumn{2}{|c|}{ Mujeres } & \multicolumn{2}{|c|}{ TOTAL } \\
\hline & $\mathbf{n}$ & $\%$ & & $\%$ & & & $\mathbf{n}$ & $\%$ & $\mathbf{n}$ & $\%$ \\
\hline $\begin{array}{l}\text { Siempre obesos } \\
\text { (desde la infancia) }\end{array}$ & 4 & $21 \%$ & 12 & $35,3 \%$ & 25 & $52,1 \%$ & 37 & $45,1 \%$ & 41 & $40,6 \%$ \\
\hline A lo largo del tiempo & 8 & $42,1 \%$ & 5 & $14,7 \%$ & 3 & $6,2 \%$ & 8 & $9,7 \%$ & 16 & $15,8 \%$ \\
\hline A raíz de los embarazos & & - & 5 & $14,7 \%$ & 10 & $20,8 \%$ & 15 & $18,3 \%$ & 15 & $14,8 \%$ \\
\hline Al dejar de fumar & 2 & $10,5 \%$ & 2 & $5,9 \%$ & & - & 2 & $2,4 \%$ & 4 & $4 \%$ \\
\hline $\begin{array}{l}\text { Post-cirugía (fármacos, } \\
\text { inmovilización) }\end{array}$ & & - & 3 & $8,8 \%$ & 3 & $6,2 \%$ & 6 & $7,3 \%$ & 6 & $5,9 \%$ \\
\hline Por fármacos & & - & 2 & $5,9 \%$ & 3 & $6,2 \%$ & 5 & $6,1 \%$ & 5 & $4,9 \%$ \\
\hline $\begin{array}{l}\text { Mantenimiento (poca } \\
\text { variación con el tiempo) }\end{array}$ & 2 & $10,5 \%$ & 4 & $11,8 \%$ & 2 & $4,5 \%$ & 6 & $7,3 \%$ & 8 & $7,9 \%$ \\
\hline $\begin{array}{l}\text { Otras causas: } \\
\text {-inactividad deportiva } \\
\text {-durante el S. Militar } \\
\text {-cambio de estado civil } \\
\text {-ansiedad } \\
\text {-menopaúsia }\end{array}$ & $\begin{array}{l}3 \\
1 \\
1 \\
1\end{array}$ & $\begin{array}{r}15,8 \% \\
5,3 \% \\
5,3 \% \\
5,3 \% \\
- \\
- \\
\end{array}$ & 1 & $\begin{array}{ll} & 2,9 \% \\
- & \\
- & \\
- & \\
1 & \\
- & \\
\end{array}$ & 2 & $\begin{array}{l}4,5 \% \\
- \\
- \\
- \\
- \\
2\end{array}$ & 3 & $3,6 \%$ & 6 & $5,9 \%$ \\
\hline Total & & 19 & & 34 & 48 & & 82 & & 101 & \\
\hline
\end{tabular}

En el grupo de mujeres premenopaúsicas, un 35,3\%, presentaban obesidad desde la infancia, y de ellas, un $25 \%$ vieron incrementado su peso con los embarazos. En éste mismo grupo, los fármacos implicados en el aumento de peso según las pacientes fueron los anticonceptivos hormonales orales y los corticoides.

En el grupo de mujeres menopaúsicas de las que presentan la obesidad desde la infancia, $(52,1 \%)$, de ellas en un $20 \%$ aumentó aún más su peso con la menopausia. En éste grupo los fármacos implicados son los corticoides con mayor frecuencia.

Debemos destacar el alto porcentaje de pacientes que presentan una persistencia de la obesidad desde la infancia un 40,6\%. En el grupo de las mujeres que son obesas desde la edad infantil un $21,6 \%$ de ellas sufrieron un aumento de peso mayor a raíz de los embarazos y el $15,5 \%$ de ellas vieron incrementado su peso al presentar la menopausia. 
FACTORES DE RIESGO ASOCIADOS A LA OBESIDAD,

HÁBITOS TÓXICOS

\begin{tabular}{|l|c|c|}
\hline TABACO & $\mathbf{n}$ & $\mathbf{\%}$ \\
\hline No consumo & 83 & 82,2 \\
\hline Consumo & 18 & 17,8 \\
\hline Total & 101 & \\
\hline
\end{tabular}

\begin{tabular}{|l|c|c|}
\hline ALCOHOL & $\mathbf{n}$ & $\mathbf{\%}$ \\
\hline No consumo & 96 & 95 \\
\hline Consumo & 5 & 5 \\
\hline Total & 101 & \\
\hline
\end{tabular}

\section{ANTECEDENTES FAMILIARES}

La obesidad se asocia de forma directa con los antecedentes familiares de la enfermedad, con la HTA y también con la DM como factores de riesgo para su padecimiento. He determinado que pacientes padecían obesidad desde la infancia y cuales de éstos obesos presentaban antecedentes familiares de ella además de tener en cuenta la presencia de HTA y DM y los antecedentes familiares de las dos enfermedades.

$\underline{\text { Tabla no } 3}$

\begin{tabular}{|c|c|c|c|c|}
\hline & TOTAL & VARONES & PRE-MENOPAÚSICAS & MENOPAÚSICAS \\
\hline \multicolumn{5}{|c|}{$\begin{array}{l}\text { Antecedentes Familiares } \\
\%\end{array}$} \\
\hline A.F Obesidad & 53,5 & 57,9 & 55,8 & 50 \\
\hline A.F DM & 31,7 & 26,3 & 41,2 & 27,1 \\
\hline A.F HTA & 26,7 & 21 & 29,4 & 27.1 \\
\hline
\end{tabular}

La presencia de A.F de obesidad, DM e HTA era muy importante en la muestra, aunque destacaba la existencia de A.F de obesidad que los refería más del $50 \%$ de todos los pacientes. Un 53,5\% presentaba A.F de obesidad, un 31,7\% los refería de DM y un 26,7\% de HTA.

Pacientes que presentaban obesidad desde la infancia además de A.F de obesidad lo refería el $15,8 \%$ de los varones, el $29,4 \%$ de las mujeres premenopáusicas y el 31,2\% de las menopaúsicas.

HTA y A.F de HTA presentaba el 5,3\% de los varones, el 5,9\% de las mujeres premenopáusicas y el $16,7 \%$ de las menopaúsicas. Presencia de DM y A.F de la enfermedad lo refería el 5,3\% de los varones y el 4,2\% de las mujeres menopaúsicas. En las mujeres premenopáusicas ninguna presentaba la enfermedad.

\section{PATOLOGÍAS ASOCIADAS I}

\begin{tabular}{|c|c|c|c|c|}
\hline & & & & Tabla $n^{0} 4$ \\
\hline & $\begin{array}{l}\text { TOTAL } \\
\%\end{array}$ & $\begin{array}{c}\text { VARONES } \\
\%\end{array}$ & $\begin{array}{c}\text { PRE-MENOPAÚSICAS } \\
\%\end{array}$ & $\begin{array}{c}\text { MENOPAÚSICAS } \\
\% \\
\end{array}$ \\
\hline \multicolumn{5}{|c|}{ Patologías Asociadas } \\
\hline HTA & 23,8 & 21 & 11,8 & 33,3 \\
\hline DM & 4 & 5,3 & 0 & 6,2 \\
\hline Osteoarticular & 57,4 & 26,3 & 50 & 75 \\
\hline Estreñimiento & 44,6 & 10,5 & 55,9 & 50 \\
\hline Pat. vascular & 45,5 & 10,5 & 35,3 & 66,7 \\
\hline Otras patologías & 48,5 & 15,8 & 44,1 & 64,6 \\
\hline
\end{tabular}

Patologías más frecuentes asociadas a obesidad que presentan los pacientes de nuestra muestra. 


\begin{tabular}{|c|c|c|c|c|c|c|c|c|}
\hline & \multicolumn{2}{|l|}{ Total } & \multicolumn{2}{|c|}{ Varones } & \multicolumn{2}{|c|}{$\begin{array}{l}\text { Mujeres } \\
\text { premenopaúsica } \\
\text { n } \%\end{array}$} & \multicolumn{2}{|c|}{$\begin{array}{l}\text { Mujeres } \\
\text { Menopaúsicas }\end{array}$} \\
\hline Patología asociada $\%$ & $90 / 101$ & 89,10 & $12 / 19$ & 63,15 & $30 / 34$ & 88,23 & $48 / 48$ & 100 \\
\hline Estreñimiento & 45 & 45,55 & 2 & 10,52 & 19 & 55,88 & 24 & 50 \\
\hline Osteoarticular: & 58 & 57,42 & 5 & 26,31 & 17 & 50,0 & 36 & 75 \\
\hline -artrosis & 52 & 86,6 & 2 & 40,0 & 15 & 44,11 & 35 & 97,22 \\
\hline -H. discal & 5 & 8,33 & 2 & 40,0 & 2 & 5,88 & 1 & 2,77 \\
\hline -oligoartropatía & 1 & 1,66 & 1 & 20,0 & & & & \\
\hline HTA & 24 & 23,76 & 4 & 21,05 & 4 & 11,76 & 16 & 33,33 \\
\hline Pat. Vascular: & 46 & 45,54 & 2 & 10,52 & 12 & 35,29 & 32 & 66,66 \\
\hline -varices & 43 & 93,47 & 1 & 100 & 12 & 100 & 31 & 91,17 \\
\hline -angina & 3 & 6,52 & & - & & & 3 & 8,82 \\
\hline DMNID & 4 & 3,96 & 1 & 5,26 & & & 3 & 6,25 \\
\hline Hiperuricemia & 3 & 2,97 & 1 & 5,26 & & & 2 & 4,16 \\
\hline Pat. Respiratoria: & 6 & 5,94 & 1 & 5,26 & 2 & 5,88 & 3 & 6,25 \\
\hline -asma & 3 & 50,0 & 1 & 100 & & & 2 & 66,33 \\
\hline -asma alérgica & 2 & 33,33 & & - & 2 & 100 & & \\
\hline -bronquitis crónica & 1 & 16,66 & & - & & & 1 & 33,33 \\
\hline Pat. Digestiva: & 4 & 3,96 & 1 & 5,26 & 1 & 2,94 & 2 & 4,16 \\
\hline -H. Hiato & 3 & 75,0 & 1 & 100 & 1 & 100 & 1 & 50,0 \\
\hline -E. Barret & 1 & 25,0 & & - & 1 & 100 & & \\
\hline Litiasis renal & 14 & 13,86 & & - & 5 & 14,70 & 9 & 18,75 \\
\hline Pat. Tiroidea & 5 & 5,94 & & - & 2 & 5,88 & 3 & 6,25 \\
\hline Pat. Ginecológica: & 21 & 20,79 & & - & 6 & 17,64 & 15 & 31,25 \\
\hline -miomas & 14 & 66,66 & & - & 3 & 50,0 & 11 & 73,33 \\
\hline -mastopatía fibroquístic & 2 & 9,52 & & - & 2 & 33,33 & & \\
\hline -pat. Ovario & 3 & 14,28 & & - & 1 & 16,66 & 2 & 13,33 \\
\hline -prolapso & 2 & 9,52 & & - & & & 2 & 13,33 \\
\hline Litiasis biliar & 5 & 4,95 & & - & 3 & 8,82 & 2 & 4,16 \\
\hline Hipercolesterolemia & 8 & 7,92 & & - & & & 8 & 16,66 \\
\hline Sin patología & 11 & 10,89 & 7 & 36,84 & 4 & 11,76 & & \\
\hline
\end{tabular}

En la tabla presentamos la relación completa de patologías asociadas a sobrepeso u obesidad que presentaban los pacientes de nuestra muestra.

La obesidad se asocia a múltiples patologías y aunque las más importantes o graves son la HTA y la DM por sus consecuencias y frecuencia de aparición, hay otras muchas patologías dónde se considera a la obesidad como factor de riesgo o agente causal de las mismas.

A pesar de ser la HTA, la DM y las enfermedades cardiovasculares los procesos más graves e importantes que puede originar o agravar la obesidad, en el caso de nuestra muestra son la patología osteoarticular, la patología vascular y el estreñimiento (por ese orden) los procesos más frecuentes asociados a la obesidad o al sobrepeso de los pacientes estudiados. 


\begin{tabular}{|c|c|c|c|c|c|c|c|c|}
\hline & \multicolumn{2}{|c|}{ Total } & \multicolumn{2}{|c|}{ Varones } & \multicolumn{2}{|c|}{$\begin{array}{c}\text { Mujeres } \\
\text { Premenopaúsica }\end{array}$} & \multicolumn{2}{|c|}{$\begin{array}{c}\text { Mujeres } \\
\text { Menopaúsicas }\end{array}$} \\
\hline & $\begin{array}{c}\mathrm{n} \\
73 / 101\end{array}$ & $\begin{array}{c}\% \\
172,27\end{array}$ & $\begin{array}{c}n \\
10 / 19\end{array}$ & $\begin{array}{c}\% \\
52,63\end{array}$ & $\begin{array}{c}n \\
20 / 34\end{array}$ & $\begin{array}{c}\% \\
58,82\end{array}$ & $\begin{array}{c}n \\
43 / 48\end{array}$ & $\begin{array}{c}\% \\
89,58\end{array}$ \\
\hline Fibra/Coadyudantes de la dieta & 39 & 53,42 & 3 & 30 & 10 & 50 & 26 & 60,46 \\
\hline Hipotensores & 21 & 20,79 & 4 & 40 & 2 & 10 & 15 & 31,25 \\
\hline Vasoprotactores & 17 & 23,28 & - & - & 1 & 5 & 16 & 37,20 \\
\hline Psicofármacos & 10 & 13,69 & - & - & 4 & 20 & 6 & 13,95 \\
\hline Protector gástrico & 12 & 16,43 & 1 & 10 & 3 & 15 & 8 & 18,60 \\
\hline Diuréticos & 11 & 15,06 & - & - & - & - & 11 & 25,58 \\
\hline Analgésicos/AINES & 28 & 27,72 & 2 & 20 & 4 & 20 & 22 & 51,16 \\
\hline Antilipémicos & 7 & 9,58 & - & - & - & - & 7 & 16,27 \\
\hline Antihiperuricémicos & 4 & 5,47 & 2 & 20 & - & - & 2 & 4,65 \\
\hline Antidiabéticos orales & 2 & 2,73 & 1 & 10 & - & - & 1 & 2,32 \\
\hline Antiagregantes plaquetarios & 6 & 8,21 & - & - & & - & 6 & 13,95 \\
\hline Otros & 10 & 13,69 & $\overline{1}$ & 10 & 2 & 10 & 10 & 23,25 \\
\hline
\end{tabular}

La relación de fármacos consumidos por los mismos destacando en frecuencia $\mathrm{y}$ porcentaje de consumo los fármacos contra la obesidad en los cuales están incluidos algunos laxantes (lactulosa), fibra adicional y coadyudantes de la dieta (HUMAMIL, YALUFOR) seguidos de los AG/AI y después los preparados para mejorar o activar la circulación.

A pesar de no haber tenido en cuenta las consecuencias psicológicas de la obesidad por no aparecer como enfermedad grave asociada, la presencia de alteraciones psicológicas entre los componentes de la muestra es muy elevada como evidencia el porcentaje de toma de psicofármacos, sobre todo en mujeres de mediana edad.

\section{RELACIÓN DE VARIABLES.}

\section{RELACIÓN DE LOS GRUPOS con el IMC}

$$
\begin{aligned}
& \underline{\text { Grupos }}=\mathbf{0}=\text { varones } \\
& \mathbf{1}=\text { mujeres premenopáusicas } \\
& \mathbf{2}=\text { menopaúsicas }
\end{aligned}
$$

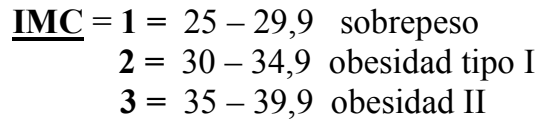

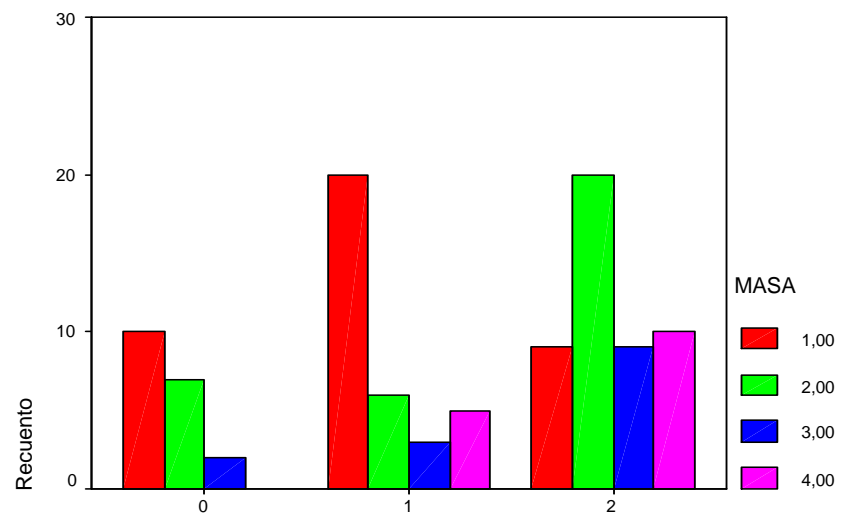




\begin{tabular}{|c|c|c|c|c|c|c|}
\hline \multicolumn{7}{|c|}{ Tabla de contingencia SEXO * MASA } \\
\hline \multicolumn{2}{|l|}{ Recuento } & & & & & \\
\hline & & \multicolumn{4}{|c|}{ MASA } & \multirow[b]{2}{*}{ Total } \\
\hline & & 1,00 & 2,00 & 3,00 & 4,00 & \\
\hline SEXO & 0 & 10 & 7 & 2 & & 19 \\
\hline & 1 & 20 & 6 & 3 & 5 & 34 \\
\hline & 2 & 9 & 20 & 9 & 10 & 48 \\
\hline Total & & 39 & 33 & 14 & 15 & 101 \\
\hline
\end{tabular}

Distribución de la muestra por grupos según su I.M.C.

E1 52,6\% de los varones presentaban sobrepeso, el 36,8\% obesidad tipo I y el 2,4\% obesidad tipo II. Ningún varón presentaba obesidad mórbida.

Las mujeres premenopaúsicas presentaban sobrepeso el 58,8\%, obesidad tipo I el 17,6\% y tipo II el 8,8\%. El 14,7\% de las premenopaúsicas presentaba obesidad mórbida.

Las mujeres menopaúsicas presentaban sobrepeso el 18,7\%, obesidad tipo I el 41,6\%, y tipo II el 18,7\%. El 20,8\% de las premenopaúsicas presentaba obesidad mórbida.

\section{RELACIÓN GRUPOS con la Edad}
$\underline{\text { Grupos }}=\mathbf{0}=$ varones
$\mathbf{1}=$ mujeres premenopáusicas
$\mathbf{2}=$ menopaúsicas

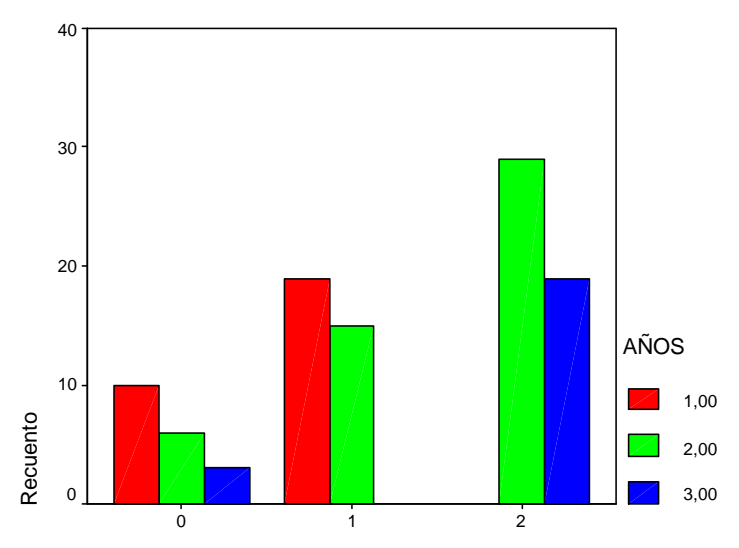

SEXO

Tabla de contingencia AÑOS * SEXO

Recuento
\begin{tabular}{|rr|r|r|r|r|}
\hline & & \multicolumn{3}{|c|}{ SEXO } & \multirow{2}{*}{ Total } \\
\cline { 3 - 6 } & & 0 & \multicolumn{1}{|c|}{1} & 2 & 29 \\
\hline ANOS & 1,00 & 10 & 19 & & 50 \\
& 2,00 & 6 & 15 & 29 & 22 \\
& 3,00 & 3 & & 19 & 101 \\
\hline
\end{tabular}

Distribución de la muestra por grupos según la edad

Con edades entre 29 - 44,9 años hay un $34,5 \%$ de varones y un $65,5 \%$ de las premenopáusicas, ninguna menopaúsica. Con edades del grupo 2 están $12 \%$ de varones, $30 \%$ premenopaúsicas y $58 \%$ de mujeres menopaúsicas. Con edades por encima de 65 años hay un $13,6 \%$ de varones, y $86,4 \%$ menopaúsicas.

$$
\begin{aligned}
\underline{\mathbf{E d a d}}=\mathbf{1} & =29-44,9 \\
\mathbf{2} & =45-64,5 \\
\mathbf{3} & =>65
\end{aligned}
$$




\section{RELACIÓN GRUPOS con los HÁBITOS TÓXICOS}

$\underline{\operatorname{Sexo}}$

$\mathbf{0}=$ varones

$\mathbf{1}=$ mujeres premenopáusicas

$\mathbf{2}=$ mujeres menopaúsicas

Tabla de contingencia SEXO * TABACO

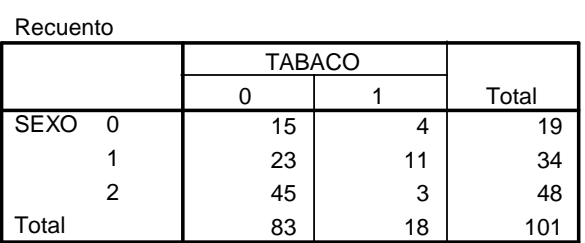

\section{Consumo}

$\mathbf{0}=$ no consumo

$\mathbf{1}=$ si consumo

El $17,8 \%$ de la muestra fumaba. Por sexo, los varones el $21 \%$, las mujeres premenopaúsicas el 32,3\% y el 6,2\% de las mujeres menopaúsicas.

Un 5\% de la muestra consumía alcohol. Por sexo, los varones lo consumían el 21\%, las mujeres premenopaúsicas el 2,9\% y ninguna de las mujeres menopaúsicas.

\section{RELACIÓN GRUPOS con el NIVEL CULTURAL}

$\underline{\operatorname{Sexo}}$

$\mathbf{0}=$ varones

$\mathbf{1}=$ mujeres premenopáusicas

$\mathbf{2}=$ mujeres menopaúsicas
Tabla de contingencia SEXO * ALCOHOL

\begin{tabular}{|c|c|c|c|}
\hline \multicolumn{4}{|c|}{ Recuento } \\
\hline & \multicolumn{2}{|c|}{$\mathrm{ALCOHOL}$} & \multirow[b]{2}{*}{ Total } \\
\hline & 0 & 1 & \\
\hline SEXO & 15 & 4 & 19 \\
\hline & 33 & 1 & 34 \\
\hline & 48 & & 48 \\
\hline Total & 96 & 5 & 101 \\
\hline
\end{tabular}

Tabla de contingencia SEXO * ESTUDIOS

Recuento
\begin{tabular}{|ll|r|r|r|r|}
\hline & \multicolumn{4}{|c|}{ ESTUDIOS } & \multirow{2}{*}{ Total } \\
\cline { 2 - 5 } & & 1 & 2 & 3 & 19 \\
SEXO & 0 & 9 & 7 & 3 & 34 \\
& 1 & 20 & 9 & 5 & 48 \\
& 2 & 44 & 3 & 1 & 48 \\
Total & & 73 & 19 & 9 & 101 \\
\hline
\end{tabular}

Un $72,3 \%$ de la muestra tenía estudios primarios, un $18,8 \%$ medios y un $8,9 \%$ superiores. De los varones, el 47,4\% primarios, 36,8\% medios y 15,8\% superiores. El 58,9\% de las premenopáusicas tenían estudios primarios, 26,5\% medios y $14,7 \%$ superiores. Las menopaúsicas $72,3 \%$ primarios, $18,8 \%$ medios y $8,9 \%$ superiores.

\section{RELACIÓN GRUPOS con la ACTIVIDAD FÍSICA}

\begin{tabular}{|c|c|c|}
\hline$\underline{\text { Sexo }}$ & $\underline{\text { Actividad }}$ & $\mathbf{0}=$ inactivo \\
\hline$\overline{\mathbf{0}=\text { varones }}$ & & $\mathbf{1}=$ activo sedentaric \\
\hline uujeres premenopáusicas & & $\mathbf{2}=$ activo moderado \\
\hline $2=$ mujeres menopaúsicas & & $\mathbf{3}=$ activo intenso \\
\hline
\end{tabular}

Tabla de contingencia SEXO * A.FíSICA

\begin{tabular}{|c|c|c|c|c|c|}
\hline & & A.F & & & \multirow[b]{2}{*}{ Total } \\
\hline & 0 & 1 & 2 & 3 & \\
\hline $\begin{array}{ll}\text { SEXO } & 0\end{array}$ & 2 & 8 & 2 & 6 & 18 \\
\hline 1 & 5 & 5 & 14 & 10 & 34 \\
\hline 2 & 39 & 3 & 1 & 5 & 48 \\
\hline Total & 46 & 16 & 17 & 21 & 100 \\
\hline
\end{tabular}


Un $45,6 \%$ de la muestra estaba inactiva, un $15,8 \%$ actividad sedentaria, un $16,8 \%$ actividad moderada y un $21,8 \%$ realizaba actividad intensa. La muestra inactiva no presentaba actividad laboral ni realizaban ninguna actividad física. Por sexos un 10,5\% de los varones no realizaban ningún tipo de actividad física, un $42,1 \%$ eran activos sedentarios, un $10,5 \%$ actividad moderada y un 36,8\% actividad intensa. En las mujeres premenopaúsicas 14,7\% inactivas, $14,7 \%$ actividad sedentaria, $41,2 \%$ actividad moderada y un $29,4 \%$ intensa. Las menopaúsicas $81,2 \%$ inactivas, $6,2 \%$ activo sedentario, $3 \%$ actividad moderada y un $10,4 \%$ actividad intensa.

\section{RELACIÓN GRUPOS con los ANTECEDENTES FAMILIARES.}

\section{$\underline{\operatorname{Sexo}}$}

$\mathbf{0}=$ varones

$\mathbf{1}=$ mujeres premenopáusicas

$\mathbf{2}=$ mujeres menopaúsicas

\section{Presencia de A.F \\ $\mathbf{0}=$ no presentan \\ $\mathbf{1}=$ presentan}

$\underline{\text { A.F }}$

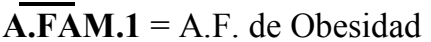

A.FAM.2 $=$ A.F de DM

A.FAM.3 = A.F de HTA

\begin{tabular}{|l|c|c|c|c|}
\hline & n & A.FAM.1 & A.FAM.2 & A.FAM.3 \\
\hline Grupos & & & & \\
\hline Varones & 19 & 11 & 5 & 4 \\
\hline Premenopaúsicas & 34 & 19 & 13 & 8 \\
\hline Menopaúsicas & 48 & 25 & 14 & 13 \\
\hline
\end{tabular}

Un 54,5\% de la muestra presentaba antecedentes familiares de obesidad. Los varones un $57,9 \%$, las mujeres premenopaúsicas un 55,9\% y las menopaúsicas un 52\%.

Un $31,7 \% \%$ de la muestra presentaba antecedentes familiares de DM. Los varones un $26,3 \%$, las mujeres premenopaúsicas un 38,2\% y las menopaúsicas un 29,2\%.

Un $24,7 \%$ de la muestra presentaba antecedentes familiares de HTA. Los varones, un $21 \%$, las mujeres premenopaúsicas un $23,5 \%$ y las menopaúsicas un $27,1 \%$ presentaban antecedentes familiares de obesidad.

\section{RELACIÓN GRUPOS con la PATOLOGÍA ASOCIADA.}

\section{$\underline{\text { Grupos }}$}

$\mathbf{0}=$ varones

$\mathbf{1}=$ mujeres premenopáusicas

$\mathbf{2}=$ mujeres menopaúsicas

$$
\begin{aligned}
& \mathbf{0}=\text { No presentan la patología } \\
& \mathbf{1}=\text { presentan la patología }
\end{aligned}
$$

Pat. asociada
P.ASOC.1 $=$ HTA
P.ASOC.2 $=$ DM
P.ASOC.3 = Pat. Osteoarticular
P.ASOC.4 = Estreñimiento
P.ASOC.5 = Pat. Vascular
P.ASOC.6 = Otras Patologías

\begin{tabular}{|l|c|c|c|c|c|c|c}
\hline & n & P.ASOC.1 & P.ASOC.2 & P.ASOC.3 & P.ASOC.4 & P.ASOC.5 & P.ASOC.6 \\
\hline Grupos & & & & & & & \\
\hline Varones & 19 & 4 & 1 & 5 & 2 & 2 & 3 \\
\hline Premenopaúsicas & 34 & 4 & 0 & 17 & 19 & 12 & 15 \\
\hline Menopaúsicas & 48 & 16 & 3 & 36 & 24 & 32 & 31
\end{tabular}

Presentan HTA el 23,8\% de los pacientes. El 21\% de los varones es hipertenso, el 11,8\% de las mujeres premenopaúsicas y el 33,3\% de las menopaúsicas.

Presenta DM el 4\% de la muestra. El 5,3\% de los varones son diabéticos y el 6,2\% de las mujeres menopaúsicas. Las mujeres premenopaúsicas ninguna presentaba la enfermedad. 
Un $57,4 \%$ de la muestra presenta patología osteo-articular. De los varones el $26,3 \%$, el $50 \%$ de las mujeres premenopaúsicas y el $75 \%$ de las menopaúsicas.

Estreñimiento presentaba el $44,6 \%$ del total de la muestra. Un 10,5\% de los varones, el $55,9 \%$ de las premenopaúsicas y el 50\% de las mujeres menopaúsicas.

Un $45,5 \%$ de la muestra padece patología vascular. Un 10,5\% de los varones, $35,3 \%$ de las premenopaúsicas y el $66,7 \%$ de la menopaúsicas

El 48,5\% de la muestra presentaba otras patologías diferentes a las anteriores. Los varones un $15,8 \%$, las mujeres premenopáusicas un $44,1 \%$ y un $64,6 \%$ de las menopaúsicas presentaban además otras patologías no incluidas en las anteriores.

\section{RELACIÓN GRUPOS COn la TOMA DE FÁRMACOS}

$\underline{\text { Sexo }}$

$\overline{\mathbf{0}=\text { varones }}$

$\mathbf{1}=$ mujeres premenopáusicas

$\mathbf{2}=$ mujeres menopaúsicas

\section{Fármacos}

$\mathbf{0}=$ No consumen

$\mathbf{1}=$ consumen

\section{Tipos de Fármacos}

Fármacos contra la obesidad.

Fármacos antihipertensivos

Fármacos analgésicos/antiinflamatorios.

Fármacos psicofármacos

Fármacos vasoprotectores

Fármacos protectores gástricos

Otros fármacos no incluidos en los anteriores.

\begin{tabular}{|l|c|c|c|c|c|c|c|c}
\hline & n & $\begin{array}{c}\text { Anti- } \\
\text { obesidad }\end{array}$ & HTA & AG/AI & $\begin{array}{c}\text { Psico- } \\
\text { fármacos }\end{array}$ & $\begin{array}{c}\text { Vaso- } \\
\text { protectores }\end{array}$ & $\begin{array}{c}\text { Protectores } \\
\text { gástricos }\end{array}$ & $\begin{array}{c}\text { Otros } \\
\text { Fcos }\end{array}$ \\
\hline Grupos & & & & & & & & \\
\hline Varones & 19 & 3 & 2 & 2 & 0 & 0 & 1 & 4 \\
\hline Premenopaúsicas & 34 & 10 & 2 & 4 & 4 & 1 & 2 & 4 \\
\hline Menopaúsicas & 48 & 27 & 20 & 21 & 6 & 16 & 9 & 26
\end{tabular}

Consumen fármacos el 39,6\% de la muestra. Los varones el 15,8\%, el 29,4\% de las mujeres premenopaúsicas y el 23,8\% de las mujeres menopaúsicas.

El $23,8 \%$ de la muestra toma antihipertensivos. Los varones un $10,5 \%$, las mujeres premenopaúsicas un 5,9\% y un $41,7 \%$ de las menopaúsicas.

Un 26,7\% toman AG-AI. De los varones un 10,5\% los consumen, el $11,8 \%$ de las mujeres premenopausicas y de las mujeres menopaúsicas el 43,7\%.

Consumían psicofármacos un $10 \%$ de la muestra. Las premenopaúsicas el $11,8 \%$ y las mujeres menopaúsicas el $12,5 \%$. Los varones no los consumían.

El 16,8\% del total de la muestra consume fármacos vasoprotectores. Sólo las mujeres, las premenopaúsicas, el 2,9\% y el 33,3\% de las menopaúsicas.

Un 12\% de la muestra consumía protectores gástricos. De los varones el 5,3\%, el 5,9\% de las premenopaúsicas y el 18,7\% de la menopaúsicas

E1 33,7\% de los pacientes consumían otros fármacos diferentes de los anteriores. De los varones el $21 \%$, el $11,8 \%$ de las mujeres premenopaúsicas y el $54,2 \%$ de las mujeres menopaúsicas. 
Si separamos a la muestra en grupos de pacientes varones, premenopáusicas y mujeres menopaúsicas si se establecen diferencias estadísticamente significativas con los hábitos tóxicos, con la actividad física y con el nivel cultural. Con las patologías asociadas no hay diferencias significativas para la DM tipo 2 y la HTA pero sí para el resto de patologías. No se establecen diferencias significativas con los antecedentes familiares, al relacionar los grupos en que he separado a la muestra con el consumo de fármacos hay diferencias estadísticamente significativas con la toma de antihipertensivos, con la toma de fármacos para combatir la obesidad, con el consumo de analgésicos-antiinflamatorios y con la toma de protectores vasculares; con la toma de psifármacos, de protectores gástricos y con los otros fármacos no se observan diferencias significativas

\section{RELACIÓN SEXO CON DISTINTAS VARIABLES}

RELACIÓN $\underline{\text { SEXO }}$ con el IMC

$$
\begin{aligned}
\text { Sexo }=\mathbf{1} \text { varones } & \quad \underline{\mathbf{M C}}=\mathbf{1}=25-29,9 \\
\mathbf{2} \text { mujeres } & =30-34,9 \\
\mathbf{3} & =35-39,9 \\
\mathbf{4} & =>40
\end{aligned}
$$

\begin{tabular}{|c|c|c|c|c|c|c|}
\hline \multicolumn{7}{|l|}{ Recuento } \\
\hline & & \multicolumn{4}{|c|}{ MASA } & \multirow[b]{2}{*}{ Total } \\
\hline & & 1,00 & 2,00 & 3,00 & 4,00 & \\
\hline HOMMUJ & 1 & 10 & 7 & 2 & & 19 \\
\hline & 2 & 29 & 26 & 12 & 15 & 82 \\
\hline Total & & 39 & 33 & 14 & 15 & 101 \\
\hline
\end{tabular}

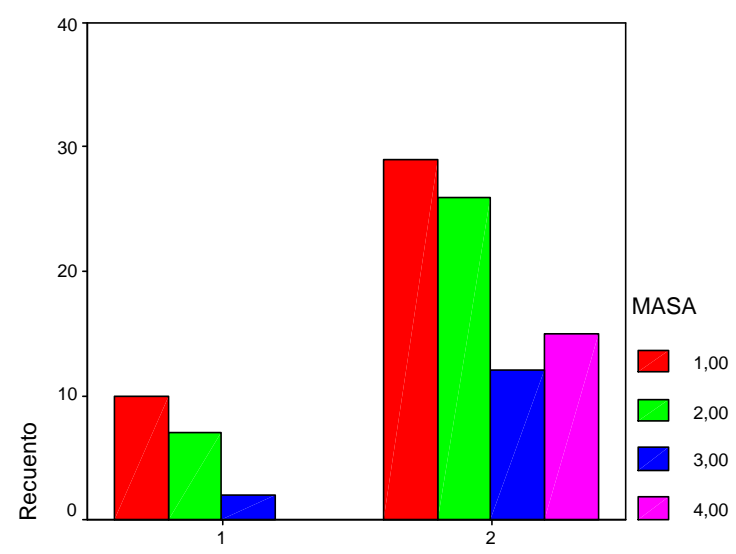

HOMMUJ

Tabla de contingencia HOMMUJ * MASA

Distribución de la muestra por sexos según su IMC.

El 52,6\% de los varones presentaban sobrepeso, el 36,8\% obesidad tipo I y el 2,4\% obesidad tipo II. Ningún varón presentaba obesidad mórbida.

Las mujeres presentaban sobrepeso el 35,4\%, obesidad tipo I el 31,7\% y tipo II el 14,6\%. El 18,3\% de las premenopaúsicas presentaba obesidad mórbida. 


$$
\begin{aligned}
\text { Sexo }=\mathbf{1} \text { varones } \\
\mathbf{2} \text { mujere } \mathrm{s}
\end{aligned} \quad \underline{\mathbf{E d a d}}=\begin{aligned}
\mathbf{1} & =29-44,9 \\
\mathbf{2} & =45-64,5 \\
\mathbf{3} & =>65
\end{aligned}
$$

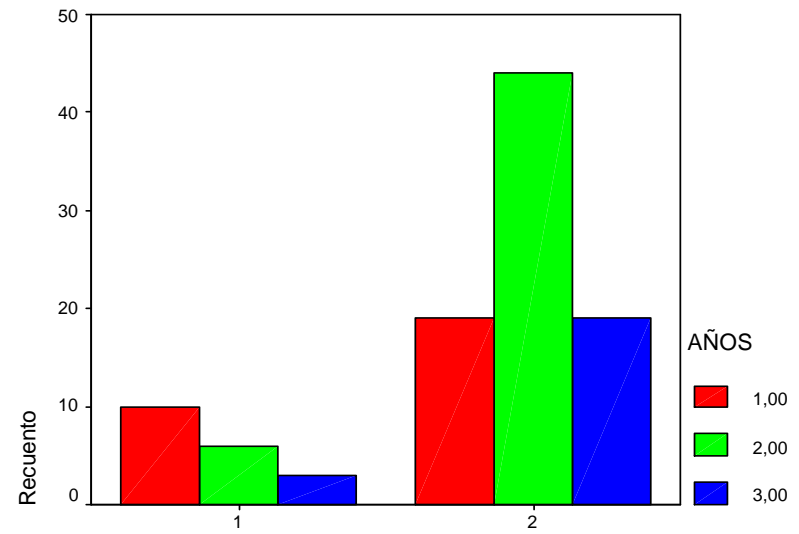

\begin{tabular}{|c|c|c|c|c|}
\hline \multicolumn{5}{|c|}{ Recuento } \\
\hline & & \multicolumn{2}{|c|}{ HOMMUJ } & \multirow[b]{2}{*}{ Total } \\
\hline & & 1 & 2 & \\
\hline ANOS & 1,00 & 10 & 19 & 29 \\
\hline & 2,00 & 6 & 44 & 50 \\
\hline & 3,00 & 3 & 19 & 22 \\
\hline Total & & 19 & 82 & 101 \\
\hline
\end{tabular}

HOMMUJ

Tabla de contingencia AÑOS * HOMMUJ

Con edades comprendidas en el grupo 1 están un 34,5\% de varones y un 65,5\% de las mujeres. Con edades del grupo 2 están un $12 \%$ de varones y un $88 \%$ mujeres y con edades comprendidas en el grupo 3 están un $13,6 \%$ de varones y el $86,4 \%$ de las mujeres.

\section{RELACIÓN $\underline{\text { SEXO }}$ con los HÁBITOS TÓXICOS}

$\underline{\text { Sexo }}$

$\mathbf{1}=$ varones

$\mathbf{2}=$ mujeres

\section{Hábitos tóxicos}

$\mathbf{0}=$ no consumen

$\mathbf{1}=$ consumen

\begin{tabular}{|c|c|c|c|}
\hline & $\mathrm{TAB}$ & & \\
\hline & 0 & 1 & Total \\
\hline HOMMUJ & 15 & 4 & 19 \\
\hline & 68 & 14 & 82 \\
\hline Total & 83 & 18 & 101 \\
\hline
\end{tabular}

Tabla de contingencia HOMMUJ * TABACO

\begin{tabular}{|c|c|c|c|}
\hline & \multicolumn{2}{|c|}{$\mathrm{ALCOHOL}$} & \multirow[b]{2}{*}{ Total } \\
\hline & 0 & 1 & \\
\hline HOMMUJ & 15 & 4 & 19 \\
\hline & 81 & 1 & 82 \\
\hline Total & 96 & 5 & 101 \\
\hline
\end{tabular}

Tabla de contingencia HOMMUJ * ALCOHOL

Fuma el $21 \%$ de los varones y el $17,1 \%$ de las mujeres.

Toman alcohol el $21 \%$ de los varones y sólo el 1,2\% de las mujeres.

\section{RELACIÓN SEXO con el NIVEL CULTURAL}

\section{$\underline{\text { Sexo }}$}

$\mathbf{1}=$ varones $\quad \mathbf{1}=$ estudios primarios

$\mathbf{2}=$ mujeres $\quad \mathbf{2}=$ estudios medios

$\mathbf{3}=$ estudios superiores 
Tabla de contingencia HOMMUJ * ESTUDIOS

Recuento
\begin{tabular}{|ll|r|r|r|r|}
\hline & & \multicolumn{3}{|c|}{ ESTUDIOS } & \multicolumn{1}{c|}{} \\
\cline { 3 - 6 } & & 1 & 2 & 3 & \multicolumn{1}{|c|}{ Total } \\
\hline HOMMUJ & 1 & 9 & 7 & 3 & 19 \\
& 2 & 64 & 12 & 6 & 82 \\
Total & & 73 & 19 & 9 & 101 \\
\hline
\end{tabular}

El 47,4\% de los varones tiene estudios primarios, un 36,8\% medios y superiores el $15,8 \%$.

Las mujeres tienen estudios primarios el $78 \%$, el $14,6 \%$ de ellas estudios medios y un $7,3 \%$ superiores.

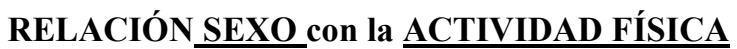

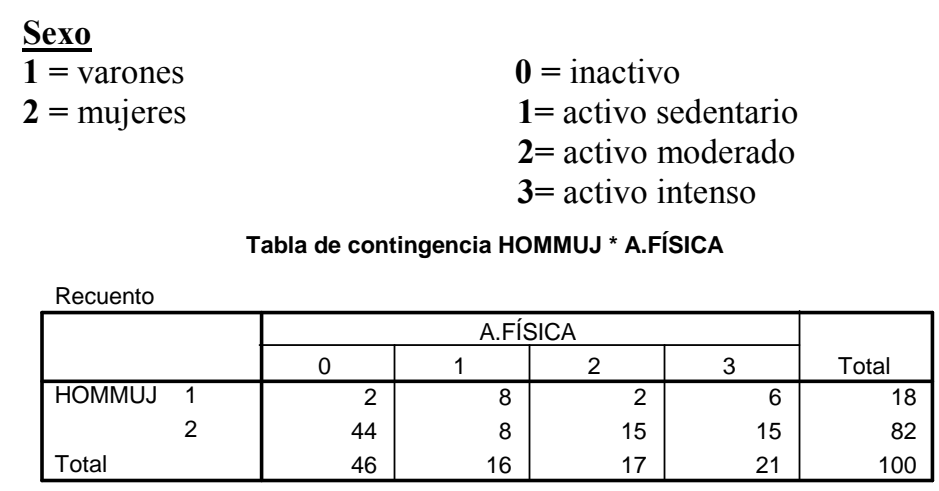

Inactivos estaban el $10,5 \%$ de los varones, activos sedentarios el $42,1 \%$, activos moderados el 10,5\% y tenían actividad intensa el 36,8\%.

Las mujeres estaban inactivas el 53,6\%, activas sedentarias el 9,7\%, activos moderado el $18,3 \%$ y tenían actividad intensa el $18,3 \%$.

\section{RELACIÓN}

\begin{tabular}{|c|c|c|}
\hline$\underline{\text { Sexo }}$ & Antecedentes familiares & A.FAMI.1= De Obesidad \\
\hline $\mathbf{1}=$ varones & $\mathbf{0}=$ no presentan & A.FAMI.2 = De DM tipo 2 \\
\hline $\mathbf{2}=$ mujeres & $\mathbf{1}=$ presentan & A.FAMI.3 = De HTA \\
\hline
\end{tabular}

\begin{tabular}{|l|c|c|c|c}
\hline & n & A.FAM.1 & A.FAM.2 & A.FAM.3 \\
\hline Sexo & & & & \\
\hline Varones & 19 & 11 & 5 & 4 \\
\hline Mujeres & 82 & 44 & 27 & 82
\end{tabular}

Presentaban antecedentes familiares de obesidad el 57,9\% de los varones y el 53,6\% de las mujeres. Antecedentes de DM tipo 2 los varones los presentaban el 26,3\% y el 32,9\% de las mujeres. Los antecedentes familiares de HTA los referían el $21 \%$ de los varones y el 25,6\% de las mujeres. 


\section{RELACIÓN $\underline{\text { SEXO con la PATOLOGÍA ASOCIADA }}$}

\section{$\underline{\operatorname{Sexo}}$}

$\mathbf{1}=$ varones

$\mathbf{2}=$ mujeres

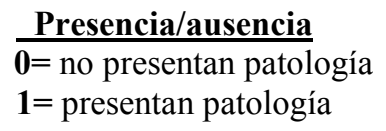

P. asociada

P.ASOC.1 $=$ HTA

P.ASOC.2 $=$ DM tipo 2

P.ASOC.3= Pat. osteoarticular

P.ASOC.4 $=$ Estreñimiento

P.ASOC.5 $=$ Pat. vascular

P.ASOC.6= Otras patologías

\begin{tabular}{|l|c|c|c|c|c|c|c}
\hline & n & P.ASOC.1 & P.ASOC.2 & P.ASOC.3 & P.ASOC.4 & P.ASOC.5 & P.ASOC.6 \\
\hline Grupos & & & & & & & \\
\hline Varones & 19 & 4 & 1 & 5 & 2 & 2 & 3 \\
\hline Mujeres & 82 & 20 & 3 & 53 & 43 & 44 & 46
\end{tabular}

El $21 \%$ de los varones presentaba HTA y el $24,4 \%$ de las mujeres. El 5,3\% de los varones y el 3,6\% de las mujeres presentaban DM. El 26,3\% de los varones y el $64,6 \%$ de las mujeres presentaban patología osteoarticular. Padecían estreñimiento el $10,5 \%$ de los hombres y el $52,4 \%$ de las mujeres. Patología vascular padecía el $10,5 \%$ de los varones y el 53,6\% de las mujeres. El $15,8 \%$ de los varones y el $56,1 \%$ de las mujeres padecían además otras enfermedades diferentes de las anteriores.

\section{RELACIÓN $\underline{\text { SEXO }}$ con el CONSUMO DE FÁRMACOS}

$\underline{\text { Sexo }}$

$\mathbf{1}=$ varones

$\mathbf{2}=$ mujeres

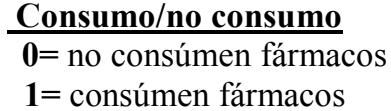

$\mathbf{1}=$ consúmen fármacos
Fármacos consumidos

FCOS. OB $=$ Antiobesidad

FCOS. HTA $=$ Antihipertensivos

FCOS. AG/AI= Analgésicos-Antiinflamatorios

FCOS. SNC $=$ Psicofármacos

FCOS.VASC $=$ Vasoprotectores

FCOS. PROT $=$ Protectores gástricos

FCOS. OTROS= Otros fármacos

\begin{tabular}{|l|c|c|c|c|c|c|c|c}
\hline & $\mathbf{n}$ & $\begin{array}{c}\text { Anti- } \\
\text { obesidad }\end{array}$ & HTA & AG/AI & $\begin{array}{c}\text { Psico- } \\
\text { fármacos }\end{array}$ & $\begin{array}{c}\text { Vaso- } \\
\text { protectores }\end{array}$ & $\begin{array}{c}\text { Protectores } \\
\text { gástricos }\end{array}$ & $\begin{array}{c}\text { Otros } \\
\text { Fcos }\end{array}$ \\
\hline Grupos & & & & & & & & \\
\hline Varones & 19 & 3 & 2 & 2 & 0 & 0 & 1 & 4 \\
\hline Mujeres & 82 & 37 & 22 & 25 & 10 & 17 & 11 & 30
\end{tabular}

Fármacos anti-obesidad consumían el $15,8 \%$ de los varones y el $45,1 \%$ de las mujeres. Antihipertensivos tomaba el $10,5 \%$ de los varones y el $26,8 \%$ de las mujeres. Analgésicos/antiinflamatorios toman el $10,5 \%$ de los hombres y el $30,5 \%$ de las mujeres. Psicofármacos consumían el 12,2\% de las mujeres, ningún varón. Vasoprotectores tomaban sólo las mujeres, un 20,7\%. Protectores gástricos consumían el 5,3\% de los hombres y el 13,4\% de las mujeres. El $21 \%$ de los varones y el $36,6 \%$ de las mujeres consumían otros fármacos diferentes de los anteriores. 
Cuando buscamos significación estadística $(\mathrm{p}<0,005)$ al relacionar las distintas variables entre sí, se encontró que entre el peso y el IMC al relacionar ambos sexos (varones y ambos grupos de mujeres) no existen diferencias estadísticamente significativas entre ellos. Lo mismo ocurre si comparamos varones y mujeres premenopáusicas. Al comparar varones con mujeres menopaúsicas en el peso no hay diferencias significativas pero si se evidencian diferencias significativas con respecto al índice de masa corporal al comparar ambos grupos. Al comparar los grupos de mujeres entre ellas no se han observado diferencias significativas en el peso y el índice de masa corporal pero sí con respecto al índice cintura/cadera.

Por sexos se observaron diferencias significativas para el consumo de alcohol pero no para el de tabaco. Si diferencias para la actividad física pero no para el nivel cultural ni para los antecedentes familiares. Con respecto a las patologías asociadas se observan diferencias significativas con todas a excepción de la DM tipo 2 y la HTA y en relación al consumo de fármacos con ningún grupo de los que toma la muestra se aprecian diferencias estadísticamente significativas

\section{RELACIÓN DE IMC con los HÁBITOS TÓXICOS}

\section{I.M.C}

$\underline{\mathbf{1}=25}-29,9$ sobrepeso

$\mathbf{2}=30-34,9$ obesidad tipo I

$\mathbf{3}=35-39,9$ obesidad tipo II

$4=>40 \quad$ obesidad mórbida

Tabla de contingencia MASA * ALCOHOL

\begin{tabular}{|c|c|c|c|c|}
\hline \multicolumn{5}{|c|}{ Recuento } \\
\hline & & \multicolumn{2}{|c|}{$\mathrm{ALCOHOL}$} & \multirow[b]{2}{*}{ Total } \\
\hline & & 0 & 1 & \\
\hline \multirow[t]{4}{*}{$\overline{M A S A}$} & 1,00 & 36 & 3 & 39 \\
\hline & 2,00 & 32 & 1 & 33 \\
\hline & 3,00 & 13 & 1 & 14 \\
\hline & 4,00 & 15 & & 15 \\
\hline Total & & 96 & 5 & 101 \\
\hline
\end{tabular}

Tabaco/alcohol

$\mathbf{0}=$ No consumo

$\mathbf{1}=$ consumo

Tabla de contingencia MASA * TABACO

Recuento

\begin{tabular}{|rr|r|r|r|}
\hline & \multicolumn{3}{|c|}{ TABACO } & \multicolumn{1}{c|}{} \\
\cline { 3 - 4 } & & 0 & 1 & \multicolumn{1}{c|}{ Total } \\
\hline MASA & 1,00 & 32 & 7 & 39 \\
& 2,00 & 26 & 7 & 33 \\
& 3,00 & 11 & 3 & 14 \\
& 4,00 & 14 & 1 & 15 \\
Total & & 83 & 18 & 101 \\
\hline
\end{tabular}

Fumaba el 7,7\% de los pacientes con sobrepeso, el 3\% con obesidad tipo I, el 7,1\% obesos tipo II y ninguna obesidad mórbida fumaba. Tomaba alcohol el $18 \%$ los pacientes con sobrepeso, el $21,2 \%$ con obesidad tipo I, el $21,4 \%$ de obesos tipo II y el $6,6 \%$ de obesidad mórbida.

\section{RELACIÓN DE IMC con el NIVEL CULTURAL}

$\begin{array}{ll}\frac{\text { IMC }}{\mathbf{1}=25-29,9} & \text { NIVEL CULTURAL } \\ \mathbf{2}=30-34,9 & \mathbf{2}=\text { Mrimarios } \\ \mathbf{3}=35-39,9 & \mathbf{3}=\text { Superiores } \\ \mathbf{4}=>40 & \end{array}$


Tabla de contingencia MASA * ESTUDIOS

Recuento
\begin{tabular}{|rr|r|r|r|r|}
\hline & & \multicolumn{3}{|c|}{ ESTUDIOS } & \multirow{2}{*}{ Total } \\
\cline { 3 - 5 } & & 1 & 2 & 3 & 39 \\
\hline MASA & 1,00 & 20 & 13 & 6 & 33 \\
& 2,00 & 28 & 3 & 2 & 14 \\
& 3,00 & 12 & 2 & & 15 \\
& 4,00 & 13 & 1 & & 1 \\
Total & & 73 & 19 & 9 & 101 \\
\hline
\end{tabular}

Con sobrepeso, un $51,3 \%$ tiene estudios primarios, un $33,3 \%$ medios y un $15,4 \%$ superiores. Con obesidad tipo I un $84,8 \%$ estudios primarios, un $9,1 \%$ medios y un $6,1 \%$ superiores. Con obesidad tipo II un $85,7 \%$ estudios primarios, un $14,3 \%$ medios y ninguno estudios superiores. Con obesidad mórbida un $86,6 \%$ tiene estudios primarios, un $6,6 \%$ medios $\mathrm{y}$ un $6,6 \%$ superiores.

\section{RELACIÓN DE IMC con los ACTIVIDAD FÍSICA}

$$
\begin{aligned}
& \frac{\mathbf{I M C}}{\mathbf{1}=25-29,9} \\
& \mathbf{2}=30-34,9 \\
& \mathbf{3}=35-39,9 \\
& \mathbf{4}=>40
\end{aligned}
$$

\begin{tabular}{|c|c|c|c|c|c|}
\hline & \multicolumn{4}{|c|}{ A.FÍSICA } & \multirow[b]{2}{*}{ Total } \\
\hline & 0 & 1 & 2 & 3 & \\
\hline $\begin{array}{ll}\text { MASA } & 1,00\end{array}$ & 11 & 7 & 11 & 10 & 39 \\
\hline 2,00 & 19 & 5 & 4 & 5 & 33 \\
\hline 3,00 & 8 & 1 & 2 & 3 & 14 \\
\hline 4,00 & 8 & 3 & 1 & 3 & 15 \\
\hline Total & 46 & 16 & 18 & 21 & 101 \\
\hline
\end{tabular}

\section{$\underline{\text { Actividad física }}$}

$$
\begin{aligned}
& \mathbf{0}=\text { inactivo } \\
& \mathbf{1}=\text { activo sedentario } \\
& \mathbf{2}=\text { activo moderado } \\
& \mathbf{3}=\text { activo intenso }
\end{aligned}
$$

Tabla de contingencia MASA * A.FíSICA

Con sobrepeso un $28,2 \%$ inactivos, $17,9 \%$ sedentarios, $28,2 \%$ moderados y $25,6 \%$ activos intensos. Con obesidad tipo I 57,6\% inactivos, $15,1 \%$ sedentarios, $12,1 \%$ moderados y $15,1 \%$ activos intensos. Con obesidad tipo II 57,1\% inactivos, 7,1\% sedentarios, $14,3 \%$ moderados y $21,4 \%$ activos intensos. Con obesidad mórbida, el 53,3\% inactivos, $20 \%$ sedentarios, $6,6 \%$ moderados y $20 \%$ activos intensos.

\section{RELACIÓN DE IMC con los ANTECEDENTES FAMILIARES}

$$
\begin{array}{llc}
\underline{\underline{\text { I.M.C}}} & \underline{\text { A.F. }} & \underline{\text { Presencia } / \text { ausencia de A.F. }} \\
\mathbf{1}=25-29,9 & \text { A.FAMI.1 }=\text { obesidad } & \mathbf{0}=\text { No presentan } \\
\mathbf{2}=30-34,9 & \text { A.FAMI.2 }=\text { DM } & \mathbf{1}=\text { presentan } \\
\mathbf{3}=35-39,9 & \text { A.FAMI.3 }=\text { HTA } & \\
\mathbf{4}=>40 & &
\end{array}
$$

\begin{tabular}{|l|c|c|c|c}
\hline & n & A.FAM.1 & A.FAM.2 & A.FAM.3 \\
\hline IMC & & & & \\
\hline $25-29,9$ & 39 & 17 & 8 & 8 \\
\hline $30-34,9$ & 33 & 20 & 12 & 9 \\
\hline $35-39,9$ & 14 & 8 & 5 & 3 \\
\hline$>40$ & 15 & 10 & 7 & 5
\end{tabular}


Con sobrepeso un $43,6 \%$ tiene A.F de obesidad, $20,5 \%$ de DM y $20,5 \%$ de HTA. Con obesidad tipo I $60,6 \%$ tiene A.F de obesidad, $36,4 \%$ de DM y $27,3 \%$ de HTA Con obesidad tipo II $57,1 \%$ tiene A.F de obesidad, 35,7\% de DM y 21,4\% de HTA .Con IMC 4 66,6\% tiene A.F de obesidad, $46,6 \%$ de DM y $33,3 \%$ de HTA.

\section{RELACIÓN DE IMC con la PATOLOGÍA ASOCIADA}

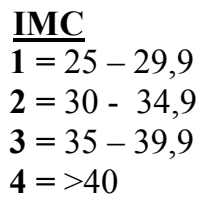

\section{Patología}

$\mathbf{0}=$ No presentan

$1=$ Presentan
Patologías asociadas

P.ASOC.1 $=$ HTA

P.ASOC.2 $=$ DM TIPO 2

P.ASOC.3 $=$ Patología osteoarticular

P.ASOC.4 $=$ Estreñimiento

P.ASOC.5 = Patología vascular

P.ASOC.6 $=$ Otras patologías

\begin{tabular}{|l|c|c|c|c|c|c|c}
\hline & n & P.ASOC.1 & P.ASOC.2 & P.ASOC.3 & P.ASOC.4 & P.ASOC.5 & P.ASOC.6 \\
\hline IMC & & & & & & & \\
\hline $25-29,9$ & 39 & 3 & 0 & 18 & 18 & 13 & 14 \\
\hline $30-34,9$ & 33 & 11 & 1 & 20 & 14 & 18 & 22 \\
\hline $35-39,9$ & 14 & 4 & 1 & 12 & 4 & 5 & 7 \\
\hline$>40$ & 15 & 6 & 2 & 8 & 9 & 10 & 6
\end{tabular}

Con sobrepeso, el 7,7\% padecían HTA, un $0 \%$ DM, 46,1\% patología osteoarticular, 46,1\% estreñimiento, 33,3\% patología vascular y un 35,9\% presentaban otras patologías diferentes de las anteriores. Con obesidad tipo I padecían HTA el 33,3\%, el 3\% DM, el 60,6\% patología osteoarticular, $42,4 \%$ estreñimiento, $54,5 \%$ patología vascular y un $66,6 \%$ presentaban otras patologías.

Con obesidad tipo II, padecían HTA el 28,6\%, 7,1\% DM, 85,7\% patología osteoarticular, $28,6 \%$ estreñimiento, $35,7 \%$ patología vascular y un $50 \%$ presentaban otras patologías. Con obesidad mórbida, padecían HTA el 40\%, 13,3\% DM, 53,3\% patología osteoarticular, $60 \%$ estreñimiento, $66,6 \%$ patología vascular y un $40 \%$ presentaban otras patologías diferentes de las anteriores.

\section{RELACIÓN DE IMC Con el CONSUMO DE FÁRMACOS}

\begin{tabular}{|c|c|}
\hline I.M.C. & Consumo/no consumo \\
\hline $\mathbf{1}=25-29,9$ & $\mathbf{0}=$ No consúmen los fármacos \\
\hline $2=30-34,9$ & $\mathbf{1}=\mathrm{Si}$ consúmen los fármacos \\
\hline $3=35-39,9$ & \\
\hline $4=>40$ & \\
\hline
\end{tabular}

\author{
Fásmacos consumidos \\ FCOS.OB $=$ Antiobesidad \\ FCOS.HTA= Antihipertensivos \\ FCOS,AG/AI = Analgésicos/antiinflamatorios \\ FCOS.SNC $=$ Psicofármacos \\ FCOS.PROT $=$ Portectores gástricos \\ FCOS.VASC $=$ Vasoprotectores \\ FCOS.OTROS $=$ Otros fármacos
}

\begin{tabular}{|l|c|c|c|c|c|c|c|c}
\hline & $\mathbf{n}$ & $\begin{array}{c}\text { Anti- } \\
\text { obesidad }\end{array}$ & HTA & AG/AI & $\begin{array}{c}\text { Psico- } \\
\text { fármacos }\end{array}$ & $\begin{array}{c}\text { Vaso- } \\
\text { protectores }\end{array}$ & $\begin{array}{c}\text { Protectores } \\
\text { gástricos }\end{array}$ & $\begin{array}{c}\text { Otros } \\
\text { Fcos }\end{array}$ \\
\hline IMC & & & & & & & & \\
\hline $25-29,9$ & 39 & 9 & 2 & 6 & 5 & 3 & 3 & 10 \\
\hline $30-34,9$ & 33 & 17 & 10 & 12 & 2 & 7 & 4 & 12 \\
\hline $35-39,9$ & 14 & 6 & 5 & 4 & 1 & 4 & 3 & 8 \\
\hline$>40$ & 15 & 8 & 7 & 5 & 2 & 3 & 2 & 4
\end{tabular}


Con sobrepeso, consumían fármacos anti-obesidad el 23,1\% de los pacientes, anti-HTA el $5,1 \%$, AG/AI el 15,4\%, psicofármacos el 12,8\%, vasoprotectores el 7,7\%, protectores gástricos el 7,7\% y $25,6 \%$ tomaban otros distintos de los anteriores.

Con obesidad tipo I consumían fármacos anti-obesidad el 51,5\%, anti-HTA el 30,3\%, AG/AI el 36,4\%, psicofármacos el 6,1\%, vasoprotectores el 21,2\%, protectores gástricos el $12,1 \%$ y $36,4 \%$ tomaban otros distintos de los anteriores. Con obesidad tipo II, consumían fármacos anti-obesidad el 42,8\%, anti-HTA el 35,7\%, AG/AI el 28,6\%, psicofármacos el 7,1\%, vasoprotectores el $28,6 \%$, protectores gástricos el 21,4\% y 57,1\% tomaban otros distintos de los anteriores. Con obesidad mórbida consumían fármacos anti-obesidad el 53,3\%, anti-HTA el $46,6 \%$, AG/AI el 33,3\%, psicofármacos el 13,3\%, vasoprotectores el 20\%, protectores gástricos el $13,3 \%$ y $26,6 \%$ tomaban otros distintos de los anteriores.

La significación estadística, al comparar el grado de obesidad (IMC) con los grupos de la muestra si existen diferencias estadísticamente significativas, pero no se observan cuando separamos a la muestra por sexos. Con los hábitos tóxicos (tabaco y alcohol) no existen diferencias significativas con el índice de masa corporal, tampoco con la actividad física, ni con el nivel cultural. Tampoco con los antecedentes familiares ni al relacionarlo con las patologías asociadas que presentaban los pacientes (DM tipo 2, HTA, patología osteoarticular, estreñimiento, patología vascular, otras patologías). En relación a la toma de fármacos, cuando comparamos el IMC con ellos, no se observan diferencias significativas con ningún grupo de fármacos salvo para el grupo de antihipertensivos. En relación con las dislipemias, tampoco se observaron diferencias significativas con los parámetros del perfil lipídico.

\section{RELACIÓN DE LA EDAD $c o n$ el IMC}

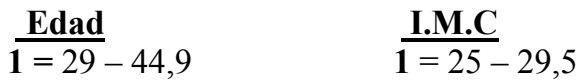

$$
\begin{aligned}
& \mathbf{2}=45-64,9 \quad \mathbf{2}=30-34,9 \\
& \mathbf{3}=>65 \quad \mathbf{3}=35-39,9 \\
& 4=>40
\end{aligned}
$$

Recuento
\begin{tabular}{|rr|r|r|r|r|r|}
\hline & \multicolumn{5}{|c|}{ MASA } & \multirow{2}{*}{} \\
\cline { 3 - 6 } & & \multicolumn{1}{|c|}{1,00} & 2,00 & 3,00 & 4,00 & \multicolumn{1}{c|}{ Total } \\
\hline ANOS & 1,00 & 17 & 7 & 3 & 2 & 29 \\
& 2,00 & 19 & 15 & 6 & 10 & 50 \\
& 3,00 & 3 & 11 & 5 & 3 & 22 \\
Total & 39 & 33 & 14 & 15 & 101 \\
\hline
\end{tabular}

Con edades del grupo 1, el 58,6\% tienen sobrepeso, el 24,1\% obesidad tipo I, un 10,3\% obesidad tipo II y un $6,9 \%$ obesidad mórbida. 
Con edades comprendidas en el grupo 2, un 38\% tiene sobrepeso, un 30\% obesidad tipo I, un $12 \%$ con obesidad tipo II y un $20 \%$ con obesidad mórbida. Con edades comprendidas dentro del grupo 3, el 13,6\% tienen sobrepeso, el 50\% tienen obesidad tipo I, un 22,7\% con obesidad tipo II y un 13,6\% con obesidad mórbida.

\section{RELACIÓN DE LA EDAD con los HÁBITOS TÓXICOS}

$\begin{array}{ll}\begin{array}{ll}\text { Edad de la muestra } \\ \mathbf{1}=29-44,9\end{array} & \frac{\text { Hábitos Tóxicos }}{\mathbf{0}=\text { No consumo }} \\ \begin{array}{l}\mathbf{2}=45-64,9 \\ \mathbf{3}=>65\end{array} & \mathbf{1}=\text { consumo }\end{array}$

Tabla de contingencia

Recuento
\begin{tabular}{|rr|r|r|r|}
\hline & & \multicolumn{2}{|c|}{ TABACO } & \multirow{2}{*}{ Total } \\
\cline { 3 - 4 } & & 0 & 1 & \multicolumn{1}{|c|}{29} \\
\hline ANOS & 1,00 & 21 & 8 & 50 \\
& 2,00 & 41 & 9 & 22 \\
& 3,00 & 21 & 1 & 101 \\
\hline
\end{tabular}

Tabla de contingencia

\begin{tabular}{|c|c|c|c|c|}
\hline & & \multicolumn{2}{|c|}{$\mathrm{ALCOHOL}$} & \multirow[b]{2}{*}{ Total } \\
\hline & & 0 & 1 & \\
\hline$\overline{A N O S}$ & 1,00 & 25 & 4 & 29 \\
\hline & 2,00 & 49 & 1 & 50 \\
\hline & 3,00 & 22 & & 22 \\
\hline Total & & 96 & 5 & 101 \\
\hline
\end{tabular}

En el grupo de edades entre 29 - 44,9 años el 27,6\% fuman. En el grupo de edad intermedia, el $18 \%$ y en el grupo de más edad fuman el $4,5 \%$ de la muestra.

Con edades comprendidas entre 29 - 44,9 años, el 13,8\% toman alcohol y con edad media el $2 \%$ lo consumen. Los mayores de 65 años no toman ninguno alcohol.

\section{RELACIÓN DE LA EDAD con el NIVEL CULTURAL}

\begin{tabular}{|c|c|}
\hline Edad de la muestra & Nivel cultural \\
\hline $\mathbf{1}=29-44,9$ & $\mathbf{1}=$ Primarios \\
\hline $2=45-64,9$ & $\mathbf{2}=$ Medios \\
\hline $3=>65$ & $\mathbf{3}=$ Superiores \\
\hline
\end{tabular}

Tabla de contingencia

Recuento
\begin{tabular}{|rr|r|r|r|r|}
\hline & & \multicolumn{3}{|c|}{ ESTUDIOS } & \multirow{2}{*}{ Total } \\
\cline { 3 - 6 } & & 1 & 2 & 3 & 29 \\
ANOS & 1,00 & 14 & 12 & 3 & 50 \\
& 2,00 & 38 & 6 & 6 & 22 \\
& 3,00 & 21 & 1 & & \\
Total & & 73 & 19 & 9 & 101 \\
\hline
\end{tabular}

En el grupo 1, el 48,3\% tienen estudios primarios, el 41,4\% medios y el $10,3 \%$ superiores. Con edades del grupo 2 , el $76 \%$ tienen estudios primarios, un $12 \%$ medios y un $12 \%$ superiores. En el grupo 3 de edad, el 95,4\% tienen estudios primarios y el 4,6\% medios. En este grupo ninguno tiene estudios superiores.

\section{RELACIÓN DE LA EDAD con la ACTIVIDAD FÍSICA}

\begin{tabular}{|c|c|}
\hline Edad de la muestra & Actividad física \\
\hline $\mathbf{1}=29-44,9$ & $\overline{\mathbf{0}=\text { Inactivo }}$ \\
\hline $2=45-64,9$ & $\mathbf{1}=$ Activo sedentario \\
\hline $3=>65$ & $\begin{array}{l}\mathbf{2}=\text { Activo moderado } \\
\mathbf{3}=\text { Activo intenso }\end{array}$ \\
\hline
\end{tabular}




\begin{tabular}{|c|c|c|c|c|c|c|}
\hline \multicolumn{7}{|c|}{ Tabla de contingencia } \\
\hline \multicolumn{7}{|c|}{ Recuento } \\
\hline & & \multicolumn{4}{|c|}{ A.FÍSICA } & \multirow[b]{2}{*}{ Total } \\
\hline & & 0 & 1 & 2 & 3 & \\
\hline ANOS & 1,00 & 2 & 7 & 11 & 9 & 29 \\
\hline & 2,00 & 23 & 9 & 7 & 11 & 50 \\
\hline & 3,00 & 21 & & & 1 & 22 \\
\hline Total & & 46 & 16 & 18 & 21 & 101 \\
\hline
\end{tabular}

Con edades del grupo 1 , el 6,9\% estaban inactivos, un 24,1\% activos sedentarios, $37,9 \%$ activo moderado y un $31 \%$ tenían actividad intensa. Con edades del grupo 2 , un $46 \%$ estaban inactivos, $18 \%$ sedentarios, $14 \%$ activo moderado y un $22 \%$ tenían actividad intensa. Con edades comprendidas en el grupo 3, un 95,4\% estaban inactivos, $0 \%$ sedentario, $0 \%$ activo moderado y $4,6 \%$ tenían actividad intensa.

\section{RELACIÓN DE LA EDAD con los ANTECEDENTES FAMILIARES}

\begin{tabular}{|c|c|c|}
\hline Edad de la muestra & Antecedentes familiares & \\
\hline $\mathbf{1}=29-44,9$ & A.FAMI.1 = De obesidad & $\mathbf{0}=$ No presentan antecedentes familiares \\
\hline $2=45-64,9$ & A.FAMI.2 = De DM tipo 2 & $\mathbf{1}=$ Si presentan antecedentes familiares \\
\hline $3=>65$ & A.FAMI.3 = De HTA & \\
\hline
\end{tabular}

\begin{tabular}{|l|c|c|c|c}
\hline & n & A.FAM.1 & A.FAM.2 & A.FAM.3 \\
\hline Edad & & & & \\
\hline $29-44,9$ & 29 & 18 & 10 & 7 \\
\hline $45-64,9$ & 50 & 26 & 17 & 11 \\
\hline$>65$ & 22 & 11 & 5 & 7
\end{tabular}

A.F de obesidad presentaba el $62,1 \%$ de los pacientes con edades entre 29 - 44,9 años, el 52\% de edad media y el $50 \%$ con más de 65 años. A.F de DM tenían el 34,5\% de los más jóvenes, el 34\% de mediana edad y el 22,7\% de los más de 65 años. A.F de HTA referían el $24,1 \%$ de los pacientes de menos edad, el $22 \%$ de mediana edad y el $31,8 \%$ de los más mayores.

\section{RELACIÓN DE LA EDAD con las PATOLOGÍAS ASOCIADA}

Edad de la muestra

$\mathbf{1}=29-44,9$

$\mathbf{2}=45-64,9$

$3=>65$

\section{Patologías asociadas}

P.ASOC.1 = Presencia de hipertensión arterial

P.ASOC.2 $=$ Presencia de diabetes

P.ASOC.3 = Presencia de patología osteoarticular

P.ASOC.4 = Presencia de estreñimiento

P.ASOC.5 = Presencia de patología vascular

P.ASOC.6 $=$ Presencia de otras patologías

\begin{tabular}{|l|c|c|c|c|c|c|c}
\hline & n & P.ASOC.1 & P.ASOC.2 & P.ASOC.3 & P.ASOC.4 & P.ASOC.5 & P.ASOC.6 \\
\hline Edad & & & & & & & \\
\hline $29-44,9$ & 29 & 34 & 0 & 44,8 & 41,4 & 10,3 & 20,7 \\
\hline $45-64,9$ & 50 & 18 & 4 & 56 & 46 & 60 & 64 \\
\hline$>65$ & 22 & 63,6 & 9,1 & 77,3 & 45,4 & 59,1 & 50
\end{tabular}

De los pacientes más jóvenes, un 3,4\% presentaba HTA, 0\% DM, el 44,8\% patología osteoarticular, el 41,4\% estreñimiento, el 10,3\% patología vascular y el 20,7\% otras patologías.

Con edades medias, el $18 \%$ presentaba HTA, el 4\% DM, el $46 \%$ estreñimiento, el $60 \%$ patología vascular, el 56\% patología osteoarticular, y el 64\% presentaba otras patologías. 
De los mayores de 65 años, el 63,6\% presentaba HTA, 9,1\% DM, 77,3\% patología osteoarticular, $45,4 \%$ estreñimiento, $59,1 \%$ patología vascular y el $50 \%$ presentaba otras patologías distintas de las anteriores.

\section{RELACIÓN DE LA EDAD con el CONSUMO DE FÁRMACOS}

Edad de la muestra:

$\mathbf{1}=29-44,9$

$2=45-64,9$

$3=>65$
Toma de fármacos:

FCOS.OB $=$ Toma de fármacos para la obesidad

FCOS.HTA = Toma de fármacos contra la hipertensión

FCOSAGAI = Toma de fármacos analgésicos/antiinflamatorios

FCOSSNC $=$ Toma de psicofármacos

FCOSVASC $=$ Toma de fármacos vasoprotectores

FCOSPROT $=$ Toma de protectores gástricos

FCOSOTRO = Toma de fármacos distintos de los anteriores

\begin{tabular}{|l|c|c|c|c|c|c|c|c}
\hline & n & $\begin{array}{c}\text { Anti- } \\
\text { obesidad }\end{array}$ & $\begin{array}{c}\text { Anti- } \\
\text { HTA }\end{array}$ & AG/AI & $\begin{array}{c}\text { Psico- } \\
\text { fármacos }\end{array}$ & $\begin{array}{c}\text { Vaso- } \\
\text { protectores }\end{array}$ & $\begin{array}{c}\text { Protectores } \\
\text { gástricos }\end{array}$ & $\begin{array}{c}\text { Otros } \\
\text { Fcos }\end{array}$ \\
\hline Edad & & & & & & & & \\
\hline $29-44,9$ & 29 & 6 & 0 & 3 & 3 & 1 & 3 & 5 \\
\hline $45-64,9$ & 50 & 20 & 9 & 14 & 4 & 9 & 4 & 17 \\
\hline$>65$ & 22 & 14 & 15 & 10 & 3 & 7 & 5 & 12
\end{tabular}

Con edades comprendidas entre 29 - 44,9 años, el 20,7\% consumían fármacos contra la obesidad, el $0 \%$ antihipertensivos, $10,3 \% \mathrm{AG} / \mathrm{AI}, 10,3 \%$ psicofármacos, 3,4\% vasoprotectores, $10,3 \%$ protectores gástricos y $17,2 \%$ tomaba además otros fármacos.

Con edad media, el $40 \%$ consumían fármacos contra la obesidad, $18 \%$ antihipertensivos, $28 \%$ AG/AI, $8 \%$ psicofármacos, $18 \%$ vasoprotectores y $8 \%$ protectores gástricos y $34 \%$ tomaban otras fármacos distintos de los anteriores.

El grupo de mayores de 65 años, un 63,6\% consumían fármacos contra la obesidad, $68,2 \%$ antihipertensivos, 45,4\% AG/AI, 13,6\% psicofármacos, el 31,8\% vasoprotectores y el $22,7 \%$ tomaban protectores gástricos y el $54,5 \%$ otros fármacos.

Al relacionar los grupos de edad con los parámetros analizados en la muestra vemos que no hay diferencias estadísticamente significativas con respecto al IMC, tampoco con los hábitos tóxicos, pero si se observan diferencias significativas al comparar grupos de edad con el nivel cultural y con la actividad física. Con las patologías asociadas se aprecian diferencias significativas con la HTA y con la presencia patología vascular, no con el resto. Con la toma de fármaco hay diferencias significativas con los antihipertensivos, no con los demás fármacos. No se observó significación estadística con los A.F. Tampoco se vieron diferencias estadísticamente significativas entre los grupos de edad y los parámetros del perfil lipídico. 


\section{VALORES ESTADÍSTICOS DESCRIPTIVOS DE LA MUESTRA}

\section{VARIABLES CUANTITATIVAS.}

\section{VALORES AL INICIO Y AL FINAL DEL ESTUDIO.}

Las tablas que se exponen a continuación corresponden a los valores estadísticos descriptivos obtenidos de variables cuantitativas de la muestra determinadas en global para todos los pacientes, separadas por grupos (varones, mujeres premenopaúsicas y mujeres menopaúsicas) y separadas por sexos (varones y ambos grupos de mujeres).

Todas las determinaciones analíticas que se realizaron como el resto de mediciones edad, peso, IMC, ICC, toma de T/A, contornos... corresponden con el inicio y final del seguimiento e intentando coincidir en el tiempo, lo más posible, con la realización de las dos densitometrías que se les solicitaron a los pacientes. El seguimiento que se realizó a cada paciente duró unos dos años.

\section{DISTRIBUCIÓN DE LA MUESTRA}

INICIO

\begin{tabular}{|c|c|c|c|c|c|c|c|c|}
\hline & \multicolumn{2}{|c|}{ Total } & \multicolumn{2}{|c|}{ Varones } & \multicolumn{2}{|c|}{ Premenopaúsia } & \multicolumn{2}{|c|}{ Menopaúsia } \\
\hline & Media & DS & Media & DS & Media & DS & Media & DS \\
\hline EDAD & 52,39 & $+/-12,04$ & 43,31 & $+/-6,58$ & 43,31 & $+/-6,58$ & 60,98 & $+/-7,94$ \\
\hline PESO & 81,74 & $+/-13,39$ & 87,97 & $+/-11,08$ & 77,8 & $+/-15,84$ & 82,06 & $+/-11,46$ \\
\hline I.M.C. & 32,58 & $+/-5,45$ & 30,34 & $+/-3,22$ & 31,36 & $+/-5,77$ & 34,33 & $+/-5,45$ \\
\hline I.C.C. & $0,84+/$ & $-7,25 \mathrm{E}-02$ & $0,94+$ & $/-3,85 \mathrm{E}-02$ & 0,80 & $+/-7,05 \mathrm{E}-02$ & 0,84 & $+/-5,45 \mathrm{E}-02$ \\
\hline
\end{tabular}

FINAL

\begin{tabular}{|c|c|c|c|c|c|c|c|c|}
\hline & \multicolumn{2}{|c|}{ Total } & \multicolumn{2}{|c|}{ Varones } & \multicolumn{2}{|c|}{ Premenopaúsia } & \multicolumn{2}{|c|}{ Menopaúsia } \\
\hline & Media & DS & Media & DS & Media & DS & Media & DS \\
\hline EDAD & 54,22 & $+/-12,12$ & 49,16 & $+/-13,47$ & 45,17 & $+/-6,66$ & 62,88 & $+/-8,13$ \\
\hline PESO & 79,16 & $+/-14,39$ & 87,87 & $+/-15,41$ & 76,36 & $+/-16,75$ & 79,61 & $+/-11,81$ \\
\hline I.M.C. & 32,05 & $+/ 5,70$ & 30,07 & $+/-4,48$ & 30,62 & $+/-5,89$ & 33,51 & $+/-5,49$ \\
\hline I.C.C. & $0,83+1$ & $-8,17 \mathrm{E}-02$ & $0,94+1$ & /-8,79E-02 & 0,79 & $+/-7,77 \mathrm{E}-02$ & 0,84 & $+/-5,96 \mathrm{E}-02$ \\
\hline
\end{tabular}

En el total de la muestra, entre el inicio ( $1^{\circ}$ determinación) y el final del seguimiento se aprecia una pérdida de peso de un 3,1\%, un descenso del IMC del 1,6\% y del ICC de un 1,1\%.

En el grupo de los varones no se observaron modificaciones en los resultados obtenidos al inicio con los que presentaron al finalizar el seguimiento.

Las mujeres premenopaúsicas, a lo largo del seguimiento presentaron una disminución del peso en un $1,8 \%$, el IMC un 2,3\% y el ICC un 1,8\%.

En la menopaúsia, el peso disminuyó un 3,6\%, el IMC un 2,9\% y el ICC un 4,8\%.

\section{PARÁMETROS ANALÍTICOS}

Las determinaciones en la bioquímica general que se analizaron en nuestra muestra sólo presentaron alteraciones los valores de glucosa, el ácido úrico, la albúmina y las proteínas totales. El resto de determinaciones analíticas mostraban valores dentro de la normalidad. 
Desestimé el resultado del hemograma porque no presentaban alteraciones sus valores. Todos presentaban rango de normalidad.

La VSG si presentó alteraciones en las diferentes determinaciones a lo largo el seguimiento como se refleja en la tabla.

Tabla no 8

\begin{tabular}{l|ll|lc|lc|cc}
\multicolumn{1}{|c|}{ INICIO } & \multicolumn{2}{|c|}{ Total } & \multicolumn{2}{|c|}{ Varones } & \multicolumn{2}{c|}{ Premenopaúsia } & \multicolumn{2}{c}{ Menopaúsia } \\
& Media & DS & Media & DS & Media & DS & Media & DS \\
\hline GLUCOSA & 95,63 & $+/-12,28$ & 99,42 & $+/-12,92$ & 90,85 & $+/-9,67$ & 97,52 & $+/-12,86$ \\
UREA & 34,92 & $+/-11,45$ & 37,50 & $+/-12,43$ & 29,09 & $+/-7,83$ & 38,08 & $+/-11,83$ \\
CREATININA & 0,91 & $+/-0,15$ & 1,06 & $+/-0,11$ & 0,84 & $+/-9,88 E-02$ & 0,90 & $+/-0,15$ \\
Á. ÚRICO & 5,20 & $+/-1,24$ & 5,76 & $+/-1,03$ & 4,47 & $+/-0,85$ & 5,49 & $+/-1,32$ \\
SODIO & 139,90 & $+/-2,37$ & 139,68 & $+/-1,20$ & 138,62 & $+/-2,03$ & 140,90 & $+/-2,51$ \\
POTASIO & 4,32 & $+/-0,33$ & 4,39 & $+/-0,39$ & 4,29 & $+/-0,26$ & 4,32 & $+/-0,35$ \\
PROTEÍNAS T. & 7,02 & $+/-0,42$ & 7,20 & $+/-0,51$ & 6,88 & $+/-0,34$ & 7,09 & $+/-0,41$ \\
ALBÚMINA & 4,10 & $+/-0,33$ & 4,45 & $+/-0,44$ & 4,01 & $+/-0,29$ & 4,08 & $+/-0,27$ \\
OSMOLARIDAD & 280,72 & $+/-5,33$ & 279,89 & $+/-3,86$ & 277,58 & $+/-4,25$ & 283,19 & $+/-5,31$ \\
V.S.G & 15,21 & $+/-8,88$ & 7,47 & $+/-4,10$ & 16,76 & $+/-8,79$ & 16,76 & $+/-8,79$
\end{tabular}

FINAL

\begin{tabular}{|c|c|c|c|c|c|c|c|c|}
\hline & \multicolumn{2}{|c|}{ Total } & \multicolumn{2}{|c|}{ Varones } & \multicolumn{2}{|c|}{ Premenopaúsia } & \multicolumn{2}{|c|}{ Menopaúsia } \\
\hline & Medi & DS & Media & DS & Media & DS & Media & DS \\
\hline GLUCOSA & 98,53 & $+/-21,51$ & 105,46 & $+/-25,92$ & 91,82 & $+/-10,69$ & 101,25 & $+/-24,99$ \\
\hline UREA & 35,06 & $+/-10,20$ & 37,23 & $+/-12,16$ & 29,71 & $+/-8,13$ & 38,44 & $+/-9,36$ \\
\hline CREATININA & 0,97 & $+/-0,15$ & 1,12 & $+/-0,10$ & 0,90 & $+/-0,12$ & 0,96 & $+/-0,14$ \\
\hline Á. ÚRICO & 5,24 & $+/-1,24$ & 5,92 & $+/-0,64$ & 4,66 & $+/-0,99$ & 5,43 & $+/-1,40$ \\
\hline SODIO & 139,88 & $+/-3,41$ & 140,23 & $+/-2,17$ & 138,96 & $+/-3,52$ & 140,46 & $+/-3,59$ \\
\hline POTASIO & 4,35 & $+/-0,35$ & 4,22 & $+/-0,42$ & 4,33 & $+/-0,34$ & 4,41 & $+/-0,33$ \\
\hline PROTEÍNAS T. & 6,94 & $+/-0,38$ & 7,01 & $+/-0,48$ & 6,90 & $+/-0,38$ & 6,96 & $+/-0,36$ \\
\hline ALBÚMINA & 4,03 & $+/-0,27$ & 4,31 & $+/-0,33$ & 3,99 & $+/-0,24$ & 3,99 & $+/-0,22$ \\
\hline OSMOLARIDAD & 280,32 & $+/-6,40$ & 281,38 & $+/-3,15$ & 277,59 & $+/-6,85$ & 281,97 & $+/-6,36$ \\
\hline V.S.G & 17,64 & $+/-10,50$ & 9,23 & $+/-3,06$ & 19,43 & $+/-10,66$ & 19,43 & $+/-10,66$ \\
\hline
\end{tabular}

Presentaban cifras elevadas de glucosa un $16,8 \%$ de los pacientes en la determinación inicial y un $14,3 \%$ en la final y en el caso del ácido úrico un $11,9 \%$ presentaba cifras elevadas en primera valoración y un $10,4 \%$ en la última. Las proteínas totales disminuyen un 1,4\% y la albúmina 2,4\%. La glucosa se incremento un 3,2\% y de un $16,4 \%$ la VSG.

El $31,5 \%$ de los varones presentaban cifras altas de glucosa al inicio y un $30,7 \%$ en la última determinación. Si consideramos que valores de glucosa por encima de $110 \mathrm{mg} / \mathrm{dl}$ indican intolerancia a la misma, el porcentaje en este grupo es alto. En los valores de ácido úrico un $10,5 \%$ de los valores lo presenta elevado al inicio y un $8,3 \%$ al final. La glucosa presenta un aumento global de un 6\%, la creatinina de un 5\%, el ácido úrico un 2,7\% y la VSG un 26,8\%. Las proteínas totales disminuyen un 2,8\% y la albúmina 2,2\%. Un $2,9 \%$ de las mujeres premenopaúsicas, en la $1^{\text {a }}$ determinación analítica presenta cifras elevadas de glucosa y un 3,5\% en la última determinación. Los valores de ácido úrico al inicio fueron normales y al final, un 3,6\% de las mujeres premenopáusicas presentaban cifras altas de ácido úrico.

La glucosa aumentó un $1,1 \%$, la urea un $2,4 \%$, la creatinina un $7,1 \%$, las proteínas totales también subieron un 1,4\% y la VSG un $63,3 \%$. 
Al inicio tenían elevadas sus cifras de glucosa un 20,8\% de las mujeres menopaúsicas y un $16,6 \%$ al final. El ácido úrico lo tenían alto un $20,8 \%$ al principio y un $18,9 \%$ al terminar el seguimiento. En general, las proteínas totales y la albúmina bajaron un 1\% las primeras y un $2,4 \%$ las segundas, mientras que la glucosa aumentó sus valores en un $4,1 \%$, la urea en un $1,1 \%$, la creatinina en un $6,6 \%$ y la VSG un $22,4 \%$.

Al correlacionar los valores obtenidos en los parámetros analíticos entre sí, se observó que presentaban significación estadística con el peso, el ácido úrico, la glucosa, la creatinina, la urea, el potasio y con el calcio. El calcio presentaba relación estadísticamente significativa con los valores de sodio, los de potasio y las proteínas totales. El magnesio con la creatinina. La fosfatasa alcalina con el sodio y el potasio; las proteínas totales con la albúmina y la calciúria presentaba relación estadísticamente significativa con el fósforo urinario. No otra significación.

VALORES DEL PERFIL LIPÍDICO.

INICIO

Tabla n' 9

\begin{tabular}{l|cc|cc|cc|cc}
\hline & \multicolumn{2}{|c|}{ Total } & \multicolumn{2}{c|}{ Varones } & \multicolumn{2}{c|}{ Premenopaúsia } & \multicolumn{2}{c}{ Menopaúsia } \\
& Media & \multicolumn{1}{c|}{ DS } & Media & DS & Media & DS & Media & DS \\
\hline COLESTEROL & 216,43 & $+/-33,49$ & 215,17 & $+/-27,62$ & 205,56 & $+/-39,30$ & 224,6 & $+/-29,11$ \\
H.D.L & 56,93 & $+/-12,71$ & 45,33 & $+/-8,9$ & 58,97 & $+/-12,07$ & 59,89 & $+/-12,08$ \\
L.D.L & 138,58 & $+/-30,57$ & 139,67 & $+/-25,60$ & 128,15 & $+/-35,24$ & 145,7 & $+/-26,93$ \\
TRIGLICÉRIDOS & 97,45 & $+/-57,96$ & 111,22 & $+/-37,99$ & 91,56 & $+/-79,08$ & 96,46 & $+/-45,44$ \\
Índice Col.H.D.L & 3,97 & $+/-1,05$ & 4,83 & $+/-0,96$ & 3,63 & $+/-1,02$ & 3,89 & $+/-0,93$ \\
I.D.L - H.D.L & 2,63 & $+/-0,93$ & 3,18 & $+/-0,85$ & 2,46 & $+/-1,10$ & 2,53 & $+/-0,75$
\end{tabular}

FINAL

\begin{tabular}{l|lc|cc|cc|cc}
\hline & \multicolumn{2}{|c|}{ Total } & \multicolumn{2}{c|}{ Varones } & \multicolumn{2}{c}{ Premenopaúsia } & \multicolumn{2}{c}{ Menopaúsia } \\
& Media & DS & Media & DS & Media & DS & Media & DS \\
\hline COLESTEROL & 214,35 & $+/-32,41$ & 214,15 & $+/-26,38$ & 207,5 & $+/-35,69$ & 219,59 & $+/-31,53$ \\
H.D.L & 54,51 & $+/-11,45$ & 45,62 & $+/-7,4$ & 57,29 & $+/-11,51$ & 55,54 & $+/-11,28$ \\
L.D.L & 139,85 & $+/-29,55$ & 142,23 & $+/-21,49$ & 132,89 & $+/-32,71$ & 144,27 & $+/-29,18$ \\
TRIGLICÉRIDOS & 96,60 & $+/-47,67$ & 111,85 & $+/-42,61$ & 87,18 & $+/-45,76$ & 98,38 & $+/-50,28$ \\
Índice Col.H.D.L & 4,12 & $+/-1,12$ & 4,86 & $+/-0,87$ & 3,76 & $+/-1,09$ & 4,12 & $+/-1,14$ \\
I.D.L - H.D.L & 2,69 & $+/-0,90$ & 3,17 & $+/-0,55$ & 2,41 & $+/-0,90$ & 2,73 & $+/-0,93$
\end{tabular}

Un $67,3 \%$ de los pacientes de la muestra presentaban cifras de colesterol alto con valores entre 200 y $275 \mathrm{mg} / \mathrm{dl}$, el $27,7 \%$ presentaban cifras dentro de la normalidad ( $<$ de $200 \mathrm{mg} / \mathrm{dl}$ ). El resto, $5 \%$ mayores de $275 \mathrm{mg} / \mathrm{dl}$. Al final del seguimiento se mantenían los porcentajes.

En la primera determinación, un 61,6\% de los pacientes tenía las cifras de LDL entre 101 y $160 \mathrm{mg} / \mathrm{dl}$, cifras mayores de $160 \mathrm{mg} / \mathrm{dl}$ las presentaban $24,2 \%$ de la muestra y menores de $100 \mathrm{mg} / \mathrm{dl}$ un $14,1 \%$. Al final del seguimiento un $73 \%$ presentaba cifras entre $101 \mathrm{y} 160 \mathrm{mg} / \mathrm{dl}$, el $20 \%$ mayor de $160 \mathrm{mg} / \mathrm{dl}$ y el resto menor de $101 \mathrm{mg} / \mathrm{dl}$.

Los triglicéridos, en la primera determinación un $86,1 \%$ tenían valores normales entre 35 y $135 \mathrm{mg} / \mathrm{dl}$, un $3 \%$ valores mayores de $201 \mathrm{mg} / \mathrm{dl}$ y el resto valores entre 166 y $200 \mathrm{mg} / \mathrm{dl}$. En la última determinación, $80,5 \%$ valores normales, $15,6 \%$ entre 136 y $200 \mathrm{mg} / \mathrm{dl}$ y el resto por encima de 200mg/dl. El 97\% del total de la muestra presenta cifras de HDL mayores de $36 \mathrm{mg} / \mathrm{dl}$ y solo un 3\% cifras bajas de HDL en la primera determinación; y en la del final 99,4\% cifras altas o normales y el resto, $0,6 \%$ bajas. 
Las modificaciones del perfil lipídico de la muestra en global indican que el colesterol disminuye un 1\%, el HDL un 3,5\%, el LDL aumenta 0,7\%, los triglicéridos disminuyen un 1\% y el índice colesterol-HDL se incrementa un 5\%. El índice LDL-HDL se mantiene sin variación. Por grupos la distribución del perfil lipídico de la muestra mostraba los datos siguientes:

Grupos

$\mathbf{0}=$ Varones

$\mathbf{1}=$ Mujeres premenopáusicas

$\mathbf{2}=$ Mujeres menopaúsicas

\section{Colesterol}

$\mathbf{1}=100-199$ (normal)

$\mathbf{2}=200-275$ (hipercolesterolemia)

$\mathbf{3}=>276$ (hipercolesterolemia severa)

\begin{tabular}{|l|crc|ccc}
\hline Colesterol & \multicolumn{3}{|c|}{$\mathbf{1}^{\mathbf{0}}$ Determinación } & \multicolumn{3}{c}{$\mathbf{2}^{\mathbf{0}}$ Determinación } \\
\hline & $\mathbf{0}$ & $\mathbf{1}$ & $\mathbf{2}$ & $\mathbf{0}$ & $\mathbf{1}$ & $\mathbf{2}$ \\
\hline$<\mathbf{2 0 0} \mathbf{m g} / \mathbf{d l}$ & $36,8 \%$ & $47 \%$ & $12,6 \%$ & $36,8 \%$ & $47 \%$ & $12,6 \%$ \\
\hline $\mathbf{2 0 0}-\mathbf{2 7 5 m g} / \mathbf{d l}$ & $63,2 \%$ & $47,1 \%$ & $83,3 \%$ & $63,2 \%$ & $47,1 \%$ & $83,3 \%$ \\
\hline$>\mathbf{2 7 6} \mathbf{m g} / \mathbf{d l}$ & $0 \%$ & $5,9 \%$ & $4,1 \%$ & $0 \%$ & $5,9 \%$ & $4,1 \%$
\end{tabular}

\section{LDL-colesterol}

\section{Grupos}

$\mathbf{0}=$ Varones

$\mathbf{1}=$ Mujeres premenopáusicas

$\mathbf{2}=$ Mujeres menopaúsicas

\section{$\underline{\mathbf{L D L}}$}

$\mathbf{1}=0-100$ (normal)

$2=101-160$ (cifras altas)

$3=>160$

\begin{tabular}{|l|ccc|ccc}
\hline LDL & \multicolumn{3}{|c|}{$\mathbf{1}^{\mathbf{0}}$ Determinación } & \multicolumn{3}{c}{$\mathbf{2}^{\mathbf{0}}$ Determinación } \\
\hline $\mathbf{0}-\mathbf{1 0 0} \mathbf{m g} / \mathbf{d l}$ & $\mathbf{0}$ & $\mathbf{1}$ & $\mathbf{2}$ & $\mathbf{0}$ & $\mathbf{1}$ & $\mathbf{2}$ \\
\hline $\mathbf{1 0 1}-\mathbf{1 6 0 m g} / \mathbf{d l}$ & $72,2 \%$ & $32,4 \%$ & $5,2 \%$ & $0 \%$ & $7,2 \%$ & $4,2 \%$ \\
\hline$>\mathbf{1 6 0} \mathbf{m g} / \mathbf{d l}$ & $22,2 \%$ & $17,6 \%$ & $29,8 \%$ & $7,7 \%$ & $21,4 \%$ & $24,3 \%$
\end{tabular}

\section{Triglicéridos}

\section{Grupos}

$\mathbf{0}=$ Varones

$\mathbf{1}=$ Mujeres premenopáusicas

$\mathbf{2}=$ Mujeres menopaúsicas

\section{Triglicéridos}

$1=35-135$ (normal)

$\mathbf{2}=136-200$ (hipertrigliceridemia)

$\mathbf{3}=>200$

\begin{tabular}{|l|ccc|ccc}
\hline Triglicéridos & \multicolumn{3}{|c|}{$\mathbf{1}^{\mathbf{0}}$ Determinación } & \multicolumn{3}{c}{$\mathbf{2}^{\mathbf{0}}$ Determinación } \\
\hline & $\mathbf{0}$ & $\mathbf{1}$ & $\mathbf{2}$ & $\mathbf{0}$ & $\mathbf{1}$ & $\mathbf{2}$ \\
\hline $\mathbf{3 5}-\mathbf{1 3 5} \mathbf{~ m g} / \mathbf{d l}$ & $72,2 \%$ & $94 \%$ & $87,5 \%$ & $66,6 \%$ & $89,3 \%$ & $78,4 \%$ \\
\hline $\mathbf{1 3 6}-\mathbf{2 0 0} \mathbf{~ m g} / \mathbf{d l}$ & $27,8 \%$ & $2,9 \%$ & $8,3 \%$ & $33,3 \%$ & $7,1 \%$ & $16,2 \%$ \\
\hline$>\mathbf{2 0 0} \mathbf{m g} / \mathbf{d l}$ & $0 \%$ & $3 \%$ & $4,2 \%$ & $0 \%$ & $3,6 \%$ & $5,4 \%$
\end{tabular}

HDL

Grupos

$\mathbf{0}=$ Varones

$1=$ Mujeres premenopáusicas

$2=$ Mujeres menopaúsicas

\section{HDL}

$\mathbf{1}=0$ - 35 (cifras bajas)

$\mathbf{2}=36-200$

\begin{tabular}{|l|ccc|ccc}
\hline HDL & \multicolumn{3}{|c|}{$\mathbf{1}^{\mathbf{0}}$ Determinación } & \multicolumn{3}{c}{$\mathbf{2}^{\mathbf{0}}$ Determinación } \\
\hline & $\mathbf{0}$ & $\mathbf{1}$ & $\mathbf{2}$ & $\mathbf{0}$ & $\mathbf{1}$ & $\mathbf{2}$ \\
\hline $\mathbf{0}-\mathbf{3 5 m g} / \mathbf{d l}$ & $11,1 \%$ & $0 \%$ & $2,1 \%$ & $7,7 \%$ & $3,6 \%$ & $5,4 \%$ \\
\hline $\mathbf{3 6}-\mathbf{2 0 0} \mathbf{~ m g} / \mathbf{d l}$ & $88,9 \%$ & $100 \%$ & $97,9 \%$ & $92,3 \%$ & $96,4 \%$ & $94,6 \%$
\end{tabular}

De los varones, un $63,2 \%$ presentaba cifras altas de colesterol, entre 200 y $275 \mathrm{mg} / \mathrm{d}$, por encima de esos valores, los varones no había ningún caso, el resto tenían valores dentro de la normalidad. Estos porcentajes se mantenían tanto al inicio como al final del seguimiento. 
Para el LDL, en la primera determinación, un 72,2\% presentaban cifras entre 101 y $160 \mathrm{mg} / \mathrm{dl}$ y un $22,2 \%$ por encima de $160 \mathrm{mg} / \mathrm{dl}$. Al final del seguimiento, un 92,3\% tenía cifras de LDL entre 101 y $160 \mathrm{mg} / \mathrm{dl}$ y el resto mayores de $160 \mathrm{mg} / \mathrm{dl}$. En cuanto a los triglicéridos, un $72,2 \%$ tenía valores dentro de la normalidad y el resto entre 136 y $200 \mathrm{mg} / \mathrm{dl}$ en la primera determinación. Al finalizar, un 66,6\% valores normales y un 33,3\% cifras entre 136 y $200 \mathrm{mg} / \mathrm{dl}$. El HDL un $88,8 \%$ presentaba cifras normales o elevadas y el resto por debajo de $35 \mathrm{mg} / \mathrm{dl}$ en el inicio. En la última determinación un 92,3\% valores normales o elevados y el resto bajos.

Presentaban en general una ligera disminución del colesterol de 0,5\% y un ascenso del LDL de $2,1 \%$, el resto de los valores del perfil lipídico se mantuvo igual.

Un colesterol por encima del umbral de normalidad con valores entre 200 y $275 \mathrm{mg} / \mathrm{dl}$ lo presentaba el $47 \%$, de las mujeres premenopaúsicas, por encima de esos valores un 5,9\%, el resto, $47,1 \%$ valores por debajo de $200 \mathrm{mg} / \mathrm{dl}$. Estos porcentajes se mantenían tanto al inicio como al finalizar el seguimiento. Para el LDL, en la primera determinación, la mitad de las mujeres premenopáusicas tenían entre 101 y $160 \mathrm{mg} / \mathrm{dl}$ y $17,6 \%$ mayores de $160 \mathrm{mg} / \mathrm{dl}$. Al final del seguimiento las mujeres premenopáusicas presentaban un $71,4 \%$ cifras entre $101 \mathrm{y}$ $160 \mathrm{mg} / \mathrm{dl}, 21,4 \%$ mayores de $160 \mathrm{mg} / \mathrm{dl}$ y el resto menores de $100 \mathrm{mg} / \mathrm{dl}$. Para los triglicéridos un $3 \%$ de ellas, presentaban valores entre 136 y $200 \mathrm{mg} / \mathrm{dl}, 3 \%$ mayores de $201 \mathrm{mg} / \mathrm{dl}$ y el resto $94 \%$, presentaban valores dentro de la normalidad. En la última determinación $89,3 \%$ valores en la normalidad y $7,1 \%$ entre 136 y $200 \mathrm{mg} / \mathrm{dl}$ y el resto mayor de $200 \mathrm{mg} / \mathrm{dl}$. Respecto al HDL todas presentaban cifras normales o elevadas en la primera determinación y en la última un $96,4 \%$ presentaba valores normales o elevados y el resto, 3,6\% cifras bajas.

En este grupo, el colesterol aumentó un 1\%, el HDL descendió un 1,7\%, el LDL un 3,1\% y los triglicéridos descendieron un 4,4\%. Los índices colesterol-HDL, y IDL-HDL sin cambios.

Las mujeres menopaúsicas, presentaban cifras de colesterol por encima de lo normal, entre 200 y $275 \mathrm{mg} / \mathrm{dl}$ un $83,3 \%$ y cifras mayores de $275 \mathrm{mg} / \mathrm{dl}$ un $4,1 \%$. Estos porcentajes se mantenían tanto al inicio como al final del seguimiento. Para el LDL, en la primera determinación, un $66 \%$ tenían valores entre 101 y $160 \mathrm{mg} / \mathrm{dl}$ y $29,8 \%$ mayores de $160 \mathrm{mg} / \mathrm{dl}$. Al final del seguimiento un 67,6\% presentaban valores entre 101 y $160 \mathrm{mg} / \mathrm{dl}, 24,3 \%$ mayores de $160 \mathrm{mg} / \mathrm{dl}$ y el resto, $4,2 \%$ menor de $101 \mathrm{mg} / \mathrm{dl}$. Los triglicéridos en la primera determinación, un $87,5 \%$ presentaban valores dentro de la normalidad (menores de $136 \mathrm{mg} / \mathrm{dl}$ ), un 4,2\% valores por encima de $200 \mathrm{mg} / \mathrm{dl}$ y el resto, $8,3 \%$ valores entre 136 y $200 \mathrm{mg} / \mathrm{dl}$ y en la última valoración un $78,4 \%$ valores normales, un $16,2 \%$ entre 136 y $200 \mathrm{mg} / \mathrm{dl}$ y $5,4 \%$ mayor de $200 \mathrm{mg} / \mathrm{dl}$. Las cifras de HDL en este grupo al inicio, un $97,9 \%$ cifras normales o altas y el resto $2,1 \%$ bajas.

En la determinación final un $94,6 \%$ las menopaúsicas presentaban valores normales o altos y el resto de porcentaje un 5,4\% presentaban valores más bajos.

Las mujeres menopaúsicas presentaron un descenso del 2,2\% en el colesterol, el HDL bajó un 6,6\% y $0,7 \%$ el LDL. Los triglicéridos, el índice colesterol-HDL y el índice IDL-HDL aumentaron sus cifras en un $2,1 \%, 7,7 \%$ y $8 \%$ respectivamente. 


\section{VALORES DE LA BIOQUÍMICA ÓSEA ESPECÍFICA. SUERO / PLASMA}

$\underline{\text { Tabla } n^{0} 10}$

INICIAL

\begin{tabular}{|c|c|c|c|c|c|c|c|c|}
\hline & \multicolumn{2}{|c|}{ Total } & \multicolumn{2}{|c|}{ Varones } & \multicolumn{2}{|c|}{ Premenopaúsia } & \multicolumn{2}{|c|}{ Menopaúsia } \\
\hline & Media & DS & Media & DS & Media & DS & Media & DS \\
\hline CALCIO & 9,47 & $+/-0,39$ & 9,61 & $+/-0,39$ & 9,47 & $+/-0,39$ & 9,68 & $+/-0,34$ \\
\hline FÓSFORO & 3,29 & $+/-0,40$ & 3,16 & $+/-0,50$ & 3,29 & $+/-0,40$ & 3,42 & $+/-0,51$ \\
\hline MAGNESIO & 1,89 & $+/-0,15$ & 2,11 & $+/-0,16$ & 1,89 & $+/-0,15$ & 1,96 & $+/-0,17$ \\
\hline FOSF. ALCALINA & 146,09 & $+/-42,19$ & 148,06 & $+/-28,76$ & 146,09 & $+/-42,19$ & 180,17 & $+/-46,51$ \\
\hline COBRE & 135,18 & $+/-25,19$ & 113,18 & $+/-15,10$ & 135,18 & $+/-25,19$ & 135,37 & $+/-32,83$ \\
\hline ZINC & 100,06 & $+/-84,64$ & 75,51 & $+/-14,78$ & 100,06 & $+/-84,64$ & 79,78 & $+/-17,83$ \\
\hline OSTEOCALCINA & 7,57 & $+/-2,16$ & 7,90 & $+/-1,75$ & 7,57 & $+/-2,16$ & 9,12 & $+/-2,60$ \\
\hline P.T.H & 49,21 & $+/-18,24$ & 49,13 & $+/-11,99$ & 49,21 & $+/-18,24$ & 72,65 & $+/-31,24$ \\
\hline FOSF. ALC. ÓSEA & 18,39 & $+/-14,70$ & 17,15 & $+/-6,70$ & 18,39 & $+/-14,70$ & 24,55 & $+/-11,22$ \\
\hline CALCIO IÓNICO & 1 & $+/-0,10$ & $1,01+/-$ & $9,20 \mathrm{E}-02$ & 1 & $+/-0,10$ & 0,99 & $+/-0,11$ \\
\hline
\end{tabular}

FINAL

\begin{tabular}{l|cc|cc|cc|cc}
\hline & \multicolumn{2}{|c|}{ Total } & \multicolumn{2}{c|}{ Varones } & \multicolumn{2}{c|}{ Premenopaúsia } & \multicolumn{2}{c}{ Menopaúsia } \\
& Media & DS & Media & DS & Media & DS & Media & DS \\
\hline CALCIO & 9,22 & $+/-0,43$ & 9,43 & $+/-0,38$ & 9,22 & $+/-0,43$ & 9,47 & $+/-0,35$ \\
FÓSFORO & 3,39 & $+/-0,46$ & 3,16 & $+/-0,39$ & 3,39 & $+/-0,46$ & 3,53 & $+/-0,53$ \\
MAGNESIO & 2,01 & $+/-0,18$ & 2,07 & $+/-0,14$ & 2,01 & $+/-0,18$ & 2,07 & $+/-0,19$ \\
FOSF. ALCALINA & 152,96 & $+/-33,92$ & 165,62 & $+/-46,76$ & 152,96 & $+/-33,92$ & 168,35 & $+/-37,67$ \\
COBRE & 144,26 & $+/-18,76$ & 109,09 & $+/-10,70$ & 144,26 & $+/-18,76$ & 200,97 & $+/-302,52$ \\
ZINC & 71,8 & $+/-15,41$ & 72,35 & $+/-25,15$ & 71,8 & $+/-15,41$ & 113,72 & $+/-141,76$ \\
OSTEOCALCINA & 7,09 & $+/-2,67$ & 7,69 & $+/-1,44$ & 7,09 & $+/-2,67$ & 10,69 & $+/-12,19$ \\
P.T.H & 61,22 & $+/-46,39$ & 48,45 & $+/-13,88$ & 61,22 & $+/-46,39$ & 82,5 & $+/-89,78$ \\
FOSF. ALC. ÓSEA & 18,16 & $+/-9,01$ & 29,33 & $+/-34,70$ & 18,16 & $+/-9,01$ & 21,76 & $+/-7,76$ \\
CALCIO IÓNICO & 1,05 & $+/-0,15$ & 0,99 & $+/-0,11$ & 1,05 & $+/-0,15$ & 1,02 & $+/-0,12$
\end{tabular}

Los valores de la bioquímica ósea en suero/plasma en la muestra en conjunto indicaron que las cifras de calcio descendieron 2,3\%, el fósforo aumentó un 2,6\%, el magnesio un 4,4\%, la fosfatasa alcalina se mantuvo igual, el cobre plasmático aumentó sus valores un 20,4\%, un $7,8 \%$ el zinc en suero, $6,4 \%$ la osteocalcina, un $14,7 \%$ aumentó sus valores la $\mathrm{PTH}$, un 2,8\% la fosfatasa alcalina ósea y un $2 \%$ el calcio iónico.

En el grupo de los varones el calcio sanguíneo disminuyó un 1,9\% sus valores, el fósforo se mantuvo igual, el magnesio disminuyó sus cifras un 1,9\%, la fosfatasa alcalina aumentó sus valores un 10,6\%, el cobre plasmático disminuyó 3,7\% también descendió un $4 \%$ el zinc en suero, un 2,7\% la osteocalcina, un 1,6\% la PTH y un $2 \%$ el calcio iónico. La fosfatasa alcalina ósea incrementó sus valores un $2,8 \%$.

En las mujeres premenopaúsicas los valores de calcio disminuyeron un 2,6\%, los de fósforo aumentaron $2,9 \%$, los de magnesio aumentaron un $6 \%$, un $4,8 \%$ los de la fosfatasa alcalina y un 6,3 aumentaron los del cobre plasmático. Las cifras de zinc en suero disminuyeron en un $29 \%$, las de osteocalcina un $6,8 \%$ y las de fosfatasa alcalina ósea un $1,1 \%$; aumentaron un 24,4\% las de PTH y un 5\% las de calcio iónico. 
Las mujeres menopaúsicas presentaron un descenso en las cifras de calcio de 2,2\%, de un $7 \%$ las de la fosfatasa alcalina y un $12,2 \%$ los valores de la fosfatasa alcalina ósea. Aumentaron las cifras de fósforo en un 3,1\%, las de magnesio un 5,3\%, el cobre plasmático y el zinc en suero en un $32,4 \%$ y $42,6 \%$ respectivamente, un $14,7 \%$ aumentó la osteocalcina, un $13,8 \%$ la PTH y un 3\% el calcio iónico.

En toda la muestra se observa una ligera hipercalcemia pero con disminución de sus valores durante el seguimiento. El calcio iónico presenta cifras dentro de lo normal con aumento de sus valores a lo largo del estudio en las mujeres y descenso en los varones pero siempre dentro del rango de normalidad. Aumentan los valores de $\mathrm{Cu}$ y $\mathrm{Mg}$ en las mujeres y descienden en los varones; con el $\mathrm{Zn}$ bajan las cifras en varones y premenopausicas y aumentan en las mujeres con menopausia.

Analítica en plasma

\begin{tabular}{|c|c|c|c|c|c|c|c|c|c|c|}
\hline & $\mathbf{C a}$ & $\mathbf{P}$ & Mg & F.A & $\mathbf{C u}$ & $\mathbf{Z n}$ & Osteo & PTH & F.A.O & $\mathbf{C a}++$ \\
\hline GLOBAL & 1 & 介 & 仓 & $=$ & 仓 & 亿 & 仓 & 介 & 仓 & 介 \\
\hline VARONES & 1 & $=$ & $\downarrow$ & 介 & $\downarrow$ & 1 & $\downarrow$ & $\downarrow$ & 介 & $\downarrow$ \\
\hline PREMENOPAÚSIA & $\downarrow$ & \} & 介 & 仓 & 亿 & $\downarrow$ & $\downarrow$ & 介 & $\downarrow$ & \} \\
\hline MENOPAÚSIA & 1 & 介 & 仓 & $\downarrow$ & 介 & 仓 & 介 & 仓 & 1 & 仓 \\
\hline
\end{tabular}

VALORES DE LA BIOQUÍMICA ÓSEA EN ORINA.

INICIO

$\underline{\text { Tabla no } 11}$

\begin{tabular}{l|cc|cc|cc|cc}
\hline & \multicolumn{2}{|c|}{ Total } & \multicolumn{2}{c|}{ Varones } & \multicolumn{2}{c|}{ Premenopaúsia } & \multicolumn{2}{c}{ Menopaúsia } \\
& Media & DS & Media & DS & Media & DS & Media & DS \\
\hline CALCIO ORINA & 13,95 & $+/-11,76$ & 14,86 & $+/-7,69$ & 17,20 & $+/-17,74$ & 11,52 & $+/-6,61$ \\
FÓSFORO ORINA & 56,99 & $+/-19,58$ & 58,88 & $+/-15,30$ & 60,74 & $+/-22$ & 53,88 & $+/-19,11$ \\
MAGNESIO ORINA & 12,39 & $+/ 27,54$ & 14,08 & $+/-31,47$ & 12,35 & $+/ 26,01$ & 11,80 & $+/-27,72$ \\
COBRE ORINA & 61,12 & $+/-66,06$ & 55,81 & $+/ 28,73$ & 55,07 & $+/-37,20$ & 67,33 & $+/-88,48$ \\
ZINC ORINA & 404,56 & $+/-402,65$ & 532,03 & $+/ 178,48$ & 349,50 & $+/-556,19$ & 395,55 & $+/-313,90$ \\
DEOXIPIRIDOLINA & 10,69 & $+/-5,51$ & 5,78 & $+/-2,18$ & 10,69 & $+/-5,51$ & 10 & $+/-4,24$
\end{tabular}

FINAL

\begin{tabular}{l|cc|cc|cc|ccc}
\hline & \multicolumn{2}{|c|}{ Total } & \multicolumn{2}{c|}{ Varones } & \multicolumn{2}{c|}{ Premenopaúsia } & \multicolumn{2}{c}{ Menopaúsia } \\
& Media & DS & Media & DS & Media & DS & \multicolumn{2}{c|}{ Media } & DS \\
\hline CALCIO ORINA & 13,25 & $+/-7,85$ & 18,71 & $+/-8,54$ & 14,48 & $+/-7,06$ & 10,43 & $+/-7,07$ \\
FÓSFORO ORINA & 54,08 & $+/-20,09$ & 63,13 & $+/-15,62$ & 59,36 & $+/-20,33$ & 47,01 & $+/-19,29$ \\
MAGNESIO ORINA & 13,03 & $+/-48,50$ & 6,58 & $+/-1,50$ & 9,36 & $+/-15,99$ & 18,32 & $+/-70,04$ \\
COBRE ORINA & 45,83 & $+/-33,38$ & 53,83 & $+/-45,77$ & 48,04 & $+/-33,04$ & 41,24 & $+/-28,52$ \\
ZINC ORINA & 417,70 & $+/-347,55$ & 433,76 & $+/-188,95$ & 374,16 & $+/-343,43$ & 440,02 & $+/-400,19$ \\
DEOXIPIRIDOLINA & 9,2 & $+/-6,21$ & 6,27 & $+/-3,18$ & 9,2 & $+/-6,21$ & 10,38 & $+/-6,96$
\end{tabular}

Cuando comparamos los resultados de la bioquímica ósea en orina, en la muestra, entre el inicio y el final del seguimiento, los resultados que se han observado reflejan que la pérdida de calcio desciende un $5 \%$, la de fósforo un $5,1 \%$ y la de cobre de un $25 \%$. 
El magnesio y el cinc, aumentan su eliminación por orina un $5 \%$ y un $2,5 \%$ respectivamente. La deoxipiridolina disminuyó un 2,1\% su eliminación.

En los varones aumentan las pérdidas de calcio en un 16,1\%, de fósforo un $6,8 \%$ y disminuye la eliminación de magnesio un $53,3 \%$, de cobre un 3,6\% y de cinc un $18,6 \%$. La deoxipiridolina aumentó su eliminación $8,6 \%$.

En las premenopáusicas disminuye la eliminación de calcio en un 15,8\%, el fósforo baja su eliminación un 2,5\%, un 24,2\% el magnesio y un $12,8 \%$ en el cobre. El zinc aumenta su eliminación un 6,6\%. La deoxipiridolina presenta disminuída su eliminación un 13,1\%

En el grupo de mujeres menopaúsicas, al comparar los resultados al inicio con el final del seguimiento, se observa una disminución en la eliminación de calcio en un 9,5\%, el fósforo $17,7 \%$ y el cobre $38,6 \%$ y ha aumentado la eliminación de magnesio un $35,6 \%$ y un $10,2 \%$ la eliminación de zinc. La deoxipiridolina aumentó un 4\% su eliminación.

Respecto a las determinaciones en orina aumentan las pérdidas de $\mathrm{Cu}$ en todos los grupos. Ca y P aumentan su eliminación en las mujeres y en la muestra global y bajan las pérdidas en los varones, respecto al $\mathrm{Zn}$, aumentan las pérdidas por orina en varones y disminuyen en la muestra en global y en las mujeres; el $\mathrm{Mg}$ aumenta su eliminación en varones y premenopáusicas y disminuye en la muestra en global y en menopáusicas. Las pérdidas de deoxipiridolina son más altas en la muestra en global y las mujeres premenopáusicas; pérdidas menores en varones y menopáusicas.

Mayor calciuria presentaron los varones pero no estaban asociadas a incremento de remodelado óseo como reflejaron otros trabajos donde una mayor eliminación de calcio en orina se asociaba a un aumento del remodelado óseo. (340,341).

Analítica orina

\begin{tabular}{|c|c|c|c|c|c|c|}
\hline & $\mathrm{Ca}$ & $\mathbf{P}$ & $\mathbf{C u}$ & $\mathbf{M g}$ & $\mathbf{Z n}$ & Deoxipidolina \\
\hline GLOBAL & $\widehat{\imath}$ & 亿 & 介 & $\downarrow$ & $\downarrow$ & 个 \\
\hline VARONES & $\downarrow$ & $\downarrow$ & 介 & 亿 & 亿 & $\downarrow$ \\
\hline PREMENOPAÚSIA & 亿 & \} & 仓 & 仓 & $\downarrow$ & 仓 \\
\hline MENOPAUSIA & Ð & 亿 & 仓 & 1 & $\downarrow$ & 1 \\
\hline
\end{tabular}




\section{MUJERES PREMENOPÁUSICAS Y MENOPAÚSICAS.}

$\underline{\text { Tabla no } 12}$

\begin{tabular}{l|cc|cc}
\hline Mujeres & \multicolumn{2}{|c|}{ Inicio } & \multicolumn{2}{c}{ Fin } \\
& MEDIA & D.S & MEDIA & D.S \\
\hline EDAD & 53,65 & $+/-11,44$ & 55,38 & $+/-11,57$ \\
PESO & 80,30 & $+/-13,53$ & 78,23 & $+/-14,09$ \\
I.M.C. & 33,10 & $+/-5,74$ & 32,26 & $+/-5,80$ \\
I.C.C. & 0,829 & $+/-6,30 \mathrm{E}-02$ & 0,825 & $+/-7,23 \mathrm{E}-02$
\end{tabular}

Consideradas en global, las mujeres presentaron una disminución en los valores del peso de un 2,6\%, el I.M.C disminuyó un 3\% y el I.C.C presentó un descenso de un 1,2\%.

VALORES DE PARÁMETROS ANALÍTICOS.

$\underline{\text { Tabla n }} \mathbf{n}^{0}$

\begin{tabular}{l|ll|ll}
\hline Mujeres & \multicolumn{2}{|c|}{ Inicio } & \multicolumn{2}{c}{ Fin } \\
& MEDIA & DS & MEDIA & DS \\
\hline GLUCOSA & 94,76 & $+/-12,04$ & 97,13 & $+/-20,45$ \\
UREA & 34,35 & $+/-11,23$ & 34,63 & $+/-9,80$ \\
CREATININA & 0,87 & $+/-0,13$ & 0,93 & $+/-0,14$ \\
Á. ÚRICO & 5,076 & $+/-1,12$ & 5,10 & $+/-1,29$ \\
SODIO & 139,95 & $+/-2,57$ & 139,82 & $+/-3,61$ \\
POTASIO & 4,311 & $+/-0,31$ & 4,37 & $+/-0,34$ \\
PROTEÍNAS T. & 6,99 & $+/-0,39$ & 6,93 & $+/-0,37$ \\
ALBÚMINA & 4,05 & $+/-0,28$ & 3,99 & $+/-0,23$ \\
OSMOLARIDAD & 280,90 & $+/-5,61$ & 280,10 & $+/-6,88$ \\
V.S.G & 16,74 & $+/-8,79$ & 19,43 & $+/-10,66$
\end{tabular}

Las mujeres presentaron un descenso de un $1 \%$ en las proteínas totales y un $1,5 \%$ en la albúmina. La glucosa incrementó sus cifras un 3,2\%, la creatinina un 6,8\%, el ácido úrico un $2 \%$ y la VSG incrementó su valor un $18 \%$ respecto de la determinación inicial.

VALORES DEL PREFIL LIPÍDICO.

$\underline{\text { Tabla n }}{ }^{0} 14$

\begin{tabular}{l|cc|cc}
\hline Mujeres & \multicolumn{2}{|c|}{ Inicio } & \multicolumn{2}{c}{ Fin } \\
& MEDIA & DS & MEDIA & DS \\
\hline COLESTEROL & 216,71 & $+/-34,78$ & 214,38 & $+/-33,66$ \\
H.D.L & 59,51 & $+/-12,01$ & 56,29 & $+/-11,32$ \\
L.D.L & 138,33 & $+/-31,71$ & 139,37 & $+/-31,03$ \\
TRIGLICÉRIDOS & 94,43 & $+/-61,25$ & 93,55 & $+/-48,34$ \\
Índice Col.H.D.L & 3,78 & $+/-0,97$ & 3,97 & $+/-1,11$ \\
I.D.L - H.D.L & 2,50 & $+/-0,91$ & 2,60 & $+/-0,93$
\end{tabular}

El perfil lipídico mostró un descenso de las cifras de colesterol de un 1,1\% y de un 5\% el HDL. Incrementó su valor un $0,7 \%$ el LDL, subió $1 \%$ los triglicéridos y de un 5,3\% y un $4 \%$ respectivamente los índices de colesterol-HDL y de IDL-HDL. 
VALORES DE LA BIOQUÍMICA ÓSEA. SUERO / PLASMA

Tabla no 15

\begin{tabular}{l|lr|lr}
\hline Mujeres & \multicolumn{2}{|c|}{ Inicio } & \multicolumn{2}{c}{ Final } \\
& MEDIA & DS & MEDIA & \multicolumn{1}{c}{ DS } \\
\hline CALCIO & 9,59 & $+/-0,37$ & 9,37 & $+/-0,40$ \\
FÓSFORO & 3,36 & $+/-0,47$ & 3,47 & $+/-0,50$ \\
MAGNESIO & 1,93 & $+/-0,16$ & 2,04 & $+/-0,19$ \\
FOSF. ALCALINA & 165,86 & $+/-47,59$ & 162,00 & $+/-36,69$ \\
COBRE & 135,30 & $+/-29,85$ & 176,07 & $+/-228,31$ \\
ZINC & 87,99 & $+/-55,99$ & 96,67 & $+/-110,93$ \\
OSTEOCALCINA & 8,45 & $+/-2,52$ & 9,15 & $+/-9,51$ \\
P.T.H & 62,91 & $+/-28,91$ & 73,54 & $+/-74,85$ \\
FOSF. ALC. ÓSEA & 21,99 & $+/-15,22$ & 20,22 & $+/-8,44$ \\
CALCIO IÓNICO & 1,00 & $+/-0,11$ & 1,03 & $+/-0,13$
\end{tabular}

Al comprobar los resultados se observó un descenso en los valores de calcio de un 2,3\%, un aumento de los de fósforo de 3,1\%, un aumento de las cifras de magnesio de 5,4\%, una disminución de las de fosfatasa alcalina de $2,4 \%$, un aumento de las de cobre en plasma y de zinc en suero de 40,7\% el primero y de 10,2 el segundo. La osteocalcina aumentó un 7,6\%, un 15,9\% la PTH y un 3\% el calcio iónico. La fosfatasa alcalina ósea disminuyó un 7,7\% sus cifras al valorar ambas densitometrías.

VALORES DE LA BIOQUÍMICA ÓSEA EN ORINA.

\begin{tabular}{l|cc|cc}
\hline Mujeres & \multicolumn{2}{|c}{ Inicio } & \multicolumn{2}{c}{ Tabla n 16 } \\
& MEDIA & DS & MEDIA & DS \\
\hline CALCIO ORINA & 13,67 & $+/-12,48$ & 12,14 & $+/-7,29$ \\
FÓSFORO ORINA & 56,59 & $+/-20,44$ & 52,24 & $+/-20,51$ \\
MAGNESIO ORINA & 12,03 & $+/-26,85$ & 14,34 & $+/-53,34$ \\
COBRE ORINA & 62,25 & $+/-71,67$ & 44,17 & $+/-30,46$ \\
ZINC ORINA & 376,63 & $+/-432,57$ & 410,62 & $+/-374,05$ \\
DEOXIPIRIDOLINA & 10,28 & $+/-4,77$ & 9,87 & $+/-6,62$
\end{tabular}

El grupo de las mujeres en conjunto disminuyó la eliminación de calcio un $11,8 \%$, el fósforo $7,7 \%$ y el cobre $29 \%$ y aumentaron la eliminación de magnesio en un $16,4 \%$ y un 8,3\% la de zinc. La deoxipiridolina disminuyó un 3,9\% su eliminación.

\section{EDAD DE MENARQUIA DE LAS MUJERES DE LA MUESTRA}

\begin{tabular}{|c|c|c|c|c|c|c|}
\hline \multirow{2}{*}{$\begin{array}{l}\text { Edad } \\
\text { (años) }\end{array}$} & \multicolumn{2}{|c|}{ Premenopáusia } & \multicolumn{2}{|c|}{ Menopausia } & \multicolumn{2}{|l|}{ Total } \\
\hline & $\mathbf{N}=\mathbf{3 4}$ & $\%$ & $\mathrm{~N}=48$ & $\%$ & $\mathbf{N}=82$ & $\%$ \\
\hline 9 & $1 / 34$ & $2,9 \%$ & $0 / 48$ & $0 \%$ & $1 / 82$ & $1,2 \%$ \\
\hline 10 & $4 / 34$ & $11,8 \%$ & $1 / 48$ & $2,1 \%$ & $5 / 82$ & $6,1 \%$ \\
\hline 11 & $10 / 34$ & $29,4 \%$ & $6 / 48$ & $12,5 \%$ & $16 / 82$ & $19,5 \%$ \\
\hline 12 & $8 / 34$ & $23,5 \%$ & $11 / 48$ & $22,9 \%$ & $19 / 82$ & $23,2 \%$ \\
\hline 13 & $4 / 34$ & $11,8 \%$ & $12 / 48$ & $25 \%$ & $16 / 82$ & $19,5 \%$ \\
\hline 14 & $6 / 34$ & $17,6 \%$ & $9 / 48$ & $18,7 \%$ & $15 / 82$ & $18,3 \%$ \\
\hline 15 & $1 / 34$ & $2,6 \%$ & $4 / 48$ & $8,3 \%$ & $5 / 82$ & $6,1 \%$ \\
\hline 16 & $0 / 34$ & $0 \%$ & $1 / 48$ & $2,1 \%$ & $1 / 82$ & $1,2 \%$ \\
\hline 17 & $0 / 34$ & $0 \%$ & $2 / 48$ & $2,1 \%$ & $2 / 82$ & $2,4 \%$ \\
\hline 18 & $0 / 34$ & $0 \%$ & $2 / 48$ & $4,2 \%$ & $2 / 82$ & $2,4 \%$ \\
\hline
\end{tabular}

La edad más frecuente de menarquia fueron los 12 años en global. 
Por grupos, en las mujeres pre menopáusicas la edad más frecuente de aparición de la menarquia fueron los 11 años y en las menopáusicas, la edad más frecuente son los 13 años.

\section{AÑOS DE VIDA FÉRTIL}

\begin{tabular}{|c|c|}
\hline Años & $\mathbf{\%}$ \\
\hline $20-27$ & 10,9 \\
\hline $28-35$ & 18,7 \\
\hline $36-42$ & 29,2 \\
\hline $\begin{array}{c}\text { Total } \\
48\end{array}$ & 58,5 \\
\hline
\end{tabular}

Un $20 \%$ de las mujeres de la muestra presentaron 36 y 37 años de vida fértil. El rango más amplio de años de vida fértil en frecuencia fue entre 34 y 39 años. (40\%)

\section{NÚMERO DE HIJOS QUE TIENEN LAS MUJERES DE LA MUESTRA}

\begin{tabular}{|c|c|c|c|c|c|c|}
\hline \multirow[t]{2}{*}{$N^{0}$ de hijos } & \multicolumn{2}{|c|}{ Premenopáusia \% } & \multicolumn{2}{|c|}{ Menopausia $\%$} & \multirow{2}{*}{$\begin{array}{l}\text { Total } \\
\mathrm{N}=82\end{array}$} & \multirow{2}{*}{$\begin{array}{c}\mathbf{\%} \\
100 \%\end{array}$} \\
\hline & $\mathrm{N}=34$ & $41,5 \%$ & $\mathrm{~N}=48$ & $58,5 \%$ & & \\
\hline $\mathbf{0}$ & $8 / 34$ & $23,5 \%$ & $10 / 48$ & $20,8 \%$ & $19 / 82$ & $23,2 \%$ \\
\hline 1 & $1 / 34$ & $2,9 \%$ & $2 / 48$ & $4,2 \%$ & $3 / 82$ & $3,6 \%$ \\
\hline 2 & $15 / 34$ & $44,1 \%$ & $10 / 48$ & $20,8 \%$ & $24 / 8$ & $29,3 \%$ \\
\hline 3 & $7 / 34$ & $20,6 \%$ & $13 / 48$ & $27,1 \%$ & $20 / 82$ & $29,3 \%$ \\
\hline 4 & $2 / 34$ & $5,9 \%$ & $4 / 48$ & $8,3 \%$ & $6 / 82$ & $7,3 \%$ \\
\hline 5 & $0 / 34$ & $0 \%$ & $4 / 48$ & $8,3 \%$ & $4 / 82$ & $4,9 \%$ \\
\hline 6 & $0 / 34$ & $0 \%$ & $2 / 48$ & $4,2 \%$ & $2 / 82$ & $2,4 \%$ \\
\hline 7 & $1 / 34$ & $2,9 \%$ & $1 / 48$ & $2,1 \%$ & $2 / 82$ & $2,4 \%$ \\
\hline 8 & $0 / 34$ & $0 \%$ & $1 / 48$ & $2,1 \%$ & $1 / 82$ & $1,2 \%$ \\
\hline 9 & $0 / 3$ & $0 \%$ & $0 / 48$ & $0 \%$ & $0 / 82$ & $0 \%$ \\
\hline 10 & 04 & $0 \%$ & $1 / 48$ & $2,1 \%$ & $1 / 82$ & $1,2 \%$ \\
\hline
\end{tabular}

La mayoría de las mujeres tienen 2 y 3 hijos con igual porcentaje (29,3\%). Por grupos, las mujeres premenopáusicas, lo más frecuente 2 hijos, (44,1\%) y las menopáusicas la mayoría tienen 3 hijos $(27,1 \%)$. Un alto porcentaje de las mujeres no tienen hijos. (25\% en cada grupo)

\section{EDAD DE MENOPAUSIA}

\begin{tabular}{|lcrl}
\hline Edad & $\mathbf{N}=\mathbf{4 8}$ & $\mathbf{\%}$ & Menopausia \\
& & & \\
\hline $\mathbf{2 9}$ & $1 / 48$ & 2,1 & Quirúrgica \\
$\mathbf{3 9}$ & $1 / 48$ & 2,1 & Quirúrgica \\
$\mathbf{4 0}$ & $3 / 48$ & 6,2 & 1Qgica y 2 Fisiológica \\
$\mathbf{4 1}$ & $0 / 48$ & 0 & Fisiológica \\
$\mathbf{4 2}$ & $3 / 48$ & 6,2 & 1Qgica y 2 Fisiológica \\
$\mathbf{4 3}$ & $4 / 48$ & 8,3 & Fisiológica \\
$\mathbf{4 4}$ & $2 / 48$ & 4,2 & Quirúrgica \\
$\mathbf{4 5}$ & $2 / 48$ & 4,2 & Fisiológica \\
$\mathbf{4 6}$ & $2 / 48$ & 4,2 & Fisiológica \\
$\mathbf{4 7}$ & $2 / 48$ & 4,2 & Fisiológica \\
$\mathbf{4 8}$ & $2 / 48$ & 4,2 & Fisiológica \\
$\mathbf{4 9}$ & $4 / 48$ & 8,3 & Fisiológica \\
$\mathbf{5 0}$ & $12 / 48$ & 25 & Fisiológica \\
$\mathbf{5 1}$ & $3 / 48$ & 6,4 & Fisiológica \\
$\mathbf{5 2}$ & $5 / 48$ & 10,4 & Fisiológica \\
$\mathbf{5 3}$ & $1 / 48$ & 2,1 & Fisiológica \\
$\mathbf{5 4}$ & $1 / 48$ & 2,1 & Fisiológica \\
& & & \\
\end{tabular}


Un 10,4\% de las mujeres presentaron menopausia quirúrgica.

La edad más temprana de aparición de la menopausia fue 29 años, quirúrgica y después 39 y 42 años también quirúrgicas.

La edad más frecuente de aparición de la menopausia fueron los 50 años con un $25 \%$. Rango de edad más frecuente entre 49 y 52 años. Todos los casos fisiológicos.

\section{PERFIL LIPÍDICO SEGÚN EL I.M.C.}

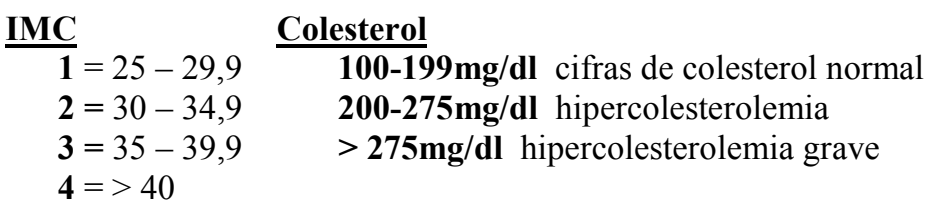

\begin{tabular}{|c|c|c|c|c|c|c|}
\hline Colesterol & \multicolumn{2}{|c|}{$100-199 \mathrm{mg} / \mathrm{dl}$} & \multicolumn{2}{|c|}{$200-275 \mathrm{mg} / \mathrm{dl}$} & \multicolumn{2}{|c|}{$>276 \mathrm{mg} / \mathrm{dl}$} \\
\hline & Inicio & Final & Inicio & Final & Inicio & Final \\
\hline IMC & & & & & & \\
\hline Sobrepeso & $38,5 \%$ & $36,7 \%$ & $53,8 \%$ & $60 \%$ & $7,7 \%$ & $3,3 \%$ \\
\hline Obesidad tipo I & $21,2 \%$ & $40 \%$ & $75,8 \%$ & $60 \%$ & $3 \%$ & $0 \%$ \\
\hline Obesidad tipo II & $28,6 \%$ & $18,2 \%$ & $71,4 \%$ & $72,7 \%$ & $0 \%$ & $9,1 \%$ \\
\hline Obesidad mórbida & $20 \%$ & $25 \%$ & $80 \%$ & $75 \%$ & $0 \%$ & $0 \%$ \\
\hline
\end{tabular}

\section{$\underline{\text { IMC }}$}

$\underline{\mathbf{1}=25}-29,9$

$2=30-34,9$

$\mathbf{3}=35-39,9$

$4=>40$
$\underline{\mathbf{L D L}}$

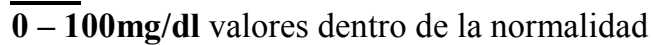

$101-160 \mathrm{mg} / \mathrm{dl}$ valores altos

$>160 \mathrm{mg} / \mathrm{dl}$ elevación grave de los valores

\begin{tabular}{|c|c|c|c|c|c|c|}
\hline LDL & \multicolumn{2}{|c|}{$0-100 \mathrm{mg} / \mathrm{dl} / \mathrm{dl}$} & \multicolumn{2}{|c|}{$101-160 \mathrm{mg} / \mathrm{dl}$} & \multicolumn{2}{|c|}{$>160 \mathrm{mg} / \mathrm{dl}$} \\
\hline & Inicio & Final & Inicio & Final & Inicio & Final \\
\hline \multicolumn{7}{|l|}{ IMC } \\
\hline Sobrepeso & $20,5 \%$ & $10 \%$ & $64,1 \%$ & $76,7 \%$ & $15,4 \%$ & $13,3 \%$ \\
\hline Obesidad tipo I & $9,1 \%$ & $8 \%$ & $63,6 \%$ & $68 \%$ & $27,3 \%$ & $24 \%$ \\
\hline Obesidad tipo II & $16,7 \%$ & $0 \%$ & $41,7 \%$ & $63,6 \%$ & $41,7 \%$ & $36,4 \%$ \\
\hline Obesidad mórbida & $6,7 \%$ & $0 \%$ & $66,7 \%$ & $83,3 \%$ & 26,7 & $16,7 \%$ \\
\hline
\end{tabular}

\section{$\underline{\text { IMC }}$}

$$
\begin{aligned}
& \frac{\mathbf{1}=25}{\mathbf{1}}-29,9 \\
& \mathbf{2}=30-34,5 \\
& \mathbf{3}=35-39,9 \\
& \mathbf{4}=>40
\end{aligned}
$$

\section{Triglicéridos}

\begin{tabular}{|c|c|c|c|c|}
\hline TG & $35-135 \mathrm{mg} / \mathrm{dl}$ & $136-200 \mathrm{mg} / \mathrm{dl}$ & \multicolumn{2}{|c|}{$>200 \mathrm{mg} / \mathrm{dl}$} \\
\hline & Inicio $\quad$ Final & Inicio $\quad$ Final & Inicio & Final \\
\hline IMC & & & & \\
\hline Sobrepeso & $84,6 \%$ & $10,3 \%$ & $2,6 \%$ & $3,4 \%$ \\
\hline Obesidad tipo I & $90,9 \%$ & $6,1 \%$ & $3 \%$ & $0 \%$ \\
\hline Obesidad tipo II & $84,6 \%$ & $7,7 \% \quad 36,4 \%$ & $7,7 \%$ & $9,1 \%$ \\
\hline Obesidad mórbida & $86,7 \% \quad 91,7 \%$ & $13,3 \% \quad 0 \%$ & $0 \%$ & $8,3 \%$ \\
\hline
\end{tabular}

35-135mg/dl valores dentro de la normalidad

$136-200 \mathrm{mg} / \mathrm{dl}$ hipertrigliceridemia

$>\mathbf{2 0 0} \mathbf{m g} / \mathbf{d l}$ hipertrigliceridemia grave

$$
\begin{aligned}
& \frac{\text { IMC }}{\mathbf{1}=25-29,9} \\
& \mathbf{2}=30-34,5 \\
& \mathbf{3}=35-39,9 \\
& \mathbf{4}=>40
\end{aligned}
$$

HDL

0-35 $\mathrm{mg} / \mathbf{d l}$ valores dentro de la normalidad

$>\mathbf{3 5 m g} / \mathbf{d l}$ valores elevados 


\begin{tabular}{|c|c|c|c|c|}
\hline HDL & \multicolumn{2}{|c|}{$100-199 \mathrm{mg} / \mathrm{dl}$} & \multicolumn{2}{|c|}{$200-275 \mathrm{mg} / \mathrm{dl}$} \\
\hline & \multirow{2}{*}{\multicolumn{2}{|c|}{ Inicio $\quad$ Final }} & \multirow[t]{2}{*}{ Inicio } & \multirow[t]{2}{*}{ Final } \\
\hline IMC & & & & \\
\hline Sobrepeso & $97,4 \%$ & $0 \%$ & $2,6 \%$ & $100 \%$ \\
\hline Obesidad tipo I & $3,1 \%$ & $8 \%$ & $96,9 \%$ & $92 \%$ \\
\hline Obesidad tipo II & $7,7 \%$ & $9,1 \%$ & $92,3 \%$ & $90,9 \%$ \\
\hline Obesidad mórbida & $0 \%$ & $8,3 \%$ & $100 \%$ & $91,7 \%$ \\
\hline
\end{tabular}

\section{PERFIL LIPÍDICO SEGÚN LA EDAD}

EDAD $\quad \underline{\text { Colesterol }}$

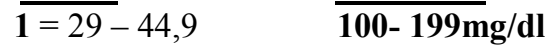

$\mathbf{3}=>65 \quad \mathbf{2 0 0}-\mathbf{2 7 5} \mathbf{~ m g} / \mathrm{dl}$

$\mathbf{2}=45-64,9 \quad>276 \mathbf{m g} / \mathbf{d l}$

\begin{tabular}{|c|c|c|c|c|c|c|}
\hline Colesterol & \multicolumn{2}{|c|}{$100-199 \mathrm{mg} / \mathrm{dl}$} & \multicolumn{2}{|c|}{$200-275 \mathrm{mg} / \mathrm{dl}$} & \multicolumn{2}{|c|}{$>276 \mathrm{mg} / \mathrm{dl}$} \\
\hline & \multirow{2}{*}{ Inicio } & \multirow{2}{*}{ Final } & \multirow{2}{*}{ Inicio } & \multirow{2}{*}{ Final } & \multirow{2}{*}{ Inicio } & \multirow{2}{*}{ Final } \\
\hline EDAD & & & & & & \\
\hline $29-44,9$ & $48,3 \%$ & $50 \%$ & $48,3 \%$ & $50 \%$ & $3,4 \%$ & $0 \%$ \\
\hline $45-64,9$ & $20 \%$ & $23,1 \%$ & $74 \%$ & $71,8 \%$ & $2 \%$ & $5,1 \%$ \\
\hline$>65$ & $22,7 \%$ & $36,8 \%$ & $77,3 \%$ & $63,2 \%$ & $0 \%$ & $0 \%$ \\
\hline
\end{tabular}

\section{EDAD $\quad$ LDL}

$\mathbf{1}=29-44,9 \quad \overline{\mathbf{0}-\mathbf{1 0 0}} \mathbf{m g} / \mathbf{d l}$

$3=>65 \quad \mathbf{1 0 1}-\mathbf{1 6 0} \mathbf{m g} / \mathbf{d l}$

$2=45-64,9 \quad>160 \mathrm{mg} / \mathbf{d l}$

\begin{tabular}{|c|c|c|c|c|c|}
\hline LDL & 0 - 100mg/dl & \multicolumn{2}{|c|}{$101-160 \mathrm{mg} / \mathrm{dl}$} & \multicolumn{2}{|c|}{$>160 \mathrm{mg} / \mathrm{dl}$} \\
\hline & Inicio Final & Inicio & Final & Inicio & Final \\
\hline EDAD & & & & & \\
\hline $29-44,9$ & $28,6 \%$ & $46,4 \%$ & $80 \%$ & $25 \%$ & $15 \%$ \\
\hline $45-64,9$ & $7,7 \%$ & $70 \%$ & $69,2 \%$ & $22 \%$ & $23,1 \%$ \\
\hline$>65$ & $9,5 \%$ & $61,9 \%$ & $73,7 \%$ & $28,6 \%$ & $21 \%$ \\
\hline
\end{tabular}

EDAD

$1=29-44,9$

$2=45-64,9$

$3=>65$
TG

$35-135 \mathrm{mg} / \mathrm{dl}$

$136-200 \mathrm{mg} / \mathrm{dl}$

$>200 \mathrm{mg} / \mathrm{dl}$

\begin{tabular}{|c|c|c|c|c|c|c|}
\hline TG & \multicolumn{2}{|c|}{$35-135 \mathrm{mg} / \mathrm{dl}$} & \multicolumn{2}{|c|}{$136-200 \mathrm{mg} / \mathrm{dl}$} & \multicolumn{2}{|c|}{$>200 \mathrm{mg} / \mathrm{dl}$} \\
\hline & Inicio & Final & Inicio & Final & Inicio & Final \\
\hline EDAD & & & & & & \\
\hline $29-44,9$ & $85,7 \%$ & $80 \%$ & $14,3 \%$ & $20 \%$ & $0 \%$ & $0 \%$ \\
\hline $45-64,9$ & $90 \%$ & $84,6 \%$ & $6 \%$ & $10,3 \%$ & $4 \%$ & $5,1 \%$ \\
\hline$>65$ & $81,8 \%$ & $72,2 \%$ & $13,6 \%$ & $22,2 \%$ & $4,5 \%$ & $5,6 \%$ \\
\hline
\end{tabular}

$\begin{array}{lc}\frac{\text { EDAD }}{\mathbf{1}=29-44,9} & \frac{\text { HDL }}{\mathbf{0}-\mathbf{3 5 m g} / \mathbf{d l}} \\ \mathbf{2}=45-64,9 & >\mathbf{3 5 m g} / \mathbf{d l} \\ \mathbf{2}=>65 & \end{array}$

\begin{tabular}{l|lc|lc}
\hline HDL & \multicolumn{2}{|c|}{$\mathbf{0}-\mathbf{3 5 m g} / \mathbf{d l}$} & \multicolumn{2}{c}{$>\mathbf{3 5 m g} / \mathbf{d l}$} \\
\cline { 1 - 4 } EDAD & \multicolumn{2}{|c|}{ Inicio } & Final & \multicolumn{2}{|c}{ Inicio } & Final \\
\cline { 1 - 4 } $\mathbf{2 9}-\mathbf{4 4 , 9}$ & $3,6 \%$ & $10 \%$ & $96,4 \%$ & $90 \%$ \\
\hline $\mathbf{4 5}-\mathbf{6 4 , 9}$ & $2 \%$ & $0 \%$ & $98 \%$ & $100 \%$ \\
\hline$>\mathbf{6 5}$ & $5 \%$ & $11,8 \%$ & $95 \%$ & $82,2 \%$
\end{tabular}


Puesto que hay una relación directa entre la edad y el perfil lipídico, a mayor edad los valores de HDL son más bajos y aumentan el resto de los lípidos. Se clasificó la muestra en tres grupos de edad y los resultados obtenidos fueron los siguientes: según el grupo de edad, al inicio del seguimiento, en el grupo más joven, el 50\% presenta valores de colesterol dentro de la normalidad y el otro $50 \%$ tenía sus cifras entre 200 y $275 \mathrm{mg} / \mathrm{dl}$, el grupo de mediana edad, la mayoría de ellos, el $71,8 \%$ presenta cifras de colesterol entre 200 y $275 \mathrm{mg} / \mathrm{dl}$, el $23 \%$ entre 100 y $199 \mathrm{mg} / \mathrm{dl}$, el resto, 5,2\% mayores de $279 \mathrm{mg} / \mathrm{dl}$. El grupo de más edad, entre 65 y 80 años, un $63,2 \%$ presentabas cifras entre 200 y $275 \mathrm{mg} / \mathrm{dl}$ y el resto $36,8 \%$ entre 100 y $199 \mathrm{mg} / \mathrm{dl}$. En la segunda valoración los porcentajes se mantenían más o menos igual.

Para el LDL en primera determinación el grupo de menos edad presentaba un 46,3\% valores de LDL entre 101 y $160 \mathrm{mg} / \mathrm{dl}$, un $28,6 \%$ entre 0 y $100 \mathrm{mg} / \mathrm{dl}$ y el $25 \%$ restante mayor de $160 \mathrm{mg} / \mathrm{dl}$. En el segundo grupo de edad un $70 \%$ tenía sus valores entre 101 y $160 \mathrm{mg} / \mathrm{dl}$, el $22 \%$ mayor de $160 \mathrm{mg} / \mathrm{dl}$ y el resto entre 0 y $100 \mathrm{mg} / \mathrm{dl}$. En el grupo de mayor edad un $60,9 \%$ tenía cifras entre 101 y $160 \mathrm{mg} / \mathrm{dl}$, un $28,6 \%$ mayores de $160 \mathrm{mg} / \mathrm{dl}$ y el resto entre 0 y $100 \mathrm{mg} / \mathrm{dl}$. En la $2^{\circ}$ determinación el grupo de menor edad presentaba un $80 \%$ cifras entre 101 y $160 \mathrm{mg} / \mathrm{dl}$, el $15 \%$ cifras mayores de $160 \mathrm{mg} / \mathrm{dl}$ y el resto entre 0 y $100 \mathrm{mg} / \mathrm{dl}$. El grupo de edad media, un $69,2 \%$ reflejaba valores entre 101 y $160 \mathrm{mg} / \mathrm{dl}$, el $23 \%$ mayor de $160 \mathrm{mg} / \mathrm{dl}$ y el resto entre 0 y $100 \mathrm{mg} / \mathrm{dl}$. El grupo de más edad presentaba un $73,7 \%$ cifras entre 101 y $160 \mathrm{mg} / \mathrm{dl}$, un $21 \%$ mayor de $160 \mathrm{mg} / \mathrm{dl}$.

Para los triglicéridos el primer grupo de edad tiene un $85,7 \%$ valores entre $35 \mathrm{y}$ $135 \mathrm{mg} / \mathrm{dl}$ y el resto $14,3 \%$ entre 136 y $200 \mathrm{mg} / \mathrm{dl}$. El grupo de edad intermedia presentaba un $90 \%$ valores entre 35 y $135 \mathrm{mg} / \mathrm{dl}, 6 \%$ entre 136 y $200 \mathrm{mg} / \mathrm{dl}$ y un $4 \%$ mayores de $200 \mathrm{mg} / \mathrm{dl}$. El grupo de más edad un $81,8 \%$ entre 35 y $135 \mathrm{mg} / \mathrm{dl}$, un $13,6 \%$ entre 136 y $200 \mathrm{mg} / \mathrm{dl}$ y el resto mayor de $200 \mathrm{mg} / \mathrm{dl}$. En la tercera determinación el grupo de menos edad tiene un $805 \%$ valores entre 35 y $135 \mathrm{mg} / \mathrm{dl}$ y el resto entre 136 y $200 \mathrm{mg} / \mathrm{dl}$. El grupo del medio 84,6\%, cifras entre 35 y $135 \mathrm{mg} / \mathrm{dl}$, el $10,2 \%$ entre 136 y $200 \mathrm{mg} / \mathrm{dl}$ y el resto $5,2 \%$ mayores de $200 \mathrm{mg} / \mathrm{dl}$. El grupo de más edad tiene un $72,2 \%$ entre 35 y $135 \mathrm{mg} / \mathrm{dl}$, un $22,2 \%$ entre 136 y $200 \mathrm{mg} / \mathrm{dl}$ y el resto un $5,6 \%$ mayor de $200 \mathrm{mg} / \mathrm{dl}$.

Para el HDL en el grupo de menos edad en la determinación inicial, sólo un 3,7\% tiene cifras bajas de HDL el resto por encima de los valores mínimos de normalidad, en el grupo de edad media un $2 \%$ presenta cifras bajas y un $4,8 \%$ en el de más edad. En la $2^{\circ}$ determinación el grupo más joven presentaba un $10 \%$ cifras bajas de HDL y un $90 \%$ por encima del valor mínimo normal, en el grupo de media edad todos tenían los valores por encima del mínimo y en el grupo de más edad un $89 \%$ tenía los valores altos y el resto bajos.

Con estos resultados, en nuestra muestra, el grupo de edad con cifras más elevadas de colesterol total corresponde al grupo de edades comprendidas entre los 44,9 -64,9 años (coincide con grupo de edad con mayor riesgo cardiovascular según los estudios realizados en este ámbito). 
Respecto al LDL, también es este grupo el presenta el mayor porcentaje de pacientes con cifras entre $101-160 \mathrm{mg} / \mathrm{dl}$ pero es el grupo de mayor edad el que presenta los valores más altos aunque también, los que presentan mejorías más notables en sus valores con las medidas higiénico-dietéticas que se prescribieron. En cuanto a los triglicéridos son similares los resultados entre los dos grupos de más edad, aunque algo peor en el grupo de edades más avanzadas, pero igual que ocurre con el LDL, también mejoraron más las cifras en ese grupo de edad con la dieta y el ejercicio físico. Respecto al HDL los peores resultados son para el grupo de mayor edad con los valores más bajos en los resultados seguidos de los pacientes más jóvenes. En ambos grupos no se aprecian mejorías entre la primera y la última determinación sino que al contrario se observa un empeoramiento importante de los valores.

\section{MEDIDAS ANTROPOMÉTRICAS. PLIEGUES Y CONTORNOS.}

Los resultados que se obtuvieron a lo largo del seguimiento presentaron un descenso de todas las medidas realizadas en todos los grupos.

\section{$\underline{\text { Muestra Total }}$}

$\underline{\text { Tabla A }}$

\begin{tabular}{|l|cr|cr|cc|rr}
\hline$n$ total & \multicolumn{2}{|c|}{ MINIMO } & \multicolumn{2}{|c|}{ MÁXIMO } & \multicolumn{2}{c|}{ Inicio } & \multicolumn{2}{c}{ Final } \\
& Inicio & Fin & Inicio & Fin & MEDIA & DS & MEDIA & DS \\
\hline P. Tricipital & 4 & 4 & 47 & 45 & 24,61 & $+/-10,44$ & 23,32 & $+/-9,99$ \\
P. Subescapular & 12 & 11 & 68 & 60 & 33,42 & $+/-10,76$ & 32,18 & $+/ 11,37$ \\
P. Abdominal & 8 & 8 & 56 & 55 & 29,50 & $+/-10,92$ & 28,31 & $+/-10,72$ \\
Contorno brazo & 25,5 & 25 & 39 & 39 & 31,04 & $+/-3,10$ & 30,45 & $+/-3,16$ \\
Contorno cintura & 71 & 67 & 127 & 138 & 96,43 & $+/-11,45$ & 93,37 & $+/-13,27$ \\
Contorno cadera & 96 & 93 & 144 & 138 & 114,76 & $+/-10,34$ & 111,56 & $+/-10,66$
\end{tabular}

En las medidas antropométricas de toda la muestra al comparar los valores entre el inicio y final del trabajo se obtuvieron los siguientes: disminuyó en $1 \mathrm{~mm}$ la medida de los pliegues tricipital, subescapular y abdominal; el contorno del brazo disminuyó $1 \mathrm{~cm}$ y descendieron los contornos de cintura y de cadera $3 \mathrm{~cm}$.

\section{$\underline{\text { Varones }}$}

$\underline{\text { Tabla B }}$

\begin{tabular}{|l|cc|cc|cc|cc}
\hline Varones & \multicolumn{2}{|c|}{ MINIMO } & \multicolumn{2}{c|}{ MÁXIMO } & \multicolumn{2}{c|}{ Inicio } & \multicolumn{2}{c}{ Fin } \\
& Inicio & Fin & Inicio & Fin & MEDIA & DS & MEDIA & DS \\
\hline P. Tricipital & 4 & 4 & 21 & 16 & 9,69 & $+/-5,42$ & 6,86 & $+/-4,18$ \\
P. Subescapular & 13 & 13 & 44 & 44 & 28,85 & $+/-8,91$ & 27,57 & $+/-12,63$ \\
P. Abdominal & 8 & 8 & 27 & 26 & 18,85 & $+/-6,09$ & 17,0 & $+/-7,51$ \\
Contorno brazo & 27 & 27 & 37 & 36 & 31,72 & $+/-3,10$ & 30,5 & $+/-3,30$ \\
Contorno cintura & 89 & 90 & 117 & 116 & 102,83 & $+/-7,6$ & 99,71 & $+/-9,97$ \\
Contorno cadera & 96 & 100 & 121 & 115 & 110,58 & $+/-5,96$ & 107,71 & $+/-5,58$
\end{tabular}

Disminuyó $3 \mathrm{~mm}$ la medida del pliegue tricipital, $1 \mathrm{~mm}$ la del subescapular y $2 \mathrm{~mm}$ del pliegue abdominal; el contorno del brazo disminuyó $1,5 \mathrm{~cm}$ y $3 \mathrm{~cm}$ los contornos de cintura y de cadera. 
Mujeres pre menopáusicas.

$\underline{\text { Tabla C }}$

\begin{tabular}{|l|cc|cc|cc|rc}
\hline Pre-menopáusicas & \multicolumn{2}{|c|}{ MINIMO } & \multicolumn{2}{|c|}{ MÁXIMO } & \multicolumn{2}{c|}{ Inicio } & \multicolumn{2}{c}{ Fin } \\
& Inicio & Fin & Inicio & Fin & Media & DS & Media & DS \\
\hline P. Tricipital & 10 & 11 & 45 & 45 & 25,03 & $+/-8,81$ & 23,0 & $+/-9,01$ \\
P. Subescapular & 12 & 11 & 54 & 50 & 30,59 & $+/-10,95$ & 28,59 & $+/-11,20$ \\
P. Abdominal & 10 & 9 & 48 & 49 & 27 & $+/-10,66$ & 24,48 & $+/-9,66$ \\
Contorno brazo & 26 & 25 & 38 & 38 & 30,05 & $+/-3,02$ & 29,57 & $+/-3,40$ \\
Contorno cintura & 71 & 67 & 115 & 112 & 90,46 & $+/-11,86$ & 85,75 & $+/-12,67$ \\
Contorno cadera & 98 & 93 & 144 & 138 & 112,21 & $+/-10,91$ & 108,75 & $+/-11,75$
\end{tabular}

El grupo presentó disminución de $2 \mathrm{~mm}$ en la medida del pliegue tricipital, $4 \mathrm{~mm}$ la del subescapular y aumentaron $1 \mathrm{~mm}$ la medida del abdominal. El contorno del brazo se mantuvo igual y disminuyó $3 \mathrm{~cm}$ el contorno de cintura y $6 \mathrm{~cm}$ el de la cadera.

\section{Mujeres menopáusicas}

$\underline{\text { Tabla D }}$

\begin{tabular}{|l|cc|cc|cc|cc}
\hline Menopáusicas & \multicolumn{2}{|c|}{ MINIMO } & \multicolumn{2}{|c|}{ MÁXIMO } & \multicolumn{2}{c|}{ Inicio } & \multicolumn{2}{c}{ Fin } \\
& Inicio & Fin & Inicio & Fin & Media & DS & Media & DS \\
\hline P. Tricipital & 11 & 11 & 47 & 44 & 28,45 & $+/-8,81$ & 26,58 & $+/-8,33$ \\
P. Subescapular & 13 & 12 & 68 & 60 & 36,62 & $+/-10,27$ & 35,58 & $+/-10,43$ \\
P. Abdominal & 10 & 9 & 56 & 55 & 34,15 & $+/-9,53$ & 33,11 & $+/-9,33$ \\
Contorno brazo & 25,5 & 26,5 & 39 & 39 & 31,55 & $+/-3,05$ & 31,06 & $+/-2,88$ \\
Contorno cintura & 72,5 & 74 & 127 & 138,5 & 98,86 & $+/-10,32$ & 97,51 & $+/-11,92$ \\
Contorno cadera & 100 & 98 & 141 & 138 & 117,57 & $+/-10,18$ & 114,19 & $+/-10,03$
\end{tabular}

El grupo presentó disminución de $2 \mathrm{~mm}$ en el pliegue tricipital, $1 \mathrm{~mm}$ el subescapular, $1 \mathrm{~mm}$ el abdominal; disminuyó $1 \mathrm{~cm}$ el contorno de cintura y $3 \mathrm{~cm}$ el de cadera. El contorno del brazo se mantuvo igual

\section{$\underline{\text { Mujeres en conjunto }}$}

Tabla E

\begin{tabular}{|l|cc|cc|cc|cc}
\hline Mujeres & \multicolumn{2}{|c|}{ MINIMO } & \multicolumn{2}{c|}{ MÁXIMO } & \multicolumn{2}{c|}{ Inicio } & \multicolumn{2}{c}{ Fin } \\
& Inicio & Fin & Inicio & Fin & Media & DS & Media & DS \\
\hline P. tricipital & 10 & 11 & 47 & 45 & 27,06 & $+/-8,91$ & 25,06 & $+/-8,73$ \\
P. subescapular & 12 & 11 & 68 & 60 & 34,18 & $+/-10,90$ & 32,68 & $+/ 11,22$ \\
P. abdominal & 10 & 9 & 56 & 55 & 31,25 & $+/-10,55$ & 29,52 & $+/-10,33$ \\
Contorno brazo & 25,5 & 25 & 39 & 39 & 30,96 & $+/-3,11$ & 30,44 & $+/-3,17$ \\
Contorno cintura & 71 & 67 & 127 & 138 & 95,46 & $+/-11,66$ & 92,70 & $+/-13,46$ \\
Contorno cadera & 98 & 93 & 144 & 138 & 115,40 & $+/-10,74$ & 111,97 & $+/-11,01$
\end{tabular}

Descendió $2 \mathrm{~mm}$ el pliegue tricipital, subescapular y abdominal, disminuyó $3 \mathrm{~cm}$ el contorno de cintura y $4 \mathrm{~cm}$ el de cadera. El contorno del brazo se mantuvo igual. 
VALORES DE TENSIÓN ARTERIAL.

Tabla F

\begin{tabular}{|l|cc|cc|cc|cr}
\hline \multirow{2}{*}{ n Total } & \multicolumn{2}{|c|}{ MINIMO } & \multicolumn{2}{c|}{ MÁXIMO } & \multicolumn{2}{c|}{ Inicio } & \multicolumn{2}{c|}{ Fin } \\
\cline { 2 - 10 } & Inicio & Fin & Inicio & Fin & MEDIA & DS & MEDIA & DS \\
\hline T/A Sistólica & 100 & 90 & 155 & 160 & 125,38 & $+/-14,13$ & 121,16 & $+/-17,71$ \\
\hline T/A Diastólica & 60 & 55 & 100 & 100 & 77,01 & $+/-9,75$ & 72,26 & $+/-10,67$ \\
\hline
\end{tabular}

Varones

\begin{tabular}{l|cc|cc|cc|cc}
\hline T/A Sistólica & 105 & 105 & 155 & 150 & 132,11 & $+/-13,78$ & 123,75 & $+/-16,64$ \\
\hline T/A Diastólica & 70 & 60 & 95 & 100 & 83,16 & $+/-8,69$ & 80,0 & $+/-12,25$ \\
\hline
\end{tabular}

Premenopáusicas

\begin{tabular}{|l|cc|cc|cc|rc}
\hline T/A Sistólica & 100 & 90 & 150 & 160 & 128,26 & $+/-12,72$ & 125,53 & $+/-17,16$ \\
\hline T/A Diastólica & 60 & 60 & 100 & 90 & 77,21 & $+/-8,68$ & 72,63 & $+/-9,06$ \\
\hline
\end{tabular}

Menopáusicas

\begin{tabular}{|l|rc|cc|cc|cr}
\hline T/A Sistólica & 100 & 90 & 150 & 160 & 128,26 & $+/-12,72$ & 125,53 & $+/-17,16$ \\
\hline T/A Diastólica & 60 & 60 & 100 & 90 & 77,21 & $+/-8,68$ & 72,63 & $+/-9,06$ \\
\hline
\end{tabular}

Mujeres (todas)

\begin{tabular}{|l|cc|cc|cc|cc}
\hline T/A Sistólica & 100 & 90 & 150 & 160 & 123,63 & $+/-13,78$ & 120,85 & $+/-17,93$ \\
\hline T/A Diastólica & 60 & 55 & 100 & 95 & 75,41 & $+/-9,42$ & 71,31 & $+/-10,17$
\end{tabular}

Los valores resultantes de las mediciones de la tensión arterial entre el inicio y el final del seguimiento para el global de la muestra reflejan descenso en los valores de $4 \mathrm{mmHg}$ en la tensión sistólica y $5 \mathrm{mmHg}$ en la diastólica.

En el grupo de los varones, las cifras de la tensión arterial sistólica bajaron $9 \mathrm{mmHg}$ y $3 \mathrm{~mm}$ los valores de la diastólica.

Las mujeres premenopáusicas presentaron un descenso de las cifras de tensión arterial de $3 \mathrm{mmHg}$ tanto en la tensión arterial sistólica como en la diastólica.

En el grupo de las mujeres menopáusicas, las mediciones de la tensión arterial reflejaron un descenso de $3 \mathrm{mmHg}$ en la tensión sistólica y de $5 \mathrm{mmHg}$ en la diastólica.

Consideradas en conjunto, el grupo de las mujeres presentó un descenso en las cifras de la tensión sistólica de $3 \mathrm{mmHg}$ y de $4 \mathrm{mmHg}$ en los valores de la tensión diastólica. 
CONTORNO DE CINTURA Y CADERA, ICC Y OBESIDAD ABDOMINAL.

$\underline{\text { Tabla } G}$

\begin{tabular}{|c|c|c|c|c|c|}
\hline VARONES & $\begin{array}{l}\text { Porcentaje } \\
(\%)\end{array}$ & $\begin{array}{l}\text { Cintura } \\
(\mathrm{cm})\end{array}$ & $\begin{array}{l}\text { Cadera } \\
\text { (cm) }\end{array}$ & ICC & \begin{tabular}{|l|} 
RCC $>0,95$ \\
Porcentaje (\%)
\end{tabular} \\
\hline $\begin{array}{l}\text { Edad (años) } \\
29-44 \\
45-79 \\
\text { Nivel Educacional } \\
\text { Primario } \\
\text { Medios } \\
\text { Superiores } \\
\text { Actividad laboral } \\
\text { Inactivo } \\
\text { Activo sedentario } \\
\text { Activo moderado } \\
\text { Activo intenso } \\
\text { Actividad doméstica } \\
\text { 0 horas } \\
1 \text { - } 3 \text { horas } \\
>3 \text { horas } \\
\text { Índice masa corporal } \\
\text { (IMC) } \\
\text { Normopeso } \\
\text { Sobrepeso } \\
\text { Obesidad } \\
\text { Obesidad Mórbida }\end{array}$ & $\begin{array}{l}57,9 \\
42,1 \\
47,4 \\
36,8 \\
15,8 \\
10,5 \\
42,1 \\
10,5 \\
36,8 \\
84,2 \\
15,8 \\
- \\
\\
- \\
52,6 \\
47,4 \\
-\end{array}$ & $\begin{array}{l}104,1 \\
103,7 \\
104,8 \\
100,5 \\
102,0 \\
90,0 \\
102,9 \\
106,0 \\
106,2 \\
122,0 \\
102,7 \\
- \\
\\
- \\
98,3 \\
107,6\end{array}$ & $\begin{array}{l}109,1 \\
107,8 \\
107,9 \\
110,3 \\
107,8 \\
96,0 \\
108,6 \\
114,0 \\
108,8 \\
100,3 \\
108,0 \\
- \\
- \\
105,4 \\
111,3\end{array}$ & $\begin{array}{l}0,93 \\
0,96 \\
0,95 \\
0,93 \\
0,93 \\
0,92 \\
0,93 \\
0,92 \\
0,97 \\
0,94 \\
0,94 \\
- \\
\\
0, \\
0,95 \\
-\end{array}$ & $\begin{array}{l}12,5 \\
42,9 \\
44,4 \\
- \\
- \\
- \\
14,3 \\
- \\
60,0 \\
33,3 \\
27,3 \\
- \\
- \\
16,7 \\
37,5 \\
-\end{array}$ \\
\hline
\end{tabular}

$\underline{\text { Tabla } H}$

\begin{tabular}{|c|c|c|c|c|c|}
\hline PREMENOPAÚSICAS & $\begin{array}{l}\text { Porcentaje } \\
(\%)\end{array}$ & $\begin{array}{l}\text { Cintura } \\
(\mathrm{cm}) \\
\end{array}$ & $\begin{array}{l}\text { Cadera } \\
(\mathrm{cm})\end{array}$ & ICC & $\begin{array}{l}\mathrm{RCC}>0,80 \\
\text { Porcentaje }(\%)\end{array}$ \\
\hline $\begin{array}{l}\text { Edad (años) } \\
29-40 \\
41-51 \\
\text { Nivel Educacional } \\
\text { Primario } \\
\text { Medios } \\
\text { Superiores } \\
\text { Actividad laboral } \\
\text { (Todas amas de casa) } \\
\text { Inactivo } \\
\text { Activo sedentario } \\
\text { Activo moderado } \\
\text { Activo intenso } \\
\text { Actividad doméstica } \\
1 \text { - } 3 \text { horas } \\
4 \text { - } 7 \text { horas } \\
>8 \text { horas } \\
\text { Índice masa corporal } \\
\text { (IMC) } \\
\text { Normopeso } \\
\text { Sobrepeso } \\
\text { Obesidad } \\
\text { Obesidad Mórbida }\end{array}$ & $\begin{array}{l}14,71 \\
20,59 \\
38,24 \\
26,47 \\
\\
0 \\
61,76 \\
38,24 \\
\\
\\
0 \\
58,8 \\
26,6 \\
14,7\end{array}$ & $\begin{array}{l}91,75 \\
89,16 \\
92,76 \\
89,66 \\
\\
0 \\
91,23 \\
90,27\end{array}$ & $\begin{array}{l}110,25 \\
110,50 \\
112,61 \\
113,5 \\
0 \\
113,5 \\
109,63 \\
\\
0 \\
105,21 \\
115,95 \\
134,66\end{array}$ & $\begin{array}{l}0,83 \\
0,78 \\
0,82 \\
0,79 \\
0 \\
0,82 \\
0,80\end{array}$ & $\begin{array}{l}80,0 \\
42,86 \\
61,54 \\
44,44 \\
\\
0 \\
57,14 \\
53,85\end{array}$ \\
\hline
\end{tabular}


$\underline{\text { Tabla I }}$

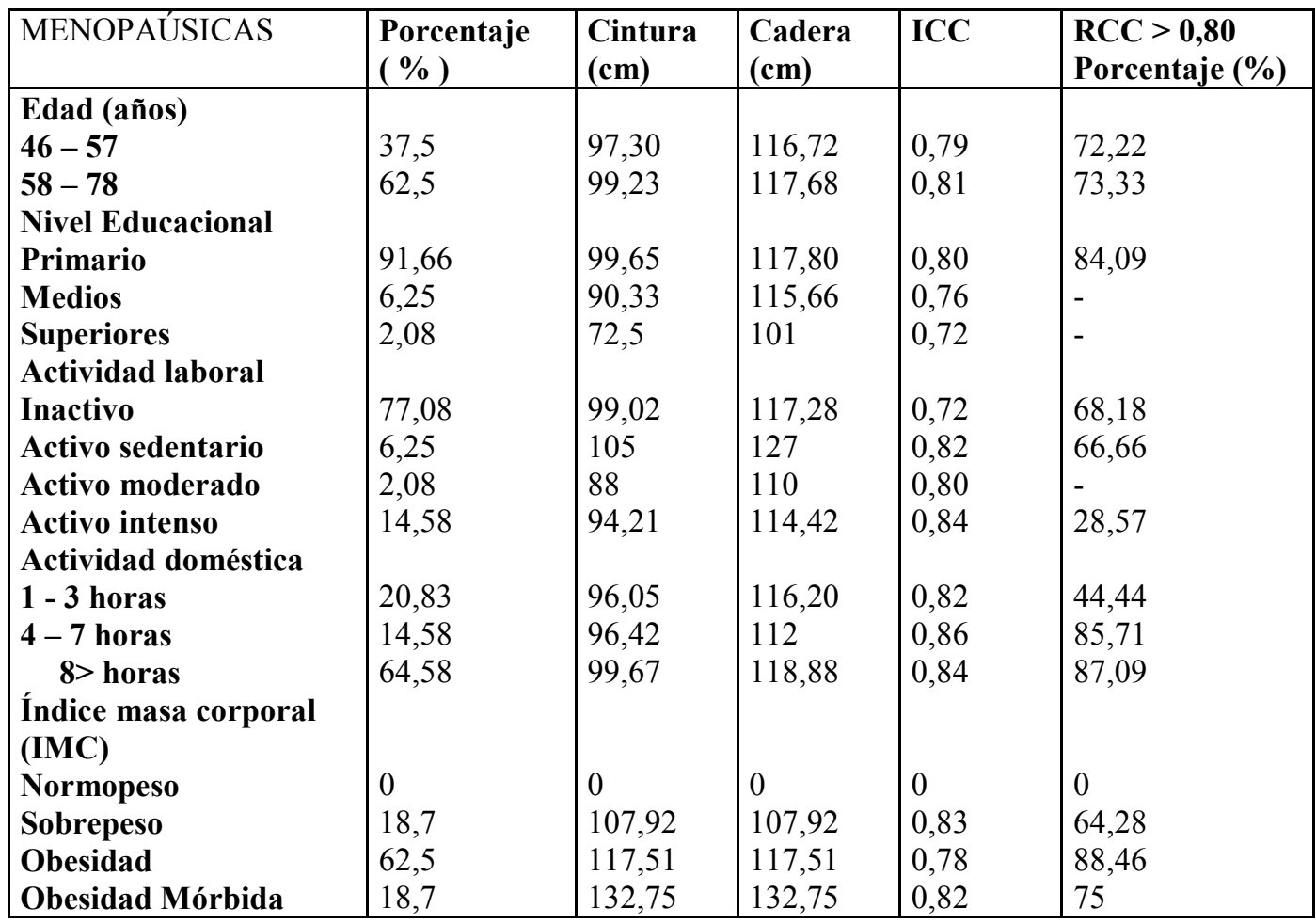

Como demuestran varios estudios, la distribución del tejido adiposo es factor predictivo para la aparición de complicaciones y/o para presentar patologías más importantes y graves asociadas a él. La acumulación de la grasa en la zona abdominal supone más riesgo de complicaciones que cuando el depósito de grasa es de distribución periférica. Se ha determinado que el índice de masa corporal y la edad son los principales factores asociados a la acumulación de la grasa en la zona central o abdominal. Así pues, la acumulación de grasa central es factor pronóstico de morbi-mortalidad, incluso más importante que el IMC ya que el aumento del índice cintura/cadera (ICC) incrementa el riesgo de enfermedad coronaria asociado de forma positiva con los hábitos tóxicos y la HTA y de forma negativa con la realización de ejercicio físico regular y el nivel cultural.

Los resultados que se obtuvieron al medir del contorno de cintura comparando, la primera valoración (inicio del seguimiento), con el final del trabajo, indican que los varones presentaban un $66,6 \%$ de valores mayores de $95 \mathrm{~cm}$ en la primera valoración frente a un $42,9 \%$ de la segunda; las mujeres premenopáusicas presentaban un $71,8 \%$ un contorno de cintura mayor de $82 \mathrm{~cm}$ al inicio del estudio y de un $62,9 \%$ al finalizarlo. Las mujeres menopáusicas con una cintura mayor de $82 \mathrm{~cm}$ suponían el $87,5 \%$ en la determinación inicial y un $91,8 \%$ al final del seguimiento.

Si valoramos las mujeres en conjunto un $81,2 \%$ de ellas tienen una cintura mayor de 82 $\mathrm{cm}$ al inicio y un $79,6 \%$ en la última valoración. 


\section{RIESGO CARDIOVASCULAR SEGÚN C.C}

\begin{tabular}{ll|l}
\hline & $\mathbf{1}^{\mathbf{a}}$ Medida & $\mathbf{2}^{\mathbf{0}}$ Medida \\
VARONES & & \\
C.C $<\mathbf{9 5}$ & $16,7 \%$ & $57,1 \%$ \\
C.C $>\mathbf{9 5}$ & $83,3 \%$ & $42,9 \%$ \\
& & \\
\hline MUJERES & & \\
C.C $<\mathbf{8 2}$ & $16,7 \%$ & $20 \%$ \\
C.C $>\mathbf{8 2}$ & $83,3 \%$ & $80 \%$ \\
\hline PREMENOPAÚSICAS & & \\
C.C $<\mathbf{8 2}$ & $28,1 \%$ & $37 \%$ \\
C.C $>\mathbf{8 2}$ & $71,9 \%$ & $63 \%$ \\
\hline MENOPAÚSICAS & & \\
C.C $<\mathbf{8 2}$ & $8,7 \%$ & $7,9 \%$ \\
C.C $>\mathbf{8 2}$ & $91,3 \%$ & $92,1 \%$
\end{tabular}

Al inicio del seguimiento el $83,3 \%$ de la muestra de los varones presentaba riesgo cardiovascular elevado y de presentar otras complicaciones según la medida del contorno de cintura. Las mujeres, en conjunto presentaban con igual porcentaje que los varones riesgo cardiovascular según su contorno de cintura. Separadas en pre y menopáusicas el riesgo es algo menor en la primeras con un 71,9\% en riesgo cardiovascular y de sufrir otras patologías y un $91,3 \%$ de riesgo en las mujeres con menopausia. El riesgo es muy elevado en la muestra y aunque todos los pacientes estudiados son obesos, es la distribución de la grasa la que determina el riesgo de morbi-mortalidad ya que a pesar de presentar un IMC normal, un contorno de cintura, indicador de la distribución grasa, con medidas por encima de los valores normales establecidos en $95 \mathrm{~cm}$ y $82 \mathrm{~cm}$ según el sexo del paciente para varones y mujeres respectivamente, el riesgo cardiovascular es igualmente elevado independientemente del peso. En el caso de las mujeres la distribución de la grasa es diferente de la del varón, en ellos la distribución es abdominal mientras que en las mujeres la distribución ginecoide, sobre todo hombros, glúteos y caderas.

Cuando consideramos los factores de riesgo cardiovascular más importantes según las guías y trabajos consultados(334): T/A mayor de 135/85mmHg, glucosa mayor de $100 \mathrm{mg} / \mathrm{dl}$, TG mayor de $150 \mathrm{mg} / \mathrm{dl}$ y HDL-colesterol menor de 40 , en la muestra cuando la consideramos en conjunto, el $6 \%$ de los pacientes presenta riesgo cardiovascular muy alto al presentar los cuatro factores de riesgo además de tener un IMC elevado, y un 9\% del total de la muestra presenta riesgo alto porque tienen tres de los factores más el peso elevado.

Separada la muestra por grupos, un 10\% de los varones presentan riesgo muy elevado con la presencia de los cuatros factores y un $21 \%$ de ellos presenta tres factores. De las mujeres premenopáusicas, un 3\% de ellas tiene un riesgo muy elevado con la presencia de los cuatro factores y un riesgo alto un 5\%; en las menopáusicas sólo un 2\% de ellas presenta un riesgo muy elevado con los cuatro factores, a pesar de ser el grupo de más edad y grado de obesidad. 
Presentaba un riesgo alto con tres factores el 10\% de las menopáusicas. Importante destacar en este grupo de mujeres, en contra de muchos de los trabajos consultados, la presencia de un importante factor de protección de riesgo cardiovascular como son los valores de HDL colesterol por encima de $35 \mathrm{mg} / \mathrm{dl}$ ya que un porcentaje elevado de ellas presentaba cifras de HDL colesterol por encima de estos valores.

En mi serie el riesgo cardiovascular va asociado principalmente con el sexo, mayor riesgo en los varones y mejor situación en global las mujeres premenopáusicas, aunque teniendo en cuenta los resultados de otros estudios, en mi grupo las mujeres menopáusicas son las que presentan menor riesgo cardiovascular a pesar de los factores negativos que llevan asociados como IMC, edad, menopausia, sedentarismo, patologías asociadas...

\section{ENCUESTA DIETÉTICA}

La encuesta dietética que se les realizó a los pacientes mostró los resultados siguientes:

\section{VARONES}

Realizaban el desayuno el $80 \%$ de la muestra. No tomaban nada a media mañana ni a media tarde prácticamente el $100 \%$ de los varones.

Dieta sosa y baja en grasas (1/3 de los pacientes). Lácteos a diario (200cc.leche, yogur esporádicos). Leche desnatada o semidesnatada. El 70\% desayuna leche con galletas o bollería. El 10\% tostada. En la comida el 20\% toma verdura, el mismo porcentaje pasta/arroz y legumbres. Pescado en la comida lo toma el $2 \%$ el resto carne. Consume fruta de postre la mitad aproximadamente de ellos. En la cena pasta 18\%, ensaladas $38 \%$ y verdura $30 \%$ son los primeros más consumidos de segundo plato la mitad carne, un $20 \%$ pescado y $25 \%$ huevos. El postre en la cena más frecuente la fruta (40\%) y el yogur (24\%).

La mayoría de los varones hace tres comidas al día, un 20\% no hace el desayuno y el 45\% come entre horas (pinchos). El 30\% de nuestra muestra come fuera de casa. Todos consumen pan (un bollo aproximadamente al día).

\section{PREMENOPAÚSICAS}

Desayunaban el 94,11\%. Desayuno 71\% leche (con o sin café). Todas toman la leche desnatada o semidesnatada. $8,7 \%$ fruta, $14,7 \%$ cereales, el mismo porcentaje tomaba galletas y bollería. Un $23,5 \%$ toman tostada con mantequilla o aceite. Media mañana, el $72 \%$ de la muestra tomaban algo: 44\% leche (con/sin café), 20,6\% fruta y $8,7 \%$ pinchos. Merienda el $84 \%$; un $55 \%$ toma lácteos (leche con/sin café o yogur) y el $23,5 \%$ fruta. 
Comida 8,7\% legumbres, 35,2\% verdura, 20,6\% ensalada, 23,5\% pasta/arroz. Un $55,9 \%$ carne, un 5,9\% pescado y 5,9\% huevos. Cena 17,6\% verdura, $23,5 \%$ ensalada, $5,9 \%$ pasta /arroz. $29,4 \%$ huevos, $32,3 \%$ carne y un $20,6 \%$ pescado. Un $74 \%$ toman fruta de postre, un $8,7 \%$ bollería y $8,7 \%$ lácteos (queso, yogur).

Prácticamente toda la muestra toma dieta sosa y baja en grasa. El consumo de lácteos en toda la muestra es aproximadamente de unos 500cc y un $8,7 \%$ toma unos $1.000 \mathrm{cc}$.

\section{MENOPAÚSICAS}

Desayunan el $97,91 \%$ de las pacientes. Un 93,75\% leche desnatada o semidesnatada (con o sin café), un 31,25\% fruta, 16,66\% cereales, $25 \%$ galletas, $31,25 \%$ tostadas y un $6,25 \%$ bollería. A media mañana el 33,33\% de la muestra toma algo. Un 18,75\% fruta, lácteos el 8,33\% y un 6,25\% pinchos. Merienda el 64,58\% de ellas de las que, el 37,5\% toma leche (con o sin café), 18,75\% fruta, 18,14\% lácteos y $8,33 \%$ galletas. En la comida el $43,75 \%$ toma verduras, seguido de pasta/arroz un $35,41 \%$, ensalada el $12,5 \%$ y el mismo porcentaje de legumbres. Carne toma el 70,83\%, pescado el $22,91 \%$ y huevos el $4,16 \%$.en la comida el postre más consumido es la fruta con el $81,25 \%$, después lácteos $6,25 \%$ y bollería el $4,16 \%$. En la cena el 10,41\% toma verdura, ensalada el $25 \%$, pasta/arroz 10,41\% y legumbres el 2,08\%. Carne consumen el $25 \%$, pescado el $35,41 \%$ y huevos el $29,16 \%$. El postre más consumido en la cena es la fruta con un $54,16 \%$, seguido de los productos lácteos con un $43,75 \%$ y después la bollería con un $2,08 \%$.

Según los resultados, toda la muestra dice tomar poca sal y dieta baja en grasas. El 14,58\% de las mujeres menopáusicas pica entre horas. El consumo de lácteos es de $800 \mathrm{cc}$ en el $56,24 \%$ de las mujeres, $18,74 \%$ toman aproximadamente $1.000 \mathrm{cc}$ y el resto, $25 \%$, toman unos $300 \mathrm{cc}$ según la encuesta que se les realizó.

Según la encuesta dietética los resultados que se obtuvieron indican que los varones son los que menos lácteos consumen aunque presentan mejor masa ósea que las mujeres. Las mujeres menopáusicas son las que más cantidad de lácteos toman a pesar de que presentan la peor situación ósea.

Las mujeres realizan una dieta más equilibrada y variada que los varones, hacen más comidas al día y consumen más pescado, también consumen más fruta, verdura y lácteos que los varones que toman más proteínas de origen cárnico. 
No he encontrado diferencias estadísticamente significativas entre el consumo de productos lácteos y la situación de la masa ósea, al igual que se observa en muchos trabajos que no muestran resultados concluyentes entre ingesta de calcio y densidad mineral ósea. En la muestra estudiada parece, incluso, tener un efecto contrario, aunque es verdad que respecto al consumo de calcio en ninguno de los grupos llegaba al consumo de las cantidades recomendadas (en torno a $1.000 \mathrm{mg} /$ día en varones y premenopáusicas y $1.500 \mathrm{mg} /$ día en mujeres menopáusicas).

Se estima que la población general entre 40 - 75 años consume un $46 \%$ menos de calcio del recomendado; en mi serie los varones sólo consumen un $25 \%$ del calcio que deberían; las mujeres premenopáusicas toman la mitad de ellas un $60 \%$ de la cantidad ideal y un 9\% aproximadamente, toman una ingesta de calcio correcta de $1.100 \mathrm{mg} /$ día. Las menopáusicas ninguna toma la cantidad recomendada, más de la mitad de ellas (57\%) ingiere unos $900 \mathrm{mg}$ /día, $19 \%$ toman $1.200 \mathrm{mg} /$ día y un $20 \%$ sólo consume unos $400 \mathrm{mg} /$ día de calcio.

Los trabajos indican que una buena protección para la masa ósea lleva asociada consumo adecuado de lácteos y de Vitamina D. Puesto que mi muestra no presenta ninguna causa para que el consumo de la Vitamina D sea deficitario he omitido su determinación, que por otra parte sólo está indicada en caso de sospecha de avitaminosis. 


\section{RESULTADOS DEXA Y EVOLUCIÓN DE LA MASA ÓSEA.}

Las tablas que aparecen a continuación muestran los valores obtenidos de los distintos parámetros estudiados en las DEXA realizadas a los pacientes. Las zonas estudiadas son columna lumbar (L2,L3,L4) y cadera. Se tuvo en cuenta el peso, la edad y el IMC que presentaban los pacientes en el momento de realización de las pruebas. Se presenta también la situación del estado de la masa ósea de la muestra según la clasificación de la O.M.S y la evolución de la masa ósea de los pacientes a lo largo del seguimiento comparando las dos DEXA.

DMO: (Clasificación O.M.S)

Densitometría normal: $<-1 \mathrm{DS}$

Osteopenia leve: $-1,01$ a $-1,69 \mathrm{DS}$

Osteopenia grave: $-1,70$ a $-2,5 \mathrm{DS}$

Osteoporosis: $>-2,5 \mathrm{DS}$

Cuando el resultado es normal, la masa ósea no presenta alteraciones y presenta valores dentro de la normalidad. Si aparece osteopenia los valores de la masa ósea están más bajos de los considerados normales, indica que se ha perdido masa ósea, que según el grado de pérdida la osteopenia se divide en leve o grave y son estados previos a padecer osteoporosis. Si los valores de masa ósea son muy bajos se habla de osteoporosis.

Hay que tener en cuenta que los procesos degenerativos óseos pueden alterar los valores reales de la masa ósea y mostrar resultados con cifras más elevadas de lo que realmente son.

VALORES DEXA. TODA LA MUESTRA.

Tabla a

\begin{tabular}{|c|c|c|c|c|c|c|}
\hline & $\begin{array}{r}1^{\circ} \text { DEXA } \\
\text { Media }\end{array}$ & & DS & $\begin{array}{c}2^{\circ} \text { DEXA } \\
\text { Media }\end{array}$ & & DS \\
\hline PESO & 80,830 & $+/-$ & 13,240 & 80,207 & $+/-$ & 13,801 \\
\hline EDAD & 52,399 & $+/-$ & 12,045 & 54,221 & $+/-$ & 12,123 \\
\hline I.M.C & 32,203 & $+/-$ & 5,263 & 32,047 & $+/-$ & 5,344 \\
\hline ÁREA C.L & 43,777 & $+/-$ & 4,902 & 43,872 & $+/-$ & 4,463 \\
\hline BMC C.L & 44,487 & $+/-$ & 9,800 & 43,516 & $+/-$ & 9,529 \\
\hline BMD C.L & 1,009 & $+/-$ & 0,165 & 0,985 & $+/-$ & 0,157 \\
\hline T C.L & $-0,672$ & $+/-$ & 1,479 & $-0,905$ & $+/-$ & 1,403 \\
\hline T C.L. P & 93,55 & $+/-$ & 14,69 & 91,05 & $+/-$ & 14,96 \\
\hline Z C.L & 0,319 & $+/-$ & 1,402 & 0,141 & $+/-$ & 1,368 \\
\hline Z C.L. P & 103,69 & $+/-$ & 16,55 & 102,05 & $+/-$ & 15,94 \\
\hline ÁREA CAD. & 35,108 & $+/-$ & 4,748 & 35,742 & $+/-$ & 4,828 \\
\hline BMC CAD. & 33,449 & $+/-$ & 8,167 & 33,691 & $+/-$ & 7,987 \\
\hline BMD CAD. & 0,947 & $+/-$ & 0,141 & 0,933 & $+/-$ & 0,136 \\
\hline T 30 CAD. & $-0,382$ & $+/-$ & 1,114 & $-0,436$ & $+/-$ & 1,023 \\
\hline T 30 CAD. P & 95,83 & $+/-$ & 13,85 & 94,54 & $+/-$ & 12,67 \\
\hline Z CAD. & 0,406 & $+/-$ & 1,081 & 0,426 & $+/-$ & 1,004 \\
\hline Z CAD. P & 106,03 & $+/-$ & 14,49 & 106,39 & $+/-$ & 13,62 \\
\hline
\end{tabular}




\begin{tabular}{|c|c|c|c|c|}
\hline Muestra global & $\begin{array}{c}\text { C. Lumbar } \\
\mathbf{1}^{\circ} \text { DEXA \% }\end{array}$ & $\begin{array}{l}\text { C. Lumbar } \\
\mathbf{2}^{\mathbf{0}} \text { DEXA \% }\end{array}$ & $\begin{array}{l}\text { Cadera } \\
\mathbf{1}^{\mathbf{0}} \text { DEXA \% }\end{array}$ & $\begin{array}{l}\text { Cadera } \\
\mathbf{2}^{\circ} \text { DEXA \% }\end{array}$ \\
\hline DMO Normal & 52,5 & 49,5 & 45,5 & 46,5 \\
\hline OSTEOPENIA & 36,6 & 36,6 & 42,6 & 37,6 \\
LEVE & 26,7 & 23,8 & 28,7 & 26,7 \\
GRAVE & 9,9 & 12,9 & 13,9 & 10,9 \\
\hline OSTEOPOROSIS & 10,9 & 13,9 & 7,9 & 11,9 \\
\hline
\end{tabular}

Al considerar el estado de la masa ósea de los pacientes según los resultados obtenidos y al equiparlos a los valores de la O.M.S apreciamos que si hay diferencias estadísticamente significativas entre la primera y la segunda determinación en los valores de la densitometría al separar la muestra por grupos (varones, mujeres premenopáusicas y mujeres menopáusicas) para los resultados de columna lumbar (L2, L3, L4) y para los de la cadera.

Cuando comparamos $1^{\mathrm{a}}$ con $2^{\mathrm{a}}$ densitometría en valores globales para toda la muestra obtenemos los siguientes resultados: en los pesos no hay diferencias estadísticamente significativas, tampoco al comparar el área de la columna lumbar de la 1 con la $2^{\text {a }}$ DEXA pero si hay diferencias significativas entre el BMC y el BMD $(\mathrm{gr} / \mathrm{cm} 2)$ de la columna lumbar entre $1^{\mathrm{a}}$ y $2^{\mathrm{a}}$ DMO y también entre T C.L, T C.L P y Z C.L y Z C.L P entre la $1^{\mathrm{a}}$ y la $2^{\mathrm{a}}$ DEXA. En la cadera al comparar 1 con $2^{\mathrm{a}} \mathrm{DMO}$ se observan diferencias significativas entre las áreas, el BMD y $\mathrm{T}$ de la cadera $\mathrm{P}$ y no hay diferencias entre las dos comparaciones de BMC, T30 cadera, $Z$ cadera y $Z$ cadera $P$.

VALORES DEXA. VARONES

$\underline{\text { Tabla b }}$

\begin{tabular}{|c|c|c|c|c|}
\hline & $\begin{array}{l}1^{\circ} \mathrm{DEX} A \\
\text { Media }\end{array}$ & DS & $\begin{array}{l}2^{\circ} \text { DEXA } \\
\text { Media }\end{array}$ & DS \\
\hline PESO & 87,684 & $\begin{array}{ll}+/- & 10,744\end{array}$ & 86,139 & $\begin{array}{ll}+/- & 10,527\end{array}$ \\
\hline EDAD & 46,968 & +/- 13,348 & 49,167 & $+/-\quad 13,479$ \\
\hline I.M.C & 30,632 & $+/-\quad 4,195$ & 29,639 & 3,276 \\
\hline ÁREA C.L & 50,975 & $+/-\quad 4,949$ & 50,662 & 3,302 \\
\hline BMC C.L & 54,881 & $+/-\quad 6,308$ & 53,945 & 7,485 \\
\hline BMD C.L & 1,085 & $+/-\quad 0,150$ & 1,066 & 0,151 \\
\hline T C.L & $-0,200$ & $+/-\quad 1,316$ & $-0,420$ & 1,350 \\
\hline T C.L. P & 98,00 & $+/-\quad 12,98$ & 95,86 & 13,36 \\
\hline Z C.L & 0,283 & $+/-\quad 1,414$ & $1,500 \mathrm{E}-02$ & 1,432 \\
\hline Z C.L. P & 102,57 & $+/-\quad 15,24$ & 100,64 & 15,05 \\
\hline ÁREA CAD. & 42,870 & $+/-\quad 4,441$ & 43,547 & 4,561 \\
\hline BMC CAD. & 44,889 & $+/-10,594$ & 45,291 & 9,417 \\
\hline BMD CAD. & 1,040 & $+/-0,163$ & 1,036 & 0,151 \\
\hline T 30 CAD. & $-0,390$ & $+/-\quad 1,228$ & $-0,201$ & 1,073 \\
\hline T 30 CAD. P & 98,43 & $+/-\quad 15,69$ & 96,62 & 13,83 \\
\hline Z CAD. & 0,504 & $+/-\quad 1,304$ & 0,498 & 1,075 \\
\hline Z CAD. $P$ & 107,21 & $+/-\quad 17,41$ & 107,77 & 14,12 \\
\hline
\end{tabular}




\begin{tabular}{|c|c|c|c|c|}
\hline Varones & $\begin{array}{c}\text { C. Lumbar } \\
\mathbf{1}^{\mathbf{0}} \text { DEXA \% }\end{array}$ & $\begin{array}{l}\text { C. Lumbar } \\
\mathbf{2}^{\mathbf{0}} \text { DEXA \% }\end{array}$ & $\begin{array}{l}\text { Cadera } \\
\mathbf{1}^{\mathbf{0}} \text { DEXA \% }\end{array}$ & $\begin{array}{l}\text { Cadera } \\
\mathbf{2}^{\mathbf{0}} \text { DEXA \% }\end{array}$ \\
\hline DMO Normal & 68,4 & 68,4 & 57,9 & 57,9 \\
\hline OSTEOPENIA & 31,8 & 26,3 & 36,8 & 36,8 \\
LEVE & 26,3 & 5,8 & 15,8 & 21 \\
GRAVE & 5,3 & 10,5 & 21 & 15,8 \\
\hline OSTEOPOROSIS & 0 & 5,3 & 0 & 0 \\
\hline
\end{tabular}

Varones: a nivel de la columna lumbar un 57,9\% de ellos mantuvo su masa ósea igual, el $5,3 \%$ la mejoró a ese nivel en torno al 3\% y el 36,8\% de ellos perdió masa ósea. De los varones que perdieron masa ósea un $57,1 \%$ perdió un $1,3 \%$ de ella entre la $1^{\circ}$ y $2^{\circ}$ DEXA y el resto de varones perdió un 5\% las cifras de masa ósea. A nivel de la cadera un 57,9\% mantuvo su masa ósea igual, un $15,8 \%$ la mejoraron alrededor de un $3 \%$ y un $26,3 \%$ perdieron masa ósea en esa zona entre un 2,6 y un $3 \%$.

Un 7,1\% presentaba signos degenerativos a nivel columna lumbar en la $2^{\circ}$ DEXA y $14,3 \%$ de ellos signos degenerativos en cadera en las dos DEXA, en ambos casos en el porcentaje con valores de osteopenia grave.

De los pacientes con DMO normal el 9,1\% presentaba signos degenerativos.

Las DEXA en el grupo de los varones mostraban los siguientes resultados: entre ambos pesos no diferencias, tampoco en el área, BMD y BMC de la columna lumbar, si diferencias en $\mathrm{T}$ de la columna lumbar, T1 columna lumbar $\mathrm{P}$ y $\mathrm{Z}$ columna lumbar $\mathrm{P}$ y no diferencias para $\mathrm{Z}$ columna lumbar. En la cadera el grupo de los varones no presentaban diferencias estadísticamente significativas en ningún parámetro.

VALORES DEXA. MUJERES PREMENOPAÚSICAS.

Tabla c

\begin{tabular}{|c|c|c|c|c|c|c|}
\hline & $\begin{array}{l}1^{\circ} \text { DEXA } \\
\text { Media }\end{array}$ & & DS & $\begin{array}{l}2^{\circ} \text { DEXA } \\
\text { Media }\end{array}$ & & DS \\
\hline PESO & 76,368 & $+/-$ & 14,929 & 76,900 & $+/-$ & 16,852 \\
\hline EDAD & 43,315 & $+/-$ & 6,585 & 45,170 & $+/-$ & 6,665 \\
\hline I.M.C & 30,485 & $+/-$ & 5,243 & 30,803 & $+/-$ & 5,827 \\
\hline ÁREA C.L & 42,857 & $+/-$ & 3,713 & 43,306 & $+/-$ & 3,181 \\
\hline BMC C.L & 45,766 & $+/-$ & 7,494 & 44,664 & $+/-$ & 7,536 \\
\hline BMD C.L & 1,063 & $+/-$ & 0,126 & 1,029 & $+/-$ & 0,144 \\
\hline T C.L & $-0,144$ & $+/-$ & 1,151 & $-0,464$ & $+/-$ & 1,321 \\
\hline T C.L. P & 98,94 & $+/-$ & 11,71 & 95,07 & $+/-$ & 13,68 \\
\hline Z C.L & 0,302 & $+/$ & 1,044 & 7,667E02 & $+/-$ & 1,192 \\
\hline Z C.L. P & 103,32 & $+1-$ & 11,27 & 100,07 & $+/-$ & 12,83 \\
\hline ÁREA CAD. & 33,325 & $+/-$ & 3,416 & 34,200 & $+/-$ & 3,264 \\
\hline BMC CAD. & 32,367 & $+/$ & 5,943 & 32,666 & $+/-$ & 6,238 \\
\hline BMD CAD. & 0,968 & $+/$ & 0,132 & 0,951 & $+/-$ & 0,132 \\
\hline T 30 CAD. & $-5,94 \mathrm{E} 02$ & $+1-$ & 1,106 & $-0,198$ & $+/-$ & 1,137 \\
\hline T 30 CAD. P & 99,41 & $+/$ & 13,61 & 97,63 & $+/-$ & 14,03 \\
\hline Z CAD. & 0,209 & $+/$ & 1,117 & 0,180 & $+/-$ & 1,093 \\
\hline Z CAD. P & 103,24 & $+/$ & 13,78 & 102,47 & $+/-$ & 13,62 \\
\hline
\end{tabular}




\begin{tabular}{|c|c|c|c|c|}
\hline $\begin{array}{l}\text { Mujeres } \\
\text { premenopáusicas }\end{array}$ & $\begin{array}{l}\text { C. Lumbar } \\
1^{\circ} \text { DEXA \% } \\
\end{array}$ & $\begin{array}{l}\text { C. Lumbar } \\
2^{\circ} \text { DEXA \% }\end{array}$ & $\begin{array}{l}\text { Cadera } \\
\mathbf{1}^{\circ} \text { DEXA \% } \\
\end{array}$ & $\begin{array}{l}\text { Cadera } \\
\mathbf{2}^{\circ} \text { DEXA \% } \\
\end{array}$ \\
\hline DMO Normal & 70,6 & 58,8 & 61,8 & 61,8 \\
\hline OSTEOPENIA & 26,5 & 35,3 & 32,3 & 29,4 \\
\hline LEVE & 20,6 & 26,5 & 23,5 & 23,5 \\
\hline GRAVE & 5,9 & 8,8 & 8,8 & 5,9 \\
\hline OSTEOPOROSIS & 2,9 & 5,9 & 5,9 & 8,8 \\
\hline
\end{tabular}

Mujeres premenopáusicas: Al comparar la $1^{\mathrm{o}}$ con la $2^{\mathrm{a}}$ DEXA en los valores de columna lumbar las mujeres premenopáusicas presentaron los datos siguientes 41,2\% mantuvieron el estado de su masa ósea igual que al inicio del estudio, 11,8\% mejoraron su masa ósea, de ellas el $75 \%$ un $3 \%$ de masa ósea y un $1 \%$ el $25 \%$ restante. Un $47,1 \%$ de las mujeres premenopáusicas sufrieron pérdida de su masa ósea y de éstas, un 50\% disminuyó un 5\% su densidad mineral ósea, un $37,5 \%$ un $1,5 \%$ y un $12,5 \%$ de las que presentaron disminución de su masa ósea en la segunda DEXA perdieron el 7\% de ella. En cuanto a los resultados obtenidos en la cadera al comparar los resultados con la segunda densitometría 55,9\% mantenían los valores de masa ósea igual, 20,6\% mejoraban los valores iniciales de su masa ósea en torno al 3\% y un $23,5 \%$ presentan pérdidas de ella que oscilan entre el $2,5 \%$ el $62,5 \%$ de las mujeres que perdieron y el $4,2 \%$ el $37,5 \%$ restante.

Un 5,8\% presentaba signos degenerativos en columna lumbar y $2,9 \%$ en cadera de los pacientes con valores de masa ósea dentro de lo normal u osteopenia leve.

Las mujeres premenopáusicas presentaban diferencias significativas a nivel de la columna lumbar en todos los parámetros comparados menos en el peso y en el área de la columna y en relación a la cadera si se establecieron diferencias significativas a nivel del área de la cadera y no al comparar el resto de parámetros

VALORES DEXA. MUJERES MENOPAÚSICAS.

$\underline{\text { Tabla d }}$

\begin{tabular}{|c|c|c|c|c|c|c|}
\hline & $\begin{array}{l}1^{\circ} \text { DEXA } \\
\text { Media }\end{array}$ & & DS & $\begin{array}{l}2^{\circ} \text { DEXA } \\
\text { Media }\end{array}$ & & DS \\
\hline PESO & 81,277 & +1 & 11,776 & 80,259 & $+/-$ & 11,852 \\
\hline EDAD & 60,983 & $+/$ & 7,944 & 62,880 & $+/-$ & 8,138 \\
\hline I.M.C & 34,042 & +1 & 5,140 & 33,922 & $+/-$ & 5,068 \\
\hline ÁREA C.L & 42,266 & $+/$ & 3,659 & 42,014 & $+/$ & 3,342 \\
\hline BMC C.L & 40,378 & +1 & 9,679 & 39,220 & $+/-$ & 8,562 \\
\hline BMD C.L & 0,946 & $+/$ & 0,173 & 0,927 & $+/-$ & 0,148 \\
\hline T C.L & $-1,206$ & +1 & 1,574 & $-1,382$ & $+/-$ & 1,347 \\
\hline T C.L. P & 88,22 & +1 & 15,49 & 86,57 & $+/-$ & 15,33 \\
\hline Z C.L & 0,341 & +1 & 1,639 & 0,279 & $+/-$ & 1,479 \\
\hline Z C.L. P & 104,30 & +1 & 20,13 & 103,93 & $+/-$ & 18,19 \\
\hline ÁREA CAD. & 34,041 & +1 & 3,125 & 34,395 & $+/-$ & 3,310 \\
\hline BMC CAD. & 30,708 & +1 & 5,441 & 30,764 & $+/-$ & 4,924 \\
\hline BMD CAD. & 0,901 & +1 & 0,124 & 0,886 & $+/$ & 0,114 \\
\hline T 30 CAD. & $-0,624$ & +1 & 1,044 & $-0,684$ & $+/-$ & 0,875 \\
\hline T 30 CAD. P & 92,31 & +1 & 12,84 & 91,61 & $+/-$ & 10,76 \\
\hline Z CAD. & 0,524 & +1 & 0,979 & 0,583 & $+/-$ & 0,897 \\
\hline Z CAD. P & 107,78 & +1 & 14,06 & 108,83 & $+/$ & 13,12 \\
\hline
\end{tabular}




\begin{tabular}{|l|c|c|c|c|}
\hline $\begin{array}{l}\text { Mujeres } \\
\text { menopáusicas }\end{array}$ & $\begin{array}{l}\text { C. Lumbar } \\
\mathbf{1}^{\mathbf{0}} \text { DEXA \% }\end{array}$ & $\begin{array}{l}\text { C. Lumbar } \\
\mathbf{2}^{\mathbf{0}} \text { DEXA \% }\end{array}$ & $\begin{array}{l}\text { Cadera } \\
\mathbf{1}^{\mathbf{0}} \text { DEXA \% }\end{array}$ & $\begin{array}{l}\text { Cadera } \\
\mathbf{2}^{\mathbf{0}} \text { DEXA \% }\end{array}$ \\
\hline DMO Normal & 33,3 & 35,4 & 29,2 & 31,2 \\
\hline OSTEOPENIA & 45,8 & 41,7 & 52,1 & 43,7 \\
LEVE & 31,2 & 25 & 37,5 & 31,2 \\
GRAVE & 14,6 & 16,7 & 14,6 & 12,5 \\
\hline OSTEOPOROSIS & 20,8 & 22,9 & 12,5 & 18,7 \\
\hline
\end{tabular}

Mujeres menopáusicas: $\mathrm{Al}$ comparar la $1^{\mathrm{o}}$ con la $2^{\mathrm{a}}$ DEXA a nivel de columna lumbar, un $29,2 \%$ de estas mujeres no presentaron modificaciones de su masa ósea, un 14,6\% mejoraron sus cifras en torno al $2,7 \%$ y perdieron masa ósea un $56,2 \%$ de ellas en torno al $4 \%$; en cuanto a la cadera, un $33,3 \%$ no presentó modificaciones en la masa ósea previa, un 43,7\% pierden masa ósea, (en torno al 5,3\%), de ellas un $42,9 \%$ pierden un $2 \%$ de su masa, un $38,1 \%$ un $4 \%$ y el 19\% restante presentan disminución de un $7 \%$ en su masa ósea.

Un 30,4\% de estas mujeres, dentro del grupo de valores de masa ósea dentro de lo normal o con osteopenia leve presentaban signos degenerativos a nivel de columna lumbar lo que indica que probablemente estos valores de normalidad no sean tales ya que los signos degenerativos se comportan como aditivos al estado de masa ósea y puede llevar a errores sobre las verdaderas cifras de masa ósea que presentan los pacientes. No aparecían signos degenerativos a nivel cadera. Al 2,1\% de las mujeres en este grupo se les colocó una prótesis de cadera.

En el grupo de mujeres menopáusicas no diferencias en el peso ni en el área de la columna lumbar si para el resto de parámetros comparados para la columna lumbar. En relación a la cadera no diferencias significativas en ninguno de los resultados salvo en el BMD que si se presentan diferencias estadísticamente significativas.

En los varones la mitad de ellos sufren descenso de su masa ósea a nivel de la columna lumbar en torno al $1,3 \%$ de pérdida. En la cadera el 37,7\% presentan descenso de su masa ósea donde el $60 \%$ pierde un 3\% de su masa. Las premenopáusicas en columna lumbar un 47\% disminuyen su DMO con pérdidas de un 5\% la mitad de ellas y un $12,5 \%$ en torno al $7 \%$. A nivel de la cadera un $23,5 \%$ pierden masa ósea, de estas el $42,9 \%$ pierden un $2,5 \%$ y el resto de ellas pierde un $4,2 \%$ de su masa ósea. Las menopáusicas en columna lumbar pierden masa ósea el 61,4\% de ellas, de las que un $40 \%$ pierden un $2 \%$, otro $40 \%$ pierde un $4 \%$ y el $20 \%$ restante pierde un $7 \%$. En la cadera un 30,4\% mantiene su masa ósea igual, un $23,9 \%$ la aumenta en torno al $2 \%$ y un $45,6 \%$ pierden masa ósea de los que un $23,8 \%$ de ellas pierden en torno al $7 \%$, un $33,3 \%$ alrededor de un $4 \%$ y el resto en torno al $2 \%$. Un $4,7 \%$ pierde un $11 \%$. 
VALORES DEXA. MUJERES

$\underline{\text { Tabla e }}$

\begin{tabular}{|c|c|c|c|c|c|}
\hline & $\begin{array}{l}1^{\circ} \mathrm{DEX} \\
\text { Media }\end{array}$ & DS & $\begin{array}{l}2^{\circ} \text { DEXA } \\
\text { Media }\end{array}$ & & DS \\
\hline PESO & 79,241 & $+/-\quad 13,311$ & 78,856 & $+/-$ & 14,153 \\
\hline EDAD & 53,657 & $+/-\quad 11,445$ & 55,387 & $+/-$ & 11,570 \\
\hline I.M.C & 32,567 & $+/-\quad 5,444$ & 32,603 & $+/-$ & 5,585 \\
\hline ÁREA C.L & 42,517 & $+/-3,671$ & 42,552 & $+/-$ & 3,316 \\
\hline BMC C.L & 42,668 & $+/-9,166$ & 41,489 & $+/-$ & 8,534 \\
\hline BMD C.L & 0,996 & $+/-\quad 0,164$ & 0,969 & $+/-$ & 0,154 \\
\hline T C.L & $-0,755$ & $+/-\quad 1,498$ & $-1,000$ & $+/-$ & 1,403 \\
\hline T C.L. P & 92,78 & $+/-\quad 14,91$ & 90,11 & $+/-$ & 15,16 \\
\hline Z C.L & 0,325 & $+/-\quad 1,409$ & 0,166 & $+/-$ & 1,364 \\
\hline Z C.L. P & 103,89 & $+/-16,86$ & 102,32 & $+/-$ & 16,19 \\
\hline ÁREA CAD. & 33,732 & $+/-\quad 3,251$ & 34,313 & $+/-$ & 3,269 \\
\hline BMC CAD. & 31,422 & $+/-5,685$ & 31,568 & $+/-$ & 5,556 \\
\hline BMD CAD. & 0,930 & $+/-\quad 0,131$ & 0,914 & $+/-$ & 0,125 \\
\hline T 30 CAD. & $-0,381$ & $+/-\quad 1,101$ & $-0,479$ & $+/-$ & 1,015 \\
\hline T 30 CAD. P & 95,37 & $+/-13,56$ & 94,15 & $+/-$ & 12,52 \\
\hline Z CAD. & 0,389 & $+/-\quad 1,045$ & 0,413 & $+/-$ & 0,997 \\
\hline Z CAD. P & 105,82 & $+/-\quad 14,03$ & 106,14 & $+/-$ & 13,61 \\
\hline
\end{tabular}

\begin{tabular}{|c|c|c|c|c|}
\hline Mujeres & $\begin{array}{c}\text { C. Lumbar } \\
\mathbf{1}^{\mathbf{0}} \text { DEXA \% }\end{array}$ & $\begin{array}{c}\text { C. Lumbar } \\
\mathbf{2}^{\mathbf{o}} \text { DEXA \% }\end{array}$ & $\begin{array}{l}\text { Cadera } \\
\mathbf{1}^{\mathbf{0}} \text { DEXA \% }\end{array}$ & $\begin{array}{c}\text { Cadera } \\
\mathbf{2}^{\mathbf{0}} \text { DEXA \% }\end{array}$ \\
\hline DMO Normal & 46,3 & 45,1 & 42,7 & 15 \\
\hline OSTEOPENIA & 37,8 & 39 & 43,9 & 38,7 \\
LEVE & 26,8 & 25,6 & 31,7 & 28,7 \\
GRAVE & 11 & 13,4 & 12,2 & 10 \\
\hline OSTEOPOROSIS & 13,4 & 15,8 & 9,7 & 32,5 \\
\hline
\end{tabular}

Un 10\% de las mujeres presentaban signos degenerativos en el grupo de masa ósea normal y un $17,5 \%$ con osteopenia. En la cadera no se apreciaron signos degenerativos.

MODIFICACIONES DE LA MASA ÓSEA ENTRE LA $1^{\circ}$ Y LA $2^{\circ}$ DEXA

\begin{tabular}{|c|c|c|c|c|c|c|}
\hline & VARONE & $\%$ & \multicolumn{2}{|c|}{ PREMENOPAÚSICAS \% } & \multicolumn{2}{|c|}{ MENOPAÚSICAS \% } \\
\hline Masa Ósea & C. Lumbar & Cadera & C. Lumbar & Cadera & C.Lumbar & Cadera \\
\hline Pérdida & 36,8 & 26,3 & 47,1 & 23,5 & 56,2 & 43,7 \\
\hline Ganancia & 5,3 & 15,8 & 11,8 & 20,6 & 14,6 & 22,9 \\
\hline Sin cambios & 57,9 & 57,9 & 41,2 & 55,9 & 29,2 & 33,3 \\
\hline
\end{tabular}

La pérdida de masa ósea para el total de la muestra rondaba el 3\%.

Tanto a nivel de la columna lumbar como en la cadera las mujeres con menopausia presentaron mayor grado de pérdida ósea pero también fueron el grupo que más la mejoró. 


\section{EVOLUCIÓN MASA ÓSEA}

\begin{tabular}{|c|c|c|c|c|c|c|c|c|}
\hline & $\begin{array}{l}\text { Total } \\
\text { Media }\end{array}$ & DS & $\begin{array}{l}\text { Varones } \\
\text { Media }\end{array}$ & DS & $\begin{array}{l}\text { Premenop } \\
\text { Media }\end{array}$ & DS & $\begin{array}{l}\text { Menopau } \\
\text { Media }\end{array}$ & DS \\
\hline C. L. & $-2,2841$ & $+/-2,954$ & $-1,261$ & $+/-2,323$ & $-2,685$ & $+/-3,167$ & $-2,430$ & $+/-3,026$ \\
\hline Cadera & $-1,0781$ & $+/-3,286$ & $2,143 \mathrm{E}-02$ & $+/-2,718$ & $-0,240$ & $+/-3,273$ & $-1,877$ & $+/-3,363$ \\
\hline
\end{tabular}

La masa ósea según los valores que se observaron en las DEXA muestran una pérdida global que ronda el 3\%; los varones son el grupo de población que menos pierde y las mujeres premenopáusicas las que presentan mayor pérdida de masa ósea.

Si valoramos en conjunto todos los datos de todos los parámetros que se han estudiado en las densitometrías obtenemos los siguientes resultados:

- toda la muestra: el peso aumentó un $0,78 \%$, el IMC descendió un $0,5 \%$, el área total de la C. L aumentó 0,23\%, el BMC (gr totales) de C. L bajó un 2,5\%, el BMD (gr/cm2) de C. L bajó un 3\%, la T C. L (valor respecto al pico de masa ósea) descendió un 34,3\%, la T C. L P ( valor respecto del pico de masa ósea en porcentaje) bajó un 2,7\%, la Z C. L (valor respecto a la edad del paciente) bajó un 54,8\%, la Z C. L P (valor respecto a la edad del paciente en porcentaje) descendió un 0,7\%. En cuanto al estudio de la cadera, el área subió 1,7\%, el BMC aumentó un 0,75\%, el BMD un 1,1\%, la T30 bajó 13,1\%, T30 P un 1,36\% y la Z subió un 5\% y la Z de la cadera $\mathrm{P}$ un $0,38 \%$.

- varones: en las DMO el peso disminuyó un 1,85\% y el IMC un 3,34\%. El área de la C. L disminuyó un 0,6\%, el BMC de C. L bajó un 1,85\%, el BMD de C. L descendió un 1,9\%, la T C. L disminuyó un $52,3 \%$, la T C. L P un $3,12 \%$, la Z C. L subió un $20 \%$ y la Z C. L P disminuyó un 2\%. Respecto al estudio de la cadera, el área aumentó un 1,6\%, el BMC un 1,32\%, el BMD disminuyó un 1\%, la T30 aumentó un 5\%, la T30 P descendió un 2,06\%, la Z se mantuvo igual sin modificaciones y la $\mathrm{Z} \mathrm{P}$, valor respecto a la edad de la paciente en porcentaje de la cadera aumentó $0,5 \%$.

- mujeres premenopáusicas: en este grupo el peso aumentó un 0,8\% y el IMC aumentó un 1,3\%. En cuanto a la columna lumbar, el área aumentó 2,3\%, el BMC descendió un 2,2\%, el BMD disminuyó un 4\%, la T C.L un 214,3\%, la T C.L P bajó un 4\%, la Z C.L subió un 95\% y la Z C.L P descendió un 3\%. Respecto a la cadera, el área subió 5,8\% el BMC aumentó un 0,9\%, BMD disminuyó un 10,5\%, la T30 subió 67,3\%, T30 P descendió un 2\% y el valor de Z disminuyó un $10 \%$ y el mismo valor en porcentaje disminuyó un $1 \%$. 
- mujeres menopáusicas: en las DEXA el peso descendió un 1,23\% y el IMC un 0,9\%. El área de la columna lumbar disminuyó un 0,5\%, el BMC un 2,5\% y el BMD también descendió un 2,13\%; la $\mathrm{T}$ aumentó un 8,3\%, la T. en porcentaje disminuyó un 2,7\%, la $\mathrm{Z}$ bajó un 29,4\% y la Z P también descendió un 0,96\%. El área de cadera aumentó un 1,17\%, el BMC subió un 0,20\%, BMD disminuyó un 2,22\%, la T30 subió un 9,68\%, T30 P descendió un 1,1\% y la Z aumentó un 11,54\% y el mismo concepto en porcentaje también aumentó un 1,11\%.

\section{RELACIÓN ESTADO DE LA MASA ÓSEA CON DISTINTAS VARIABLES.}

Relación masa ósea/ grupos (varones, mujeres premenopáusicas y menopáusicas)

\begin{tabular}{llll}
\hline $\mathbf{1}$ DMO & Valor & Significación & \\
\hline C. Lumbar & 33,498 &, 000 & Significativo \\
\hline Cadera & 23,209 &, 003 & Significativo \\
\hline $\mathbf{2}^{\mathbf{a}}$ DMO & & & \\
\hline C. Lumbar & 26,002 &, 001 & Significativo \\
\hline Cadera & 24,836 &, 002 & Significativo
\end{tabular}

Relación masa ósea/ IMC

\begin{tabular}{llll}
\hline $\mathbf{1}^{\mathbf{a}}$ DMO & Valor & Significación & \\
\hline C. Lumbar & 0,073 &, 779 & NS \\
\hline Cadera & 7,799 &, 801 & NS \\
\hline $\mathbf{2}^{\mathbf{a}}$ DMO & & & \\
\hline C. Lumbar & 4,573 &, 971 & NS \\
\hline Cadera & 16,814 &, 157 & NS
\end{tabular}

\section{Relación masa ósea/ Edad}

\begin{tabular}{llll}
\hline $\mathbf{1}^{\mathbf{a}} \mathbf{D M O}$ & Valor & Significación & \\
\hline C. Lumbar & 20,881 &, 007 & NS \\
\hline Cadera & 29,081 &, 000 & Significativo \\
\hline $\mathbf{2}^{\mathbf{a}} \mathbf{D M O}$ & & & \\
\hline C. Lumbar & 16,529 &, 035 & NS \\
\hline Cadera & 22,745 &, 004 & Significativo
\end{tabular}

Relación masa ósea/ Sexo

\begin{tabular}{llll}
\hline $\mathbf{1}^{\mathbf{a}} \mathbf{D M O}$ & Valor & Significación & \\
\hline C. Lumbar & 15,902 &, 003 & Significativo \\
\hline Cadera & 14,212 &, 007 & NS \\
\hline $\mathbf{2}^{\mathbf{a}} \mathbf{D M O}$ & & & \\
\hline C. Lumbar & 15,792 &, 003 & Significativo \\
\hline Cadera & 16,489 &, 002 & Significativo
\end{tabular}

Relación masa ósea/ Tóxicos

Tabaco

\begin{tabular}{llll}
\hline $\mathbf{1}^{\mathbf{a}}$ DMO & Valor & Significación & \\
\hline C. Lumbar & 2,729 &, 604 & NS \\
\hline Cadera & 3,935 &, 415 & NS \\
\hline $\mathbf{2}^{\mathbf{a}}$ DMO & & & \\
\hline C. Lumbar & 3,597 &, 463 & NS \\
\hline Cadera & 7,142 &, 129 & NS
\end{tabular}


Relación masa ósea/ Tóxicos

\begin{tabular}{llll} 
Alcohol & \multicolumn{3}{l}{} \\
\hline $\mathbf{1}^{\mathbf{a}}$ DMO & Valor & Significación & \\
\hline C. Lumbar & 11,803 &, 019 & NS \\
\hline Cadera & 8,122 &, 087 & NS \\
\hline $\mathbf{2}^{\mathbf{a}}$ DMO & & & \\
\hline C. Lumbar & 12,098 &, 017 & NS \\
\hline Cadera & 6,996 &, 136 & NS
\end{tabular}

Relación masa ósea/ Nivel cultural

\begin{tabular}{llll}
\hline $\mathbf{1}^{\mathbf{a}}$ DMO & Valor & Significación & \\
\hline C. Lumbar & 16,473 &, 036 & NS \\
\hline Cadera & 8,002 &, 433 & NS \\
\hline $\mathbf{2}^{\mathbf{a}}$ DMO & & & \\
\hline C. Lumbar & 18,779 &, 016 & NS \\
\hline Cadera & 9,514 &, 301 & NS
\end{tabular}

Relación masa ósea/ Actividad física

\begin{tabular}{llll}
\hline $\mathbf{1}^{\mathbf{a}}$ DMO & Valor & Significación & \\
\hline C. Lumbar & 13,859 &, 313 & NS \\
\hline Cadera & 15,560 &, 330 & NS \\
\hline $\mathbf{2}^{\text {a }}$ DMO & & & \\
\hline C. Lumbar & 13,516 &, 333 & NS \\
\hline Cadera & 12,191 &, 431 & NS
\end{tabular}

Si separamos la muestra según el $I M C$ no se aprecian diferencias significativas entre $1^{\mathrm{a}}$ y $2^{\mathrm{a}}$ densitometrías ni para la columna lumbar ni para la cadera. Al separar la muestra según los grupos si se observan diferencias estadísticamente significativas entre $1^{\mathrm{a}}$ y $2^{\mathrm{a}}$ densitometría, tanto para la columna lumbar como en la cadera.

Según la edad si existen diferencias estadísticamente significativas para C.L pero no para la cadera. Si comparamos los resultados de las densitometrías óseas al separar a los pacientes por sexo (varones y mujeres, ambos grupos) si se aprecian diferencias significativas tanto para la cadera como para la columna lumbar.

Respecto a los hábitos tóxicos no se han apreciado diferencias significativas ni para consumo de tabaco ni para el de alcohol de la muestra en global considerando consumo/no consumo de hábitos tóxicos. Tampoco comparando masa ósea $1^{\mathrm{a}}$ y $2^{\mathrm{a}}$ densitometría con los estudios y la actividad física se han observado diferencias estadísticamente significativas.

Al relacionar resultados de la masa ósea a nivel C.L y cadera consideradas en global con las patologías asociadas que presenta la muestra no se han establecido diferencias estadísticamente significativas con ninguna de ellas como tampoco para los A.F de HTA, obesidad y DM que se tuvieron en cuenta en la muestra. 
En el análisis bivariado, al comparar los resultados de la primera con la segunda DEXA, tanto de la muestra en global como de la muestra separada por grupos (varones, mujeres premenopáusicas y menopáusicas) no se encontró significación estadística, salvo al comparar el área $(\mathrm{cm} 2)$ y BMC (gr) de la C.L y de la cadera, tanto en toda la muestra en global como en los grupos donde si se observó significación estadística.

Al comparar las densitometrías de los varones con el grupo de mujeres menopáusicas se establecieron diferencias significativas entre el área y el BMC tanto de la cadera como de la columna lumbar. Cuando comparamos $1^{\mathrm{a}}$ con $2^{\mathrm{a}}$ densitometría en valores globales para toda la muestra obtenemos los siguientes resultados: en los pesos no hay diferencias estadísticamente significativas, tampoco al comparar el área de la columna lumbar de la $1^{\mathrm{a}}$ con la $2^{\mathrm{a}}$ DEXA pero si hay diferencias significativas entre el $\mathrm{BMC}$ y el $\mathrm{BMD}(\mathrm{gr} / \mathrm{cm} 2)$ de la columna lumbar entre $1^{\mathrm{a}}$ y $2^{\mathrm{a}}$ DEXA y también entre $\mathrm{T} 1$ de columna lumbar, T1 columna lumbar $\mathrm{P}$ y $\mathrm{Z}$ de columna lumbar y $\mathrm{Z}$ columna lumbar $\mathrm{P}$ entre la $1^{\mathrm{a}}$ y la $2^{\mathrm{a}}$ DMO. En la cadera al comparar $1^{\mathrm{a}}$ con $2^{\mathrm{a}}$ DEXA se observan diferencias significativas entre las áreas, el BMD y $\mathrm{T}$ de la cadera $\mathrm{P}$ y no hay diferencias entre las dos comparaciones de BMC, T30 cadera, $\mathrm{Z}$ cadera y $\mathrm{Z}$ cadera $\mathrm{P}$.

Las DMO en el grupo de los varones mostraban los siguientes resultados: entre ambos pesos no diferencias, tampoco en el área, BMD y BMC de la columna lumbar, si diferencias en $\mathrm{T}$ de la columna lumbar, T1 columna lumbar P y Z columna lumbar P y no diferencias para $\mathrm{Z}$ columna lumbar. En la cadera el grupo de los varones no presentaban diferencias estadísticamente significativas en ningún parámetro.

Las mujeres premenopáusicas presentaban diferencias significativas a nivel de la columna lumbar en todos los parámetros comparados menos en el peso y en el área de la columna y en relación a la cadera si se establecieron diferencias significativas a nivel del área de la cadera y no al comparar el resto de parámetros.

En el grupo de mujeres menopáusicas no diferencias en el peso ni en el área de la columna lumbar si para el resto de parámetros comparados para la columna lumbar. En relación a la cadera no diferencias significativas en ninguno de los resultados salvo en el BMD que si se presentan diferencias estadísticamente significativas. 


\section{RELACIÓN DMO CON RESTO DE VARIABLES \\ RELACIÓN DMO - GRUPOS DE LA MUESTRA}

Cuando relacionamos la densidad mineral de C.L al inicio de la muestra con los grupos de la muestra los varones y las mujeres premenopáusicas presentan con más frecuencia una densitometría normal, seguida de osteopenia leve, ningún caso de osteoporosis en los varones y sólo un caso en las premenopáusicas. En las menopáusicas hay más densitometrías con osteopenia leve que normales y con igual porcentaje osteoporosis que osteopenia grave. En la segunda DEXA empeora la situación de la masa ósea en los varones y mujeres premenopáusicas, aunque lo más frecuente es DEXA normal y después osteopenia leve aparece un caso de osteoporosis en el varón y dos en las mujeres. Las menopáusicas en esta DEXA más frecuente DEXA normal, disminuyen los casos de osteopenia leve pero aumenta el porcentaje de osteoporosis. Osteopenia grave se mantienen los casos. Respecto a la cadera, en la $1^{\text {a }}$ determinación igual situación que en C.L para varones y premenopáusicas, no osteoporosis en el varón y dos casos en las mujeres. Las menopáusicas situación en cadera similar que en C.L. en la $2^{\mathrm{a}}$ DEXA a este nivel se mantiene la misma situación en los tres grupos aunque ligero empeoramiento de la masa ósea en ellos.

DEXA/ grupos: peor situación mujeres menopáusicas pero el empeoramiento de la masa ósea es similar. Por grupos todos pierden igual.

\section{RELACIÓN DMO - IMC}

A nivel C.L en $1^{\text {a }}$ DEXA independiente del IMC lo más frecuente DEXA normal, seguida de osteopenia leve. En sobrepeso mayor porcentaje de osteoporosis que en obesidad. En la $2^{\mathrm{a}}$ DEXA se mantienen porcentajes similares aunque aparecen más casos de osteoporosis en sobrepeso y obesidad tipo I, en grados de IMC más altos la presencia de osteoporosis se mantiene. A nivel de la cadera en la $1^{\text {a }}$ DEXA lo más frecuente cifras de masa ósea normal, seguida de osteopenia leve, en todos los grados de obesidad, pero en sobrepeso y obesidad tipo I es donde hay más casos de osteopenia grave y osteoporosis. En $2^{\mathrm{a}}$ DEXA se mantienen los mismos resultados.

DEXA/IMC: peor masa ósea el sobrepeso. Igual masa ósea la obesidad tipo I y II. A mayor IMC mejor masa ósea a nivel C.L pero en obesidad tipo II y mórbida la situación de la masa ósea se mantiene y en los demás empeora. En cadera la obesidad tipo II mejor masa ósea y después en mórbida; se mantiene la situación entre las dos DEXA 


\section{RELACIÓN DMO - EDAD}

A nivel C.L en $1^{a}$ DEXA lo más frecuente DMO normal, seguida de osteopenia leve. El grupo de edad entre 45-65 años presenta el mayor porcentaje de osteopenia grave y un importante grado de osteoporosis que es igual al porcentaje de la enfermedad que sufren las mujeres de más edad. En la $2^{\mathrm{a}}$ DEXA se mantienen porcentajes similares aunque empeora la situación sobre todo en los pacientes más jóvenes. En C.L en la $2^{\text {a }}$ densitometría más osteoporosis en edad media 45-65años. A nivel de la cadera en la 1a DEXA lo más frecuente son cifras de masa ósea normal, seguida de osteopenia leve. No osteoporosis en menores de 45 años. El grupo que presenta más casos de osteopenia grave y también de osteoporosis es el grupo de más edad, mayores de 65 años. En la $2^{\text {a }}$ DEXA aparece osteoporosis en el grupo de menor edad y empeora el porcentaje de osteoporosis en el grupo de más de 65 años.

DEXA/edad: C.L peor situación edad entre 45-64,9 años. Cadera mejor situación 2944,9 años. Peor situación a mayor edad.

\section{RELACIÓN DMO - SEXO}

Lo más frecuente en ambos sexos es la DMO normal. En la $1^{\mathrm{a}}$ DEXA y en C.L los varones no tienen osteoporosis y sólo un caso de osteopenia grave, las mujeres presentan alta prevalencia de osteoporosis que de osteopenia grave con igual porcentaje en las dos situaciones, cerca del 25\% de las muestra; a este nivel en la $2^{\mathrm{a}}$ densitometría aparece osteoporosis en los varones y en las mujeres aumenta su prevalencia al disminuir las DEXA normales. Respecto a la cadera lo más frecuente es masa ósea normal seguida de osteopenia leve. No aparece a este nivel osteoporosis en los varones pero si en las mujeres con similar porcentaje que a nivel de la C.L, aquí ligeramente más bajo. En la segunda densitometría situación similar a la inicial, algún caso más de osteoporosis en las mujeres y se mantienen sin la enfermedad los varones.

DEXA/sexo: en C.L mucho peor situación en las mujeres aunque la progresión a osteoporosis es similar en ambos sexos. En la cadera no osteoporosis en los varones y ligera pérdida de masa ósea en las mujeres.

\section{RELACIÓN DMO - TÓXICOS}

Respecto al consumo de tóxicos no hay diferencias en las DEXA entre consumo/no consumo de tabaco y alcohol, en ambos casos la situación es igual. A nivel de la C.L lo más frecuente es la masa ósea normal, seguida de osteopenia leve, la osteoporosis es muy frecuente en los no consumidores de hábitos tóxicos y sólo hay un caso de la enfermedad en los fumadores a este nivel. 
La situación se mantiene en la $2^{\mathrm{a}}$ DEXA pero empeora el porcentaje de osteoporosis en los no consumidores. A nivel de la cadera la frecuencia es similar aunque no hay empeoramiento de la masa ósea entre ambas DEXA y no hay ningún caso de osteoporosis en los consumidores.

DEXA/ hábitos tóxicos: tanto en C.L como en cadera peor masa ósea en no consumidores, en C.L un caso de osteoporosis en los fumadores que se mantienen en el seguimiento, los no consumidores empeoran bastante su masa ósea a este nivel. En cadera no osteoporosis en los fumadores y se mantiene la frecuencia de osteoporosis que es similar a la de la C.L y la masa ósea entre las dos DEXA. En los consumidores de alcohol un solo caso de osteoporosis en C.L (ningún caso en cadera), mucho peor situación en los que no lo consumen con porcentajes importantes tanto de osteopenia grave como de osteoporosis.

\section{RELACIÓN DMO - NIVEL CULTURAL}

Hay una asociación entre bajo nivel cultural y osteoporosis aunque lo más frecuente es tener una densitometría normal. En C.L sólo un caso de osteoporosis en nivel cultural medio y uno en estudios superiores, en la $2^{\mathrm{a}}$ DEXA se repite la situación a este nivel pero se dobla el porcentaje de osteoporosis en paciente con nivel cultural alto. Para la cadera, en ambas densitometrías lo más frecuente es masa ósea normal. A este nivel no aparecen casos de osteoporosis en nivel cultural medio ni en estudios superiores y el porcentaje de osteoporosis en estudios primarios es similar a la que presentan estos pacientes a nivel de la C.L.

DEXA/nivel cultural: en C.L más osteoporosis en bajo nivel cultural, después en pacientes con estudios superiores. A nivel de la cadera sólo osteoporosis en estudios primarios no en el resto. Se mantiene la situación a lo largo del estudio aunque ligeramente peor los de menor nivel cultural.

\section{RELACIÓN DMO - ACTIVIDAD FÍSICA}

A nivel de la C.L en las dos DEXA lo más frecuente es la normalidad de la masa ósea, después la osteopenia leve. Más casos de osteopenia grave y osteoporosis en pacientes inactivos seguidos de los pacientes que realizaban una actividad intensa. A nivel de la cadera la situación es similar a la de la C.L pero se aprecia ligera mejoría a nivel de la masa ósea en la cadera sobre todo en el grupo que presentaba con más frecuencia osteopenia grave. 
DEXA/actividad física: en C.L inactivos tienen más osteoporosis después en activo intenso. Menos osteoporosis en pacientes que realizan ejercicio físico moderado. A lo largo del estudio empeora la situación en todos los grupos aunque más en inactivos y activos intensos. En cadera los peores los inactivos, poca osteoporosis en el resto y poca variación entre los dos estudios.

\section{DMO/antecedentes familiares:}

A.F de Obesidad: lo más frecuente tanto a nivel C.L como cadera en presencia o no de A.F de obesidad es masa ósea normal seguida de osteopenia leve. En $1^{\text {a }}$ DEXA más frecuente la osteopenia grave que la osteoporosis a este nivel y en $2^{\mathrm{a}}$ DEXA se igualan los porcentajes entre osteoporosis y osteopenia grave, algo más frecuente la presencia de osteoporosis en los pacientes con A.F de obesidad. En la cadera más frecuente la osteopenia grave que la osteoporosis, en la $1^{\text {a }}$ DEXA igual porcentaje de osteoporosis en ambos grupos de pacientes y en la $2^{\text {a }}$ DEXAla osteoporosis es el doble de frecuente en los que tienen A.F de obesidad que en los que no los tienen.

A.F de obesidad: a nivel C.L, en $1^{a}$ DEXA más frecuencia de osteoporosis en los pacientes con A.F aunque la padecen los dos grupos, en la $2^{\mathrm{a}}$ DEXA a este nivel se mantiene el porcentaje de la enfermedad en los que tienen A.F y casi dobla la frecuencia en los que presentan antecedentes igualando la prevalencia con los primeros. En la cadera igual porcentaje de osteoporosis en los dos grupos pero a lo largo del estudio aumenta casi el doble el porcentaje de osteoporosis en los que tienen A.F de obesidad.

A.F de DM: peores datos de masa ósea los pacientes sin A.F de DM. Presencia de osteoporosis alta en los que no tienen A.F de DM. Empeora la situación entre ambas densitometrías y en los dos grupos. La situación es similar para la C.L y la cadera donde la DEXA más frecuente es la normal seguida de osteopenia leve. Porcentaje alto de osteopenia grave y osteoporosis ligeramente más bajo en osteopenia leve pero distribución mucho más elevada para los pacientes sin A.F de DM.

A.F de DM: tanto a nivel de la C.L como de la cadera mucho más frecuente la osteoporosis en el grupo de los que no tienen A.F de DM y la situación empeora en los dos grupos entre las dos DEXA. La evolución de la masa ósea es similar pero mucho más frecuente la osteoporosis entre los que no tienen A.F de DM.

A.F de HTA: situación parecida a lo que ocurre con la DM, más presencia de osteoporosis en pacientes sin A.F de HTA. 
Empeora la situación de la masa ósea entre ambas DEXA tanto a nivel C.L como cadera pero, mientras que a nivel de la columna hay pacientes sin antecedentes de HTA pero con osteoporosis, a nivel de la cadera en la $1^{\text {a }}$ DEXA no hay ningún paciente con la enfermedad, en la segunda DEXA se multiplica por tres el número de casos y pasan a ser la mitad de los que presentan los pacientes sin A.F de HTA.

A.F de HTA: igual situación que en el caso de los A.F de DM. Mucho más frecuencia de osteoporosis en el grupo de los que no refieren A.F de HTA. En C.L empeora la situación en ambos grupos entre las dos densitometrías. En la cadera en la $1^{\text {a }}$ DEXA no casos de osteoporosis en los pacientes que no tienen A.F de HTA aunque en la segunda densitometría mejora la situación en los que presentan A.F de HTA y se multiplica por tres los casos de osteoporosis entre los que no tienen A.F de HTA.

\section{Dmo/patologías asociadas:}

- HTA: a nivel C.L igual porcentaje de osteoporosis entre los hipertensos que entre los que no lo son al inicio del seguimiento; al final del trabajo la evolución a osteoporosis es peor en los no hipertensos que casi doblan el número de pacientes que presentan osteoporosis. A nivel de la cadera igual distribución de la masa ósea entre los que paceden HTA como los que no y la evolución de la masa ósea a este nivel igual en los dos estudios.

- DM: sólo osteoporosis en pacientes sin enfermedad a nivel de la C.L y empeora la masa ósea entre las dos DEXA en los no diabéticos. Los que presentan DM no modifican la masa ósea a este nivel ni presentan osteoporosis. A nivel de la cadera un caso de DM con osteoporosis, mayor presencia de osteoporosis en los no diabéticos pero no se modifica la masa ósea a lo largo del seguimiento.

- Patología osteo-articular: mucho más alto el porcentaje de osteoporosis en los pacientes con este tipo de patología que entre los que no la presentan; igual situación a nivel C.L como en cadera y en ambos casos empeora la situación de la masa ósea entre las dos DEXA. Presencia de osteoporosis en pacientes con la patología y en los que no la presentan pero tres veces más frecuente la enfermedad en los que sufren patología osteo-articular asociada. La distribución se mantiene a lo largo del trabajo.

- Estreñimiento: a nivel C.L igual porcentaje de osteoporosis en presencia de estreñimiento como en ausencia, entre las dos DEXA empeora la situación pero se mantiene el porcentaje. En la cadera doble de pacientes con osteoporosis en los que presentan la enfermedad asociada que en los que no la padecen; se mantienen los porcentajes durante el seguimiento. 
- Patología vascular: tanto en cadera como a nivel C.L igual presencia de osteoporosis entre los que presentan esta patología como los que no la sufren. No se modifica la masa ósea entre los dos estudios pero mientras que la frecuencia de osteoporosis a nivel C.L es igual en los dos grupos, a nivel de la cadera la presencia de osteoporosis es el doble de frecuente en los que sufren patología vascular que en los que no la presentan.

- Otras patologías: peor situación masa ósea en los casos que presentan otras patologías a nivel columna lumbar y empeora la situación entre las dos DEXA. A este nivel los pacientes con otras patologías más del doble de frecuente la osteoporosis que los que no presentan otras patologías. En la cadera la situación es a la inversa, es más frecuente la osteoporosis en pacientes que no tienen otras patologías asociadas aunque la diferencia no es muy llamativa. No modificación de la masa ósea entre las dos DEXA.

En conjunto al relacionar la DMO con las distintas variables se observa peor situación de masa ósea a nivel C.L. Por edad en C.L peor situación entre 45-64,9 años, en cadera peor situación en grupo de mas edad y la mejor situación a este nivel los de edad más joven. Edad media la peor situación en global en las DMO. En relación al IMC mejor masa ósea las de grados más altos de obesidad pero estos mantienen la masa ósea y el sobrepeso y la obesidad tipo I empeora la situación sobre todo a nivel columna lumbar. Por sexos mucho peor situación las mujeres. Hábitos tóxicos no modificación masa ósea los fumadores y no comparable el alcohol por el bajo consumo. Peor evolución y situación bajo nivel cultural, también los que más empeoran. Inactivos y activos intensos peor situación de la masa ósea. HTA la patología asociada que menos diferencia presenta en la situación de la masa ósea entre los que la padecen y los que no. Peor evolución en los que no la sufren. DM baja prevalencia peor situación a nivel cadera en los que la padecen. Patología osteoarticular mucho más frecuente osteoporosis en los que presentan esta enfermedad y peor evolución a lo largo del seguimiento, los que no presentan esta enfermedad mantienen el porcentaje de osteoporosis.

En el estreñimiento igual presencia de osteoporosis en los que lo padecen como en los que no y se mantiene en el tiempo aunque empeora el porcentaje de osteoporosis en los dos grupos de pacientes. En cadera ocurre lo mismo pero la frecuencia de osteoporosis es el doble de frecuente en los que presentan estreñimiento que en los que no. Con la patología vascular igual situación que para el estreñimiento con igual porcentajes y evolución. Con la presencia de otras patologías a nivel C.L doble de frecuente la osteoporosis los que presentas otras enfermedades que los que no las presentan con peor evolución para los que las padecen. 
A nivel cadera peor porcentaje de osteoporosis en los que no presentan otras enfermedades asociadas pero se mantiene la situación no empeora. En los que padecen otras enfermedades menos osteoporosis aunque no mucha diferencia y en este grupo empeora la masa ósea.

Con los A.F de obesidad más osteoporosis en C.L en los que los tienen pero en la $2^{\mathrm{a}}$ DEXA se iguala la frecuencia en los dos grupos, en cadera igual porcentaje de osteoporosis en la $1^{\circ}$ DEXA pero en la $2^{\mathrm{a}}$ empeora la situación en los que tienen A.F y doblan el porcentaje. Con A.F de DM a nivel de la C.L mucho más elevada la frecuencia de osteoporosis en los que no tienen A.F de la enfermedad aunque la presentan los dos grupos. En la $2^{\mathrm{a}}$ DEXA empeora la masa ósea en ambos grupos y aumentan la prevalencia de osteoporosis. En cadera en pacientes con A.F de DM no hay osteoporosis en la primera DEXA si en los que no tienen estos antecedentes; en la $2^{\mathrm{a}}$ DEXA aparecen varios casos de la enfermedad en los que tienen A.F de DM y el otro grupo mantiene la masa ósea como al inicio. Respecto a los A.F de HTA a nivel C.L mucho más elevada la frecuencia de osteoporosis en los que no presentan A.F y aumentan la prevalencia en ambos grupos de forma similar. En la cadera en la $1^{\text {a }}$ DEXA no osteoporosis en los que tienen A.F de HTA si en el otro grupo, en la $2^{\mathrm{a}}$ DMO mejora el porcentaje de osteoporosis en los que no tienen A.F y se multiplica por tres la osteoporosis en los pacientes que tienen A.F de HTA. 
DISCUSIÓN 


\section{DISCUSIÓN}

Tanto la obesidad como la osteoporosis son un importante problema de salud pública ya que afectan a porcentajes muy elevados de población. Ambas enfermedades están consideradas como las grandes pandemias del siglo XXI de los países desarrollados y en vías de desarrollo y aunque son enfermedades totalmente diferentes, presentan muchas cosas en común.

Ambas son enfermedades crónicas, multicausales y multifactoriales. La osteoporosis es la enfermedad más frecuente del tejido óseo y la obesidad es la enfermedad metabólica más prevalente en el mundo occidental, las dos causan una elevada morbi-mortalidad y los costes socio-sanitarios que generan son muy importantes. Según datos del Ministerio de Sanidad un 7\% del gasto sanitario se destina a la obesidad y sus complicaciones, sobre todo cardiovasculares. (191)

Como diferencia entre ellas, es que mientras la obesidad es una enfermedad "evidente", la osteoporosis es una patología "silente" de diagnóstico y tratamiento generalmente tardío y cuando ya se han presentado complicaciones. La importancia de la obesidad radica en que conlleva asociada mayor prevalencia de presentar otras enfermedades crónicas, al estar la obesidad considerada como factor de riesgo para su padecimiento, como enfermedades cardiovasculares, HTA, apnea del sueño, DM tipo 2, dislipemias, hiperuricemia, patología osteo-articular, algunos tipos de cáncer... $(28,32,175,176)$ pero también, sobre todo el sobrepeso y la obesidad tipo I es factor protector para otras patologías como la osteoporosis.

Según el IMC el riesgo de comorbilidades asociadas a la obesidad es muy importante; su presencia se incrementa según aumenta el grado de obesidad, el riesgo va desde aumentado en personas que presentan sobrepeso, a riesgo severo y muy severo para obesidad grado II y obesidad mórbida respectivamente. $(21,177,178,179,180)$ La principal comorbilidad asociada al aumento de peso es la patología cardiovascular, donde la propia obesidad en sí misma, está considerada, de forma directa, factor de riesgo independiente de otros factores como la edad, sexo, colesterol, tabaco...pero también de forma indirecta ya que la obesidad es factor predisponente para padecer entre otras enfermedades HTA, DM, dislipemias, hiperuricemia...que afectan al sistema cardiovascular. $(21,81)$ 
Según los autores del estudio Framinghan Herat Study (238) la HTA y el colesterol aumentan el riesgo de enfermedad coronaria, la HTA aumenta el riesgo de ictus y relacionan DM con enfermedad cardiovascular. También asocian aumento de triglicéridos y colesterol LDL con enfermedad coronaria y mortalidad. Este trabajo relaciona con el riesgo cardiovascular factores ambientales como hábitos tóxicos, ejercicio físico y susceptibilidad genética.

Los factores asociados a la acumulación de grasa abdominal como el contorno de cintura indican que un valor mayor de $95 \mathrm{~cm}$ en los varones y mayor de $82 \mathrm{~cm}$ en las mujeres, se asocia riesgo cardiovascular aumentado y mayor riesgo de mortalidad, a la vez que estos riesgos aumentan según aumenta el contorno de cintura, a pesar de que algunos autores concluyen en sus trabajos que la distribución de la grasa en la zona abdominal es independiente de la progresión del daño vascular. (239)

La obesidad como factor de riesgo cardiovascular en sí misma,(240) produce una disminución significativa de la esperanza de vida ya que aumenta la mortalidad global hasta en un $30 \%$ por cada 5 puntos adicionales al IMC(31); Lee IM et al y Manson JE et al $(13,14)$ determinaron un mayor riesgo de muerte en sujetos con IMC mayor de $27 \mathrm{y}$ claro aumento del riesgo de muerte si el IMC es mayor de 30 tanto para los varones como para las mujeres; si tengo estos datos en cuenta, la muestra estudiada presenta riesgo aumentado de sufrir patología cardiovascular y mayor riesgo de muerte en más del $46 \%$ de los pacientes por presentar un IMC $>30$.

Teniendo en cuenta la RCC, en nuestra muestra el varón tipo con riesgo de muerte y enfermedad cardiovascular aumentado, es un varón mayor de 45 años, con bajo nivel cultural, obeso pero con actividad física intensa. Las mujeres premenopáusicas presentan un mayor riesgo asociado a alto IMC $>27$, inactividad pero con un elevado nivel cultural, las menopáusicas asocian mayor riesgo a inactividad, mínimo nivel cultural y IMC > 30. En las mujeres no hay diferencias entre los grupos de edad respecto al riesgo aumentado de muerte y de padecer enfermedad cardiovascular, por lo que este riesgo, en mi trabajo se relaciona más con el sexo, riesgo más alto en sexo masculino, con un grado de obesidad importante y con la menopausia.

Los datos del estudio SEEDO 2000(10) presentan un porcentaje de obesos en España entre 25- 60 años del 14,5\% en global, con un 15,7\% de varones y un 13,39\% de mujeres obesas. El sobrepeso de un $39 \%$ en total y un $49 \%$ para los varones y un $32 \%$ para las mujeres; las cifras globales de obesidad mórbida en España son de un 0,5\%. 
Nuestra muestra presenta toda ella un IMC elevado mayor o igual a 25 , y la distribución no es muy homogénea debido a que el número de pacientes varones es bajo, un $18,8 \%$ respecto al $81,2 \%$ de mujeres, por lo que no podemos equiparar los datos. Por grupos de edad el grupo mayoritario es el que tenía entre 45 - 64,5 años que era casi la mitad de la muestra, 49\%, 28,4\% tenía entre 29 y 44,9 años y un $22 \%$ eran mayores de 65 años por lo que algo más del $80 \%$ de la muestra presentaba una edad equiparable al grupo de estudio de la $\operatorname{SEEDO_{(10)}}$ y la distribución según el IMC de mi población estudiada mostraba que el $38,6 \%$ de los pacientes presentaba sobrepeso, valores iguales a las del estudio SEEDO 2000(10), obesidad presentaba el 46,54\% de la muestra y el $14,92 \%$ obesidad mórbida; este tipo de obesidad sólo la presentaba las mujeres, los varones no presentaba ninguno este grado de obesidad.

Tanto el estudio SEEDO 2000(10) como otros muchos trabajos (182,183) concluyeron que las mujeres mayores de 45 años y con bajo nivel cultural es el grupo de población en España con más riesgo de presentar obesidad (8,184,185) sin embargo en nuestra muestra el grupo con mayor porcentaje de obesidad y menor nivel cultural es el grupo de mujeres menopáusicas lo que indica que en nuestros pacientes el grado de obesidad está más en relación con la edad que con el nivel educacional que en nuestra muestra. Es el grupo de mujeres más jóvenes el que presentaba mayor nivel cultural, más del $55,5 \%$ de ellas referían estudios superiores. El menor nivel cultural en la muestra lo presentaban las mujeres de más edad y los varones presentaban el mayor porcentaje de estudios medios.

En la muestra estudiada el IMC se asocia de forma negativa a la edad, al sexo, al nivel cultural y a la baja actividad física, IMC mayor en mujeres mayores, más frecuente en menopáusicas, con nivel cultural bajo y poca actividad física.

Un 16,6\% de las mujeres menopáusicas presentan obesidad mórbida, el 72,7\% del total en la muestra, los varones ninguno de ellos presentaba este grado de obesidad que se asocia en nuestra muestra a sexo femenino y a edad avanzada, aunque hay que matizar que el número de varones en nuestra muestra es bajo como ya he comentado.

La actividad física también presentaba influencia en la muestra ya que el grupo de mujeres de menor edad era el grupo de población que más ejercicio realizaba, aspecto que contradice los resultados del estudio SEEDO 2000(10) y otros trabajos que indican que mujer joven, con bajo nivel cultural y baja actividad es indicador de aumento de prevalencia de obesidad, sin embargo es cierto que una mínima actividad física es factor predisponente de obesidad ya que un obeso al tener menor movilidad promueve más sedentarismo y da lugar al círculo vicioso obesidad-sedentarismo-obesidad. 
Esto se pone de manifiesto en la muestra estudiada ya que un $45,5 \%$ del total de la muestra estaba inactivo, el resto realizaba diferente grado de actividad. La muestra inactiva no presentaba ni actividad laboral ni actividad física aunque llevaba una vida normal. Por sexos un $10,5 \%$ de los varones no realizaban ningún tipo de actividad física, más del $42 \%$ realizan actividad laboral pero no ejercicio físico extra (activos sedentarios), un 36,8\% de ellos tiene actividad intensa. Las mujeres premenopáusicas, son las que más ejercicio físico realizan, más del 70\% de ellas trabaja fuera de casa y hace ejercicio físico de forma regular además de la actividad laboral. Las mujeres menopáusicas, el 81,2\% inactivas aunque todas realizaban las tareas domésticas.

La presencia de obesidad está relacionada con factores medioambientales y el estilo de vida; la obesidad es la $2^{\text {a }}$ causa prevenible de muerte después del tabaco. El aumento de peso también es cada vez más frecuente en la población infanto-juvenil ligado, muchas veces con el estilo de vida y por supuesto con los antecedentes familiares de obesidad ya que está demostrado que la probabilidad de padecer la enfermedad si uno o los dos progenitores son obesos es muy elevada. La insistencia en la edad infantil sobre la importancia de una vida saludable es determinante para prevenir la obesidad en la edad adulta sobre todo teniendo en cuenta la elevada presencia de adultos obesos que han padecido obesidad infantil y muchos de ellos la han mantenido a lo largo del tiempo.

La obesidad se asocia de forma directa con los antecedentes familiares de obesidad, con la HTA y también con la DM como factores de riesgo para su padecimiento. En nuestra muestra he determinado que pacientes padecían obesidad desde la infancia, persistencia de la misma a lo largo del tiempo y cuales de éstos obesos presentaban antecedentes de la enfermedad, también he tenido en cuenta la presencia de HTA y DM y la presencia de A.F de estas enfermedades como factor de riesgo para su padecimiento.

Aunque los A.F no son un factor modificable, según todos los trabajos consultados, la presencia de A.F en alguno o los dos progenitores de los pacientes que las padecen es muy elevado como concluyen los autores Mo-suwan y Geater A.F(186) en su trabajo publicado en el Internacional Journal of Obesity que indicaban que el riesgo de padecer obesidad se multiplicaba por 3,1 en pacientes con A.F de la enfermedad, en el caso de la HTA, la presencia de A.F de la enfermedad aumentan el riesgo de padecerlas por 4 según los resultados de los estudios de Corvol $P$ et al y de William RR et al $(187,188)$ y entre 2 y 4 veces para la DM en el caso de que alguno de los progenitores sufra DM tipo 2 según Pierce $M$ et al(189). 
Los A.F de DM eran 2,3 veces más frecuentes en pacientes con DMNID que en los no diabéticos según Elbagir MN et al.(190)

En la muestra, para el caso de la obesidad, más del $50 \%$ de los pacientes presentaba A.F de obesidad en alguno de los padres, respecto a la HTA el 27\% presentaba A.F de le patología y en la DM el 32\% referían A.F de la misma.

La obesidad desde la infancia es la causa más frecuente de obesidad en global, y todos los pacientes que la presentaban referían A.F de la enfermedad. El 53,5\% del total de la muestra tenían A.F de obesidad, porcentaje muy elevado en la muestra, incluso mayor que los resultados que presentaron Mo-suwan, Geater A.F et al. (186) En los varones, la presencia de A.F de obesidad la refieren casi el $58 \%$ de ellos y obesidad desde la infancia con A.F de obesidad presentaba el 15,8\%. En las mujeres, la obesidad desde la infancia es la causa más frecuente en ambos grupos pero la presencia de A.F es mayor en las mujeres premenopáusicas que en las menopáusicas con un 56\% y un 50\% respectivamente. Premenopáusicas con obesidad desde la edad infantil y A.F de la enfermedad casi el $30 \%$ de ellas, menopáusicas con obesidad infantil y A.F de obesidad el $31,2 \%$.

En el caso de la hipertensión arterial un 26,7\% de los pacientes tenía antecedentes familiares de la enfermedad, porcentaje similar a la presencia de la patología en la muestra, presente en un $23,8 \%$, valor más bajo que la media de la población española que según los datos de la $E S N$ (191) ronda el 34\%. La presencia de HTA es más frecuente en las mujeres menopáusicas y también la presencia de A.F, después en los varones donde se iguala en porcentaje los que presentan la enfermedad y los que refieren A.F, sin embargo los varones hipertensos que presentan A.F de la enfermedad sólo son el 25\%.

Las premenopáusicas doblan en número la presencia de A.F a las que sufren HTA y las que asocian enfermedad y A.F son la mitad de las hipertensas. Las mujeres menopáusicas presentan un mayor porcentaje de hipertensión que de A.F y la presencia de los dos factores asociados, hipertensión y A.F de la enfermedad lo refieren le mitad de las menopáusicas hipertensas.

En el caso de las mujeres, los A.F de la enfermedad son mucho más elevados que la presencia de HTA, sin embargo hipertensión arterial y A.F aparecen en la mitad de las pacientes que sufren la enfermedad, en los varones se iguala presencia de enfermedad y de A.F pero HTA con A.F de la misma sólo aparece en un cuarto de los hipertensos. 
En relación a ésta patología, según las características de la muestra, podemos determinar que la presencia de hipertensión arterial será más elevada en un futuro según el porcentaje de estos antecedentes familiares existente. Si consideramos los resultados de Juhaeri et al que concluyeron que indistintamente del sexo, el aumento del peso se relacionaba con el incremento de la T/A y con el aumento de su incidencia, en nuestra serie, el aumento de la T/A si está relacionado con el sexo, es más frecuente en las mujeres, asociado a la edad y al IMC como también concluyó el trabajo de Josep Redon y Empar Lurbe(242) Si relacionamos HTA y DM mis resultados en relación a la prevalencia y distribución por sexos coincide con el estudio de Según Cosin Aguilar et al (192), sin embargo concluyen que existe mayor prevalencia de DM en los pacientes hipertensos que mi muestra no se produce.

La presencia de diabetes, era baja en la muestra, aunque la presencia de antecedentes familiares de ésta patología tiene un elevado porcentaje, un 31,7\%. En la muestra la presencia de la enfermedad es de un 4\%, La presencia conjunta de A.F y enfermedad es del $3 \%$.

Respecto a la DM es mucho más frecuente los antecedentes familiares de la misma en mujeres premenopáusicas, sin embargo ninguna de ellas presentaba la enfermedad, por lo que para el sexo femenino, la DM se asocia a la edad y a la menopausia más que con el grado de obesidad. Si tenemos en cuenta los resultados obtenidos la presencia de DM en nuestra muestra será mucho más alta dentro de unos años ya que, el riesgo de padecer la enfermedad se multiplica por 2 o 3 según los antecedentes familiares.

Según los resultados del trabajo de Fox et al(193) la prevalencia de DM se asocia 23 veces más a la probabilidad de padecer enfermedad cardiovascular, también la intolerancia a la glucosa se asocia a un aumento de riesgo de 1,5 veces de presentar patología cardiovascular según Kannel WB et al(194) y este riesgo, según Goldschmid et $a l(195)$, es mayor en mujeres que en varones resultados que coinciden con los míos, sin embargo respecto a los datos de España en cuanto a distribución de la prevalencia, los datos se invierten ya que en nuestro país es más frecuente la DM en los varones que en las mujeres con un 12\% y un $8 \%$ respectivamente según el estudio de Goday A,(196) sobre epidemiología de la DM y sus complicaciones no coronarias.

Un aumento de la prevalencia de la obesidad lleva a un aumento de la prevalencia de la DM según los resultados de Eckel RH et al (197) en un estudio para la Asociación Americana de Diabetes y la Asociación Americana del corazón sin embargo en nuestra muestra, que toda presenta un IMC elevado, la prevalencia de la enfermedad es muy baja. 
Los A.F de obesidad son más frecuentes en los varones que en las mujeres, en la HTA son más frecuentes en las mujeres con similar porcentaje en ambos grupos sin embargo, en el caso de la DM los A.F están más presentes en las mujeres pero son mucho más frecuentes en el grupo de las mujeres premenopáusicas. La presencia de antecedentes familiares de las tres enfermedades es más alta en mujeres premenopáusicas pero también son las que menos casos de las patologías presentan. En la muestra estas comorbilidades asociadas a la obesidad son más frecuentes en mujeres, asociadas a la edad y la menopausia. Los varones refieren más antecedentes familiares de obesidad y menos de DM e HTA. Las menopáusicas comentan menor porcentaje de A.F de las patologías, sin embargo son las que más las sufren. Según estos datos la intervención temprana es la mejor opción para prevenir la obesidad y evitar comorbilidades.

No sólo la obesidad es causa prevenible, la HTA y la DM también lo son, es posible disminuir su prevalencia o alargar en el tiempo el momento de su aparición si en pacientes con antecedentes familiares de estas patologías son sometidos a medidas preventivas.

La mejoría importante y muy significativa que hemos obtenido en los valores de la T/A en todos los pacientes sólo con medidas higiénico-dietéticas basadas en dieta hipocalórica e hiposódica y con ejercicio físico hacen posible confirmarlo a pesar de que la pérdida de peso en la muestra no ha sido muy significativa.

Todos los grupos presentaron descensos importantes de las cifras de tensión arterial con las medidas higiénico-dietéticas prescritas (dietas bajas en calorías, no abuso de la sal y ejercicio físico regular según posibilidades); el descenso más llamativo tuvo lugar en el grupo de los varones donde el descenso en la T/A sistólica fue de 9 $\mathrm{mmHg}$ y en $3 \mathrm{mmHg}$ disminuyó la diastólica; en el grupo de las mujeres la disminución de las cifras fue de $3 \mathrm{mmHg}$ para la T/A sistólica y $4 \mathrm{mmHg}$ para la diastólica.

La menopausia tiene cifras de T/A más altas que las premenopáusicas. La mejoría de la T/A es evidente con la disminución del peso, este beneficio es independiente de la alimentación y mejora con el ejercicio físico.

En la tesis se ve una mejoría significativa en las cifras tensionales a pesar de que la disminución del IMC es muy pequeña, esto puede indicar dos cosas: la primera que pequeñas reducciones del peso son importantes en el control de las cifras tensionales como ya constató Stevens VJ et al (30) en su trabajo al comprobar que la disminución de peso también hacía desceder las cifras de la tensión arterial y la segunda, la más 
probable según mi trabajo, que una dieta saludable y ejercicio físico regular mejora las cifras de la T/A de forma importante y en los casos de HTA con valores moderados con una dieta controlada, controles periódicos y ejercicio físico regular adaptado al paciente podría no ser necesario el empleo de fármacos antihipertensivos o retrasarlos en el tiempo.

Además de las enfermedades anteriores hay otras muchas asociadas a la obesidad como las dislipemias, hiperuricemia, alteraciones psicológicas, patología osteoarticular... En la muestra las patologías más frecuentes que padecían los pacientes son la patología osteo-articular presente en un $57,4 \%$ de ellos, seguida de la patología vascular 45,5\% y después del estreñimiento con igual porcentaje.

La presencia de colelitiasis en el 5\% sólo en mujeres, las dislipemias diagnosticadas como tal patología las presentaba el 8\%, también sólo en mujeres y sólo en la menopausia, las enfermedades respiratorias las referían un 6\% de la muestra con distribución bastante similar en ambos grupos.

Un 3\% de pacientes referían cardiopatía isquémica pero las alteraciones vasculares las presentaba un $43 \%$ de los pacientes.

Por grupos, los varones presentaban con mayor frecuencia patología osteoarticular, seguida de la HTA y el estreñimiento con igual porcentaje y la patología vascular en tercer lugar; las mujeres premenopáusicas presentaban en primer lugar el estreñimiento como patología asociada más frecuente, seguida de la patología osteoarticular y patología vascular. En el grupo de mujeres menopáusicas la presencia de patología osteo-articular está presente en 3/4 de ellas seguida de la patología vascular y el estreñimiento.

Hay que resaltar que la totalidad de las mujeres menopáusicas presentaban patologías asociadas que confirma que la edad es factor de riesgo importante para presentar enfermedades y aunque en ésta muestra el sexo es también factor relevante no podemos confirmarlo dado el pequeño tamaño de la muestra en los varones. En general el sexo masculino presentaba menos patologías que las mujeres.

El consumo de fármacos está en relación a las patologías presentadas. Los fármacos más consumidos por la muestra son la fibra y los coadyuvantes de la dieta, el segundo lugar es para los analgésicos-antiinflamatorios y después los vasoprotectores. Por grupos, los varones consumen más hipotensores, después fibra y coadyuvantes de la dieta y en tercer lugar analgésicos-antiinflamatorios. Las mujeres premenopáusicas lo que más consumen son fibra y coadyuvantes de la dieta, seguido de psicofármacos y analgésicos-antiinflamatorios en igual porcentaje de consumo. 
Las mujeres menopáusicas presentan el mismo orden de consumo que la muestra en global, fibra, anti-inflamatorios y analgésicos y vasoprotectores. A pesar de no haber considerado dentro de la encuesta las alteraciones psicológicas de la muestra como enfermedad grave como tal, hay que señalar que la baja autoestima, la depresión, ansiedad...están muy presentes en la muestra como demuestra el consumo de psicofármacos.

Antes del estudio Framinghan,(238) el tabaco no era considerado como factor de riesgo de patología cardiovascular, incluso se puso en duda la evidencia del riesgo en un trabajo de la American Heart Association(197) donde se concluía que la que la asociación de consumo de cigarrillos - riesgo cardiovascular no era evidente.

Después de este esta publicación el Framinghan Study y el Albany Cardiovascular Health Center Study(175) demostraron que los fumadores presentaban un aumento del riesgo de infarto de miocardio o muerte súbita. Además relacionaban este riesgo con el número de cigarrillos consumidos día. En nuestro país, Grau M et al (198) en su trabajo Trends in Cardiovascular Risk Factor Prevalence (1995 - 2005) in Northeartern Spain determinaron que la prevalencia de tabaquismo en España es muy elevada, aunque ha disminuido ligeramente en los varones y ha aumentado en las mujeres en la última década, según estos datos, fuma el $35 \%$ de los varones en España y el 23\% de las mujeres.

En mi serie fuma el $17,8 \%$ de los pacientes; por grupos fuma el $21 \%$ de los varones, el 32,3\% de las mujeres premenopáusicas y el 6,2\% de las menopáusicas, datos que no coinciden con las prevalencia del país donde fuman más los varones. Un 5\% toma alcohol, por grupos el $21 \%$ de los varones y el $2,9 \%$ de las mujeres premenopáusicas, no consumen alcohol las menopáusicas. Insistir en el bajo número de varones de la serie pero a diferencia de muchos trabajos consultados donde el sexo masculino presenta peores prevalencias en patologías y riesgo de morbi-mortalidad en mi serie, este grupo, a pesar de tener en principio más factores de riesgo no es el más representativo.

Al relacionar la muestra por grupos, varones, mujeres pre y menopáusicas con las patologías asociadas no hay diferencias significativas entre los grupos ni para DM ni para HTA pero sí para el resto de enfermedades asociadas. Separada la muestra por sexos, varones y mujeres, ocurre al contrario se observan diferencias significativas para todas las enfermedades asociadas pero no para la DM ni para la HTA. Por sexos si hay diferencias significativas para el consumo de alcohol pero no para el consumo de tabaco. 
Las alteraciones metabólicas más asociadas a la obesidad están relacionadas sobre todo con el perfil lipídico. Generalmente hay aumento del colesterol total y los triglicéridos, el LDL-colesterol suele estar elevado o normal y suelen tener un nivel bajo de colestrol-HDL. También presentan intolerancia a la glucosa y aumento del ácido úrico. Pequeñas pérdidas de peso mejoran el riesgo cardiovascular, aumenta las cifras de colesterol-HDL, baja los valores de colesterol total y los de colesterol-LDL. También disminuye el ácido úrico y la T/A. La realización de ejercicio físico de forma regular tiene similares efectos que la pérdida de peso. (199)

En la muestra, en cuanto a los valores obtenidos en las analíticas, los varones son los que peores resultados presentan; respecto a las cifras de glucosa aunque disminuye el porcentaje total de varones con hiperglucemia, el incremento de las cifras de glucosa es de un 6\%, lo mismo ocurre con las mujeres menopáusicas, presentan valores elevados un porcentaje importante de ellas que mejora al final del estudio, pero el incremento de las cifras también es alto, un $4 \%$ aunque mejor que el de los varones.

La hiperuricemia, relacionada con la obesidad y la menopausia está presente en un tercio de las mujeres con menopausia aunque mejora ligeramente el porcentaje de las que la presentan y también bajan las cifras. Las mujeres premenopáusicas, las que mejores valores analíticos presentan de inicio, no tienen elevadas las cifras de ácido úrico pero a lo largo del estudio casi un $4 \%$ de ellas presentan hiperuricemia. La creatinina aumenta en todos los grupos por igual en torno al 6\%. Las proteínas totales descienden sus valores en todos los grupos salvo en el grupo de mujeres premenopáusicas que aumentan en un $1,4 \%$ sus cifras. Los varones presentan el descenso más acusado de las proteínas totales con un 2,8\%. En el caso de la albúmina también desciende en todos los grupos salvo el de mujeres premenopáusicas que no se modifica.

En la muestra la hiperuricemia se asocia al grado de obesidad y al incremento de las cifras de glucosa y calcio.

Cuando correlacionamos cifras de colesterol plasmático elevadas $(>200 \mathrm{mg} / \mathrm{dl})$ e hipertensión arterial, factores importantes de riesgo cardiovascular según los datos del estudio Framinghan Heart Study(238) y los resultados de los trabajos de The Pooling Proyect Research Group, (200) se observó que aumentaba la mortalidad global; en mi serie un porcentaje muy alto, $67,3 \%$ presenta cifras por encima de $200 \mathrm{mg} / \mathrm{dl}$ y un $5 \%$ mayores de $275 \mathrm{mg} / \mathrm{dl}$ a pesar de que el diagnóstico de hipercolesterolemia como tal sólo estaba presente en el 8\% de la muestra y sólo en menopáusicas. 
Los peores resultados de colesterol lo presentaban las mujeres premenopáusicas con casi un $6 \%$ de ellas con cifras por encima de $275 \mathrm{mg} / \mathrm{dl}$. También son importantes las cifras del LDL, lipoproteína que transporta el colesterol, las conclusiones de los estudios de Gofman JW et al y Kannel WB et al (201,202) junto con los resultados del estudio Lipid research Clinics Program(203) resaltan las importancia de sus valores, indican que es un importante indicador de inicio de tratamiento para combatir la hipercolesterolemia y es factor de riesgo cardiovascular.

También insisten en la importancia de una detección precoz de sus valores en edades tempranas para la prevención cardiovascular. En la muestra un cuarto de ella presentaba cifras de LDL-colesterol por encima de $160 \mathrm{mg} / \mathrm{dl}$, peores en menopáusicas y varones.

Según Gofman JW et al y Kannel et al, (201,202) niveles altos de HDL colesterol se asocian a menor presencia de enfermedad cardiovascular que sujetos con cifras bajas, pero hubo que esperar a la publicación de los resultados del estudio Framinghan y los de Cooperative Lipoprotein Study para que el HDL fuera relacionado con la aterosclerosis. Gordon DJ et al en un estudio prospectivo en población americana para relacionar HDL colesterol con el riesgo cardiovascular concluyeron que un aumento de $1 \mathrm{mg} / \mathrm{dl}$ en la concentración de HDL se asocia a una disminución del riesgo coronario de un $2 \%$ en varones y un $3 \%$ en las mujeres. El grupo de menopáusicas presentan las cifras más altas de HDL en la muestra a pesar de tener el resto de valores del perfil lipídico peor, en este caso sería factor protector, los varones presentan las cifras más bajas de colesterol-HDL aunque a lo largo del seguimiento en ningún grupo mejoraron los valores.

Los TG no está tan claro que sean factor de riesgo como demuestra el trabajo de Sarwar $N$ et al (204) que realizó un metaanálisis de riesgo cardiovascular en 2007, en mi muestra, los valores de TG no son demasiado altos, los datos peores los varones.

En España según un metaanálisis de estudios transversales de Medrano et al (205) en 2005 en la población española reflejó que la presencia de hipercolesterolemia, con cifras por encima de $250 \mathrm{mg} / \mathrm{dl}$ es del $23 \%$ de la población, cifras similares a las de mi trabajo en el que destaca la baja frecuencia de hipertrigliceridemia que presentaba la muestra y el elevado porcentaje de altas cifras de LDL, este parámetro es el que más empeora en global, todos los grupos aumentas sus cifras menos el grupo de las menopáusicas. 
Colesterol, LDL y triglicéridos aumentan con la menopausia mientras que disminuye el HDL-colesterol, sin embargo en la muestra estudiada, el grupo de mujeres menopausia es el que presenta cifras más altas de HDL, TG normales casi en la totalidad del grupo y las cifras de LDL disminuyeron aunque de forma poco importante así que en este trabajo sólo puedo asociar a la menopausia la hipercolesterolemia no el resto de parámetros lipídicos puesto que sus cifras están prácticamente en su totalidad, dentro de los valores normales.

Peores cifras de analítica las mujeres menopáusicas, después los varones. Mejoran los resultados en menopausia y empeoran en premenopáusicas.

Si tenemos en cuenta los resultados de Anderson y Konz (206) que observaron que por cada $\mathrm{kg}$ de peso perdido disminuyen entre $1 \%$ y $2 \%$ los valores del perfil lipídico y la glucemia en nuestra serie, esto ocurre en las mujeres menopáusicas, donde mejoran todos los resultados, sin embargo, aunque Solá et al (207) también concluyeron que con la pérdida de peso mejoran los factores de riesgo asociados a la obesidad, estos autores referían mejores resultados para los varones, datos que no se observan en mi estudio, aunque tampoco se refleja pérdida de peso en este grupo.

Puesto que la obesidad protege contra la osteoporosis y evita que se pierda masa ósea he determinado la situación de la masa ósea que presentaban los pacientes de la muestra al inicio y al final del estudio y he valorado su evolución durante los dos años de seguimiento a la vez que he relacionado con ella los diferentes parámetros estudiados y las variables analizadas. He determinado la influencia tanto del IMC como del resto de factores estudiados sobre la masa ósea. La obesidad protege frente a la osteoporosis por distintos mecanismos: incrementando la concentración plasmática de estrógenos libre, promoviendo la formación ósea mediante estímulos mecánicos y proporcionando un acolchamiento natural alrededor de los huesos en caso de caídas como demuestran distintos trabajos que han correlacionado de forma positiva la masa ósea con masa grasa $(208,209)$. Las personas con peso elevado y cierto grado de obesidad, presentan alta protección contra las fracturas osteoporóticas. (210) Hay factores fisiológicos que influyen tanto en la obesidad como en el estado de la masa ósea como son además de la edad, la pubertad, gestación y menopausia sin embargo los estudios que evalúan factores determinantes de densidad mineral ósea son poco consistentes. Factores reproductivos como edad de menarquia, embarazo, lactancia presentan diferente grado de asociación con la DEXA e incluso ausencia de asociación como ocurre con los hábitos tóxicos, tabaco, alcohol, cafeína y con el consumo de fibra y calcio. 
Los resultados más consistentes se han establecido entre la asociación de la actividad física, IMC, edad, raza, A.F de osteoporosis y niveles de densidad mineral ósea. Determinante también de la densidad minaral ósea es la menopausia.

La densitometría ósea es el factor predictor más importante del riesgo de fracturas, por cada DS se pierde un $12 \%$ de masa ósea. Las densitometrías fueron obtenidas por DEXA que según la OMS es la mejor técnica diagnóstica. Esta técnica emplea dos haces emitidos por una fuente de rayos $\mathrm{X}$ de distinta energía que diferencian la atenuación del tejido blando; presenta como ventajas la baja radiación, alta precisión y fiabilidad y posibilidad de medir esqueleto axial y periférico. Es valor predictivo de fracturas. Cosas en contra su alto coste, gran tamaño, espacio y manejo por especialista. Sus principales indicaciones son determinar la densidad mineral ósea (BMD) y valoración del tratamiento. Se expresa en gr/cm2 (valor de masa ósea) y son las diferencias más pequeñas detectables.

El DEXA, puede hacer un estudio comparativo entre varias densitometrías y nos dice si es o no significativo el resultado porque el aparato lleva incluido el nivel de confianza. El riesgo de fractura aumenta con disminución de la masa ósea, aunque no hay umbral, el riesgo es continuo. A menor DMO mayor riesgo de fractura. Se estudia columna lumbar desde L1-L4 para valorar masa ósea y es la zona óptima para monitorizar la respuesta al tratamiento. En la cadera además de valorar la masa ósea, es la zona óptima para valorar riesgo de fractura (cuello, trocánter, cadera total). El triángulo de Ward no es relevante y puede dar falsos positivos ya que el aparato escoge la zona de menor masa ósea por defecto y los resultados pueden no ser precisos. (128)

La masa ósea se expresa en relación a dos factores: Z-escore y T-escore:

- Z-escore: masa esperada en relación con la edad y los años de la paciente

- T-escore: compara datos obtenidos del paciente con los del joven normal.

La situación de la masa ósea de este trabajo indica una prevalencia de osteoporosis más baja que los datos obtenidos por otros autores si tenemos en cuenta los resultados de la muestra en global (varones y mujeres pre y menopáusicas), año 2000 un 10,9\% osteoporosis en C.L y un 7,9\% en cadera. Dos años después un 13,9\% osteoporosis en C.L y un $11,9 \%$ en cadera. Por sexos las mujeres presentan cifras de osteoporosis tanto al inicio (13,5\%) como dos años después $(15,3 \%)$ similares o incluso algo más altas que en los trabajos consultados; en España la osteoporosis ronda el 13\%, pero si dividimos a las mujeres en pre y menopáusicas la presencia de osteoporosis en las últimas es muy elevada. 
Diez Curiel et al (123) en 1997 en una muestra de mujeres entre 40 -70 años observaron que un $12 \%$ de ellas a nivel de la C.L y un $7 \%$ a nivel de la cadera presentaba la enfermedad. Datos más elevados obtuvo Esteban y cols en una muestra de mujeres menopáusicas en un trabajo de 1998 donde un 17\% presentaba osteoporosis en C.L y un 16,7\% en cadera; en mi trabajo, las mujeres premenopáusicas (29-50 años) presentaban cifras bajas de patología, un $2,9 \%$ en C.L y un 5,9\% en cadera al inicio, año 2000 y un $5,9 \%$ en C.L y un $8,8 \%$ en cadera en la segunda determinación (2002), sin embargo en el grupo de mujeres menopáusicas un 20,8\% presentaba osteoporosis en C.L y un $12,5 \%$ en cadera y dos años después, un $22,9 \%$ en C.L y un $18,7 \%$ en cadera presentaban la enfermedad cifras con valores superiores a los estudios consultados a pesar de que esta muestra presenta como factor protector un alto IMC. La población en los trabajos comparados es normal sin enfermedades ni tratamientos asociados y mi muestra y en especial el grupo de mujeres menopáusicas todo él presentaba patologías asociadas y un porcentaje alto tomaba algún tipo de tratamiento. Pérez Castrillón et al en el año 2003 en mujeres españolas concluyó que el 22\% de ellas presentaba la enfermedad en C.L cifras similares a las de mi serie aunque este grupo era de mujeres hipertensas, realizaban tratamiento aunque no concluyó que la presencia de osteoporosis se asociara a la HTA e forma significativa.

Factores de riesgo más asociados a osteoporosis: edad, sexo, raza, menopáusica precoz sobre todo quirúrgica, alcohol, tabaco, inactividad física, corticoides y A.F de osteoporosis. Tienen un efecto protector de la masa ósea el ejercicio físico, la nuliparidad, la menarquía precoz, años de vida fértil, peso elevado y menarquia tardía y se asocia baja masa ósea la menopausia, sobre todo si es precoz, la multiparidad, la lactancia y el bajo peso. Según los resultados de Díaz Curiel et al (123) la menopausia de más de 10 años de evolución es factor predictor de baja masa ósea. Los pacientes que presentaban los factores de menopausia precoz, de más de 10 años de duración, A.F de osteoporosis, dieta baja en calcio, edad, peso, IMC presentaban masa ósea baja. Los factores más importantes para presentar baja masa ósea en este trabajo son la menopausia de más de 10 años, menor peso y tener más de 70 años.

En mi serie la baja masa ósea sólo ha presentado una significación estadística con el sexo, la edad y la menopausia; es cierto que peri menopausia y menopáusicas de más de 10 años de evolución también pueden relacionarse en mi muestra con masa ósea anómala ya que el grupo de edad entre 45 - 65 años es el que peor situación de masa ósea presenta con igual grado de obesidad que el grupo de mayores de 65 años. 
También es cierto que empeora la situación de la masa ósea a lo largo del estudio más en este grupo de edad media que en los de mayor edad, estos resultados sobre todo a nivel C.L porque en la cadera la evolución es peor en el grupo de edad más joven y en el de más edad. En España la situación de la enfermedad también se incrementa con la edad, así en mujeres de más de 50 años la enfermedad supone en $22,3 \%$ en C.L y el $9,1 \%$ en cuello de fémur.

Otros autores como Diez et al (89) han identificado cuatro factores de riesgo de baja masa ósea como son la edad menor de 55 años, peso menor de $70 \mathrm{Kg}$, vida fértil menor de 32 años y paridad de más de 2 hijos. Las diferencias de masa ósea entre varones y mujeres y también entre las mujeres entre sí dependen de la menopausia ya establecida o la edad senil según otros autores $(162,211,212)$. Los resultados de la muestra estudiada no dependen en sí de la situación hormonal como tal ya que los mejores valores de masa ósea en global los presentan las mujeres menopáusicas que además presentan factores negativos como son la paridad, tienen más hijos, edad de menarquia más tardía, más años de menopausia y además ser el grupo de más edad, por tanto, estos factores que tienen un efecto negativo de la masa ósea en relación a otros trabajos, en mi grupo, no se corresponde por lo que la masa ósea va asociada al grado de obesidad. Según mis resultados la mejor situación de masa ósea con menos osteopenia grave y osteoporosis, la presenta el grupo de menor edad, aunque sobre todo a nivel de la cadera es el que peor evoluciona a lo largo del seguimiento, además el $60 \%$ de las mujeres menopáusicas han tenido una vida fértil de menos de 32 años y este grupo cerca del $50 \%$ de ellas tienen tres hijos o más y este grupo es el que en global presenta la mejor situación de masa ósea asociada al mayor grado de obesidad por lo que los resultados de los autores anteriores no se cumplen en mi serie.

Un factor a tener en cuenta es el elevado número de pacientes tanto en las premenopáusicas como las menopáusicas que no tienen hijos, en ambos grupos en torno al 25\% que sería factor protector, como también lo es en mi serie los años de vida fértil, más del 40\% de las mujeres tienen entre 34-39 años que también protege la masa ósea.

Sólo aparece en la muestra un caso de menopausia tardía (>52 años). Riesgo menopausia precoz ( $<40$ años) hay dos casos en la muestra, en ambos por avariectomía, que asocia riesgo elevado de pérdida de masa ósea.

No se interrogó a las mujeres sobre la lactancia por lo que es un dato que no puedo comparar. 
Los trabajos que han evaluado factores determinantes de densidad mineral ósea muestran resultados inconsistentes para algunos de estos factores. La edad de menarquia, embarazo, lactancia (213,214) encuentran distinta asociación con la densidad mineral ósea e incluso otros trabajos $(211,215,216)$ ausencia de asociación. Igual pasa con el tabaco, consumo de calcio, alcohol, cafeína (217,218,219). Los resultados más consistentes se han encontrado en la asociación de actividad física (218,220,221,222,223,224), IMC $(216,218,223,225$,$) , edad, raza, A.F de osteoporosis (226) y niveles de densidad mineral ósea.$ Menopausia estudios relación con masa ósea (214,223) con premenopáusia $(211,220,221,227,228)$ donde han encontrado los resultados con participación de otros determinantes. Otros autores como Kanis et al (229) en sus trabajos concluyeron que entre otros factores, el bajo IMC, el tabaco, el ejercicio, el alcohol y los corticoides se asociaron de forma significativa con la masa ósea; sin embargo la edad a la menopausia y los factores dependientes del estilo de vida como tabaco, alcohol, cafeína, ingesta baja de calcio en la dieta y ejercicio físico han mostrado mayor variabilidad y menor uniformidad entre los diferentes estudios, como en el $\operatorname{EPOS}_{(230)}$ donde los ni factores relacionados con el estilo de vida, ni la edad a la menopausia fueron significativos. Igual pasó con la relación tabaco riesgo de fractura en un estudio británico (231) donde no fue concluyente la relación.

En mi serie la DMO se asocia fundamentalmente al sexo, menopausia y edad mostrando significación estadística. También aparece relación con el bajo nivel cultural y la actividad física en pacientes inactivos y con actividad física intensa pero la relación no es estadísticamente significativa.

La evolución de la masa ósea en pacientes inactivos y con actividad física intensa presenta peor evolución sobre todo a nivel de la C.L como igual pasa con los pacientes que tiene nivel cultural alto.

En este trabajo, la edad tiene efecto negativo sobre la masa ósea al igual que el sexo y la falta de estrógenos, por tanto a más años de vida fértil mayor masa ósea, también la falta de actividad física y el IMC y el ICC en la muestra no parecen presentar efectos positivos sobre la masa ósea a pesar de que diferentes trabajos indican que tienen efecto protector sobre la misma según sus resultados. La edad de menopausia en la muestra indica que el $25 \%$ de las mujeres la presentó a los 50 años y un 10,4\% a los 52 años.

Un $28 \%$ de las menopáusicas tiene tres hijos y un $21 \%$ dos, igual porcentaje que las que no tienen ninguno. De las mujeres premenopáusicas, el 44\% tiene dos hijos y un 23,5\% ninguno. Edad de menarquia más frecuente con un 29,4\% los 11 años. 
La ingesta elevada de alcohol y tabaco se ha relacionado con el riesgo de fractura. En mi muestra existe un mayor riesgo de fractura por consumo de hábitos tóxicos en los varones ya que el $21 \%$ de ellos consume tabaco y alcohol de forma habitual, premenopáusicas un 32,3\% fuma y 2,9\% toma alcohol. Las menopáusicas no beben y sólo el 6,2\% consumen alcohol y aunque el porcentaje de fumadores es alto en la muestra, los resultados que he obtenido al relacionar hábitos tóxicos con la densidad mineral ósea no han sido significativos.

Si tenemos en cuenta la prevalencia de osteoporosis en función de la edad, la osteoporosis propende a las fracturas, la HTA y los accidentes cerebrovasculares. Según los resultados de Kanis J.A et al (212) para el riesgo de fractura la edad es 7 veces más importante que las mediciones de la densidad mineral ósea. En mi serie, en función de la edad, los varones no presentan osteoporosis, las mujeres premenopáusicas un 2,9\% de ellas la presentan a nivel de C.L y un 5,8\% en cadera, las menopáusicas un $21,7 \%$ la presentan en C.L y un 13\% en cadera por lo que el riesgo de fractura según el estado de la masa ósea es más alto en las mujeres de más edad y asociado al déficit estrogénico. Si los descensos en la densidad mineral ósea de una DS se acompañan de un riesgo de fractura de cerca del doble,(129) en mi muestra, el 10,9\% presentó un riesgo de fractura multiplicado por dos en C.L en la $1^{\text {a }}$ densitometría y aumentó el riesgo al 13,9\% en la segunda determinación.

A nivel de la cadera este doble riesgo de fractura lo presentó un 7,9\% de la muestra en la primera determinación de masa ósea y aumentó al $11,9 \%$ en la $2^{\mathrm{a}}$ densitometría.

Respecto a los marcadores de remodelado óseo liberados por osteoblastos y osteoclastos y los fragmentos de colágeno que se liberan en la resorción de hueso reflejan la situación en un momento dado de la actividad ósea pero no son útiles para el diagnóstico de osteoporosis,(232) ni para valorar la masa ósea y en principio, no está indicada su determinación en la práctica habitual al igual que la determinación de vitamina D que se deja para la sospecha de hipovitaminosis. En la osteoporosis primaria el laboratorio es normal.(233)

Entre los marcadores de formación, están la F.A total, F.A.O, Osteocalcina y propéptidos carboxi y aminoterminal del procolágeno I y como marcadores de resorción el calcio urinario, hidroxiprolina, F.A tartrato resistente, piridolina, deoxipiridolina, telopéptido carboxiterminal del colágeno I y a y b Cross laps, entre otros. 
Existen estudios que determinan el aumento de los valores de los marcadores de resorción ósea en pacientes que sufren osteoporosis aunque no está claro si este aumento tiene valor predictivo sobre el riesgo de fractura. Garnero et al (234) lo afirman y apuntan que la combinación de una densidad mineral ósea baja con el incremento de ciertos marcadores se traduciría en un aumento del riesgo de fractura vertebral y no vertebral.

La F.A total como marcador de formación si la función hepática es normal es un marcador válido aunque tiene baja sensibilidad y especificidad. La deoxipiridolina como marcador de resorción es de origen óseo fundamentalmente al no absorberse con la dieta y presenta buena correlación con el aumento de la resorción ósea.

La concentración de calcio en sangre es constante. La calcemia suele disminuir levemente en el varón según disminuyen las proteínas totales y la albúmina situación que no se produce en las mujeres que presentan valores más constantes. En los resultados de la muestra los valores de calcio en los varones eran similares a los de las mujeres menopáusicas; los valores más bajos en las mujeres premenopáusicas. La albúmina y las proteínas totales sufrían un descenso más acentuado en los varones pero no presentaban cifras de calcio sérico más bajas a pesar de que la pérdida de proteínas lo lleva asociado. El calcio iónico representa la fracción fisiológica más importante del calcio, debe solicitarse en dudas de valor real del calcio ya que éste total puede bajar en casos de hemodilución o disminución de la albúmina sérica.

Los valores de calcio urinario son más altos en premenopáusicas por la acción de los estrógenos que disminuyen la excreción urinaria de calcio situación que se produce en mi muestra ya que los valores de excreción urinaria de calcio son más altos en premenopaúsia que en menopausia pero, he de mencionar que en la muestra estudiada los valores de calciuria son mucho más altos en los varones que en las mujeres con cifras cuatro veces superiores en los primeros respecto a las féminas.

La PTH también eleva sus valores en las mujeres pero no los varones que presentan disminución de sus cifras en torno al 1\%. Las mujeres premenopáusicas son las que presentan mayor incremento en los valores de PTH con un aumento en las cifras del 24,3\%, el resto de grupos el aumento ronda el 15\%. Los valores más altos de PTH se observaron en el grupo de mujeres menopáusicas, relacionados a su vez con la mayor edad de las pacientes. 
La velocidad de formación ósea está aumentada en la mujer con déficit de estrógenos donde aparece aumento de F.A. sérica, F.A.O, de osteocalcina y de deoxipiridolina. El grupo de mujeres menopáusicas, presentan un metabolismo óseo acelerado con valores aumentados de estos parámetros. En las premenopáusicas los valores son similares a los de los varones. Los valores de deoxipiridolina son similares en ambos grupos de mujeres pero con cifras un 50\% más alta que las que presentan los varones (dentro de los parámetros normales). Presentaban cifras un 33\% por encima de lo normal.

En relación a los valores de PTH y F.A.O la evolución es sexo dependiente, la primera presenta valores más altos en las mujeres que en los varones y la F.A.O al contrario. La deoxipiridolina aumenta en premenopaúsia y en la muestra en global y disminuyen sus cifras los varones y las mujeres menopáusicas.

Al margen de que la menopausia sea la principal causa de la enfermedad en mujeres, un estudio realizado en el Clínico de Barcelona ha revelado que otras alteraciones metabólicas asociadas como el déficit de vitamina $\mathrm{D}$, el aumento de PTH, la hipercalcemia... son muy frecuentes en mujeres postmenopáusicas. En mi serie, las cifras más elevadas de PTH las presentan las mujeres y su evolución a lo largo del estudio es ascendente, mientras que presentan un descenso de sus cifras de PTH los varones pero sus valores están dentro de la normalidad.

Gianini et al,(241) en un estudio realizado en mujeres postmenopáusicas con osteoporosis, concluyeron que la calciuria era un hallazgo frecuente en ellas pero no encontraron diferencias en la masa ósea entre las mujeres que presentaban hipercalciuria y las que no, ni en C.L ni en cadera (235). En mi trabajo tampoco he encontrado relación entre los valores de los marcadores óseos y la densidad mineral ósea y aunque la calciuria elevada se asocia a un aumento del remodelado óseo en mi serie no se produce ya que las pérdidas de calcio son más importantes en los varones y éstos no presentan la enfermedad.

La medición de marcadores óseos asociados a otros factores de riesgo puede ser útil para identificar de forma precoz la respuesta a un tratamiento y su determinación puede ayudar en la toma de decisiones terapéuticas puntuales, aunque hay que tener en cuenta su gran variabilidad biológica y su ritmo circadiano.(236) pero su determinación no es válida para diagnóstico de osteoporosis ni para valorar la situación de la masa ósea. 
A tener en cuenta al comparar los datos y los resultados de mi trabajo con los de otros testudios que como datos favorables indicar que el seguimiento de los pacientes fue continuo, se les realizaba un seguimiento cada 3 meses aproximadamente, el cumplimiento por parte de los pacientes fue muy regular tanto en acudir a las revisiones como en la realización de las medidas antropométricas, analíticas correspondientes y las DMO. La realización de ejercicio físico y el cumplimiento de la dieta fue más variable. Durante el seguimiento, las pérdidas de pacientes fueron pocas, tres varones no se hicieron las DMO aunque si acudían a las revisiones y se realizaron las analíticas; las mujeres, en todas se realizó la DMO al inicio del estudio pero al final se perdieron algunas del grupo de menopaúsicas, una por enfermedad, otra por cambio de ciudad y dos no acudieron a realizarse la segunda DMO. En un caso se realizó la segunda DMO a nivel de la columna lumbar pero no en cadera por prótesis. Todo el seguimiento lo realizó la misma persona al igual que las medidas antropométricas, con los mismos aparatos de medida y en similar situación. Como cosas negativas en el trabajo el tamaño muestral, mayor al inicio, y aunque era escogido al azar, al final la muestra quedó determinada según la regularidad del cumplimiento del seguimiento por parte de los pacientes, por lo que, el sesgo de selección está en el interés de los pacientes sobre su situación; otro punto importante en contra de la validez de los resultados es el bajo número de pacientes varones aunque esto es una situación reiterativa en muchos de los estudios de obesidad consultados. 
CONCLOSIONNFS 
1 El IMC presenta diferencias estadísticamente significativas entre los grupos de varones y mujeres pre y menopaúsicas y se asocia de forma negativa con la edad, el sexo, nivel cultural y baja actividad física. Tambiénexiste de forma estadísticamente significativa, asociación negativa entre el IMC con los valores de glucosa, proteínas y PTH.

2 La obesidad desde la infancia es la causa más frecuente de obesidad en global y está asociada en todos los grupos a A.F. de la enfermedad.

3 Todos los grupos presentaron descensos importantes de las cifras de tensión arterial con las medidas higienico-dietéticas prescritas.

4 El riesgo calculado de presentar patología cardiovascular y de mortalidad es muy elevado en la muestra. El porcentaje más alto de riesgo en menopáusicas asociado sobre todo al IMC y a la edad.

5 En cuanto a las comorbilidades asociadas, en toda la muestra se observa una relación estadísticamente significativa de la edad con la HTA y la patología vascula pero no con el resto de patologías asociadas. La diabetes mellitus no presenta una asociación con los grupos ni sexo ni edad.

6 El consumo de fármacos antihipertensivos tiene una relación estadísticamente significativa con el IMC, la edad y la pertenencia a los distintos grupos.

7 La situación de la masa ósea refleja peor situación en columna lumbar, en sujetos entre 4565 años, con bajo nivel cultural, inactivos o activos intensos, con patología osteo-articular y A.F de obesidad. Por grupos todos pierden igual. Peor evolución en los no hipertensos. Peor masa ósea los no diabéticos. Con patología vascular peor masa ósea a nivel de la cadera. Peor situación de la DMO en los casos que presentan otras patologías.

8 No se evidencia en este trabajo una relación entre los valores de los parámetros analíticos óseos determinados y la situación de la masa ósea.

9 Las densitometrías realizadas en los varones a lo largo del seguimiento, mostraban diferencias significativas en la $\mathrm{T}$-score y $\mathrm{Z}$-score, tanto en los valores absolutos como en porcentaje de la columna lumbar. la cadera no presentaban diferencias estadísticamente significativas con ningún parámetro. 
10 Las mujeres premenopáusicas presentaban diferencias significativas al comparar ambas densidades óseas a nivel columna lumbar, con todos los parámetros comparados menos con el peso y con el área de la columna. Respecto a la cadera, sólo aparecieron diferencias significativas sólo a nivel del área de la cadera, no con el resto de parámetros.

11 En las mujeres menopúsicas, al comparar ambas densitometrías, no aparecieron diferencias significativas ni en el peso ni en el área de la columna lumbar, pero si para el resto de parámetros comparados. En relación a la cadera no diferencias significativas en ninguno de los resultados salvo en el BMD que las diferencias que se observaron eran estadísticamente significativas. 
BIBLIOGGRAFIA 
1. Pilar Riobó. La obesidad, un reto de Salud Pública. Mundo Científico 213. junio 2000.

2. B. Moreno Esteban. Obesidad: enfermedad en aumento. Mundo Cientifico 213 Junio 2000.

3. Inmaculada Bautista - Castaño, Jesús Molina - Cabrillana, José Alberto Montoya Alonso y Luis Serra Majem. Factores de riesgo cardiovascular en el sobrepeso y la obesidad. Variaciones tras tratamiento de pérdida ponderal. Med Clin (Barc) 2003; 121 (13):485 - 91.

4. Alemany M y Remesar X. Desarrollo posnatal de la obesidad y otras alteraciones del control del peso corporal. Med Clin (Barc) 1991; 97:190-196.

5. Noemí G. P. De Villar, Viviana Loria y Susana Monereo, en nombre del Grupo del Grupo de Obesidad de la SEEN. Med Clin (Barc) 2003; 1221 (13): 500-10.

6. Vazquez R. Et al. Obesidad. La epidemia del siglo XXI. Economía de la salud 2002;1:3-5.

7. IOTF (International Obesity Task Force) About obesity. 2002. Disponible en:www.obesity.chair.ulaval.ca/IOTF.htm

8. Aranceta J, Pérez Rodrigo C, Serra Majem L, Ribas L, Quiles Izquierdo J, Vioque J et al. Prevalence of obesity in Spain: the SEEDO `97 study. Spanish Collaborative Group for the Study of Obesity. Med Clin (Barc)1998;111:441-445.

9. Gutiérrez-Fisac Juán L. La obesidad: una epidemia en curso. Med Clin (Barc)1998; 111:456458.

10. Consenso SEEDO 2000 para la evaluación del sobrepeso y la obesidad y el establecimiento de criterios de intervención terapeútica. SEEDO.Med. Clin. (Barc.) 2000;115;587-97.

11. Wolf, A. M., y Gollditz, G. A.: The cost of obesity. PharmacoEconomic, 5 (sup,.1):34-37,1994.

12. Kristen E. Grant. Resa M. Chandler, Arthur L. Castle and John L. IVY. Chromium and exercise training: effect on obese women. Medicine \& Science in Sport \& Exercisi. Vol. 29. N ${ }^{o}$. 8. Pp. 992-998. 1997.

13. Lee IM, Manson JE, Hennekens CH, Paffenbarger RS. Body weight and mortality. A 27-years follow-up of middle-aged men JAMA 1993 ;270-2823-2828.

14. Manson JE, Willet WC, Stampfer MJ, Colditz GA, Hunter DJ, Hankinson SE et al. Body weight and mortality among women. N Engj J Med 1995;333:677-685.

15. Sánchez Luque Juan José, Ortiz García Carmen, Luque Martín Juan Sebastián, Rajano Martín José Carlos, Caro Guerra Enrique, Morell Ocaña Miguel. Valoración de la Obesidad central como factor de riesgo cardiovascular en diabéticos tipo II.

16. Estudio Prospectivo Delphi. Libro Blanco Obesidad. Madrid, 2000;III:19-23.

17. Ryan AS, Pratley RE, Elahi D, Goldberg AP. Resistive training increases fat-free mass and maintains RMR despite weight loss in postmenopausal women. J Appl Physiol 1995;79:818-23.

18. .Lauritzen C. Climateric and obesity. I Internacional Congress on Menopau and Obesity. Roma 1980.

19. González Carlos A, Pera Guillen, Agudo Antonio, Amiano Pilar, Barricarte Aurelio, Beguiristain José M, Chirlaque $M^{a}$ Dolores, Dorronsoro Miren, Martínez Carmen, Navarro Carmen, Quirós José R, Rodríguez Mauricio y Torm $M^{a}$ José. Factores asociados a la acumulación de grsa abdominal estimada mediante índices antropométricos. Med Clin (Barc)2000; 114:401-406. 
20. Wing RR, Matthews KA, Kuller LN, et al. Weight gain at the time of menopause. Arch <intern Med 1991;151:97-102.

21. Wajchenberg BL. Subcutaneaus and visceral adipose tisue: their relation to the metabolic syndrome. Endocrine Rewiews 2000;21;697-738.

22. Pouliot MC, Després JP, Lemieux S, Moorjani S, Bouchard C, Tremblay A, et al. Wiast circunference and abdominal sagital diameter: best simple anthropometric indexes for abdominaal visceral adipose tisue accumulation and related cardiovasculaar risk in men and woman. Am J Cardiol 1994; 73: 460-468.

23. Jover Sanz E. Indice cintura /cadera y factores de riesgo. An Med Interna 1993;14:1-2.

24. D.B. Allison et al, JAMA, 282, 1550. 1999.

25. M. Muelas. Obesidad en la mujer. Cambios de peso en la menopausia. Salud de la mujer y endocrinología. JANO. Mujer y Humanidades. Vol. III No 2 Julio 2004.

26. Arlot ME, Sornay-Rendu E, Garnero P, Vey-Marty B, Delmas PD (1997). Apparent pre-and postmenopausal bone loss evaluated by DXA at different skeletal sites in women: the OFELY cohort. J Bone Miner Res 12:683-690.

27. Bjarnason NH, Christiansen C. Early response in biochemical markers predicts long-term response in bone mass during hormone replacement therapy in early in early postmenopausal women. Bone 2000,26(6)561-9.

28. Pi Sunyer FX. Clinical guidelines on the identification, evaluation, and treatment of overweight and obesity in adults. The evidence report. Obes Res 1998;6 (Supl 2):51-209.

29. Álvarez León Eva Elisa, Ribas Barba Lourdes y Serra Majem Lluis. Prevalencia del síndrome metabólico en la población de la Comunidad Canaria. Med Clin (Barc)2003:120(5):172-4.

30. J. Stevens et al, New England J. med, 338. 1. 1998.

31. Calle E E, Thin MJ, Petrelli JM, Podriguez C, Heath CW, Body mass index and mortality in a prospective cohort of U.S adults. New England J. Med, 341, 1097. 1999.

32. Mus A Spadano J, Coakley AE, Colditz G, Dietz WH. The disease burden associated with overweight and obesity. JAMA, 282. 1523, 1999

33. Brown JP, Josse RG, for the Scientific Advisory Council of the Osteoporosis Society of Canada. 2002 clinical practice guidelines for the diagnosis and management of osteoporosis in Canada. CMAJ 2002;167(Suppl 10):1-34.

34. WHO Study Group: Assessment of fracture risk and its application to screening for postmenopausal osteoporosis. Worl Health Organization, Geneva 1994.

35. Matkovic V (1991) Calcium metabolism and calcium requirement during skeletal modelling and consolidation. Am J Clin Nutr; 54: 245-260.

36. Matkoviv V., Heaney R. P. 1992: "Calcium balance dduring human growth: evidence for threshold behaviour”. Am J Clin Nutr 55; 992-996.

37. Gail P. Dalsky, Ph. D,; Karen S. Stocke, B.S.; Ali A. Ehsani, M.D.; Eduardo slatopolsky, M.D.; Waldon C. Lee; and Stanley J. Birge, Jr., M.D.; St. Louis, Missouri. Weight-Bearing Exercise Training and Lumbar Bone Mineral Content in Postmenopausal Women. Annals of Internal Medicine. 1989; 108:824-828.

38. Stevenson J., "Pathogenesis, Prevention, and Treatment of Osteoporosis", Obstetrics, vol.46: 203-207,1994. 
39. Shea B, Wells G, Cranney A, Zytaruk N, Robinson V, Griffith L, et al. Calcium supplementation on bone loss in posmenopausal women women (Cochrane Review). En : The Cochrane Library. Chichester: John Willey and Sons, 2004.

40. Shea B, Wells G, Cranney A, Zytaruk N, Robinson V, Griffith L, et al. metaanalysis of therapies for postmenopausal osteoporosi. Endocr Rev 2002;23:552-9.

41. Seeley et al. Amatomy and Physiology. 1998

42. Vander et al. Human Phisiology. $5^{a}$ ed. 1990.

43. Mataix J. Manual de Fisiología. Sistema endocrino, 1997.

44. Fernández-Tresguerres Jesús A. Fisiología Endocrina. EUDEMA UNIVERSIDAD. Manuales.

45. Carral San Laureano F., Olivera Fuster G., y Aguilar Diosdado M. Homeostasis del calcio, fósforo y magnesio. Medicina Integral, Vol. 36, Núm. 7, Octubre 2000.

46. Tang G., "Menopausal Osteoporosis”, International journal of gynecology and obstetrics, vol. 46:203-207, 1994.

47. Mark B. Andon. PhD, FACN, Munro Peacock, MD, Robert L. Kanerva, MS and José A.S. De Castro, MD. Calcium Absorption from Apple and Orange Juice Fortified with Calcium Citrate Malate. Journal of the American College of Nutrition. Vol. 15. No 3, 313-316 (1996).

48. Black D. y col., "Why Elderly Women Should Be Screened And Treated To Prevent Osteoporosis”. The American journal of medicine, vol 98 (suppl 2A):67-75,feb 1995.

49. Cuadros López J. Y col. "Correlación de los Estados Endocrino y Óseo en menopáusicas Naturales con y sin Fracturas”. Acta ginecológica, vol. 48:61-66,1991.

50. Rico H. y col., "Total And Regional Bone Mineral Content In Relation To Menopause", Mauritas, vol. 15:233-240,1992.

51. Melton LJ III. How many women have osteoporosis now? J Bone Min Res 1995; 10:175-177.

52. Orozco P. actualización en el abordaje y tratamiento de la osteoporosis 2001. Inf Ter Sist. Nac. Salud 2001.25(5);117-141.

53. Siris E, Miller P, Barret-Connor E, Faulkner K, Werthen L, Abbott T, et al. Identification and fracture ourcomes of undiagnosed low bone mineral density in post-menopausal women. JAMA $2001 ; 286 ; 2815-22$

54. Bonaiuti D, Shea B, Lovine R, Negrini $S$, Robinson V,Kemper $H$, et al. exercice for preventing and treating osteoporosis in postmenopausal women (Cochrane Review). En : The Cochrane Library. Chichester: John Willey and Sons, 2004.

55. Amber A Mckenna, Jasminka Z Ilich, Mark B Andon, Changzheng Wang and velimir Markovic. Zinc balance in adolescent females consuming a low-or high-calcium diet.. Am Clin Nutr 1997; 65:1460-4.

56. Alemany M. Elementos minerales. En: Enciclopedia de las dietas y la Nutrición. Barcelona: Planeta, 1995;6: 139-212.

57. Baumgartner T. trace elements in clinical nutrition. Nutr Clin Pract. 1993; 51:157.

58. Foresta C, Ruzza A, Mioni $R$ et al. Osteoporisis and the decline of gonadal function in the elderly men. Horm Res 1984; 19: 18-22.

59. Mellish RWE, Garrahan NJ, Comston JE. Age-related changes in trabecular width and spacing in human iliav crest bone biopsies. Bone Miner 1989; 6:331-338. 
60. National Osteoporosis Foundation. Osteoporosis: review of the evidence for prevention, diagnosis and treatment and cost-effectiveness analysis. Osteoporos Int 1998;8(Suppl 4);1-88.

61. Grupo de Trabajo de la Sociedad Española de Investigaciones Oseas y Metabolismo Mineral (SEIOMM). Osteoporosis postmenopausica. Guía de práctica clínica. Rev Clin Esp 2003;203:496-506.

62. Riggs BL, Melton LJ III. Involutional osteoporosis. N Engl J Med 1986; 314: 1.676-1.686.

63. M. H. J. Knapen, A. C. Nieuwenhuijzen Kruseman, R. S. M. E. Wouters, C. Vermeer. Correlation of Serum Osteocalcin Fractions with Bone Mineral Density in Women During the First 10 Years after Menopause. Calcif Tissue Int (1998)63:375-379.

64. García Vadillo JA. Diagnóstico de la osteoporosis en Atención Primaria. Salud Rural. Vol. XIX. $N^{\circ}$ 7. segunda quincena de abril de 2002.

65. Rico Lenza Horacio. Marcadores biológicos del recambio óseo. Medicina y Práctica clínica. Marzo 1998. Volumen 3, Número 1.

66. Burtis WJ, Lang R. chemical abnormalities. Orthop Clin North Am 1984 ; 15 :653-669.

67. Nordin BEC. Diagnostic procedures in desorders of calcium metabilism. Clin Endocrinol 1978;8:55-67.

68. Food sand Nutrition Board. IOM (Institute of Medicine). Calcium. Dietary Reference Intakes for Calcium, Phosphorus, Magnesium, Vitamina D and Flouride. Washintong DC: National Academy Press, 1997;4:71-145.

69. NIH Consensus Conference. Osteoporosis prevention, diagnosis, and therapy. JAMA 2001;285:785-95.

70. Barret-Connor E. The economic and human cost of osteoporotic fracture. Am J Med 1995; 98 (Supl 2A): 3-8.

71. Obrant KT, Bengner U, Johnell O, Nilsson BE, Sernbo I. Increasing age-adjusted risk of fragility fractures; a sign of increasing osteoporosis in succesive generations. Calcif Tissue Int 1989; 44: 157-164.

72. Sue A. Brown, MD, Clifford J. Rosen, MD. Osteoporosis. The Medical Clinics of North America 87 (2003) 1039-1063.

73. Krane SM. Osteoporosis. En: Isselbacher KJ, editor. Harrison's Principles of Internal Medicine (14. ${ }^{a}$ ed.). nueva York:Mc Graww-Hill, 1997;2.247.

74. Richard Derman, MD. Identifying the Osteopenic Patient and Preventing Worsening of the Disease. Current Women's Health Reports 2003, 3:199-206.

75. Cummings S. y col., "Bone Mass Measurements And Risk of fracture in Caucasian Women: A Review of Findings from Prospective Studies", The American journal of medicine., vol. 98 (suppl 2A9: 24-28, feb 1995.

76. Pouilles J. y col., "Facteurs de risque de L'ostéoporose Vertébrale: RésultatsD'une étude de 2279 femmes adressées a une consultation de ménopause », Revue du rhumatisme, vol. 58 (3) : 169-177, 1991.

77. Rapado A., Yagüe M., Díaz Curiel M.,Peramo B., Velazco C. Osteoporosis en el varón. Med Clin (Barc) 1990;95:389-393.

78. Castro Pérez de Castro A. Osteoporosis postmenopaúsica. Problemas en Medicina práctica: osteoporosis en atención primaria. Salud Rural. Vol. XIX. $N^{o} 8.1^{a}$ quincena de mayo 2002. 
79. Smith R. osteoporosis. En: Grossman A, editor. Clinical endicrinology. Oxfort: Oxford Blackwell Scientific Publications, 1992 ;40 :556-570.

80. M.R. Sowers, J.S. Finkelstein, B. Ettinger, I. Bondarenko, R.M. Neer, J.A. Cauley, S. Sherman, G.A. Greendale. The association of endogenous hormone concentrations and bone mineral density measures in pre- and perimenopausal women of four ethnic groups: SWAN. International Osteoporosis Foundation and National Osteoporosis Foundation 2003.

81. M. Revilla, L.F. Villa, E. R. Hernández, A. Sánchez-Atrio, J. Cortes, H. Rico. Maturitas 28 (1997) 69-74.

82. Chesnut CH III, Rosen CJ, for the Bone Quality Discussion Group. Reconsidering the effects of antiresorptive therapies in reducing osteoporotic fractures. J Bone Miner Res 2001;16:2163-72.

83. Kanis JA. Osteoporosis and its consecuences. En: Kanis JA, editor. Osteoporosis. Oxford:Onsey Mead, 1994; 1-21.

84. Peris P. Bone densitometry, 2000. Med Clin (Barc) 2000; 114:540.

85. Peris P, Guañabens N, Monegal A, Suris X, Alvarez L, Martínez de Osaba MJ et al. Aetiology and presenting sympton in male osteoporosis. Br J Rheumatol 1995;34:936-41.

86. Cooper C, Campion G, Melton LJ III. Hip fractures in the elderly: a wordwide projection. Osteoporosis Int 1992;2:285-9.

87. Compston JE, Papapoulos SE, Blanchard F. report en osteoporosis in the European Community : Current status and recommendations for the future. Osteoporosis Int 1998;8:531534.

88. Grupo osteoporosis se semFYC. Osteoporosis. Guía de abordaje. Recomendaciones semFYC. Barcelona: EdiDe, 2000.

89. Díez A, Puig J, Nogués X, Knobel H, Mínguez S, Supervía A et al. Cribado de riesgo óseo mediante factores clínicos en mujeres tras menopausia fisiológica. Med Clin (Barc) 1998; 110:121-124.

90. Documento de la Sociedad Española de Reumatología sobre la osteoporosis posmenopáusica. Rev Esp Reumatol 2001;28:148-153.

91. Espallargues M, Estrada MD, Sola M, Sampietro-Colom L. Guía per a la indicació de la densitometria óssia en la valoració del risc de fractura. Barcelona: Agéncia dÁvaluació de Tecnologia Médica. Servei Catalá de la Salut. Departament de Sanitat i Seguretat Social. Generalitat de catalunya, junio de 1999 (BR99005).

92. Sánchez Silvestre A., Soriano Rodriguez J.R., Villalta Sánchez A., Díaz Jiménez J. Y García Ruso F. Osteoporosis, "La epidemia silente del siglo XX”: Actuaciones preventivas higiénicodietéticas. Salud Rural. $N^{o} 10.1^{a}$ quincena de junio de 1998.

93. López-Herce J.A. et al. Fisiología y etiología de la osteoporosis. Medicina y Práctica clínica. Marzo 1998. volumen 3. Número 1.

94. Eastell R, Blumshon A. the value of biochemical markers of bone turnover in osteoporosis. $J$ Rheumatol 1997;24:1.215-1.227.

95. Riggs BL. Osteoporosis. En: Wyngaarden JB Jr, Smith LH, editors. Cecil texbook of medicine. Filadelfia:WB Saunders, 1988;1.510.

96. Heidi D. Nelson, MD, MPH; Mark Helfand; MD, MPH; Steven H. Wolf, MD, MPH; and Janet D. Allan, PhD, RN. Screening for Postmenopausal Osteoporosis: A Review of the Evidence fro the U.S. Prevevtive Services task Force. Ann Intern Med. 2002; 137: 529-541. 
97. Henrik G. Ahiborg, M.D., Olof Johnell, M.D., Ph.D., Charles H. Turner, Ph. D., Gunnar Rannevik, M. D., Ph. D., and Magnus K. Karlsson, M.D., Ph.D. Bone Loss and Bone Size after Menopause.The New England Journal of Medicine.2003; 349; 327-334.

98. PD Delmas. HRT in the prevention and treatment of osteoporosis. 1999. Vol. 4, 155-163. Isis Medical Media. Limited.

99. G. M. Fogelholm, H. T. Sievänen, T. K. Kukkonen-Harjula and M.E. Pasanen. Bone mineral density reduction, maintenance and regain of body weight in premenopausal, obese women. Osteoporos Int (2001) 12:199-206.

100.S.S. Harris, B. Dawson-Hughes. Weight, Body Composition, and Bone Density in Postmenopausal Women. Calcif Tissue International (1996) 59;428-432.

101. P. Ravn, G. Cizza, N.H. Bjarnason, D. Thompson, M. Daley, R.D. Wasnich, M. Mcclung, D. Hosking, A.J. Yates, and C. Christiansen for Early Postmenopausal Intervention Cohort (Epic) Study Group. Low body mass index is an important risk factor for low bone mass and increased bone loss in early postmenopausal women. American Society for Bone \& Mineral Research. 1999 Vol. 14, No9.

102. Gómez C, Naves ML, Díaz López JB, Barreto S Cannata JB. Could we asume in the clinical practice the WHO densitometric training for the diagnosis of osteopenia and osteoporosis? Osteoporosis Int. 1996, 6(Supl 1), 154.

103. D. Karasik, L.A. Cupples, M. T. Hannan, and D.P. Kiel. Age, gender, and body mass effects on quantitative trait loci for bone mineral density: the Framingham Study. Bone 0 (2003) 000-000.

104. Sophie Gillett-Guyonnet, Fati Nourhashemi, Sandrine Andrieu, Christelle Cantet, Jean Louis Albarede, Bruno Vellas, Hélène Grandjean. Body composition in French women 75+ years of age: The EPIDOS study. 2003 Published by Elsevier Science Ireland Ltd. Doi:10.1016/S0047637(02)00198-7.

105. Jilka RL. Cytokines, bone remodelling, and estrogen deficiency: a 1998 update. Bone 1998;23:75-81.

106. Chan GK, Duque G. Age-related bone loss: old bone, neww facts. Gerontology 2002;48:62-71.

107. Ettinger MP. Againg bone and osteoporosis. Arch Intern Med 2003;163:2237-46.

108. Crncevic Z, Raisz LG. Causes el secondary osteoporosis. 1 Clin Densitom 1998;2:79-92.

109. Díaz Curiel, García JJ, Carrasco JL, Honorato J, Pérez Cano R, Raspado A. et al. Prevalence of osteoporosis assessed by densitometry in the Spanish female population. Med. Clin (Barc) 2001;116:86-88.

110. Melton LJ III. Hip fractures: A worldwide problem today and tomorrow. Bont, 1993;14(1):S1S8.

111. Ettinger B, Black D, Mitlak BH et al. Reduction of vertebral fracture risk in postmenopausal women with osteoporosis treated with raloxifene. JAMA 1999;282:637-645.

112. Cooper C, Atkinson EJ, Jacobsen Sj, et al. Population-based study of survival following osteoporotic fractures. Am J Epidemiol 1993;137:1001-5

113. Ismail AA, $O^{`}$ Neill $T W$, el al. Mortality associated with vertebral deformity in men and women: results from the European Prospective Osteoporosis Study (EPOS). Osteoporosis Irit 1998;8:291-7.

114. Melton LJ. Excess mortality following vertebral fractures. J Am Geriatr Soc 2000;48:338-8.

115. Crilly LS. Steroid hormones, ageing and bone. Clin Endocrinol Metab 1981; 1:115-138. 
116. Kanis JA, and the WHO Study Group. Assessment of fracture risk and its application to screening for postmenopausal osteoporosis: synopsis of a WHO report. Osteoporos Int 1994; $4: 368-81$.

117. Diez A, Puig J Martínez MT, Diez JL, Aubia J Vivancos J. Epidemiology of fracturess of the próximal femur associated with osteoporosis en Barceloma, Spain. Calcif Tissue lut. 1989; 44:382-386.

118. Genant HK, Cooper C, Peor G, Reid I, Ehrlich G, et al. diagnosis and management el Osteoporosis in Postmenopausal women: Clinical guidelines. Clinical Ther 1999;21:1026-44.

119. Knobel H, Minguez S. epidemiología de la osteoporosis. En:Díez A, editor. Osteoporosis. Barcelona: Editorial MCR, S.A., 1992;25-36.

120. Blak DM, Arden NK, Palermo L, Pearson J, Cumming SR. prevalent vertebral deformities predict hip fractures and new vertebral deformitiesbut not wrist fractures. J Bone Miner res 1999;14:821-828

121. Ismail AA, Cockerill W, Cooper $C$ et al. prevalent vertebral deformity predicts incident hip though not distal forearm fracture: Results from the European Prospective Osteoporosis Study. Osteoporosis Int 2001;12:85-90.

122. Klotzbuecher CM, Ross PD, Landsman PB et al. Patiens with prior fractures have an increased risk of future fractures : summary el the literature and statistical synthesis. J Bone Miner Res 2000;15:721-39.

123. Díaz Curiel M, Carrasco de la Peña, JL, Honorato Pérez J, Pérez Cano R, Raspado A, Ruiz Martínez I. Study of bone mineral density in lumbar spine and femoral neck in a Spanish population. Osteoporosis Int 1997; 7: 59-64.

124. JANO. MUJER Y HUMANIDADES. Vol III. No 3: Diciembre 2004

125. Kanis JA, Glüer C-C (2000). An update on the diagnosis and assessment of osteoporosis with densitometry. Osteoporos Int 11:192-202.

126. Maunier Pj, Delmas PD, Eastell R, el al. Diagnosis and management el Osteoporosis in postmenopausal women: Clinical guidelines. Clinical Ther 1999;21:1026-44.

127. Yabur JA, Mautalen C, Rapado A, et al. Comité de Expretos de la SOBONN. Aspectos Diagnóstocos y Terapéuticos de la Osteoporosis, Caracas, junio de 1998. rev Esp Enf Metab Oseas 1998;7:1-1

128. Lenchik L, Leib ES, Hamdy RC, Binkley NC, Miller PD., Watts NB. Executive Summary. International Society for Clinical Densitometry. Position Development Conference. J Clin Densitom 2002;5(Suppl 1);1-3.

129. Lewis S, Altman R. Bone densitometry. Arthritis Rheum 1998; 441-444.

130. Royal College of Physicians. Working Party reports. Osteoporosis update clinical guidelines for prevention and treatment. Online Publications 2001.

131. Kanis J. y col., “Treatment of Osteoporosis in Elderly Woman”, The American journal of medicine, vol. 98 (suppl 2A);60-66, Feb 1995.

132. Ribot C, Pouilles JM, Bonneu M, Tremoliers F. Assessment of the risk of postmenopausal osteoporosis using clinical factors. Clin Endocrinol 1992;36:225-8.

133. Ribot C. y col., "Can we detect woman with low bone mass using clinical risk Factors?", The American journal of medicine, vol. 98 (suppl 2A):52-55, Feb 1995.

134. Seeman E, Melton LJ, O־Fallon WM et al. Risk factors for osteoporosis in men. Am J Med 1983; 75:977-983. 
135. Bell NH, Epstein S, Greene A et al. Osteoporosis and the vitamin D-endocrine system in obese subjects. J Clin Invest 1985; 76: 370-373.

136. R. Patel, G. M. Blake, R. J. M. Herd, I. Fogeman. The Effec of Weight Change on DXA Scans in a 2.Year Trial of Etidronate Therapy. Calcif Tissue Int (1997) 61:393-399.

137. Al- Gramdi SM, Cameron EC, Sutton RA. Magnesium deficiency; Pathophysiologic and clinical overwiew. Am J Kidney Dis 1994;24:737-52.

138. Papadimitropoulos E, Wells G, Shea, Gillepsie W, Weaver B, Zytaruk N, et al. Meta-analyses of the therapies for postmenopausal osteoporosis. VIII: meta-analysis of the efficacy of vitamin D treatment in preventing osteoporosis in postmenopausal women. Endocr Rev 2002;23;560-9.

139. Trouerbach WTh, Birkenhager JC, Schmitz PIM et al. A cross-sectional study of age-related loss of mineral contant of phalangeal bone in men and women. Skeletal Radiol 1988; 17:333343.

140. Cummings $R$ G. 1990: "Calcium intake and bone mass: a qquantitative review of the evidence”. Calcif Tisuue Int 47; 194-201.

141. C. A. Wigderowitz, T. Cunningham, D.I Rowley. P.A. Mole, C. R. Paterson. Peripheral bone mineral density in patients with distal radial fractures. Bone Joint Surg. 2003; 85-B:423-5.

142. Sistema Nacional de Salud. Vol. 25-N 5 - 2001. Actualización en el abordaje y tratamiento de la osteoporosis 2001.

143. Anónimo. Osteoporosis prevención, diagnosis, and therapy. JAMA 2001; 785-795.

144. Meunier P, y col., "Prevention Of Hip Fractures", The American journal of medicine, vol. 95 (suppl 5A):75-78, November 1993.

145. Naves M, Díaz-López JB, Gómez C, et al. Estudio de incidencia de fracturas osteoporóticas en una cohorte mayor de 50 años durante un periodo de 6 años de seguimiento. Medicina Clínica 2000, 115:650-653.

146. Melton LJ III, Chrischilles EA, Cooper C, Lane A, Riggs BL. How many women have osteoporosis? J Bone Min Researh 1992; 7: 1005-1010.

147. J. Rymer, J. Robinson and I. Fogelman. Ten years of treatment with tibolone $2.5 \mathrm{mg}$ daily: effects on bone loss in postmenopausal women. Climateric 2002;5:390-398.

148. Cannata JB. Necesidades de calcio. El calcio en el tratamiento de la osteoporosis. El Documento Canario sobre la Osteoporosis 1997;27-29.

149. Nelson DA, Bouxsein ML. Exercise maintains bone mass, but do people maintain exercise? 1 Bone Miller Res 2001;16:202-205.

150. New SA. Nutrition, bone mass and preventing fracture. Osteoporosis 2000;8:1-4.

151. Forwood MR. Mechanical effects on the skeleton: Are there clinical implications? Osteoporosis Int. 2001,12:77-83.

152. Melton LJ III, Atkinson EJ, OConnor MK, O`Fallon WM, Riggs BL. Bone density and fracture risk in men. J Bone Miner Res 1998;13:1915-1923.

153. Eastell R, Boyle IT, Compston J, Cooper C, Fogelman I, Francis RM et al. Manegement of male osteoporosis; report of the UK Consensus Group. Q J Med 1998;91:71-92.

154. Peris Bernal P. Osteoporosis del varón. ¿Cómo diagnosticarla y tratarla? Rev Esp Reumatol 2001;28:135-142. 
155. Raisz LG. Local and systemic factors in pathogenesis of osteoporosis. N Engl 1989; 318:818826.

156. SEIOMM/FHOEMO. V Reunión de la SEIOMM. Octubre de 2000. Sevilla.

157. Dargent-Molina P, Douchin MN, Corner C, Meunier PJ, Breat G; EPIDOS Study Group. Use of clinical risk factors in elderly women with low bone mineral density to identify women at higher risk of hip fracture: The EPIDOS prospective study. Osteoporosis Int 2002;13:593-9.

158. Adolfo Díez. Jordi Puig, Xavier Nogués, Hernando Knobel, Silvia Minguez, August Supervia, Leonardo Mellibovski, María Dolors Arnau, Ramón Carreras, Sergi Serrano y Jaume Aubia. Cribado de riesgo óseo mediante factores clínicos en mujeres tras menopausia fisiológica. Med Clin (Barcelona) 1998;110: 121-124.

159. Melton LJ III, Atkinson EJ, Fallon WM, Hashner HW, Riggs BL. Long term fracture prediction by bone mineral assessed at different skeletal sites. J Bone Miner Res 1993; 8: 1227-1233.

160. Michaelsson K, Bergstrom H, Mallmin H, Holmberg L, Wolk A, Ljunghall S. Screening for osteopenia and osteoporosis: selection by body composition. Osteoporosis Int 1996; 6: 120126.

161. Díaz Curiel M., Rapado Errazti M Y Garcés M. V.. Desarrollo de un cuestionario de factores de riesgo de baja masa ósea. Reemo 2003;12 (1): 4-9.

162. Ribor C, Pouilles JM, Bonneu M, Tremoliers F. Assessment of the risk of postmenopausal osteoporosis using clinical factors. Clin Endocrinol 1992; 36:225-8.

163. Eriksson SAV, Isberg BO, Lindgren JU. Prediction of vertebral strength by dual photon absorptiometry and quantitative computed tomography. Calcif Tissue Int 1989; 44:243-250.

164. Genant HK,Block JE, Steiger P, Gluer CC, Ettinger B, Harris ST.appropriate use of bone densitometry. Radiology 1989; 170:817-822.

165. Seeley DG, Browner WS, Nevitt MC, Genant HK, Scott JC, Cummings SR. Wich fractures are associated with low appendicular bone mass in elderly women? Ann Intern Med 1991; 115: 837-842.

166. Nuria Guañabens. Osteoporosis. Med. Clin (Barc) 2003; 121 (16): 625 - 30.

167. D. O'Gradaigh, I. Debiram, S. Love, H.K. Richards, J.E. Compston. A prospective study of discordance in diagnosis of osteoporosis using spine and proximal femur bone densitometry. Osteoporosis Int. 2003;14:13-18.

168. Rizzoli R. y col., "The role of dual energy X-ray absorptiometry of lumbar spine and proximal femur in the diagnosis and follow-up of osteoporosis", The American journal of medicine, vol.98 (suppl 2A):33-36, Feb 1995.

169. Gómez C, Díaz JB, Naves ML, Altadill A, Fernández JL, Cannata JB. Diagnóstico densitométrico de osteoporosis. Rev Esp Enf Metab Óseas 1995; 4 (Supl A): 18.

170. Osteoporosis Int (1999) 10:85-90. International Osteoporosis Foundation and National Osteoporosis Foundation. S. M. Cadarette, S. B. Jaglal and T. M. Murray. Validacion of the Simple Calculated Osteoporosis Risk Estimation (SCORE) for Patient Selection for bone densitometry.

171. Nevitt M, Johnell O, Black D, Ensrud K, Genant H, Cummings SR. Bone mineral density predicts non-spine fractures in very elderly women. J Bone Min Res 1994; 9 (Supl):153.

172. Consensus Development Conference: diagnosis, prophylaxis, and treatment of osteoporosis. Am J Med 1993; 94:646-650. 
173. Consensus Development Conference (Draft). Who are candidates for preventive and therapeutic therapy for osteoporosis? Proceeding of the World Congress of Osteoporosis and Consensus Development Conference. Amsterdam, 22-23 de mayo de 1996.

174. Cummings SR, Bates D, Black DM. Clinical use of bone densitometry. JAMA 2002;288:188997.

175. Ernst ND, Obarzanek E, Clark MB, Brieffel RR, Brown CD, Donato K. Cardiovascular health risks related to overweight. J Am Diet Assoc 1997;97 (Suppl 7):47-51.

176. Colditz GA, Willet WC, Rotnitsky A, Manson JE. Weight gain as a risk factor for clinical diabetes mellitus in women. Ann Intern Med 1995;122:481-6.

177. Després JP, Lemieux I, Prud'homme D 2001 Treatment of obesity: need to focus on high risk abdominally obese patients. BMJ 322:716-720.

178. Schneider HJ, Glaesmer H, Klotsche J, Böhler S, Lehnert H, Zeiher AM, März W, Pittrow D, Stalla GK, Wittchen HU 2007 Accuracy of anthropometric indicators of obesity to predict cardiovascular risk. J Clin Endocrinol Metab 92:589-594.

179. de Koning L, Merchant AT, Pogue J, Anand SS 2007 Waist circumference and waist-to-hip ratio as predictors of cardiovascular events: meta-regression analysis of prospective studies. Eur Heart $J$ 28:850-856.

180. Gelber RP, Gaziano JM, Orav EJ, Manson JE, Buring JE, Kurth T 2008 Measures of obesity and cardiovascular risk among men and women. J Am Coll Cardiol 52:605-615.

181. Fox CS, Massaro JM, Hoffmann U, Pou KM, Maurovich-Horvat P, Liu CY, Vasan RS, Murabito JM, Meigs JB, Cupples LA, D'Agostino Sr RB, O'Donnell CJ 2007 Abdominal visceral and subcutaneous adipose tissue compartments: association with metabolic risk factors in the Framingham Heart Study. Circulation 116:39-48.

182. Gutierrez-Fisac JL, Rodriguez C. prevalencia de la obesidad en España. Med. Clin (Barc) 1993;102: 10-13.

183. Regidor E, Rodriguez C, Gutierrez-Fisac JL. Indicadores de salud. Tercera evaluación en España del programa de europeo de salud para todos. Madrid: Ministerio de Sanidad y Consumo, 1995; 235-238.

184. Aranceta J, Pérez-Rodrigo C, Serra-Majem Ll, Ribas L, Quiles-Izquierdo J, Vioque J, et al. Influence of sociodemographic factors in the prevalence of obesity in Spain. The SEEDO'97 Study. Eur J Clin Nutrition 2001;55:430-5.

185. Gutiérrez-Fisac JL, Regidor E, Banegas Banegas JR, Rodríguez Artalejo F. The size of obesity differences associated with educational level in Spain, 1987 and 1995/97. J Epidemiol Community Health 2002;56:457-60.

186. Mo-suwan L, Geater AF. Risk factors for childhood obesity in a transitional society in Thailand. International Journal of Obesity, 1996, 20: 697-703.

187. Corvol P et al. Can the genetic factors influence the treatment of systemic hypertension? The case of the renin-angiotensinaldosterone system. American Journal of Cardiology, 1992, 70: 14D-20D.

188. Williams RR et al. Genetic basis of familial dyslipidemia and hypertension: 15-year results from Utah. American Journal of Hypertension, 1993, 6: 319S-327S.

189. Pierce M, Keen H, Bradley C. Risk of diabetes in offspring of parents with non-insulindependent diabetes. Diabetic Medicine, 1995, 12: 6-13.

190. Elbagir MN et al. A population-based study of the prevalence of diabetes and impaired glucose tolerance in adults in northern Sudan. Diabetes Care, 1996, 19: 1126-1128. 
191. Ministerio de Sanidad y Consumo. Encuesta Nacional de Salud de España 2001. Madrid: Ministerio de Sanidad y Consumo; 2003

192. Cosín Aguilar J, Hernándiz Martínez A, Masramón Morell X, Arístegui Urretarazu R, Aguilar Llopis A, Zamorano Gómez JL. Sobrepeso y obesidad en pacientes con hipertensión arterial. Estudio CORONARIA. Med. Clin (Barc). 2007;129:641-5.

193. Fox C, Coady S, Sorlie P, Levy D, Meigs JB, D'Agostino RB Jr. Trends in cardiovascular complications of diabetes. JAMA. 2004;292:2495-9.

194. Kannel WB, McGee DL. Dibetes and glucose intolerance as risk factors for cardiovascular disease: the Framingham study. Diabetes Care. 1979;2:120-6.

195. Goldschmid M, Barrett-Connor E, Edelstein S, Wingard DL, Cohn BA, Herman WH. Dyslipemia and ischemic heart disease mortality among men and women with diabetes. Circulation. 1994;89:991-7.

196. Goday A. Epidemiología de la diabetes y sus complicaciones no coronarias. Rev Esp Cardiol. 2002;55:657-70.

197. Eckel RH, Kahn R, Robertson RM, Rizza RA. Preventing cardiovascular disease and diabetes: a call to action from the American Diabetes Association and the American Heart Association. Diabetes Care. 2006;29:1697-9.

198. Grau M, Subirana I, Elosua R, Solanas P, Ramos $R$, Masiá R, et al. Trends in cardiovascular risk factor prevalence (1995-2000-2005) in northeastern Spain. Eur J Cardiovasc Prev Rehabil. 2007;14:653-9.

199. Pasanisi F, Contaldo F, De Simone G, Mancini M. Benefits of sustained moderate weight loss in obesity.Nutr Metab Cardiovasc Dis 2001;11: 401-6.

200. The Pooling Project Research Group. Relationship of blood pressure, serum cholesterol, smoking habit, relative weight and ECG abnormalities to the incidence of major coronary events: final report of the pooling Project. J Chronic Dis. 1978;31:201-306.

201. Gofman JW, Young W, Tandy R. Ischemic heart disease, atherosclerosis and longevity. Circulation. 1966;34:679-97.

202. Kannel WB, Castelli WP, Gordon T. Cholesterol in the prediction of atherosclerotic disease. New perspectives based on the Framingham Study. Ann Intern Med. 1979;90:85-91.

203. Lipid Research Clinics Program. The Lipid Research Clinics Coronary Primary Prevention Trial results II: the relationship of reduction in incidence of coronary heart disease to cholesterol lowering. JAMA. 1984;251:365-74.

204. Sarwar N, Danesh J, Eiriksdottir G, Sigurdsson G, Wareham N, Bingham S, et al. Triglycerides and the risk of coronary heart disease: 10,158 incident cases among 262,525 participants in 29 Western prospective studies. Circulation. 2007;115:450-8.

205. Medrano MJ, Cerrato E, Boix R, Delgado-Rodríguez M. Factores de riesgo cardiovascular en la población española: metaanálisis de estudios transversales. Med Clin (Barc). 2005;124:60612.

206. Anderson JW, Konz EC. Obesity and disease management: effects of weight loss on comorbid conditions. Obes Res 2001;9(Suppl 4):326-34.

207. Solà E, Morillas C, Garzón S, Royo T, Núñez A, Bautista A, et al. Factores de riesgo cardiovascular en pacientes con obesidad y sobrepeso: influencia de la pérdida de peso. Med Clin(Barc)2002;119:485-8 
208. De Vernejool MC. Nutrition et maladies osseuses. En: Basdevant A, Laville M, Lerebours E, editores. Traité de nutrition clinique de Ladulte. Paris Flammarion, 2001: 583-587.

209. Glauber HS, Vollmer WN, Nevitt MC, Gamble GD, Ensrud KE, Orwoll ES. Body weight versus body fat distribution, adiposity, and frame size as predictors of bone density. J Clin Endocrinol Metab 1995; 80: 118-123.

210. Cummings SR, Nevitt MC, Browner WS, Stone K, Fox KM, Ensrud KE et al. Risk factors for hip fracture in white women. Study of Osteoporotic Fractures Research group. N Engl J Med 1995; 332: 767-773.

211. Mazess R, Barden H. Bone density in premenopausal women: effects of age, dietary intake, physical activity, smoking, and birth-control pills. Am J Clin Nutr 1991;53:132-142.

212. Kanis JA, Johnell O, De LAET c, Jonsson B, Oden A, Ogelsby AK. International variations in hip fracture probabilities: implications for risk assessment. J Bone Miner Res. 2002; 17:123744.

213. Rosenthal D et al. Age and bone mass in premenopausal women. J Bone Miner Res 1989;4:533-538.

214. Aloia J, Cohn S, Vaswani A, Yeh J, Yuen K, Ellis K. Risk factors for postmenopausal osteoporosis. Am J Med 1985;78:95-100.

215. Kritz D, Barrett E, Hollenbach K. Pregnancy and lactation as determinants of bone mineral density in postmenopausal women. Am J Epidemiol 1992;136(9):1052-1059.

216. Alderman B, Weiss N, Daling J, Ure C, Ballard J. Reproductive history and postmenopausal risk of hip and forearm fracture. Am J Epidemiol 1986;124(2):262-267.

217. Slemenda CW, Hui SL, Longscope C, Wellman H, Johnston CC (1990) Predictors of bone mass in perimenopausal women: a prospective study of cldata using photon abs sorptiametry. Ann Intern Med ; 112: 96-101.

218. Hirota Tnara M, Ohguri M, Manago E, Hirota K. Effect of diet and lifestyle on bone mass in asian young women. Am J Clin Nutr 1992;55:1168-1173.

219. Lloyd T, Schaeffer J, Walker M, Demers L. Urinary normal concentrations and spinal bone densities of premenopausal vegetarian and nonvegetarian women. Am J Clin Nutr 1991;54:1005-1010.

220. Fehily A, Coles R, Evans W, Elwood P. Factors affecting bone density in young adults. Am J Clin Nutr 1992;56:579-586.

221. McCulloch R, Bailey D, Houston S, Dodd B. Effects of physical activity, dietary calcium intake and selected lifestyle factors on bone density in young women. Can Med Assoc J 1990;142(3):221-227.

222. Uusi K, Sievänen H, Vuori I, Pasanen M, Heinonen A, Oja P. Associatons of physical activity and calcium intake with bone mass and size in healthy women at different ages. $J$ Bone Miner Res 1998;13(1):133-142.

223. Parra S, Hernández M, Tamayo J, López L, Meneses F. Exercise and reproductive factors as predictors of bone density among osteoporotic women in Mexico city. Calcif Tissue Int 1996;59:89-94.

224. Ho S, Wong E, Gaen S, Lau J, Chan C, Chung P. Determinants of peak bone mass in chinese women aged 21-40 years.III.Physycal activity and bone mineral density. Jour Bone Min Res 1997; 12(8):1262-1271. 
225. Nieves J, Golden A, Siris E, Kelsey J, Lindsay R. Teenage and current calcium intake are related to bone mineral density of the hip and forearm in women aged 30-39 years. Am J Epidemiol 1995;141(4):342-351.

226. Parra S, Hernández M, Tamayo J, Fernández M, Meneses F. Factores de riesgo en la osteoporosis:evidencias clínicas y epidemiológicas. Gac Med Mex 1994;130:231-240.

227. Lloyd T, Buchanan J, Ursino G, Myers C, Woodward G, Halbert D. Long-term oral contraceptive use does not affect trabecular bone density. Am J Obstet Gynecol 1989;160(2):402-404.

228. Rose D, Goldman M, Connolly J, Strong L. High-fiber diet reduces serum estrogen concentrations in premenopausal women. Am J Clin Nutr 1991;54:520-525.

229. Kanis JA, Borgstrom F, De Laet C, Johansson H, Johnell O, Jonsson B, et al. assessment of fracture risk. Osteoporos Int. 2005; 16:581-9.

230. Roy DK, O'Neill TW, Finn JD, Lunt M, Silman AJ, Felsenberg D, et al; European Prospective Osteoporosis Study (EPOS). Osteoporos Int. 2003;14:19-26.

231. Van Staa TP, Geusens P, Kanis JA, Leufkens HG, Gehlbach S, Cooper C. A simple clinical score for estimating the long-term risk of fracturein post-menopausal women QJM. 2006; 99:673-82.

232. Metz JA, Anderson JJ, Gallagher PN Jr. Intakes of calcium, posphourus and protein, and physical-activity level are related to radial bone mass in young women. Am J Clin Nutr 1993; 58: $537-542$.

233. Osteoporosis postmenopaúsica. Guia de práctica clínica. Grupo de trabajo de la Sociedad Española de Investigación Ósea y Metabolismo Mineral(SEIOMM). Rev Clin Esp 2003;203:496-506.

234. Garnero P, darte C, Delmas PD. A model to monitor the efficacy of alendronate treatment in women whit osteoporosis using a biochemical marker of bone turnover. Bone. 1999, 24:603-9.

235. Zárate A, Hernández M, Morán C, Angeles L. Enfoque moderno de la osteoporosis. Rev Fac Med UNAM 2003;46:49-51.

236. Document de consenso 2006 de la Sociedad Española de reumatología sobre la osteoporosis posmenopáusica.

237. J. González Macías, E.Jodar, M. Muñoz, A. Díez Pérez, N. Guañabens y E. Fuster.En nombre del Grupo de estudio OPINHO-PC. Factores de riesgo de la osteoporosis en mujeres atendidas en Atención Primaria y en consultas hospitalarias. Estudio OPINHO-PC.Rev Clin Esp. 2009;209(7):319-324.

238. Christopher J O"Donnel, Roberto Elosua. Factores de riesgo cardiovascular. Perspectivas derivadas del Framinghm Heart Study. Rev Esp Cardiol. 2008;61:299-310.

239. Caroline K. Kramer, Denise von Mühlen, Jorge L. gross and Elisabeth Barrett-Connor. A Prospective Study of Abdominal Obesity and Coronary Artery Calcium Progressión in older Adults. Journal of Clinical Endocrinology \&Metabolism. Vol 94 No 12 5039-5044.

240. J. Aranceta, M. Foz, B. Gil, E. Jover, T. Mantilla, J. Millán, S. Monereo y B. Moreno. Documento de Consenso: obesidad y riesgo cardiovascular. Clin Invest Arterioscl 2003;15(5):196-233.

241. Giannini S, Nobile $M$, Dalle L, Lodetti $M G$, Sella $S$, Vittadello $G$, et al. Hypercalciuria is a common and important finding in posmenopausal women with osteoporosis. Eur J Endocrinol 2003 ;149: 209-13. 
242. Josep Redon, Empar Lurbe. Hypertension arterial y obesidad. Med Clin (Barc) 2007; 129:655657. 